\title{
AVALIAÇÃO NO CAMPO DE UM TDR SEGMENTADO PARA DETERMINAÇÃO DA UMIDADE DO SOLO
}

\author{
ROgERIO CICHOTA
}

Dissertação apresentada à Escola Superior de Agricultura "Luiz de Queiroz", Universidade de São Paulo, para obtenção do título de Mestre em Agronomia, Área de Concentração: Física do Ambiente Agrícola.

PIRACICABA

Estado de São Paulo - Brasil

Fevereiro - 2003 


\title{
AVALIAÇÃO NO CAMPO DE UM TDR SEGMENTADO PARA DETERMINAÇÃO DA UMIDADE DO SOLO
}

\section{ROGERIO CICHOTA}

\author{
Engenheiro Agrícola
}

Orientador: Prof. Dr. QUIRIJN DE JONG VAN LIER

Dissertação apresentada à Escola Superior de Agricultura "Luiz de Queiroz", Universidade de São Paulo, para obtenção do título de Mestre em Agronomia, Área de Concentração: Física do Ambiente Agrícola.

PIRACICABA

Estado de São Paulo - Brasil

Fevereiro - 2003 
Dados Internacionais de Catalogação na Publicação (CIP) DIVISÃO DE BIBLIOTECA E DOCUMENTAÇÃO - ESALQ/USP

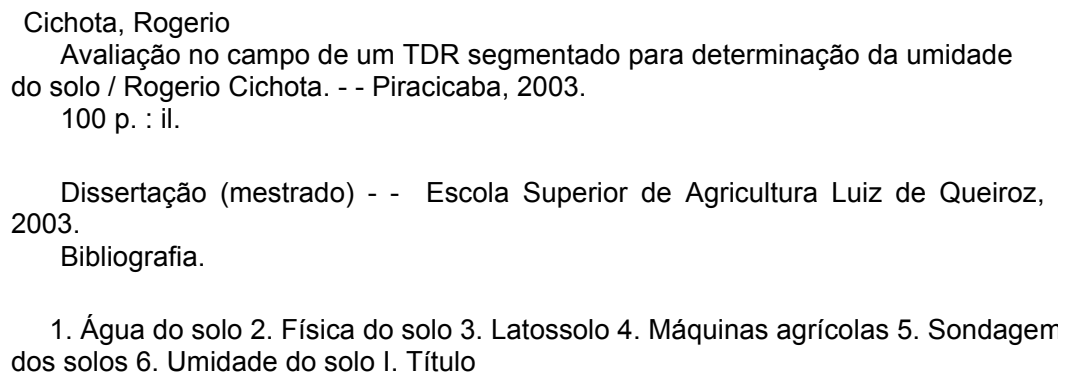
2003.

Bibliografia.

1. Água do solo 2. Física do solo 3. Latossolo 4. Máquinas agrícolas 5. Sondagem dos solos 6 . Umidade do solo I. Título

CDD 631.43 
Aos meus pais, Terezinha e Leonides, dedico. 


\section{AGRADECIMENTOS}

Ao povo brasileiro, financiador último de minha formação

Ao meu orientador, Prof. Dr. Quirijn de Jong van Lier

Aos demais professores da ESALQ, aos meus colegas e amigos e a todos que de alguma forma colaboraram para a realização deste trabalho. 


\section{SUMÁRIO}

Página

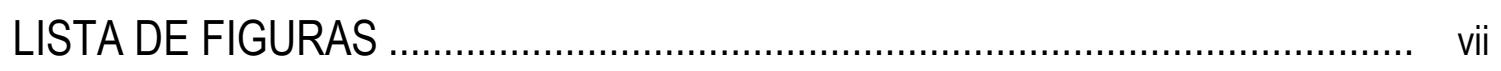

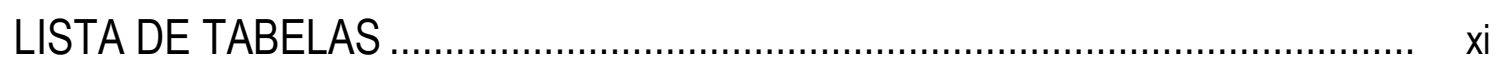

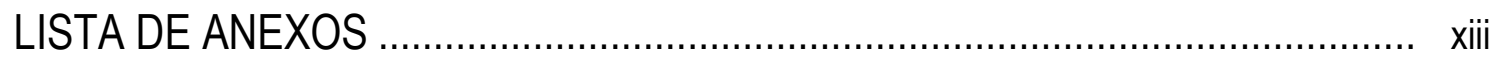

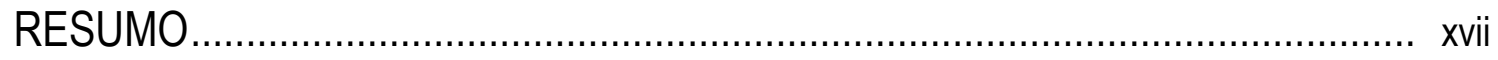

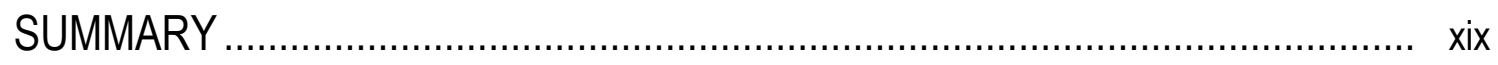

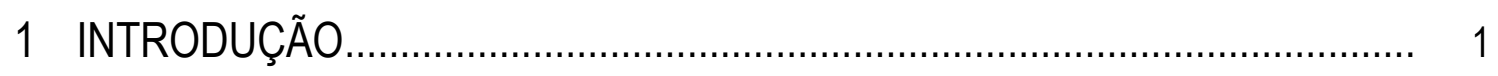

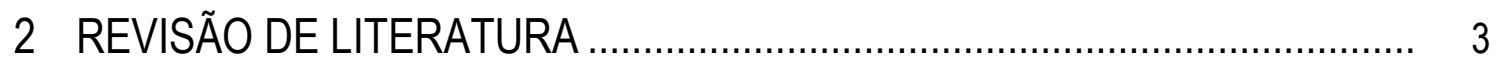

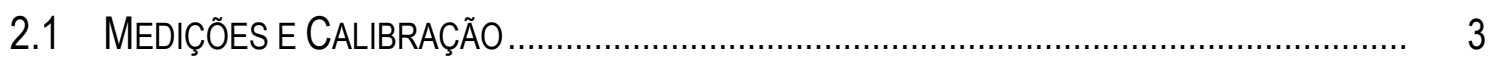

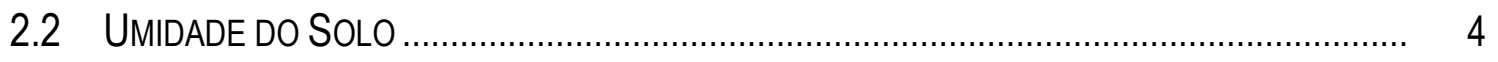

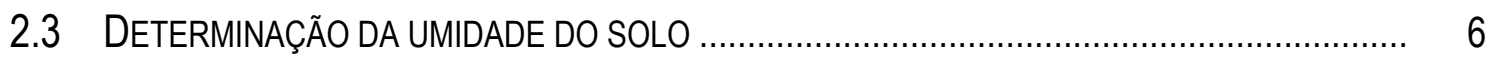

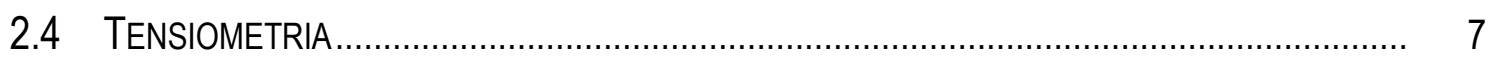

2.5 REFLECTOMETRIA NO DOMÍNIO DO TEMPO _........................................................ 12

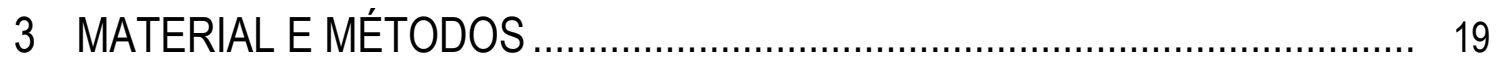

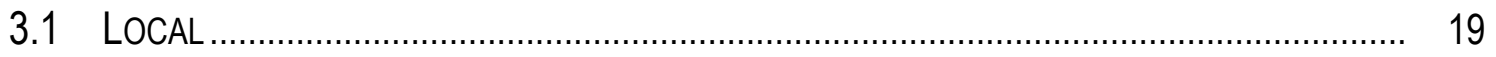

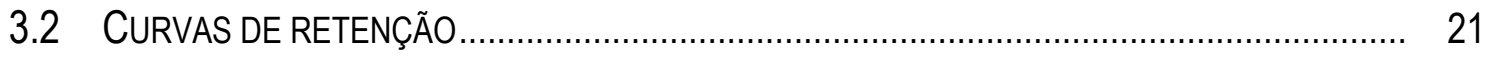




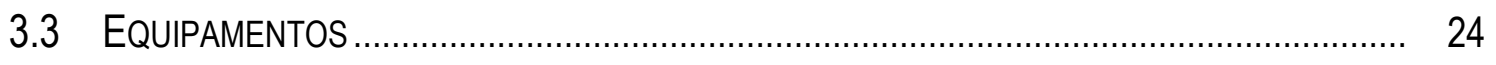

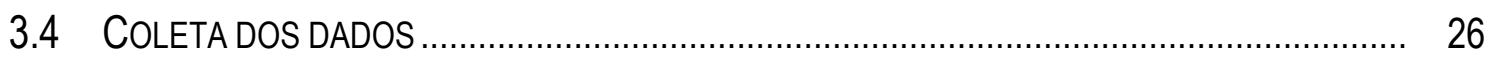

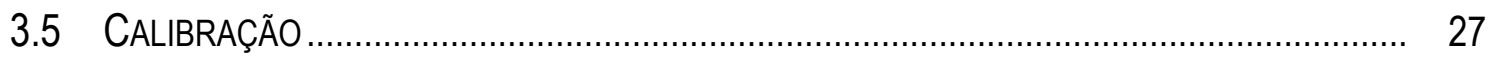

3.6 ANÁLISE ESTATISTICA _......................................................................................... 28

4 RESULTADOS E DISCUSSÃO ......................................................... 29

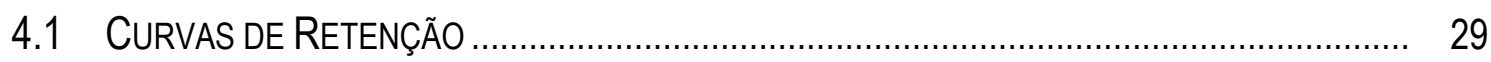

4.2 ATRIBUTOS FísICOS.......................................................................................... 33

4.2.1 Densidade do solo .......................................................................................... 33

4.2.2 Densidade dos sólidos.................................................................................... 33

4.2.3 Granulometria .......................................................................................... 34

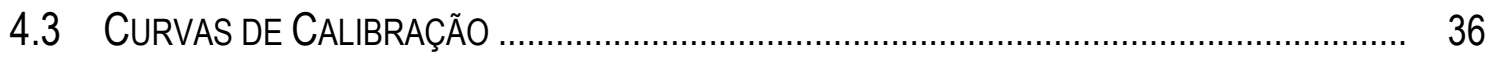

4.3.1 Dados de Campo .................................................................................. 36

4.3.2 Ajuste das Equações de Calibração do TDR......................................................... 51

4.3.3 Atributos do Solo e a Calibração ……………………........................................ 67

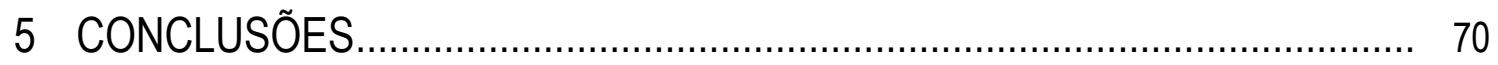

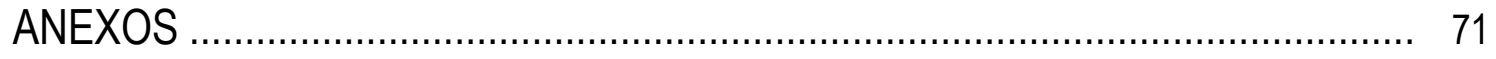

REFERÊNCIAS BIBLIOGRÁFICAS ......................................................... 94 


\section{LISTA DE FIGURAS}

Página

1 Diagrama de um tensiômetro com manômetro de mercúrio.......................................... 9

2 Equipamentos laboratoriais para determinação da curva de retenção da água no solo, (a) funil com placa porosa, (b) câmara de Richards.

3 Diagrama dos componentes básicos de um equipamento de TDR

4 Tipos de sondas de TDR que permitem identificar diferentes camadas (a) sonda com segmentos de diferentes bitolas, (b) sondas de diferentes comprimentos e (c) sonda segmentada eletronicamente por diodos.

5 Disposição de cada conjunto ou bateria; sonda de TDR no centro e tensiômetros ao redor.

6 Vista geral do experimento já coberto pela lona; à esquerda encontram-se os manômetros e os conectores dos cabos do TDR

7 Vista do experimento em fase de instalação, mostrando a disposição dos manômetros ao fundo e sua ligação com as baterias por meio de conduítes (posteriormente enterrados).

8 Esquema da disposição das baterias na transeção e da amostragem para confecção das curvas de retenção

9 Trado para acesso a camadas profundas e amostrador de Uhland. 
10 Esquema da caixa de areia utilizada para a determinação da umidade das amostras para potenciais matriciais de $-0,05$ a $-0,40 \mathrm{kPa}$.

11 Equipamento de TDR - emissor de pulso/leitor, cabos e sonda, no detalhe vê-se os segmentos de cada haste.

12 Repetições e médias das curvas de retenção experimentais, para o ponto 20A com todas as repetições (a) e com a eliminação de um dado discrepante (b), e o ponto $30 \mathrm{~A}$ com todos os dados (c) e com a eliminação de uma repetição discrepante (d)..........

13 Média das densidades do solo observadas para cada camada e média geral de todas as camadas. Barras marcadas com letras minúsculas iguais não diferiram, ao nível de probabilidade de $5 \%$, pelo teste de Tukey.

14 Médias das densidade dos sólidos observadas ao longo da transeção por camada e média geral. Barras marcadas com letras minúsculas iguais não diferiram, ao nível de probabilidade de $5 \%$, pelo teste de Tukey

15 Teores médios por camada para (a) areia, (b) argila e (c) silte, e (d) variação das médias ao longo da transeção. Barras marcadas com letras minúsculas iguais não diferiram, ao nível de probabilidade de $5 \%$, pelo teste de Tukey.

16 Amplitudes e médias para a umidade e a leitura do TDR, no primeiro período de coleta de dados (2000). (a-e) Umidade nas camadas $A$ a $E$, (f) umidade geral por camada; ( $g-k$ ) leitura do TDR nas camadas A a E e (I) TDR geral por camada. Barras marcadas com letras minúsculas iguais não diferiram, ao nível de probabilidade de $5 \%$, pelo teste de Tukey.

17 Amplitudes e médias para a umidade e a leitura do TDR, no segundo período de coleta de dados (2001). (a-e) Umidade nas camadas A a E, (f) umidade geral por camada; ( $g-k$ ) leitura do TDR nas camadas A a E e (I) TDR geral por camada. Barras marcadas com letras minúsculas iguais não diferiram, ao nível de probabilidade de $5 \%$, pelo teste de Tukey.

18 Percentagem de pontos com umidade (a) e leitura do TDR (b) semelhantes na transeção, por camada e período 
19 Percentagem de pontos com resultados coincidentes da análise de semelhança das médias $(\mathrm{Cc})$ e percentagem apenas dos pontos semelhantes nos dois períodos (SI), para umidade (a) e leitura do TDR (b), em função da profundidade.

20 Fração de pontos semelhantes em função da distância de comparação para umidade obtida por tensiometria, no primeiro período de observação (2000).

21 Fração de pontos semelhantes em função da distância de comparação para umidade obtida por tensiometria, no segundo período de observação (2001).

22 Fração de pontos semelhantes em função da distância de comparação para umidade obtida por tensiometria, para todos os dados $(2000+2001)$.

23 Fração de pontos semelhantes em função da distância de comparação para leitura do TDR, no primeiro período de observação (2000).

24 Fração de pontos semelhantes em função da distância de comparação para leitura do TDR, no segundo período de observação (2001).

25 Fração de pontos semelhantes em função da distância de comparação para leitura do TDR, para todos os dados $(2000+2001)$.

26 Equação de calibração do TDR (modelo linear), ajustada a todos os pares de dados $\theta$-T TDR obtidos.

27 Exemplos de curvas de calibração do TDR para os modelos das equações ( 9 ), ( 13 ) e ( 14 ), com os dados das hastes 6 (a) e 19 (b) do primeiro período, 31 (c) e 45 (d) do segundo período.

28 Equações de calibração do TDR e pares de dados $\theta$-T TDR observados para o primeiro período - 2000 (a) e para o segundo período - 2001 (b)

29 Percentagem de equações de calibração com coeficientes de determinação da regressão linear em quatro classes por camada, para o primeiro período (a), segundo período (b) e todos os dados juntos (c). 
30 Fração de pontos semelhantes em função da distância de comparação para 0 coeficiente angular da regressão tempo TDR×umidade, para o primeiro período (2000).

31 Fração de pontos semelhantes em função da distância de comparação para coeficiente angular da regressão tempo TDR×umidade, para o segundo período (2001).

32 Fração de pontos semelhantes em função da distância de comparação para coeficiente angular da regressão tempo TDR×umidade, para os dados dos dois períodos $(2000+2001)$. 


\section{LISTA DE TABELAS}

Página

1 Permissividade relativa de alguns constituintes do solo............................................. 14

2 Valores dos parâmetros usados na equação de correção das leituras do TDR, fornecido pelo fabricante.

3 Parâmetros do modelo de Mualem-van Genuchten ajustados aos dados observados nos 24 pontos (números 2 a 48) e cinco camadas (A a E) - $\theta_{\mathrm{s}}$ e $\theta_{\mathrm{r}}$ em $\mathrm{m}^{3} \mathrm{~m}^{-3}$ e $\alpha$ em $\mathrm{kPa}^{-1}$ - com as respectivas medidas estatísticas de ajuste: Coeficiente de determinação - $R^{2}$, teste $\mathrm{F}$ e sua probabilidade, o número de pares de dados $-\mathrm{N}$, e o desvio padrão da regressão - Dp.

4 Coeficientes de correlação das amplitudes da umidade $(A \theta)$ e das leituras do TDR ( $A T_{T D R}$ ) entre os dois períodos e entre as amplitudes da umidade e da leitura do TDR para $01^{\circ}$ período $\left(\theta-\mathrm{T}_{\mathrm{TDR} 1}\right)$ e $02^{\circ}$ período $\left(\theta-\mathrm{T}_{\mathrm{TDR} 2}\right)$.

5 Coeficientes de correlação entre a leitura do TDR e a umidade para cada camada, utilizando apenas as médias de cada ponto e com todos os dados

6 Coeficiente de correlação para a percentagem de pontos semelhantes por camada entre dois períodos de observação.

7 Semelhança entre os valores de umidade por camada e bateria para os dois períodos (1-semelhante, 0-não semelhante, com IC de 95\%)

8 Semelhança entre os valores da leitura do TDR por bateria e camada para os dois períodos (1-semelhante, 0-não semelhante, com IC de 95\%) 
9 Coeficientes de correlação entre os coeficientes angular e linear das retas ajustadas aos dados de umidade e leitura do TDR, para os dados coletados nos dois períodos e todos juntos.

10 Coeficientes de correlação para os coeficientes angular e de determinação das retas ajustadas aos dados de umidade e leitura do TDR, entre os dois períodos de observação.

11 Semelhança entre os valores obtidos nos dois períodos dos coeficientes angulares das retas da regressão linear dos valores de umidade e leitura do TDR, por bateria $\mathrm{e}$ camada (1-semelhante, 0-não semelhante, com IC de 95\%).

12 Coeficientes angulares das retas da regressão linear dos valores de umidade e leitura do TDR por ponto para o primeiro período (2000). Valores seguidos de mesma letra, na linha, não diferem ao nível de probabilidade de $95 \%$.

13 Coeficientes angulares das retas da regressão linear dos valores de umidade e leitura do TDR por ponto para o segundo período (2001). Valores seguidos de mesma letra, na linha, não diferem ao nível de probabilidade de $95 \%$.

14 Coeficientes angulares das retas da regressão linear dos valores de umidade e leitura do TDR por ponto para todos os dados juntos $(2000+2001)$. Valores seguidos de mesma letra, na linha, não diferem ao nível de probabilidade de $95 \%$.

15 Resultados da análise de semelhança entre os coeficientes angulares para cada camada e período.

16 Coeficientes de correlação entre o coeficiente angular das retas de calibração e alguns atributos físicos do solo, analisados para os dois anos de observação em separado e em conjunto. 


\section{LISTA DE ANEXOS}

Página

A Umidade média $\left(\theta_{\mathrm{m}}\right)$, Desvio padrão $(\mathrm{Dp})$, número de observações $(\mathrm{n})$, intervalo de confiança a $95 \%$ de probabilidade para a média (IC95\%), número de pontos concordantes $(\mathrm{nC})$ e sua percentagem $(\% \mathrm{C})$ por camada para os dados do primeiro período de observações (2000).

B Leitura média do TDR, (TTDR), Desvio padrão (Dp), número de observações (n), intervalo de confiança a 95\% de probabilidade para a média (IC95\%), número de pontos concordantes $(\mathrm{nC})$ e sua percentagem $(\% \mathrm{C})$ por camada para os dados do

primeiro período de observações (2000).

C Umidade média $\left(\theta_{\mathrm{m}}\right)$, Desvio padrão $(\mathrm{Dp})$, número de observações $(\mathrm{n})$, intervalo de confiança a $95 \%$ de probabilidade para a média (IC95\%), número de pontos concordantes $(\mathrm{nC})$ e sua percentagem $(\% \mathrm{C})$ por camada para os dados do segundo período de observações (2001).

D Leitura média do TDR, (TTDR), Desvio padrão (Dp), número de observações (n), intervalo de confiança a $95 \%$ de probabilidade para a média (IC95\%), número de pontos concordantes $(\mathrm{nC})$ e sua percentagem $(\% \mathrm{C})$ por camada para os dados do segundo período de observações (2001).

E Umidade média $\left(\theta_{\mathrm{m}}\right)$, Desvio padrão $(\mathrm{Dp})$, número de observações $(\mathrm{n})$, intervalo de confiança a $95 \%$ de probabilidade para a média (IC95\%), número de pontos 
concordantes $(\mathrm{nC})$ e sua percentagem $(\% \mathrm{C})$ por camada para todos os dados observados.

F Leitura média do TDR, ( $\left.T_{T D R}\right)$, Desvio padrão (Dp), número de observações (n), intervalo de confiança a 95\% de probabilidade para a média (IC95\%), número de pontos concordantes $(\mathrm{nC})$ e sua percentagem $(\% \mathrm{C})$ por camada para todos os dados observados.

G Valores dos coeficientes linear (a), angular (b) e de determinação $\left(R^{2}\right)$, o desvio padrão da regressão (DPR), a estatística $\mathrm{F}$ e sua respectiva probabilidade, para os ajustes do modelo linear nos dois períodos de observação e todos juntos para os dados agrupados por camada e com todas as camadas em conjunto.

H Coeficientes linear (a), angular (b) e de determinação $\left(R^{2}\right)$, o desvio padrão da regressão (DPR), a estatística $\mathrm{F}$ e sua respectiva probabilidade, para os ajustes do modelo linear nos dois períodos de observação e todos juntos para os dados agrupados por haste com todas as camadas em conjunto.

I Coeficientes linear (a), angular (b) e de determinação (R2), o desvio padrão da regressão (DPR), a estatística $F$ e sua respectiva probabilidade, para os ajustes do modelo linear nos dois períodos de observação e todos juntos aos dados da camada A.

J Coeficientes linear (a), angular (b) e de determinação (R2), o desvio padrão da regressão (DPR), a estatística $F$ e sua respectiva probabilidade, para os ajustes do modelo linear nos dois períodos de observação e todos juntos aos dados da camada B

K Coeficientes linear (a), angular (b) e de determinação (R2), o desvio padrão da regressão (DPR), a estatística $\mathrm{F}$ e sua respectiva probabilidade, para os ajustes do modelo linear nos dois períodos de observação e todos juntos aos dados da camada C

L Coeficientes linear (a), angular (b) e de determinação (R2), o desvio padrão da regressão (DPR), a estatística $\mathrm{F}$ e sua respectiva probabilidade, para os ajustes do 
modelo linear nos dois períodos de observação e todos juntos aos dados da camada D

M Coeficientes linear (a), angular (b) e de determinação (R2), o desvio padrão da regressão (DPR), a estatística F e sua respectiva probabilidade, para os ajustes do modelo linear nos dois períodos de observação e todos juntos aos dados da camada $\mathrm{E}$

$\mathrm{N}$ Exemplos de curvas de calibração para os dados agrupados por haste. A primeira coluna corresponde ao primeiro período, a segunda ao segundo período e a terceira coluna com todos os dados em conjunto. Primeira linha corresponde à bateria $1, a$ segunda à 10 e a terceira à 19. Dados da camada $A(\diamond)$, camada $B(\circ)$, Camada $C$ $(\mathbf{x})$, camada $\mathrm{D}(\square)$ e camada $E(\Delta)$.

O Exemplos de equações de calibração para os dados agrupados por haste. A primeira coluna corresponde ao primeiro período, a segunda ao segundo período e a terceira coluna com todos os dados em conjunto. Primeira linha corresponde à bateria 28 , a segunda à 36 e a terceira à 45 . Dados da camada $A(\diamond)$, camada $B$ (○), Camada $\mathrm{C}(\mathbf{x})$, camada $\mathrm{D}(\square)$ e camada $\mathrm{E}(\Delta)$.

P Equações de calibração e dados observados agrupados por camada. A primeira coluna corresponde ao primeiro período, a segunda ao segundo período e a terceira coluna com todos os dados em conjunto. Primeira linha corresponde à camada $\mathrm{A}, \mathrm{a}$ segunda à $\mathrm{B}$ e a terceira à $\mathrm{C}$

Q Equações de calibração e dados observados agrupados por camada. A primeira coluna corresponde ao primeiro período, a segunda ao segundo e a terceira coluna com todos os dados em conjunto. Primeira linha corresponde à camada $D$, a segunda à $\mathrm{E}$ e a terceira à todas juntas.

$\mathrm{R}$ Exemplos de equações de calibração com os dados dos dois períodos para os segmentos da camada A. (a) bateria 1, (b) bateria 10, (c) bateria 19, (d) bateria 28, (e) bateria 36 e (f) bateria 45. ( $\square$ ) Dados de 2000 e ( $\Delta$ ) de 2001 
S Exemplos de equações de calibração com os dados dos dois períodos para os segmentos da camada B. (a) bateria 1, (b) bateria 10, (c) bateria 19, (d) bateria 28 , (e) bateria 36 e (f) bateria 45. () Dados de 2000 e $(\Delta)$ de 2001.

T Exemplos de equações de calibração com os dados dos dois períodos para os segmentos da camada C. (a) bateria 1, (b) bateria 10, (c) bateria 19, (d) bateria 28, (e) bateria 36 e (f) bateria 45. ( $\square$ ) Dados de 2000 e ( $\Delta$ ) de 2001.

U Exemplos de equações de calibração com os dados dos dois períodos para os segmentos da camada D. (a) bateria 1, (b) bateria 10, (c) bateria 19, (d) bateria 28 , (e) bateria 36 e (f) bateria 45. () Dados de 2000 e ( $\triangle$ ) de 2001

V Exemplos de equações de calibração com os dados dos dois períodos para os segmentos da camada E. (a) bateria 1, (b) bateria 10, (c) bateria 19, (d) bateria 28, (e) bateria 36 e (f) bateria 45. () Dados de 2000 e ( $\Delta$ ) de 2001 


\section{AvALIAÇÃo NO CAMPO dE UM TDR SEgmENTADO PARA DETERMINAÇÃO DA UMIDADE DO SOLO}

Autor: ROGERIO CICHOTA

Orientador: Prof. Dr. QUIRIJN DE JONG VAN LIER

\section{RESUMO}

Das várias proposições para a determinação da umidade do solo, a técnica da reflectometria no domínio do tempo (TDR) vem despertando bastante interesse, pois apresenta características desejáveis, como a mensuração em tempo real e a possibilidade de leituras automatizadas. Por outro lado, além do custo elevado dos equipamentos, este método ainda apresenta necessidade de calibração. $O$ desempenho no campo também carece ser mais bem estudado. Com o objetivo de avaliar a performance de um equipamento de TDR com sondas segmentadas em condições de campo, utilizando como método de referência a tensiometria, foram conduzidos experimentos em dois períodos de anos consecutivos, com a coleta de valores da umidade do solo e da respectiva leitura do TDR, em 48 baterias compostas de uma haste de TDR de cinco segmentos e um tensiômetro para cada segmento, dispostas em uma transeção em um Latossolo Vermelho-amarelo no campus da ESALQ/USP em Piracicaba/SP. Embora trabalhosa, a tensiometria mostrou-se suficiente como método de referência para a umidade no 
campo, pois sua metodologia é bem estabelecida e seu funcionamento não influencia nem é influenciado pelo TDR. As umidades observadas, obtidas a partir do potencial matricial e das curvas de retenção, mostraram padrão de variação semelhante entre os dois períodos, ao contrário das leituras do TDR, que exibiram médias e amplitudes pouco correspondentes entre os pontos num período e noutro. A correlação entre a umidade e a leitura do TDR foi em geral bastante reduzida e quanto mais restrito o conjunto analisado, como por haste ou segmentos, melhores resultados foram obtidos. As curvas de calibração mostraram grande variabilidade entre segmentos, tanto para o coeficiente de determinação como para o padrão da resposta, expresso pelo coeficiente angular das retas. Ajustes efetuados com os dados agrupados por haste ou por camada exibiram aumento da dispersão e forte diminuição do coeficiente de determinação. As retas de calibração também exibiram padrões diferenciados entre os períodos e ajustes com os dados dos dois conjuntos mostraram-se em geral ruins. Não foi possível identificar nenhum padrão para as variações da calibração ao longo da transeção, para algumas camadas houve indícios de dependência espacial, mas nenhuma relação definida com os atributos físicos determinados foi encontrada. Os resultados deste trabalho vêm complementar outros estudos reportados na literatura, mostrando que a aplicabilidade deste modelo de TDR segmentado é praticamente inviável, pois as variações da resposta do TDR são muito grandes entre as várias hastes ou mesmo entre segmentos de uma mesma haste, ou ainda entre os dois períodos. 0 trabalho também mostra a importância de estudos no campo para a validação de novos métodos ou equipamentos de determinação da umidade do solo. 


\title{
Field Evaluation of TDR MuLtileVel Probe FOR SOIL WATER CONTENT MEASUREMENT
}

\author{
Author: ROGERIO CICHOTA \\ Adviser: Prof. Dr. QUIRIJN DE JONG VAN LIER
}

\section{SUMMARY}

Among many methods to assess soil water content, time domain reflectometry (TDR) is of recent interest due to its many desirable features as real-time method allowing automation. On the other hand, the equipment is expensive and needs calibration. More studies about its field performance are also required. With the objective of evaluating a TDR device with multilevel probes at field conditions, using tensiometry as reference method for soil water content, two experiments were conducted in consecutives years, by collecting values of soil water content and the respective TDR response in 48 batteries, that were made up of a TDR probe with 5 segments and a tensiometer for each segment, installed in a Red-yellow Oxisol (Hapludox) at the ESALQ/USP campus in Piracicaba/SP - Brasil. Although laborious, tensiometry showed to be a good reference to assess soil water content, because its methodology is well established and its functioning does not influence nor is influenced by the TDR. Soil water content obtained by matric potential and retention curves showed similar patterns in both periods, contrasting with TDR 
response that did not exhibit correspondence for average or range of measures between periods. The correlation between soil water content and TDR response was in general very small, and smaller data sets, per probes or per segment, showed better correlations. The calibration curves showed much variability among segments, both for the determination indexes and the response pattern. Data fitting per probe or level showed increased dispersion and strong reduction for determination indexes. Calibration also showed different patterns between periods and fitting with data from both periods were in general bad. It was not possible to identify tendencies for variations of calibration along the transect, nor correlation with offer soil attributes. These results complement other studies reported in the literature, showing that this type of probe is hard to be used, due the high variations among probes or even among segments of one probe, besides of variations in time. The importance of field studies for validation of new methods or devices for soil water content measurements are also presented. 


\section{INTRODUÇÃO}

O estudo de métodos e equipamentos para a quantificação do teor de água no solo sempre teve grande relevância, tanto no aspecto científico como também no aspecto econômico, dada a importância da água no crescimento e rendimento das plantas e suas implicações em várias das propriedades físicas do solo.

Um método de quantificação ideal deve basear-se numa propriedade física do solo dependente apenas do conteúdo de água e também deve ser simples de ser executado, produzindo resposta diretas, rápidas e confiáveis. Além disso, não pode trazer riscos ao operador ou ao ambiente, e ser de custo acessível.

Várias são as proposições para a determinação da umidade, ou teor de água, do solo, porém nenhuma consegue satisfazer todas as necessidades e requisitos básicos para que se torne o método ideal. 0 que resta à pesquisa é continuar aprimorando estas várias propostas, reduzindo, eliminando ou contornando os pontos negativos. Dos vários métodos existentes, a reflectometria no domínio do tempo, ou reflectometria de microondas - TDR (time domain reflectometry), vem despertando muito interesse ultimamente, devido principalmente à possibilidade de leituras em tempo real e automatizadas. 0 método baseia-se na relação que existe entre a umidade do solo e sua constante dielétrica, porém ainda guarda dois principais problemas: o custo elevado dos equipamentos, devido principalmente à eletrônica sofisticada para medição do tempo da ordem de nanossegundos, e a necessidade de calibração. Neste último aspecto têm-se várias pesquisas tentando encontrar uma relação entre a umidade do solo e a leitura do aparelho, porém nenhuma ainda é utilizável universalmente sem um procedimento de verificação. Muitas vezes utiliza-se uma relação matemática particular ao solo ou experimento, sem tentativas de generalizações. 0 surgimento de modelos diferenciados de equipamentos 
também pode implicar numa mudança do comportamento da resposta do aparelho à umidade do solo e uma calibração universal torna-se muito mais difícil.

A calibração, ou sua validação, no campo, bem como o comportamento desta frente à variabilidade natural do solo ainda são pouco estudados. Resultados de um estudo deste tipo poderiam lançar mais luz sobre a aplicabilidade desta técnica. A calibração no campo é interessante pois é realizada com o solo em sua condição natural, com sua estrutura e variabilidade originais. No entanto, o problema principal desta calibração é obter os dados de umidade com os quais será efetuado o ajuste da curva de calibração. 0 método de referência para determinação de umidade é o método gravimétrico, porém, por ser destrutivo, este método não permite a realização de muitas repetições, o que torna 0 ajuste final mais difícil. $O$ uso de outro método indireto poderia possibilitar várias repetições, por outro lado a calibração deste método pode propagar erros na leitura a ser usada como referência. $O$ uso da tensiometria para estimar a umidade parece ser uma boa possibilidade, pois apesar de ser trabalhosa, a metodologia para a determinação do teor de água no solo através da curva de retenção com as medidas do tensiômetro é bem estabelecida, possibilitando medições mais pontuais que a sonda de nêutrons, por exemplo, e não influencia nem é influenciada pelo funcionamento do dispositivo de TDR.

O objetivo geral deste trabalho foi avaliar o desempenho de um equipamento de TDR com sondas segmentadas em condições de campo, buscando identificar variações do comportamento do equipamento de TDR frente a variabilidade natural do solo e ao longo do tempo, verificando suas implicações na calibração do aparelho. Também objetivou-se estudar a viabilidade da calibração no campo de um aparelho de TDR através do uso da tensiometria como método de referência. 


\section{REVISÃO DE LITERATURA}

\subsection{Medições e CaLIBRAÇÃo}

Praticamente todo trabalho científico na área das ciências agronômicas, assim como em muitas outras, está relacionado à determinação de grandezas e das relações entre grandezas. As grandezas físicas são medidas por instrumentos para serem comparadas entre si ou a outras de interesse da pesquisa e para isso devem estar em conformidade com algum padrão, ou seja, as medições devem ser relativas a uma medida materializada ou a um sistema de medição estabelecido (Barthem, 2001).

A expressão de uma medição requer pelo menos duas notações: o número, que representa a quantidade mensurada, e a unidade, que expressa o padrão de referência utilizado. Como normalmente a medição está sujeita a desvios relativos ao instrumento ou à operação de medição em si, ao que se denomina acaso, um outro membro pode ser adicionado na expressão do resultado da medição: uma estimativa dos erros, normalmente o desvio padrão (Vuolo, 1996; Pimentel-Gomes, 2000).

As grandezas físicas básicas (massa, distância, etc.) assim como, algumas grandezas derivadas (pressão, voltagem, etc.) e de uso generalizado na sociedade possuem padrão internacional e órgãos que referendam os instrumentos e equipamentos de medição destas grandezas. Métodos de medição alternativos ou ainda medições de grandezas de interesse em áreas mais restritas, especialmente em pesquisa, não apresentam em geral padrões definidos e a aferição de suas leituras requer procedimento específico. 0 surgimento de novos métodos e equipamentos também requer que se verifique a correspondência de suas medidas com aquelas 
consideradas de referência. Quer sejam tradicionais, alternativos ou novos, os equipamentos e métodos de mensuração, para uso com segurança e confiabilidade mínimas, devem passar pelo processo denominado de calibração.

Calibração é o conjunto de operações que visam estabelecer, sob condições especificas, a relação entre os valores indicados por um instrumento de medição ou sistema de medição, valores representados por uma medida materializada ou um material de referência, e os valores correspondentes das grandezas estabelecidas por padrões. Suas finalidades principais são a apuração da confiabilidade das medições e a seleção ou o teste de viabilidade do uso de um instrumento ou sistema de medição (Sebrae, 2001).

O processo de calibração consiste basicamente na coleta de dados (leituras) do aparelho ou sistema a ser calibrado; da coleta dos respectivos valores de referência e da análise da relação entre elas. Esta análise fornece a relação matemática ou estatística entre o valor de referência e a leitura do dispositivo calibrado, em adição, e talvez mais importante ainda, fornece a estimativa dos erros de medição. Erro é entendido como a diferença do valor medido para 0 valor real, que não pode ser conhecido e cuja estimativa é feita com base no valor de referência (Vuolo, 1999). A quantificação dos erros possibilita estimar a incerteza atribuível à medição, ou seja, caracterizar a dispersão dos valores medidos atribuível ao mensurando (Vuolo, 1999).

\subsection{UMIDADE DO SOLO}

A água é uma substância que se apresenta em grande quantidade no planeta Terra. Apesar de ser um composto simples, sua importância na definição do aspecto físico e especialmente biológico da Terra é enorme. A vida simplesmente não é possível sem ela. Sua estrutura química, como molécula polar, Ihe permite agir como solvente universal e aderir às superfícies, bem como em outras moléculas de água. Daí surgem as forças de adesão e coesão, donde deriva, nas interfaces sólido-líquido-gás, o fenômeno da capilaridade, responsável principal pelo poder de penetração da água em meios porosos e de sua retenção nos poros. 
O solo é um meio poroso granulado composto basicamente de rochas degradadas, matéria orgânica, ar e água. A fração sólida, ou matriz do solo, apresenta variações bastante lentas no tempo, ao passo que as quantidades de ar e água que preenchem os interstícios dos poros variam com facilidade e rapidez. A água no solo é retida pelas superfícies dos sólidos, por interações elétricas basicamente, com força grande, mas restrita às proximidades das superfícies. Ela também pode se retida por forças capilares, inversamente proporcionais ao diâmetro dos poros (ver, por exemplo, Libardi, 2000). Assim, a água no solo pode apresentar-se fortemente presa às superfícies ou em poros microscópicos, ou até praticamente livre de interações com os sólidos, nos macroporos. A faixa entre a quantidade de água que é retida pelo solo por no mínimo alguns dias contra a força gravitacional e aquela em que as plantas ainda conseguem extraí-la do solo contra as forças capilares é, em geral, a de maior interesse para as pesquisas agronômicas e onde os equipamentos de quantificação da água do solo devem atuar com mais eficiência. Quanto maior a faixa de uso de um aparelho melhor ele será considerado.

O conteúdo de água de um solo é um de seus atributos mais importantes, e um dos mais variáveis. 0 deslocamento e reciclagem de vários elementos químicos, o desenvolvimento dos processos bioquímicos do solo, o crescimento das plantas e uma série de outras propriedades físicas do próprio solo como densidade, resistência à penetração, tensão de cisalhamento, etc., são significativamente influenciadas pelo teor de água. Sua quantificação é portanto de grande relevância para um amplo conjunto de disciplinas.

Em geral não é conveniente trabalhar-se com a quantidade absoluta de água no solo, mas sim com uma forma intensiva de expressá-la, a qual denomina-se teor de água ou umidade do solo. Pode-se ainda expressar a umidade em base de massa $\left(\mathrm{U}, \mathrm{kg} \mathrm{kg}^{-1}\right)$ ou em base de volume $\left(\theta, \mathrm{m}^{3} \mathrm{~m}^{-3}\right)$, que é a forma mais usual (Gardner, 1986; Dirksen, 1999):

$$
\begin{gathered}
U=\frac{m_{a}}{m_{s}} \\
\theta=\frac{V_{a}}{V_{s}}
\end{gathered}
$$


Nessas equações, $m_{a}(\mathrm{~kg})$ é a massa de água no solo, $m_{s}(\mathrm{~kg})$ é a massa de solo seco, $V_{a}\left(m^{3}\right)$ é o volume de água no solo e $V_{s}\left(m^{3}\right)$ é o volume total do solo. Sendo conhecidas as massas específicas do solo $\left(\rho_{\mathrm{s}}, \mathrm{kg} \mathrm{m}^{-3}\right)$ e da água $\left(\rho_{\mathrm{a}}, \mathrm{kg} \mathrm{m}^{-3}\right)$, as duas formas de expressar a umidade podem ser relacionadas conforme eq. ( 3 ):

$$
\theta=\mathrm{U} \cdot \frac{\rho_{\mathrm{s}}}{\rho_{\mathrm{a}}}
$$

\subsection{DeTERMINAÇÃO DA UMIDADE DO SOLO}

Os métodos de determinação do conteúdo de água no solo são comumente divididos em métodos diretos e indiretos.

Os métodos diretos ou gravimétricos baseiam-se na pesagem de amostras de solo úmido e depois da secagem, que pode ser realizada em estufa ou num forno de microondas (Cauduro \& Dorfman, s.d; Gardner, 1986). A diferença entre as duas medidas representa a massa de água presente naquela amostra. Presume-se que esta proporção represente a condição do solo no momento da coleta da amostra. Com a quantificação destas massas determina-se a umidade gravimétrica $(U)$ do solo e caso a densidade do solo ou o volume da amostra também for conhecida pode-se obter a umidade volumétrica $(\theta)$ pela equação ( 3 ).

Este método é simples e barato, além de ser bastante preciso, motivo pelo qual é considerado método de referência. Porém, é um método trabalhoso, que demanda certo tempo entre a coleta da amostra e a obtenção do resultado, além de ser um método não automatizável e destrutivo: uma amostra deve ser retirada do campo e levada ao laboratório, o que impossibilita repetições num mesmo ponto.

Os métodos indiretos utilizam uma propriedade física do solo que é dependente da quantidade de água presente nele (Gardner, 1986). Há vários processos e equipamentos que permitem a determinação indireta do teor de água do solo, como por exemplo os métodos elétricos (resistência ou a capacitância do solo), os métodos térmicos (condutividade térmica), os 
métodos radioativos (atenuação de nêutrons rápidos ou de raios gama), a tensiometria (potencial matricial) e a reflectometria no domínio do tempo (constante dielétrica relativa), entre outras.

A grande vantagem dos métodos indiretos e não destrutivos é a repetibilidade da leitura num mesmo ponto, pois após serem instalados permanecem utilizáveis por certo tempo, sem a necessidade de revolver o solo. Muitas vezes também podem ser automatizados. Porém as propriedades utilizadas por estes métodos não são unicamente dependentes do conteúdo de água do solo e quando a mineralogia, o teor de sais, a densidade ou a temperatura variam, a relação entre a resposta do aparelho e a umidade do solo pode ser alterada. 0 estudo de novos métodos ou aparelhos de medição e uma calibração bem feita são expedientes que proporcionam a aplicabilidade destes métodos.

\subsection{TENSIOMETRIA}

A energia potencial da água no solo não saturado é menor do que se estivesse livre, fora da influencia da matriz do solo, no mesmo nível gravitacional. Esta diferença energética é provocada principalmente pela ação de três forças que se opõe à gravidade e a evaporação para manter a água no solo. Estas forças são a adesão aos componentes sólidos do solo; a capilaridade, devido às forças de coesão entre as moléculas de água e de adesão entre estas e os vários constituintes do solo, e a atração osmótica causada pela diferença de concentração iônica entre dois pontos (Dirksen, 1999). Dessa forma diz-se que a água fica "retida" no solo.

0 estado de energia com que a água encontra-se retida num meio poroso, como 0 solo, pode ser descrito pelo seu potencial $(\psi)$, que pode ser expresso de forma intensiva em função da massa $\left(\mathrm{J} \mathrm{kg}^{-1}\right)$ ou do peso, para convenientemente ter unidade de altura $\left([\mathrm{h}]=\mathrm{J} \mathrm{N}^{-1}=\right.$ $\mathrm{m})$ ou em função do volume, tendo unidade de pressão $\left([\mathrm{p}]=\mathrm{J} \mathrm{m}^{-3}=\mathrm{Pa}\right.$ ). Estas duas últimas unidades são convenientes para serem usadas em relações entre profundidades e distâncias e também são as unidades utilizadas pelos equipamentos de medição. A relação entre os dois meios equivalentes de expressar o potencial da água no solo é dada pela eq. ( 4 ). 


$$
p=\rho_{a} \cdot g \cdot h
$$

Onde $\rho_{\mathrm{a}}$ representa a massa específica da água $\left(\mathrm{kg} \mathrm{m}^{-3}\right)$ e $\mathrm{g}$ a aceleração gravitacional $\left(\mathrm{m} \mathrm{s}^{-2}\right)$.

O potencial total da água no solo pode ser sub-dividido em alguns componentes distintos: os potenciais gravitacional, de pressão, osmótico e matricial.

O potencial da água e sua relação com o conteúdo de água são uma parte fundamental da caracterização das propriedades hidráulicas de um solo (Klute, 1986). 0 estado energético com que a água se encontra retida no solo é muito mais importante que a quantidade para a determinação do seu movimento e dos solutos no solo e deste para as plantas (Cassel \& Klute, 1986). Os primeiros estudos sobre as relações entre o teor de água no solo e o potencial matricial surgiram no início do século XX. Gardner et al. (1922) propuseram um equipamento com uma cápsula porosa de cerâmica e um manômetro para efetuar a medição do potencial da água no solo. Desde então estudos vêm comprovando esta técnica e novas variações surgiram, mas a essência do tensiômetro continua a mesma.

O uso da tensiometria é bastante difundido em várias áreas de pesquisa em física do solo (Bruce \& Luxmoore, 1986; Klute \& Dirksen, 1986; Dirksen, 1999), bem como em sistemas de controle de irrigação (Pessoa, 1983; Bruce \& Luxmoore, 1986). A elevada variabilidade do potencial matricial não é um fator critico para a sua utilização na determinação da umidade do solo via curva de retenção (Marciano et al., 1998).

O tensiômetro é composto basicamente por um recipiente fechado cheio d'água com uma cápsula porosa em uma extremidade que é inserida no solo. Como o potencial muda com a variação da quantidade de água no solo, a água do tensiômetro flui para fora quando o potencial diminui e para dentro quando este aumenta. 0 movimento da água através da cápsula proporciona equilíbrio entre a energia no solo e no interior do tensiômetro pela ocorrência de variações na pressão do interior deste que é medida por um manômetro. Com o equilíbrio estabelecido obtém-se a altura ou a pressão que corresponde ao potencial da água no solo. 


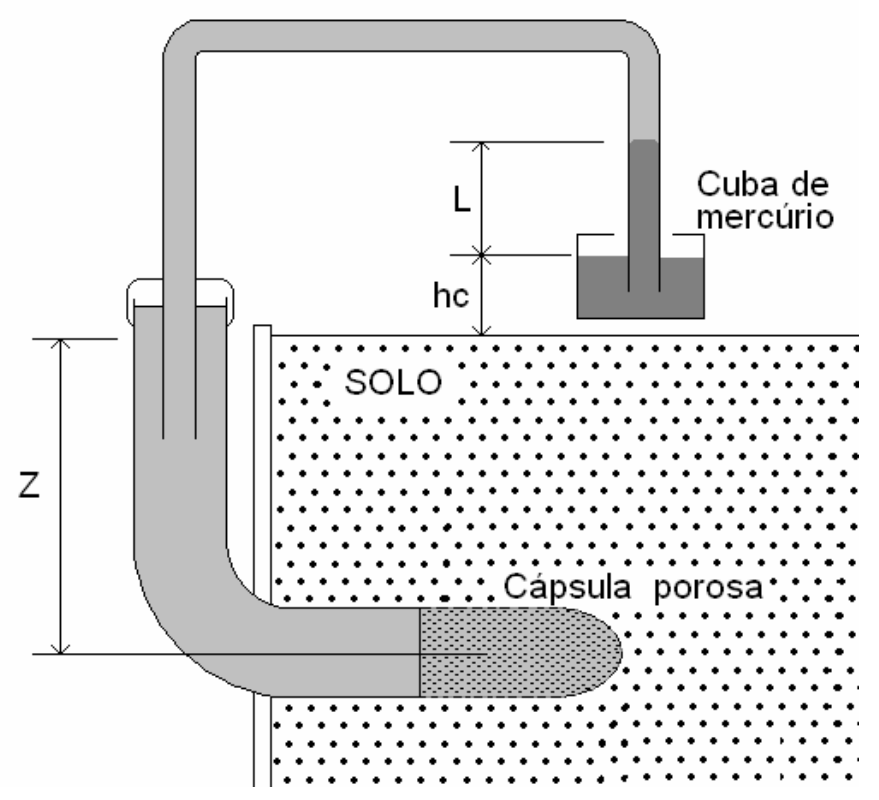

Figura 1 - Diagrama de um tensiômetro com manômetro de mercúrio.

As maiores variações entre tipos diferentes de tensiômetros estão principalmente no manômetro. Os manômetros de coluna de água são mais precisos, pois uma pequena variação no potencial gera uma grande variação na altura da coluna. Se ao invés de água for utilizado mercúrio (Figura 1), a sensibilidade aumenta por um fator de 12,5, porém a precisão decai na mesma razão. Outros tipos de manômetros e transdutores podem ser usados, existindo vários modelos, que podem apresentar grande sensibilidade e precisão, porém são muito mais caros, necessitam calibração, manutenção, e sua resposta é influenciada pela temperatura mais significativamente que os manômetros de água e mercúrio. Assim, em experimentos de campo utiliza-se normalmente o modelo com manômetro de mercúrio (Dirksen, 1999).

Para tensiômetros com manômetro de mercúrio calcula-se o potencial matricial $(\psi \mathrm{m}, \mathrm{m})$ em função da ascensão do mercúro $(L, m)$ pela equação:

$$
\psi_{\mathrm{m}}=-12,5 \mathrm{~L}+\mathrm{h}_{\mathrm{c}}+\mathrm{Z}
$$

onde $h_{c}(m)$ é a altura da cuba e $Z(m)$ a profundidade de instalação do tensiômetro.

O tempo de resposta de um tensiômetro depende de fatores como a condutância da cápsula e sua instalação no solo (Klute \& Gardner, 1965; Dirksen, 1999). Quanto maior a 
condutância menor será o tempo de resposta, e em solos com muito baixa condutividade ou no caso de um contato ruim com o solo, por má instalação ou em solos muito expansivos, o tempo de resposta aumentará e pode comprometer a medição. Quanto menor o volume de água necessário a ser trocado para estabelecer o equilíbrio entre solo e tensiômetro, menor será 0 tempo de resposta. Alguns transdutores fornecem leituras quase instantâneas, ao passo que manômetros de água são os mais demorados (Dirksen, 1999).

À temperatura ambiente, em torno de $25^{\circ} \mathrm{C}$, a água entra em ebulição quando a pressão do ar reduz-se a $3 \mathrm{kPa}$, o que equivale, ao nível do mar, a uma pressão relativa à atmosférica de $-95 \mathrm{kPa}$. Na prática, admite-se um funcionamento confiável até -80 a $-90 \mathrm{kPa}$ (Klute, 1986, Arruda et al. 1987). A variação das leituras aumenta quando o potencial fica mais negativo. A formação de bolhas de ar na água do tensiômetro é prejudicial ao correto funcionamento do tensiômetro e por esse motivo a água utilizada deve ser deaerada, o material de confecção deve ser impermeável e ainda evita-se trabalhar em condição muito seca. Caso formem-se bolhas deve-se fluxar o tensiômetro, ou seja, trocar a água expulsando as bolhas. Para diminuir os erros pelo efeito da temperatura, o manômetro no campo deve estar protegido da luz direta do sol e ainda é aconselhável efetuar as leituras preferencialmente ao longo do tempo na mesma hora do dia.

Para transformar as medições do potencial matricial do tensiômetro em umidades é necessário conhecer a relação entre o potencial matricial e o teor de água de um solo, que é descrita pela curva de retenção da água no solo.

Para confecção da curva de retenção obtém-se pares de dados de umidade e potencial da água, em geral utilizando-se amostras montadas em laboratório ou coletadas indeformadas num local representativo do terreno. Estas amostras são submetidas a tensões ou pressões conhecidas e, por meio de pesagem, determina-se a umidade correspondente. Para potenciais pequenos, a tensão pode ser facilmente aplicada por uma coluna d'água em desnível (Figura 2a), utilizando-se placas porosas ou outro material poroso que proporcione bom contato e entre em equilíbrio com a amostra de solo. A areia fina pode ser um bom material para tensões equivalentes a até 1,2 m (Dirksen, 1999). Para potenciais maiores equipamentos com placas 
porosas e pressão controlada são utilizados (Figura 2b), como a câmara de Richards (Klute, 1986; Dirksen, 1999).

Existem vários modelos matemáticos que podem ser ajustados aos dados de umidade e potencial para descrever a curva de retenção (Bruce \& Luxmoore, 1986). Um dos mais utilizados é o modelo descrito pela equação (6), conhecido como modelo de Mualem-van Genuchten (Mualem, 1976; van Genuchten, 1980), que relaciona a umidade a base de volume $(\theta)$ ao valor absoluto do potencial matricial $\left(\left|\psi_{\mathrm{m}}\right|\right)$ :

$$
\theta=\theta_{r}-\frac{\theta_{s}-\theta_{r}}{\left[1-\left(\alpha \cdot\left|\psi_{m}\right|\right)^{m}\right]^{n}}
$$

Este modelo considera um patamar mínimo para umidade $\left(\theta_{r}\right)$, a umidade residual, geralmente não nulo, que é atingido em potenciais infinitamente negativos, e um patamar máximo, $\theta_{\mathrm{s}}$ (umidade de saturação), atingida com potencial matricial nulo. Estes dois parâmetros podem ser mensurados ou estimados e os parâmetros empíricos $\alpha$, $m$ e $n$ são estimados por regressão. Este modelo é bastante utilizado por apresentar bom desempenho, mas como em qualquer modelo, a extrapolação de valores para fora da faixa observada deve ser feita com cautela.

A retenção de água no solo, assim como outras propriedades hidráulicas, apresenta variabilidade elevada (Souza \& Reichardt, 1996; Marciano et al., 1998). Ao se confeccionar a curva de retenção de um solo podem ocorrer erros consideráveis se poucas amostras forem utilizadas, ou se elas forem mal coletadas ou mal trabalhadas. A variância das leituras e a variabilidade espacial devem sempre ser preocupação em trabalhos com a curva de retenção (Bruce \& Luxmoore, 1986; Cassel \& Klute, 1986). A rotina de laboratório para determinação dos pontos para compor a curva de retenção também deve ser executada com cuidado. Um mau contato das amostras com as placas porosas e falhas na determinação do volume ou da umidade correspondente a certo potencial podem alterar sensivelmente o padrão final da curva obtida ou aumentar a dispersão dos pontos, e em conseqüência a variância ou a incerteza da relação. Descrições mais detalhadas destas rotinas, bem como da amostragem podem ser encontradas na literatura (Cauduro \& Dorfman, s.d; Klute, 1986; Dirksen; 1999). 

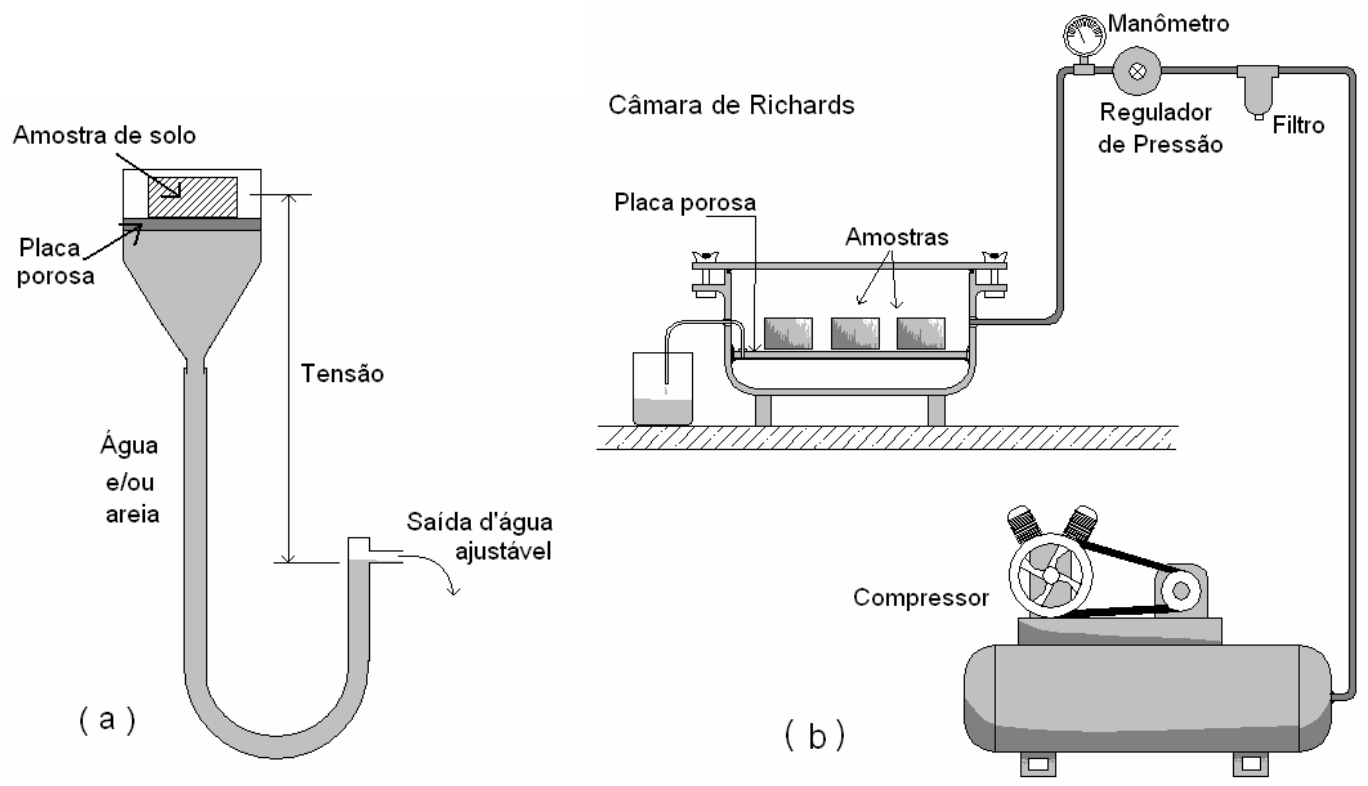

Figura 2 - Equipamentos laboratoriais para determinação da curva de retenção da água no solo, (a) funil com placa porosa, (b) câmara de Richards.

\subsection{REFLECTOMETRIA NO DOMÍNIO DO TEMPO}

Qualquer material, puro ou composto, pode ser descrito e ter seu estado caracterizado por algumas grandezas físicas (massa, volume, temperatura, umidade, etc.). Nesse sentido 0 comportamento dielétrico de um dado material é descritível pela sua permissividade ( $\varepsilon$, expressa em F m${ }^{-1}$ ), ou, como é mais comum, pela permissividade relativa ou constante dielétrica (k), que é a razão da permissividade do material pela do vácuo $\left(8,854 \cdot 10^{-12} \mathrm{~F} \mathrm{~m}^{-1}\right)$. 0 nome "constante dielétrica" não é muito apropriado pois essa propriedade é bastante variável, função da freqüência, da temperatura, da umidade, etc. do material (Dirksen, 1999). A permissividade relativa indica em quanto aumenta a capacitância de um capacitor ao substituir o vácuo como meio dielétrico pelo material em questão (Tomaselli, 1997).

A permissividade como uma característica eletromagnética pode ser expressa matematicamente por um número com uma parte real ( $\varepsilon^{\prime}$ ou k') e outra imaginária ( $\varepsilon^{\prime \prime}$ ou k”):

$$
\varepsilon=\varepsilon^{\prime}+\mathrm{j} \varepsilon^{\prime \prime} \text { ou } k=k^{\prime}+\mathrm{jk} k^{\prime \prime}
$$


Para 0 solo, considerando freqüências altas da ordem de $10^{6} \mathrm{~Hz}$, a parte imaginária pode ser desprezada e então a permissividade de um material pode ser conhecida pela mensuração apenas de sua parte real (Tomaselli, 1997). As teorias do eletromagnetismo fornecem também a relação expressa na equação (7), onde a velocidade de um pulso eletromagnético $\left(\mathrm{v}, \mathrm{em} \mathrm{m} \mathrm{s}^{-1}\right)$ em um meio condutor é dada pela razão da velocidade da luz no vácuo $\left(c=3.10^{8} \mathrm{~m} \mathrm{~s}^{-1}\right)$ e a raiz quadrada da permissividade relativa do material circundante $(\mathrm{k})$.

$$
v=\frac{c}{\sqrt{k}}
$$

Esta relação mostra que as interações eletromagnéticas com o meio retardam o pulso, ou seja, extraem parte de sua energia. Quantificar esta perda e conseqüentemente determinar a permissividade relativa exige dispositivos com precisão suficiente para medir velocidades de ordem de grandeza semelhante à da luz. Se através de uma haste metálica de comprimento $L$ for emitido um pulso de voltagem, ele irá se propagar até o final da haste onde encontrará um estrangulamento eletrônico, causado pela mudança de impedância, e um pulso ressonante irá retornar até 0 início. Medindo o tempo $t$ transcorrido entre a emissão do pulso e a recepção do eco pode-se determinar a velocidade de propagação (eq. (8)) e assim a permissividade dielétrica relativa do meio que contém a haste (eq. (9)). Este é o princípio de funcionamento da reflectometria no domínio do tempo.

$$
\begin{aligned}
& v=\frac{2 . L}{t} \\
& k=\left(\frac{c . t}{2 . L}\right)
\end{aligned}
$$

A medição da constante dielétrica dos materiais encontrou aplicações já no começo do século XX, inicialmente nas pesquisas físicas e químicas e posteriormente em disciplinas aplicadas da engenharia, especialmente em algumas áreas da eletrônica, como em testador de cabos telefônicos, por exemplo. Investigações a cerca da interação da transmissão de ondas de rádio e 0 meio ambiente mostraram as primeiras relações entre os vários materiais e a velocidade de propagação das ondas eletromagnéticas. No solo estudou-se o comportamento destas transmissões e a sua relação com a umidade, temperatura e conteúdo de sal nos solos, 
inclusive com a variação das freqüências utilizadas. Destes estudos surgiram as primeiras iniciativas de utilizar a medição da constante dielétrica para a determinação da umidade em meios porosos (Fletcher, 1939). A Tabela 1 exibe o valor da permissividade relativa de alguns materiais, onde se pode observar que a permissividade da água é muito superior à dos outros materiais constituintes do solo, fazendo com que a permissividade relativa aparente do solo seja definida basicamente pelo seu teor de água.

Tabela 1. Permissividade relativa de alguns constituintes do solo.

\begin{tabular}{lc}
\hline Material & Permissividade relativa \\
\hline Ar & 1 \\
Água $\left(20^{\circ} \mathrm{C}\right)$ & 80 \\
Gelo $\left(-3^{\circ} \mathrm{C}\right)$ & 3 \\
Basalto & 12 \\
Granito & $7-9$ \\
Silte seco & 3,5 \\
Areia seca & 2,5 \\
\hline
\end{tabular}

Fonte: Curtis \& Defandorf, 1929, in Noborio, 2001.

O procedimento de medida da constante dielétrica usando reflectometria no domínio do tempo, no entanto, somente foi introduzido em 1969 por Fellner-Feldegg, e o uso deste procedimento para determinação da quantidade de água no solo por Davis e Chudobiak (1975). Vários estudos posteriores contribuíram para uma melhor compreensão das interações das várias características e propriedades do solo com seu comportamento dielétrico (Hipp, 1974; Hoekstra \& Denaley, 1974; Baker \& Lascano, 1989).

Trabalhos posteriores vêm apurando o conhecimento do uso desta técnica em equipamentos para determinação de umidade e seu relacionamento com o comportamento dielétrico dos solos. Os estudos procuram verificar a existência de influências na resposta dos equipamentos frente às mudanças na permissividade do solo induzidas em função de variações nos atributos físico-químicos do solo. 
Os relatos são por vezes contraditórios, alguns afirmando que há influencias significativas e outros assegurando ser negligenciável o efeito da variação dos atributos do solo. O que se percebe é que alguns tipos de solo, por sua constituição físico-química, tornam seu comportamento dielétrico mais sensível a variações na granulometria, densidade ou constituição químico-mineralógica. De um modo geral, a densidade do solo não se apresenta como um fator restritivo ao uso desta técnica. Sua influencia é pequena para a maioria dos solos, sendo importante em solos expansivos. (Topp et al., 1980; Sabburg et al., 1997; Noborio, 2001). Um problema com relação à densidade é a instalação do equipamento, pois perturbações no entorno das hastes podem alterar sensivelmente o desempenho do equipamento de TDR (Dasberg et al., 1995; Bridge et al., 1996). A granulometria também pode afetar a relação da umidade e a permissividade aparente do solo, o que pode ser explicado pela influência da mineralogia, em especial das argilas, na permissividade da água no solo. A influência do teor de argila é associada à retenção da água na superfície das partículas, de modo que a permissividade da água é reduzida (Topp et al., 1980; Dirksen \& Dasberg, 1993; Bridge et al., 1996; Chudinova \& Ponizovskii, 1998; Ponizovsky et al., 1999). $O$ efeito da estrutura do solo no comportamento da permissividade do solo parece ser negligenciável (Keng \& Topp, 1983). Também verificaram-se variações importantes no comportamento dielétrico do solo em ambientes tropicais, onde os solos possuem alto teor de óxidos de ferro e alumínio, mas essas interações ainda não são muito bem conhecidas (Dirksen \& Dasberg, 1993; Robinson, 1994; Tomaselli, 1999). $O$ efeito do teor de sal também mostrou-se pouco significativo, sendo importante apenas se for muito elevado (Topp et al., 1980; Dasberg \& Dalton, 1985). A presença de teores salinos, no entanto, altera o formato do sinal eletromagnético do TDR, permitindo assim a utilização do TDR para estimar a salinidade do solo ou ainda o movimento de solutos (Dalton \& van Genuchten, 1986; Vogeler et al., 1996). A temperatura altera a permissividade dos materiais e assim também exerce influência no uso do TDR na determinação da umidade do solo. O grau de interferência da temperatura na permissividade aparente do solo é controverso, mas em geral pequeno; apenas em solos muito úmidos esta influência pode ser apreciável (Topp et al., 1980; Pepin et al., 1995; Or \& Wraith, 1999).

Várias possibilidades do uso da técnica do TDR vêm sendo estudadas. Tipos de sonda ou haste, cabos e outros componentes do equipamento, assim como métodos para 
automatização da técnica foram pesquisados (Topp et al., 1982b; Topp \& Davis, 1985; Herkelrath et al. 1991; Dasberg \& Hopmans, 1992; Hook et al., 1992; Knight,1992; Whalley, 1993; Dasberg et al., 1995; Hook \& Livingston, 1995; Hook \& Livingston, 1996; Huisman, 2001).

O equipamento utilizado para a determinação da permissividade dielétrica aparente do solo é constituído basicamente de um emissor de pulso, cabos, hastes (normalmente duas ou três) e um interpretador de sinal, que percebe a emissão do pulso eletromagnético e a chegada do pulso refletido, determinando assim o tempo de percurso (Figura 3). Uma característica importante que estimula o uso do TDR é o pequeno grau de perturbação do solo em sua instalação, porém quando se deseja conhecer a umidade em camadas mais profundas ou em várias camadas simultaneamente, é necessário cavar uma trincheira para atingir a profundidade desejada ou fazer uso de hastes modificadas. Para conhecer a permissividade relativa de uma certa camada do solo algumas sugestões foram apresentadas. Podem ser utilizadas hastes com segmentos de espessuras diferentes (Figura 4a), gerando vários pontos de reflexão do pulso eletromagnético, sendo porém bastante difícil a decodificação da resposta (Topp et al.,1980; Topp \& Davis, 1985; Feng et al., 1999). Também é possível utilizar um conjunto de hastes com comprimentos diferentes (Figura $4 b$ ), onde a resposta para a camada entre 0 término de uma haste e outra é o resultado da diferença entre as respostas das hastes (Miyamoto et al., 2001). Ainda sugere-se o uso de diodos que proporcionam um curto circuito entre as hastes, o que produz a reflexão do pulso e portanto a identificação da camada (Figura 4c). O uso de diodos também proporciona uma melhora na interpretação da resposta do TDR, ou seja, na identificação dos momentos da emissão e recepção do pulso eletromagnético (Zegelin et al., 1989; Hook et al., 1992; Hook \& Livingston, 1995). Com essa tecnologia surgiu o TDR de hastes segmentadas, que consiste de um conjunto de duas hastes subdivididas eletronicamente por diodos que delimitam a extensão dos segmentos. A leitura de cada segmento é feita pela emissão de um pulso e 0 fechamento de um diodo, seguida de outro pulso e o fechamento do diodo localizado no outro extremo do segmento. A diferença entre as duas leituras corresponde à leitura no segmento. Uma grande vantagem deste tipo de haste é a possibilidade de mensuração do perfil de umidade do solo com um mínimo de alteração na sua estrutura e com um único conjunto de hastes, o que facilita sua instalação e a medição em profundidade sem a necessidade de abertura de uma trincheira. 


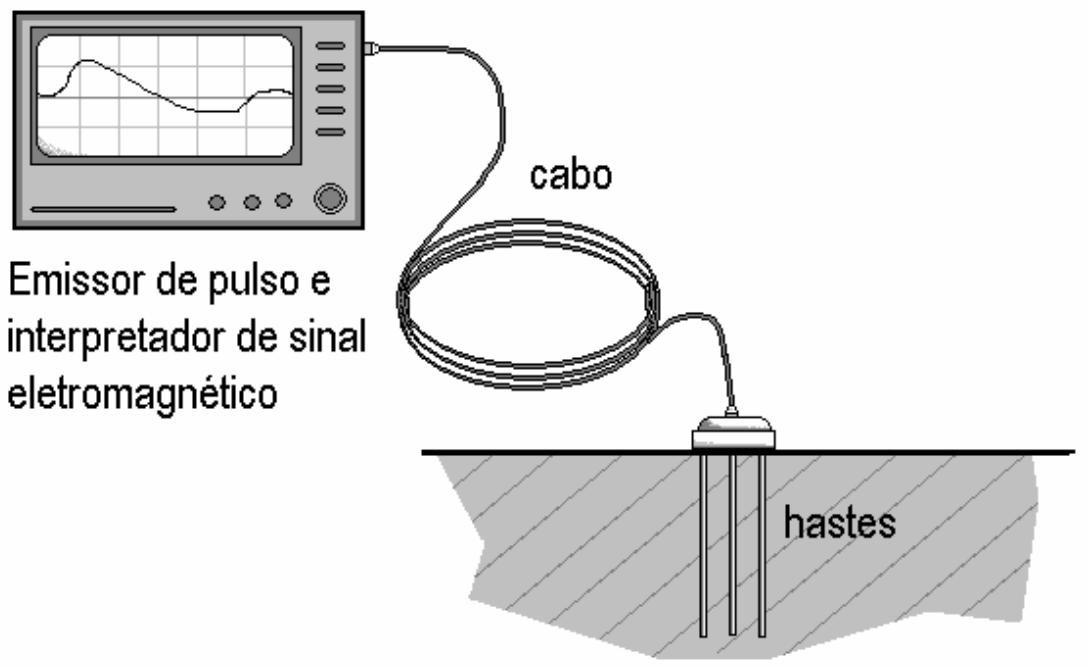

Figura 3 - Diagrama dos componentes básicos de um equipamento de TDR.
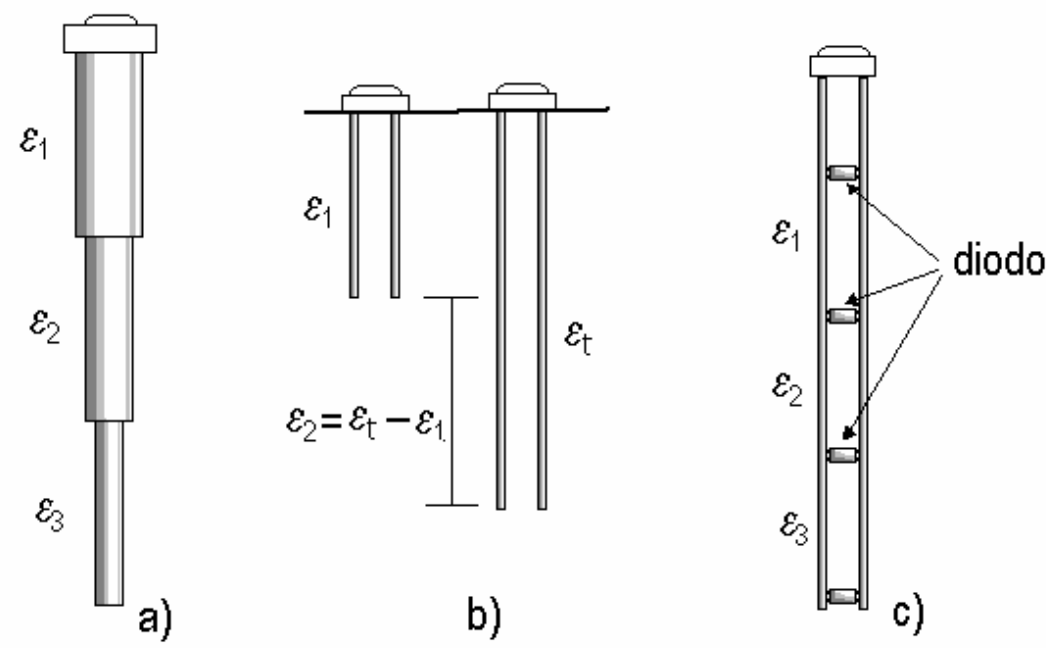

Figura 4 - Tipos de sondas de TDR que permitem identificar diferentes camadas (a) sonda com segmentos de diferentes bitolas, (b) sondas de diferentes comprimentos e (c) sonda segmentada eletronicamente por diodos.

Em 1980, Topp et al. propuseram uma relação empírica entre umidade do solo $(\theta)$ e constante dielétrica $(\mathrm{k})$, que serviria para uma ampla gama de tipos e texturas de solos, motivo pelo qual esta relação ficou conhecida como "Equação Universal" de calibração do TDR:

$$
\theta=0,053+0,0229 k-0,00055 k^{2}+0,0000043 k^{3}
$$

Vários estudos mostraram concordância com este modelo de calibração (por exemplo, Topp et al., 1982a; Topp \& Davis, 1985; Drungil et al., 1989; Grantz et al. 1990), por outro lado 
diversos trabalhos relatam discordâncias, sendo então propostos outros modelos (Dobson et al., 1985; Ledieu, 1985; Hook et al., 1992; Jacobsen \& Schjonning, 1992; Roth et al.; 1992; Dirksen \& Dasberg, 1993; Young et al; 1997; Yu et al., 1997; Yu et al., 1999). Estes modelos podem ser empíricos, teóricos ou mistos. Verifica-se que nenhum dos modelos se ajusta adequadamente a todos os dados reais. Por isso é comum efetuar-se uma calibração particular para cada situação de uso, em especial quando uma acurácia maior é desejada.

A calibração pode ser efetuada por uma relação entre a umidade e a permissividade dielétrica, em geral uma relação polinomial, ou entre a umidade e o tempo mensurado pelo TDR, que resulta comumente em uma reta. Considerando que a permissividade dielétrica aparente do solo é o somatório ponderado (pelo volume) da permissividade de seus constituintes, é possível chegar a uma relação linear entre o teor de água do solo e o tempo medido pelo TDR (eq. ( 11 )). Esta é a relação comumente utilizada para equipamentos de TDR com hastes segmentadas, mas outras relações lineares também são utilizadas.

$$
\theta=\left(\frac{T_{\text {tdr }}}{T_{\text {ar }}}-\frac{T_{\mathrm{s}}}{T_{\text {ar }}}\right) \cdot \frac{1}{\left(\sqrt{k_{a}}-1\right)}
$$

Nesta equação, $T_{\text {tdr }}$ é o tempo medido pelo aparelho de TDR, $T_{\text {ar }}$ é o tempo medido no ar, $T_{s}$ é os tempo estimado para a leitura nos sólidos do solo e $k_{a}$ a permissividade relativa da água.

A calibração no campo ou sua validação, além do comportamento da relação entre permissividade dielétrica e umidade frente à variabilidade natural do solo in situ ainda não são muito estudadas (Topp \& Davis, 1985, Dasberg et al., 1995, Serrarens et al., 2000). A principal razão para isso é a dificuldade de se estimar a umidade simultaneamente por um outro método, sem interferir na leitura do TDR. Assim não é conhecido se há algum tipo de interação das características in situ do solo e a calibração do TDR, tanto em termos de variabilidade geral como em variabilidade espacial. Também é incógnito o grau de variação entre hastes instaladas em conjunto num mesmo terreno, nem seu comportamento ao longo do tempo. Um estudo neste sentido deve melhorar o conhecimento sobre a aplicabilidade desta técnica no campo. 


\section{MATERIAL E MÉTODOS}

\subsection{LOCAL}

Visando a obtenção de leituras simultâneas do TDR e de tensiômetros, um experimento foi realizado em um terreno localizado no campus da ESALQ/USP, em Piracicaba, SP (coordenadas $22^{\circ} 42^{\prime} 30^{\prime \prime}$ S e $47^{\circ} 38^{\prime} 00^{\prime \prime}$ W). 0 solo do local, visualmente homogêneo, é um Latossolo Vermelho-amarelo, Álico, de textura média, e o relevo varia de suave ondulado a plano, com declividade inferior a $0,01 \mathrm{~m} \mathrm{~m}^{-1}$. Os equipamentos de medição foram instalados em uma transeção seguindo aproximadamente uma linha de mesma cota, dispostos em 48 baterias, separadas de um metro entre si. Cada bateria foi composta por uma sonda segmentada de TDR e cinco tensiômetros (Figura 5) instalados a aproximadamente $0,10 \mathrm{~m}$ ao redor da haste do TDR, com o meio de suas cápsulas porosas nas profundidades de $0,075,0,225,0,375,0,525$ e 0,675 $\mathrm{m}$, correspondendo à profundidade média de cada segmento do TDR.

O local, livre de plantas, foi todo coberto com lona plástica preta, num entorno de $10 \mathrm{~m}$ ao redor da transeção (Figura 6), tendo em vista que a instalação foi concebida para experimentos com o método do perfil instantâneo de determinação da condutividade hidráulica do solo (Mello Filho et al., 2002). Os manômetros de mercúrio e os conectores dos cabos do TDR ficavam no limite desta cobertura, estando ligados às baterias por meio de conduítes (Figura 7). Após a instalação determinou-se a altura da cuba ( $h_{c}$, Figura 1 e eq. ( 5 )) para cada bateria por meio de régua d'água. 


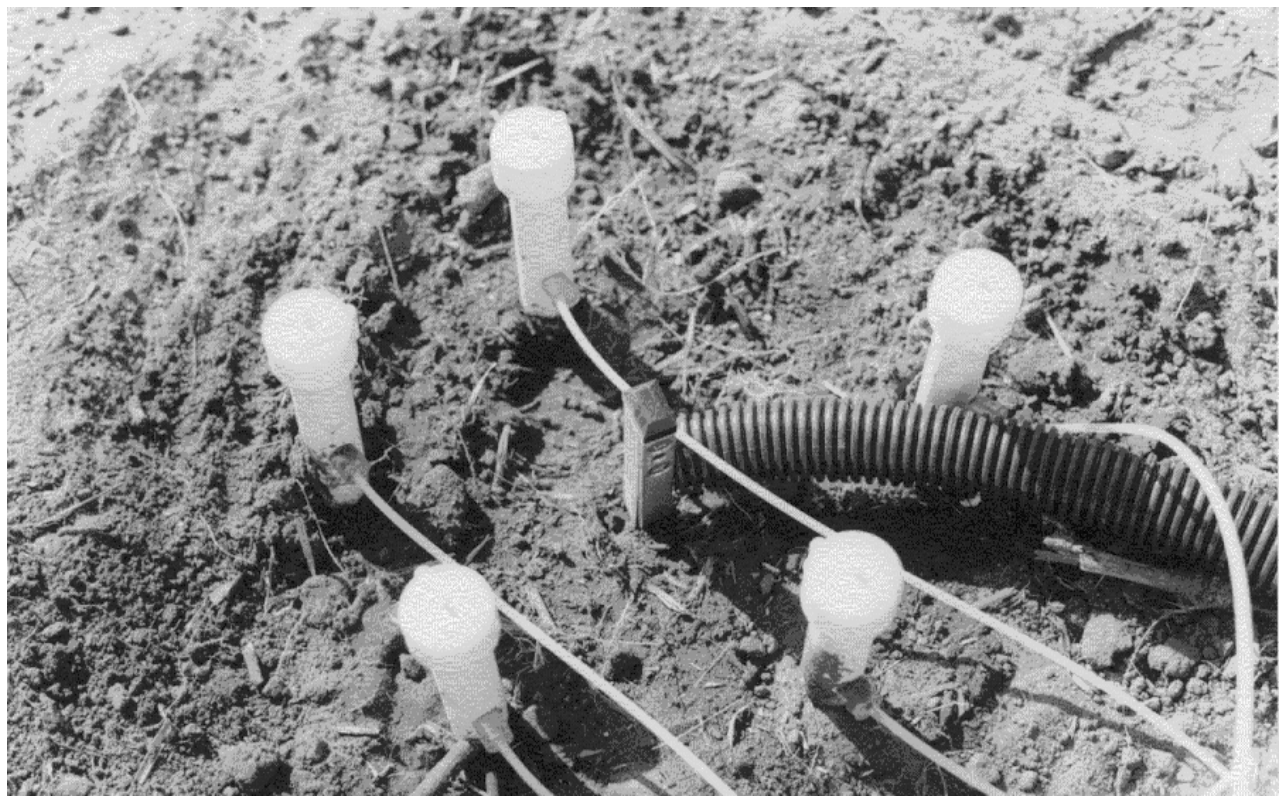

Figura 5 - Disposição de cada conjunto ou bateria; sonda de TDR no centro e tensiômetros ao redor.

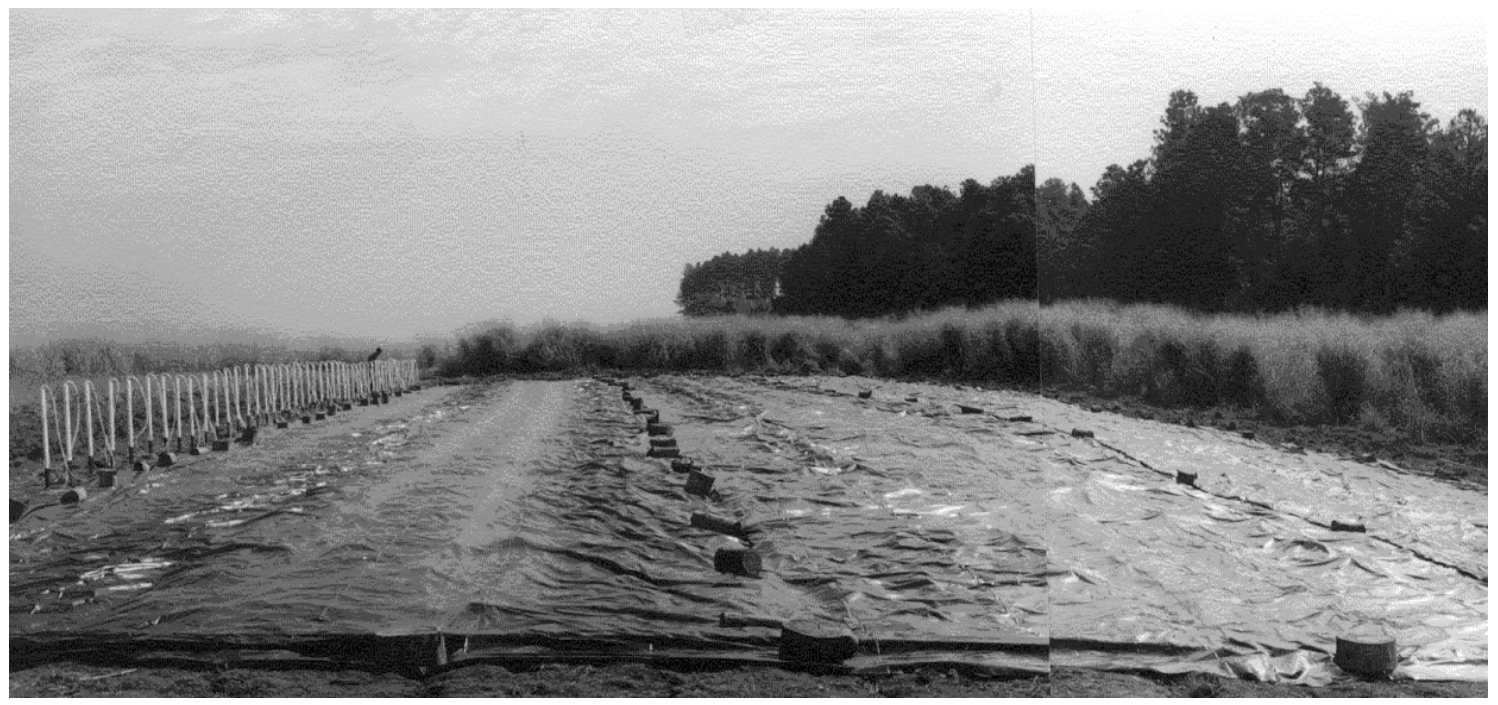

Figura 6 - Vista geral do experimento já coberto pela lona; à esquerda encontram-se os manômetros e os conectores dos cabos do TDR. 


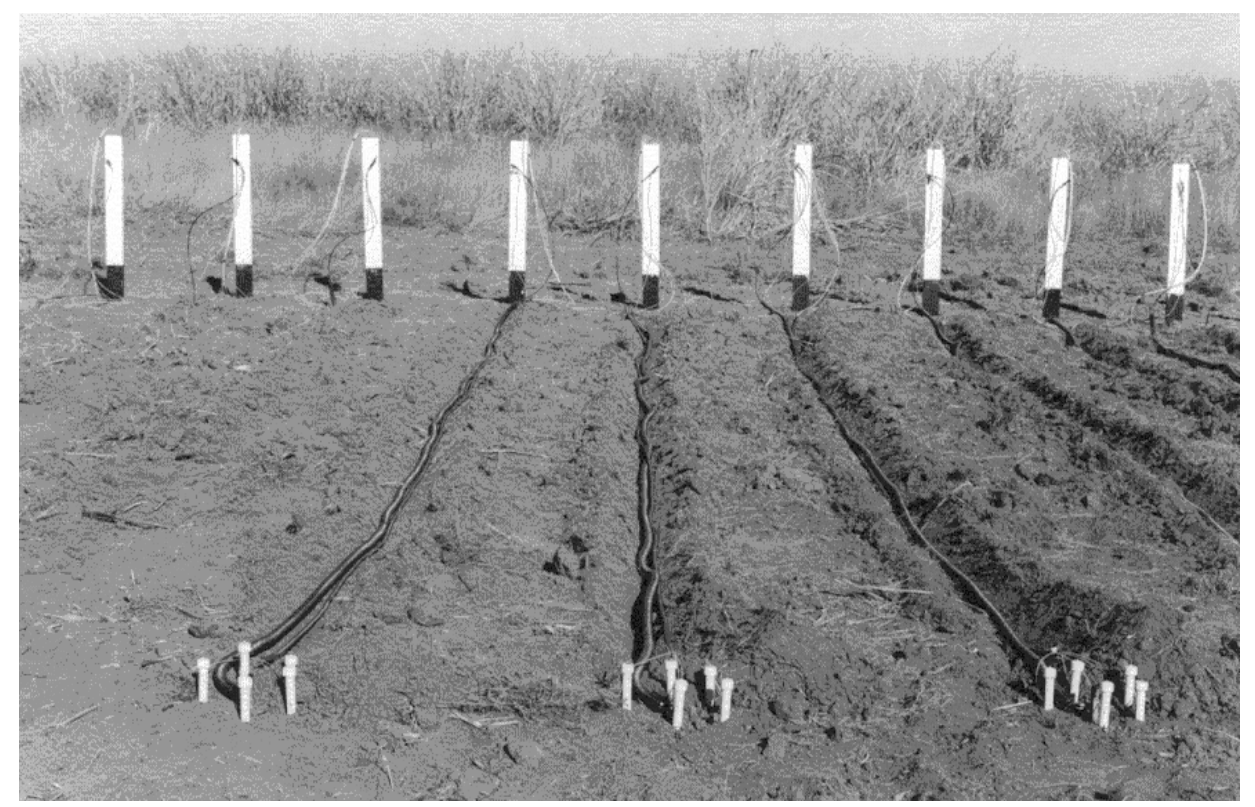

Figura 7 - Vista do experimento em fase de instalação, mostrando a disposição dos manômetros ao fundo e sua ligação com as baterias por meio de conduítes (posteriormente enterrados).

\subsection{CURVAS DE RETENÇÃo}

Objetivando a diminuição dos erros relacionados à variabilidade do solo, ao invés de utilizar uma curva para toda a área, foram confeccionadas 24 curvas de retenção ao longo da transeção para cada camada. Para isso, amostras de solo foram coletadas entre cada duas baterias e as respectivas curvas foram utilizadas para os dois pontos vizinhos, imediatamente anterior e posterior (Figura 8). Desta forma, a distância média entre o ponto de coleta das amostras para a confecção das curvas e a bateria de tensiômetros a que representa foi de $0,5 \mathrm{~m}$. Para atingir as várias profundidades foi utilizado um trado com $0,15 \mathrm{~m}$ de diâmetro, confeccionado para abrir buracos com fundo plano (Figura 9). Utilizou-se um amostrador de Uhland com anéis com diâmetro de $0,046 \mathrm{~m}$ e $0,03 \mathrm{~m}$ de altura para fazer amostragens nas profundidades médias de $0,075,0,225,0,375,0,525$ e $0,675 \mathrm{~m}$.

Depois de coletadas, as amostras foram protegidas por papel alumínio, numeradas, embaladas em saco plástico e guardadas em refrigerador até o momento de seu processamento. 
Paralelamente foram coletadas amostras para determinação de alguns atributos físicos, os quais foram a densidade do solo, a densidade de partículas e os teores de argila, silte e areia, que poderiam estar relacionados a variações nas leituras do TDR.

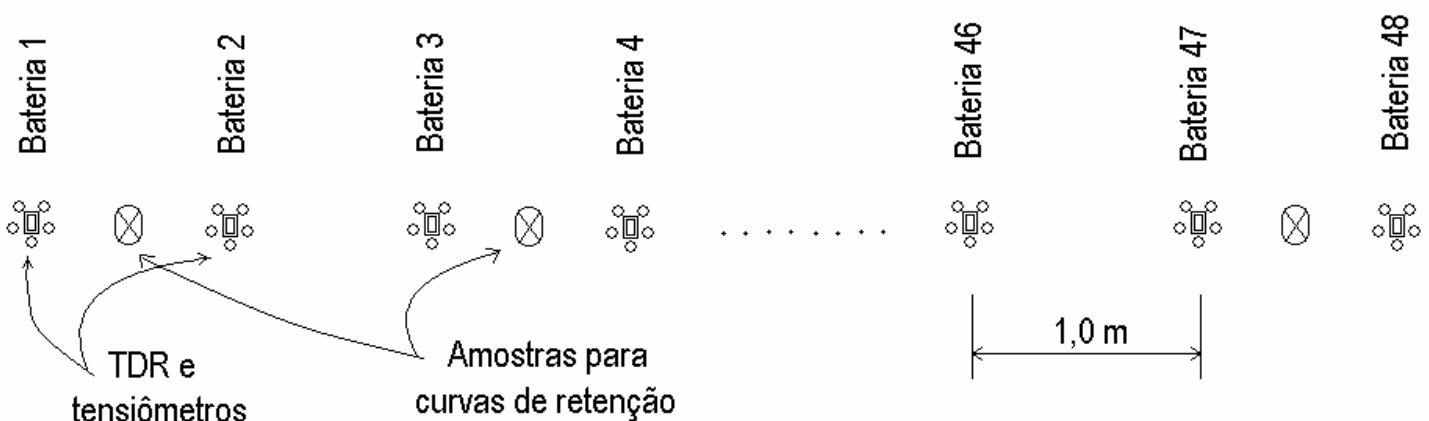

Figura 8 - Esquema da disposição das baterias na transeção e da amostragem para confecção das curvas de retenção

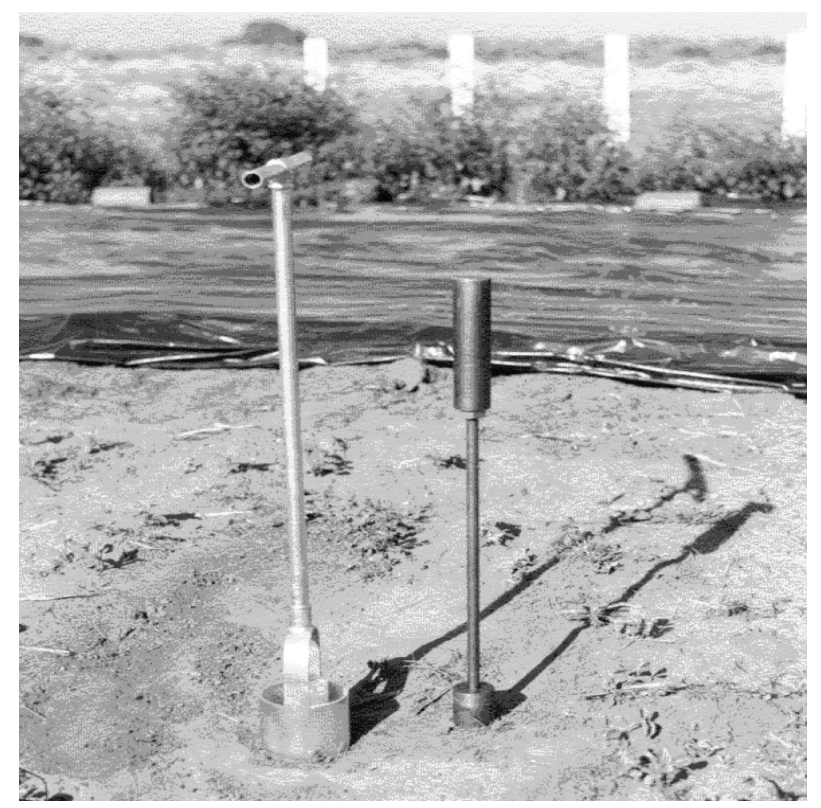

Figura 9 - Trado para acesso a camadas profundas e amostrador de Uhland.

Os pares de dados para a confecção da curva característica de retenção de água no solo (tensão e umidade) foram obtidos no laboratório de física do solo do Departamento de Ciências Exatas da ESALQ/USP. Os dados correspondentes às tensões de 0,5; 1,0; 2,0; 4,0 e $6,0 \mathrm{kPa}$ foram obtidos em caixa de areia (Figura 10), e os pontos de 10,33,50 e $100 \mathrm{kPa}$ foram 
obtidos em uma câmara de pressão de Richards, seguindo procedimento semelhante ao descrito por Klute (1986). De posse dos dados de tensão versus umidade ajustou-se o modelo de Mualem-van Genuchten (eq. (6)) aos dados. Para estimar os parâmetros do modelo foram utilizadas rotinas computacionais que utilizam o método estatístico da minimização dos quadrados dos erros (Sen \& Srivastava, 1990)

A caixa de areia usada consistiu de num conjunto de caixa de plástico de 0,28 metros por 0,35 metros, com uma camada de areia (peneira 100) de $0,1 \mathrm{~m}$ de altura. Esta caixa é acoplada a um tubo de PVC de 1,20 m de comprimento, contendo a mesma areia, ligado por uma mangueira a um tubo de vidro escalonador de tensões (Figura 10), funcionando por equilíbrio entre o potencial matricial (areia e solo) e o gravitacional (escalonador de tensões), de forma semelhante a um funil de tensão ou uma mesa de tensão.

A determinação da densidade do solo foi efetuada pelo procedimento clássico com coleta de amostra indeformada e secagem em estufa, enquanto a densidade dos sólidos seguiu procedimento do balão volumétrico, conforme descrito em Cauduro \& Dorfman (s.d.). A granulometria foi determinada pelo método da pipeta. Estas análises também foram efetuadas no laboratório de física do solo do Departamento de Ciências Exatas da ESALQ/USP. 


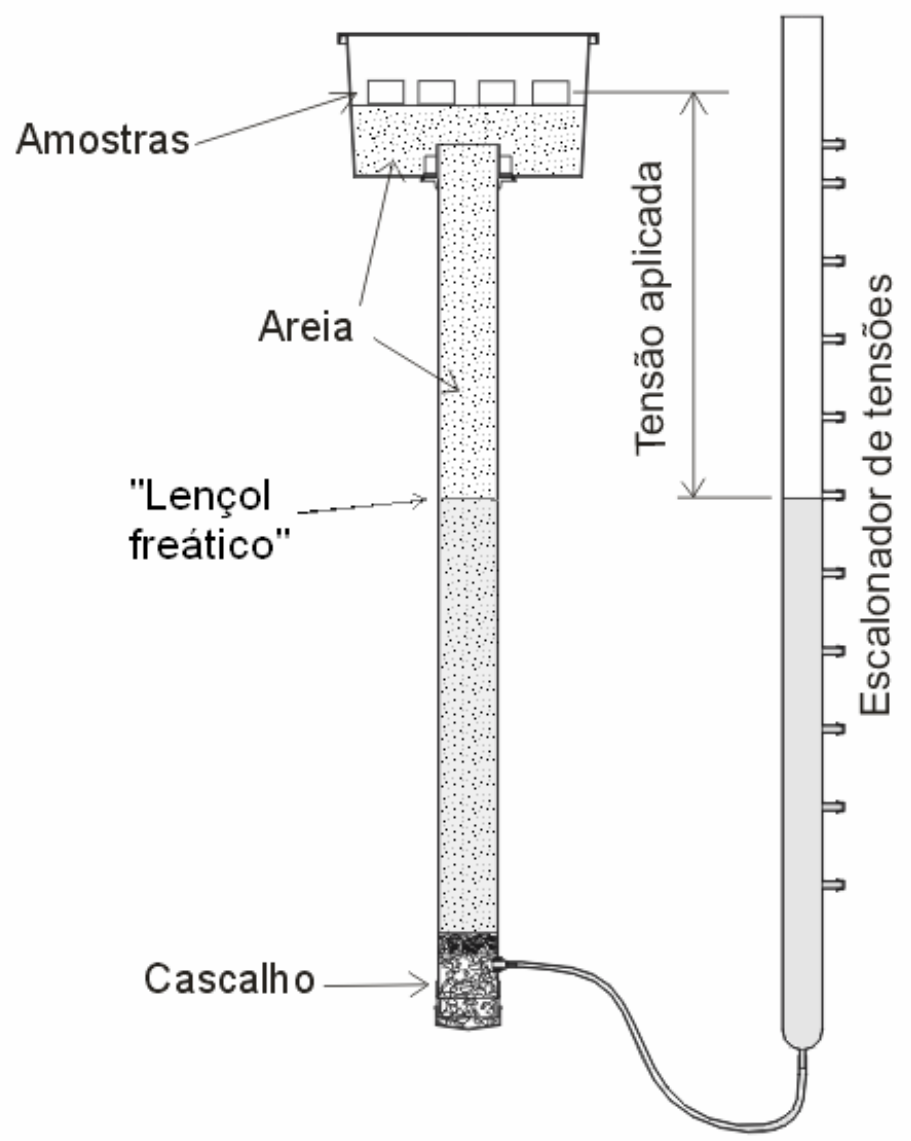

Figura 10 - Esquema da caixa de areia utilizada para a determinação da umidade das amostras para potenciais matriciais de $-0,05$ a $-0,40 \mathrm{kPa}$.

\subsection{EQUIPAMENTOS}

O dispositivo de TDR que foi utilizado é produzido pela ESI (Environmental Sensors Inc., Victoria, BC, Canadá), sendo denominado Moisture Point, modelo MP-917, com hastes, ou sondas, divididas eletronicamente em cinco segmentos de $0,15 \mathrm{~m}$ cada (Figura 11). A leitura efetuada por este equipamento corresponde à permissividade aparente do solo integrada ao longo de cada segmento, ou seja, estima a umidade para a camada de espessura igual a do segmento. Cada haste é composta por duas guias metálicas unidas por seis diodos, que delimitam os segmentos, e pela fiação que os controla, tudo inter-guias e encapsulado por resina epóxi. O módulo de leitura, que emite, recebe e interpreta o pulso eletromagnético, bem como 
controla o abrir e fechar dos diodos, é portátil, fornecendo leituras em nanossegundos para cada segmento em seqüência. A ligação entre as hastes e o módulo de leitura é feita por cabos coaxiais para o pulso eletromagnético e cabos de cobre para controle dos diodos. Os princípios de funcionamento deste tipo de sonda podem ser encontrados na literatura (Zegelin et al., 1989; Livingston \& Hook, 1996) ou na página da empresa na internet (http://www.esica.com).

Devido à disposição entre as hastes de seus componentes, diodos e os fios que os controlam, a leitura inicial obtida pelo TDR deve ser corrigida. A correção é simples e determinada pela equação ( 12 ), onde o tempo corrigido $\left(T_{C}\right)$ é obtido a partir do tempo medido $\left(T_{m}\right)$ dividido por um fator $c_{1}$ e diminuído de $c_{2}$, cujos valores são específicos para cada segmento. A Tabela 2 expõe os valores dos parâmetros utilizados na correção das leituras do aparelho de TDR fornecidos pelo fabricante. Os segmentos são descritos por letras em ordem alfabética de cima para baixo.

$$
\mathrm{T}_{\mathrm{C}}=\frac{\mathrm{T}_{\mathrm{m}}}{\mathrm{C}_{1}}-\mathrm{C}_{2}
$$

Tabela 2. Valores dos parâmetros usados na equação de correção das leituras do TDR, equação (12), fornecidos pelo fabricante.

\begin{tabular}{cccc}
\hline Segmento/camada & Profundidade $(\mathrm{m})$ & $\mathrm{c}_{1}$ & $\mathrm{C}_{2}$ \\
\hline A & $0-0,15$ & 0,659 & 1,013 \\
B & $0,15-0,30$ & 0,658 & 1,136 \\
C & $0,30-0,45$ & 0,627 & 0,611 \\
D & $0,45-0,60$ & 0,693 & 0,897 \\
E & $0,60-0,75$ & 0,679 & 0,937 \\
\hline
\end{tabular}

Os tensiômetros utilizados possuíam manômetros de mercúrio sendo construídos em tubo de PVC com cápsulas de cerâmica porosa, testadas para garantir que possuíssem pressão de borbulhamento superior a $80 \mathrm{kPa}$.

A instalação dos equipamentos de TDR seguiu procedimento recomendado pelo fabricante, onde é inserida no solo uma guia metálica que é substituída pela haste. A guia possui dimensões levemente inferiores às da haste, 0 que concorre para que haja um bom contato desta 
com o solo. Um procedimento semelhante foi seguido para os tensiômetros, com a utilização de um trado para fazer o furo guia. Uma descrição dos procedimentos utilizados na instalação dos tensiômetros pode ser encontrada em Bruce \& Luxmoore (1986). Para prevenir ainda mais quaisquer problemas de contato das sondas TDR ou das cápsulas dos tensiômetros com o solo, a instalação foi efetuada cerca de 60 dias antes do início da coleta da primeira série de dados.

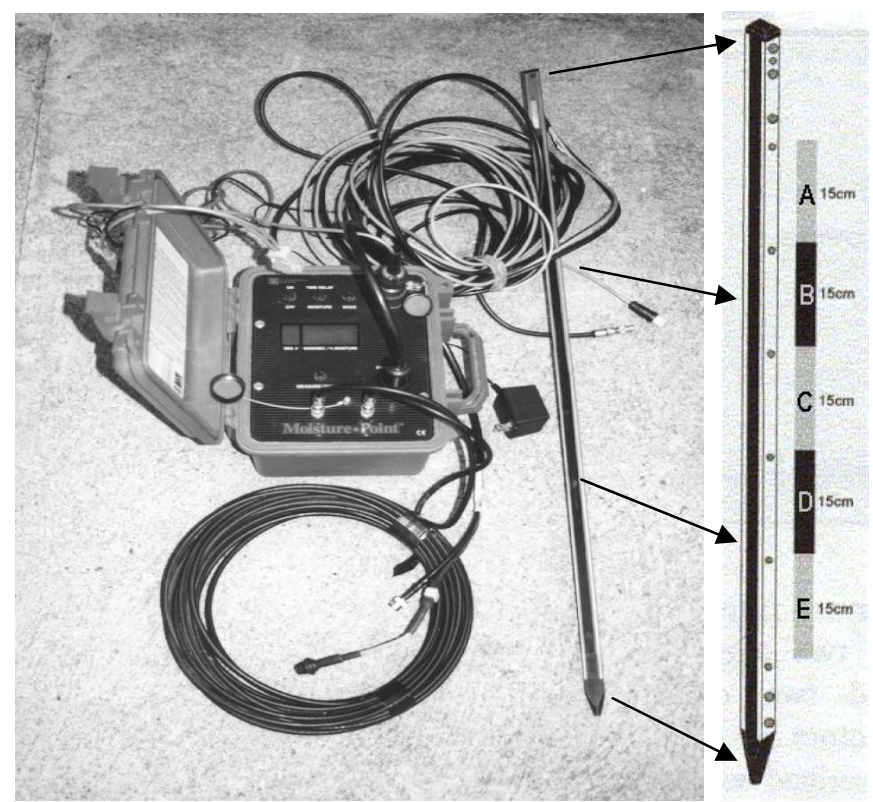

Figura 11 - Equipamento de TDR - emissor de pulso/leitor, cabos e sonda, no detalhe vê-se os segmentos de cada haste.

\subsection{COLETA DOS DADOS}

Foram coletados dois conjuntos de dados compostos da leitura do aparelho de TDR e da leitura do manômetro de mercúrio. 0 primeiro conjunto corresponde ao período de observação no ano de 2000, entre os dias 19 de julho e 15 de agosto, o segundo ao período em 2001, entre os dias 03 de outubro e 22 de novembro. A umidade foi obtida utilizando-se as curvas características de retenção de água no solo obtidas em laboratório. As leituras foram tomadas simultaneamente, ponto a ponto, de forma a representarem a condição do solo no mesmo 
instante. O horário de leitura foi preferencialmente o início da manhã, e o intervalo entre as leituras foi de poucas horas inicialmente e aumentou no transcorrer do experimento, chegando a ser de alguns dias no final. Como a área experimental ficou coberta por lona plástica, não foi possível resolver eventuais problemas com os tensiômetros ou com as hastes do TDR, resultando na perda das observações em alguns pontos, como será visto mais adiante.

\subsection{CALIBRAÇÃo}

As equações para relacionar o teor de água no solo com as leituras do equipamento de TDR basearam-se num modelo de regressão linear simples:

$$
\theta=a+b \cdot T_{T D R}
$$

Foram utilizados os valores de umidade em base de volume $\left(\theta, \mathrm{m}^{3} \mathrm{~m}^{-3}\right)$ e a leitura corrigida do TDR (TTDR, ns), para estimar os parâmetros da equação ( 13 ) (a e b) pelo método dos quadrados mínimos (Sen \& Srivastava, 1990), atribuindo pesos iguais a todos os pontos. Paralelamente foram feitos ajustes polinomiais, buscando verificar desvios sistemáticos em relação ao modelo linear.

Além dos modelos linear e polinomial, também foi testada a adequação dos dados à chamada equação universal (eq.( 10 )) (Topp et al, 1980), utilizando os valores de permissividade relativa do solo obtido a partir das leituras do TDR aplicadas na equação ( 9 ), e à equação sugerida pelo fabricante do equipamento, baseada no modelo da equação ( 11 ):

$$
\theta=\frac{T_{T D R}-1,55}{(\sqrt{80,32}-1)}
$$

Foram efetuados ajustes de calibração para cada ponto, com todos os segmentos de cada haste, bem como de cada segmento de haste separadamente, e por camada utilizando todos as hastes em conjunto. Estes ajustes foram efetuados para cada um dos conjuntos correspondendo a cada período de observação, bem como para o conjunto total de dados. 


\subsection{ANÁLISE ESTATÍSTICA}

Os dados de campo e em especial as curvas de calibração foram estudadas com base nas medidas estatísticas clássicas, como média, desvio padrão e amplitude, e, principalmente, nas análises de tendência, semelhança e correlação. Os métodos e parâmetros para estas análises são descritos na literatura (Costa Neto, 1977; Sen \& Srivastava, 1990; Pimentel-Gomes, 2000 e outros). Foram testadas as correlações e semelhanças para os valores médios e para as amplitudes de leitura para cada período, entre os diferentes pontos (bateria e camada), e entre os períodos.

As curvas de calibração foram analisadas quanto ao seu desempenho em descrever a relação entre umidade e a leitura do TDR pelo exame dos gráficos e dos parâmetros de significância e qualidade do ajuste. A significância foi testada pelo teste $F$ e a qualidade do ajuste pelo coeficiente de determinação $\left(R^{2}\right)$. A análise de semelhança baseou-se no valor dos parâmetros da reta, coeficiente angular (b), e seus respectivos intervalos de confiança. Foram estudadas as correlações entre os parâmetros da curva de calibração e de suas semelhanças entre os vários pontos, ao longo da transeção, entre camadas e entre os dois períodos.

Além das análises de tendência ao longo da transeção, também foram estudados os padrões de variação da média de pontos semelhantes em função da distância que os separam, buscando assim identificar padrões de dependência espacial.

Visando identificar dependência do comportamento da relação da umidade do solo e a resposta do TDR com as variações das propriedades do solo, foram efetuadas análises de correlação entre os parâmetros das curvas de calibração e os atributos físicos do solo, sendo complementadas com a contraposição dos padrões de variação dos atributos e dos parâmetros das curvas.

Pela análise dos erros, da correlação e dos padrões de variação e semelhança buscou-se mostrar o desempenho deste modelo de TDR no campo e suas possíveis relações com alguns atributos físicos do solo. Comparou-se ainda o desempenho do equipamento nos dois períodos, proporcionando uma indicação do seu comportamento ao longo do tempo. 


\section{RESULTADOS E DISCUSSÃO}

\subsection{CuRVAS de RETENÇão}

Para a confecção das curvas características de retenção da água no solo foram obtidas aproximadamente 2.500 observações (tensãoxumidade), provenientes das 360 amostras (24 pontos $\times 5$ camadas $\times 3$ repetições) submetidas a 7 diferentes tensões. Analisando os resultados, decidiu-se eliminar 104 observações. Em alguns casos foi eliminado apenas um valor obtido em uma das repetições, como no exemplo do ponto 20, camada A (Figura 12a e 12b). Em 10 pontos uma repetição foi eliminada por completo por não apresentar resposta à variação de tensão, como, por exemplo, o ponto 30, camada A (Figura 12c e 12d). Estes procedimentos foram adotados para evitar distorção na interpretação dos dados devido a problemas sistemáticos, provocados por erros provavelmente de operação ou de equipamento (Sen \& Srivastava, 1990). Embora introduza um componente subjetivo e resulte na eliminação de informação, este procedimento se justifica pelo fato de uma curva de retenção não apresentar, em condições normais, discrepâncias tão evidentes quanto as exibidas nos exemplos da Figura 12. Possiveis erros experimentais, como o mau contato com a placa porosa ou uma amostra compactada durante a amostragem, podem explicar satisfatoriamente bem estes desvios e estas informações destoantes não ajudariam no estudo em questão.

Para evitar excesso de subjetividade na eliminação de observações, alguns critérios foram estabelecidos. Casos como o da Figura 12a podem ser tratados pela observação dos resíduos (Sen \& Srivastava, 1990), observações com desvios maiores que a média das demais podem indicar um dado discrepante ("outlier"). Se toda uma repetição for diferente (Figura 12c) a 
análise é mais complicada. Para as curvas de retenção deste trabalho analisaram-se os desvios de cada conjunto em relação à sua média, pois um desvio muito menor é um bom indicador para conjuntos discrepantes. No exemplo do ponto $30 \mathrm{~A}$, a repetição 1 apresenta um desvio $50 \%$ menor que a média das três repetições e $61 \%$ menor que a média dos desvios da camada $A .0$ critério geral utilizado para a eliminação de uma repetição foi que ambas as comparações deveriam apresentar índices iguais ou superiores a 45\%. Embora tenham sido utilizados estes critérios, não é possível eliminar o componente subjetivo, pois a própria definição dos limites de eliminação é arbitrária. Além disso o próprio uso de um indicador específico pode também ser criticado. E ainda assim não é incomum olhar para um conjunto de dados e encontrar um dado diferenciado e que não foi, mesmo assim, indicado como discrepante pelos indicadores e critérios utilizados. Consultar a bibliografia e discutir casos com colegas pesquisadores é sempre recomendado, assim como o uso do senso crítico por parte do próprio pesquisador.
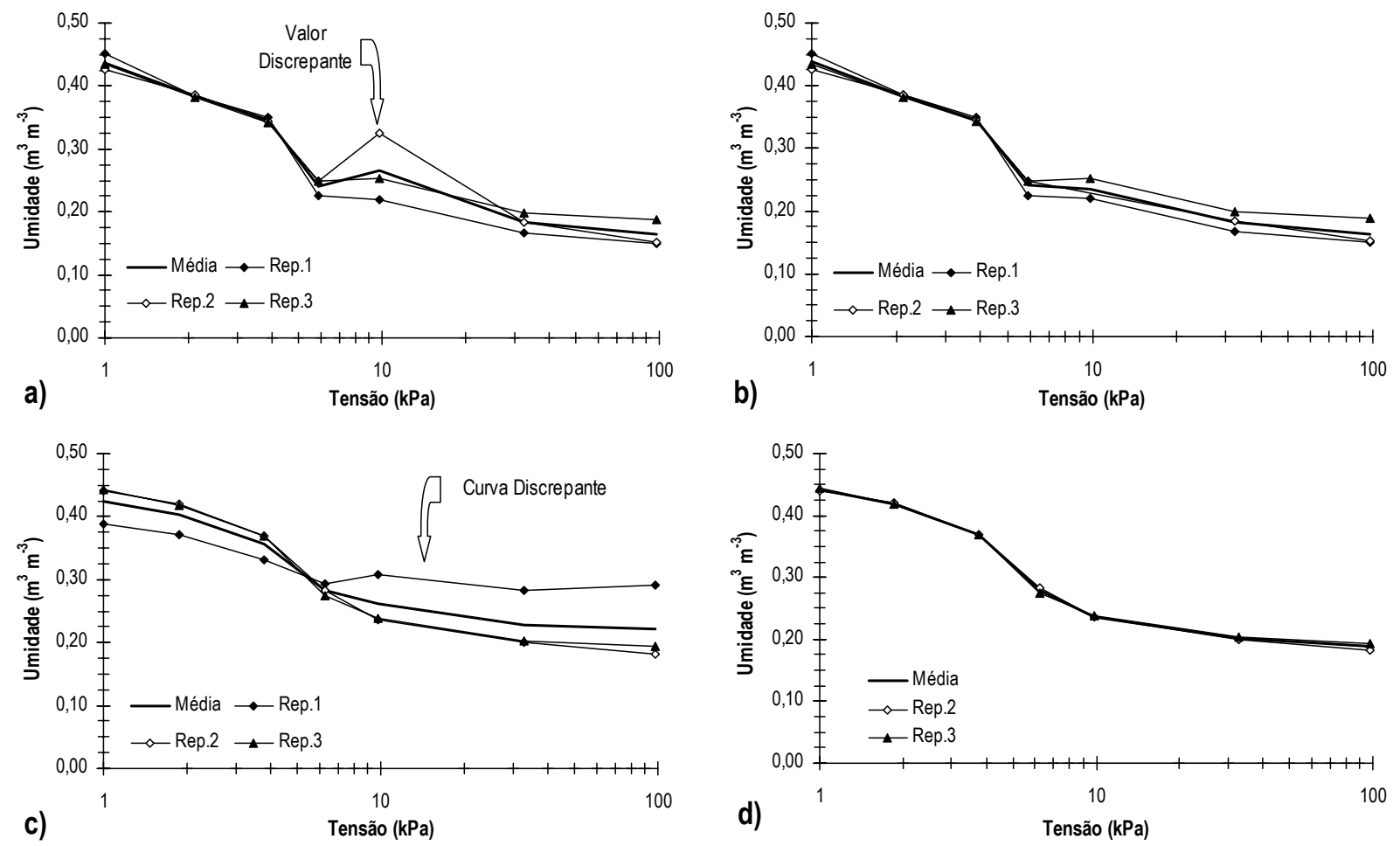

Figura 12 - Repetições e médias das curvas de retenção experimentais, para o ponto $20 \mathrm{~A}$ com todas as repetições (a) e com a eliminação de um dado discrepante (b), e o ponto $30 \mathrm{~A}$ com todos os dados (c) e com a eliminação de uma repetição discrepante (d). 
Aos pares de dados umidadextensão foram ajustadas equações seguindo o modelo de Mualem-van Genuchten (Mualem, 1976; van Genuchten, 1980) para descrever as curvas de retenção de água no solo (Eq. ( 6 )). A Tabela 3 mostra os parâmetros encontrados para cada ponto, juntamente com os respectivos coeficientes de determinação $\left(R^{2}\right)$, valores de $F$ e sua significância, assim como o desvio padrão da regressão e o número de pares de dados utilizados para cada curva.

O parâmetro $\theta_{\mathrm{s}}$ mostrou-se menos variável ao longo da transeção para cada camada, ao passo que o parâmetro $\theta_{\mathrm{r}}$ possui variabilidade superior. Em média $\theta_{\mathrm{s}}$ diminui com a profundidade, enquanto $\theta_{\mathrm{r}}$ aumenta, o que pode indicar granulometria mais fina e/ou compactação. A análise granulométrica e de densidade corrobora com esta indicação (ver item 4.2). Os coeficientes de determinação foram em geral elevados, e a regressão mostrou-se significativa, pelo teste $F$, para todos os pontos. Os valores dos desvios não são muito elevados, em média inferiores a $0,02 \mathrm{~m}^{3} \mathrm{~m}^{-3}$, novamente indicando bom ajuste. Isto permite uma maior segurança ao utilizar estas curvas para estimar o teor de água do solo, necessário para a calibração. A baixa variabilidade entre curvas vizinhas, que distam de 2,0 m em média, possibilita sua extrapolação também com mais confiança até a bateria de tensiômetros mais próxima (em média a 0,50 m). 
Tabela 3. Parâmetros do modelo de Mualem-van Genuchten ajustados aos dados observados nos 24 pontos (números pares de 2 a 48) e cinco camadas (A a E) - $\theta_{\mathrm{s}}$ e $\theta_{\mathrm{r}} \mathrm{em} \mathrm{m}^{3} \mathrm{~m}^{-3}$ e $\alpha$ em kPa-1 - com as respectivas medidas estatísticas de ajuste: Coeficiente de determinação - $R^{2}$, teste $F$ e sua probabilidade, o número de pares de dados - N, e o desvio padrão da regressão - Dp.

\begin{tabular}{|c|c|c|c|c|c|c|c|c|c|c|c|c|c|c|c|c|c|c|c|c|c|c|c|c|c|c|c|}
\hline & ateria & 2 & 4 & 6 & 8 & 10 & 12 & 14 & 16 & 18 & 20 & 22 & 24 & 26 & 28 & 30 & 32 & 34 & 36 & 38 & 40 & 42 & 44 & 46 & 48 & Todos & Média \\
\hline & $\theta \mathrm{s}$ & 0,477 & 0,412 & 0,446 & 0,408 & 0,412 & 0,446 & 0,476 & 0,408 & 0,430 & 0,444 & 0,415 & 0,431 & $\begin{array}{l}, 412 \\
\end{array}$ & 0,400 & 0,439 & 0,487 & 0,413 & 0,470 & 0,454 & 0,411 & 0,423 & 0,400 & 0,388 & 0,436 & 0,428 & 0,431 \\
\hline \multirow{7}{*}{$\frac{\pi}{0}$} & $\theta r$ & 0,229 & 0,156 & 0,194 & 0,170 & 0,168 & 0,209 & 0,184 & 0,140 & 0,172 & 0,167 & 0,141 & 0,145 & 0,189 & 0,134 & 0,192 & 0,155 & 0,153 & 0,194 & 0,167 & 0,126 & 0,225 & & 129 & 0,145 & 162 & 0,159 \\
\hline & $\alpha$ & $\begin{array}{l}0,252 \\
1070\end{array}$ & $\begin{array}{l}0,164 \\
1772\end{array}$ & $\begin{array}{l}0,384 \\
\end{array}$ & $\begin{array}{l}0,323 \\
3\end{array}$ & $\begin{array}{l}0,149 \\
\end{array}$ & $\begin{array}{l}0,026 \\
1,06\end{array}$ & 0,060 & 0,284 & 0,273 & 0,323 & 0,355 & 0,305 & 0,258 & 0,343 & 0,247 & 0,259 & 0,342 & $0^{2}$ & 0,449 & 0,414 & 0,447 & & & 240 & 322 & j,286 \\
\hline & $\begin{array}{l}n \\
m \\
m\end{array}$ & $\begin{array}{l}1,0 / 0 \\
1,104\end{array}$ & $\begin{array}{l}1,1,12 \\
0.894\end{array}$ & $\begin{array}{l}2,1,22 \\
0.453\end{array}$ & $\begin{array}{l}3,481 \\
0.277\end{array}$ & $\begin{array}{l}2,058 \\
1,307\end{array}$ & $\begin{array}{l}1,496 \\
13,545\end{array}$ & $\begin{array}{l}0,931 \\
2.243\end{array}$ & $\begin{array}{l}3,4711 \\
0,362\end{array}$ & $\begin{array}{l}2,288 \\
0,654\end{array}$ & $\begin{array}{l}2,412 \\
0,581\end{array}$ & $\begin{array}{l}4,718 \\
0257\end{array}$ & $\begin{array}{l}2,0663 \\
0511\end{array}$ & $\begin{array}{l}2,497 \\
0,552\end{array}$ & $\begin{array}{r}4,900 \\
0242\end{array}$ & $\begin{array}{l}3,114 \\
0.20\end{array}$ & $\begin{array}{l}2,755 \\
\end{array}$ & 69 & 2,417 & 4,829 & 3,535 & 5,517 & 994 & , 772 & 17 & 884 &, 420 \\
\hline & $R^{2}$ & 08668 & 09770 & 09299 & 09710 & 09844 & 09515 & 09648 & 0980 & & & & & & & 0004 & & & & & & & & & & & \\
\hline & & & & & & & & & & & & & & & & 2704 & 0,9384 & 0,9506 & 0,9145 & 0,097/7 & 0,9861 & 0,9496 & 0,9371 & 0,9946 & 0,9961 & 0,8817 & 0,951 \\
\hline & & & $<0,0001$ & $<0,0001$ & $<0,0001$ & 001 & 0001 & $<0,0001$ & $<0,0001$ & $<0,0001$ & 01 & $\begin{array}{l}20,0,4 \\
<0,001\end{array}$ & $\begin{array}{r}187,2 \\
<0,0001\end{array}$ & $\begin{array}{r}98,8 \\
<0,0001\end{array}$ & $<0,0001$ & $\begin{array}{l}20,7,0 \\
<0,0001\end{array}$ & $\begin{array}{r}6,0,0,0 \\
<0,0001\end{array}$ & $\begin{array}{c}0,0,6 \\
<0,0001\end{array}$ & $\begin{array}{c}40,1 \\
<0,0001\end{array}$ & $\begin{array}{r}y, z \\
0,0078\end{array}$ & $\begin{array}{r}20,0,9 \\
<0,0001\end{array}$ & $<0,0001$ & $\begin{array}{r}5,9 \\
<0,0001\end{array}$ & $\begin{array}{r}138,1 \\
<0,0001\end{array}$ & $\begin{array}{l}102,0,9 \\
<0,0001\end{array}$ & $\begin{array}{r}90,0001 \\
<0,8\end{array}$ & \\
\hline & $\mathrm{N}$ & & $x$ & 1 & 21 & & & 21 & 21 & 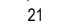 & & & 21 & 1 & & & . & (1) & & & & & & & 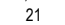 & 490 & 20,4 \\
\hline & $\mathrm{Dp}$ & 0,031 & 0,016 & 0,026 & 0,017 & 0,013 & 0,022 & 0,019 & 0,017 & 0,024 & 0,023 & 0,014 & 0,016 & 0,019 & 0,013 & 0,007 & 0,037 & 0,027 & 0,035 & 0,068 & 0,013 & 0,027 & 0,029 & 0,007 & 0,008 & 0,035 & 0,022 \\
\hline \multirow{9}{*}{$\begin{array}{l}\infty \\
\text { 票 }\end{array}$} & $\theta \mathrm{s}$ & 0,387 & 0,316 & 0,326 & 0,357 & 0,333 & 0,306 & 0,393 & 0,355 & 0,370 & 0,346 & 0,330 & 0,381 & 0,356 & 0,337 & 0,345 & 0,336 & 0,320 & 0,304 & 0,328 & 0,326 & 0,350 & 0,394 & 0,340 & 0,376 & 0,345 & 0,346 \\
\hline & $\theta r$ & & 0,134 & 0,175 & 0,193 & 0,145 & 0,247 & 0,150 & 0,137 & 0,139 & 0,114 & 0,151 & 0,312 & 0,151 & 0,146 & & 0,220 & 0,112 & 0,169 & 0,060 & 0,127 & 0,201 & 0,147 & 0,143 & 0,185 & 0,160 & 0,163 \\
\hline & $\alpha$ & 0,509 & 0,236 & 0,652 & 0,413 & 0,240 & 0,613 & 0,188 & 0,349 & 0,586 & 0,683 & 0,379 & 0,303 & & 0,345 & 0,375 & 0,379 & 0,479 & 0,096 & 0,502 & 0,362 & 0,512 & 0,454 & 0,358 & 304 & 441 & 398 \\
\hline & n & & 1,948 & & & & & 1,0 & 5,093 & & 4,332 & 7,003 & 2,622 & & 15,632 & 10,305 & 10.266 & & & 21,404 & & & & & & 775 & \\
\hline & $\mathrm{m}$ & 0,374 & 0,438 & 0,184 & 0,522 & 0,518 & 0,020 & 1,100 & 0,189 & 0,242 & 0,093 & 0,126 & 2,214 & 0,371 & 0,077 & 0,071 & 0,102 & 0,181 & 0,791 & 0,004 & 0,224 & 0,011 & 0,100 & 0,190 & 0,162 & 0,158 & ,346 \\
\hline & $\mathrm{R}^{2}$ & $\begin{array}{c}0,8370 \\
20,5\end{array}$ & $\begin{array}{l}0,9755 \\
159,0\end{array}$ & $\begin{array}{c}0,8921 \\
18,6\end{array}$ & $\begin{array}{c}0,9002 \\
36,1\end{array}$ & $\begin{array}{l}0,9860 \\
280,7\end{array}$ & $\begin{array}{c}0,7287 \\
6,0\end{array}$ & $\begin{array}{l}0,9846 \\
255,8\end{array}$ & $\begin{array}{c}0,9585 \\
92,4\end{array}$ & $\begin{array}{l}0,9621 \\
101,4\end{array}$ & $\begin{array}{c}0,8882 \\
29,8\end{array}$ & $\begin{array}{c}0,9465 \\
71,8\end{array}$ & $\begin{array}{c}0,7540 \\
10,7\end{array}$ & $\begin{array}{l}0,9684 \\
122,6\end{array}$ & $\begin{array}{l}0,9811 \\
208,1\end{array}$ & $\begin{array}{c}0,8224 \\
18,5\end{array}$ & $\begin{array}{c}0,7872 \\
14,8\end{array}$ & $\begin{array}{l}0,9917 \\
388,4\end{array}$ & $\begin{array}{l}0,9833 \\
132,7\end{array}$ & $\begin{array}{c}0,4508 \\
3,3\end{array}$ & $\begin{array}{l}0,9643 \\
108,0\end{array}$ & $\begin{array}{c}0,7420 \\
11,5\end{array}$ & $\begin{array}{c}0,9226 \\
47,7\end{array}$ & $\begin{array}{l}0,9819 \\
217,6\end{array}$ & $\begin{array}{c}0,9245 \\
49,0\end{array}$ & $\begin{array}{l}0,7474 \\
349,1\end{array}$ & $\begin{array}{l}0,889 \\
100,2\end{array}$ \\
\hline & Prob. & 0,0003 & $<0,0001$ & 0,0020 & $<0,0001$ & $<0,0001$ & 0,0362 & $<0,0001$ & $<0,0001$ & $<0,0001$ & $<0,0001$ & $<0,0001$ & 0,0055 & $<0,0001$ & $<0,0001$ & 0,0005 & $\begin{array}{l}0,0014 \\
0,014\end{array}$ & $<0,0001$ & $<0,0001$ & 0,0888 & $<0,0001$ & 0,0037 & $<0,0001$ & $<0,0001$ & $<0,0001$ & $<0,0001$ & \\
\hline & N & 21 & 21 & 14 & 21 & 21 & 14 & 21 & 21 & 21 & 20 & 21 & 19 & 21 & 21 & 21 & 21 & 18 & 14 & 21 & 21 & & 21 & 21 & 21 & 477 & 19,9 \\
\hline & Dp & 0,031 & 0,011 & 0,017 & 0,021 & 0,010 & 0,015 & 0,010 & 0,019 & 0,015 & 0,026 & 0,018 & 0,016 & 0,015 & 0,012 & 0,033 & 0,026 & 0,007 & 0,008 & 0,037 & 0,015 & 0,027 & 0,026 & 0,010 & 0,023 & 0,034 & 0,019 \\
\hline \multirow{9}{*}{$\begin{array}{l}0 \\
\pi \\
8\end{array}$} & $\theta s$ & 0,315 & 0,297 & 0 & 0,2 & 0,2 & 0,43 & 0,32 & 0,3 & 0,3 & $0,36$. & 0,3 & 0,3 & 0,3 & 0,3 & 0 & 0,3 & 0,3 & 0,3 & & 0, & & & & & 313 & 323 \\
\hline & $\theta r$ & & & & & & & & 0,1 & & & & 0,2 & & & & 0, & & & & & & & & & & \\
\hline & $\alpha$ & 0,0 & 0,196 & 0,159 & 0,404 & 0,206 & 0,00 & 0,32 & 0,337 & 0,599 & 0,91 & 0,48 & 1,96 & 0.323 & 0,3 & 0,3 & 0,3 & 0,3 & & & & & & & & & \\
\hline & $n$ & 1,2 & 1,817 & 1,406 & 2,437 & 4,009 & 0,1 & 1,71. & 3,740 & 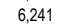 & 3,65 & 5,53 & 1,45 & 12,841 & 17,3 & 4,3 & 7,7 & & & & 12 & & & & & & 202 \\
\hline & $\mathrm{m}$ & 3,076 & 0,413 & 1,657 & 0,221 & 0,255 & 0,640 & 0,516 & 0,150 & 0,068 & 0,119 & 0,087 & 0,284 & 0,026 & 0,062 & 0,124 & 0,102 & 0,142 & 0,926 & 0,014 & $\begin{array}{l}0,0240 \\
0,024\end{array}$ & 0,606 & 0,023 & $\begin{array}{l}\text {, } \\
0,152\end{array}$ & $\begin{array}{l}0,267 \\
0,091\end{array}$ & $\begin{array}{l}0,114 \\
0,000\end{array}$ & $\begin{array}{l}1,202 \\
0,407\end{array}$ \\
\hline & $R^{2}$ & 0,8102 & 0,9832 & 0,9382 & 0,9162 & 0,9581 & 0,8467 & 0,9064 & 0,9871 & 0,8824 & 0,9667 & 0,9806 & 0,7068 & 0,9472 & 0,9861 & 0,9823 & 0,9728 & 0,9906 & 0,9930 & 0,7854 & 0,9415 & 0,5751 & 0,8896 & 0,9924 & 0,9864 & 0,8121 & ,.914 \\
\hline & 80 & & & $\begin{array}{l}60,7 \\
\end{array}$ & 24,6 & 91,5 & 12 & $\begin{array}{l}38,7 \\
\end{array}$ & & 30,0 & & & & & & & & & & & & & & & & 2,1 & 3,9 \\
\hline & $\begin{array}{l}\text { Prob } \\
N\end{array}$ & $\begin{array}{l}0,0008 \\
21\end{array}$ & $<0,0001$ & $<0,0001$ & $\begin{array}{l}0,0008 \\
14\end{array}$ & $\begin{array}{r}<0,0001 \\
21\end{array}$ & $\begin{array}{c}0,0065 \\
14\end{array}$ & $\begin{array}{l}<, 0001 \\
21\end{array}$ & $<0,0001$ & $<0,0001$ & $<0,0001$ & $<0,0001$ & $\begin{array}{l}0,0068 \\
21\end{array}$ & $<0,0001$ & $<0,0001$ & $<0,0001$ & $<0,0001$ & $<0,0001$ & $<0,0001$ & $\frac{0,0021}{20}$ & $<0,0001$ & 0,1149 & $<0,0001$ & $<0,0001$ & $<0,0001$ & $<0,0001$ & \\
\hline & $\mathrm{Dp}$ & 0,019 & 0,008 & 0,010 & $\begin{array}{l}14 \\
0,013\end{array}$ & 0,012 & $\begin{array}{l}14 \\
0,018\end{array}$ & 0,016 & 0,007 & 0,017 & 0,014 & 0.008 & $\begin{array}{l}21 \\
0.015\end{array}$ & 0.013 & $\begin{array}{c}21 \\
0.010\end{array}$ & $\begin{array}{l}21 \\
0.009\end{array}$ & 0.013 & 0,008 & 0,006 & 0.038 & 0.014 & 0.031 & 0.022 & 0.007 & 0.007 & 0.025 & $\begin{array}{l}20,0 \\
0,014\end{array}$ \\
\hline \multirow{9}{*}{ 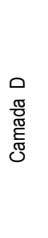 } & $\theta \mathrm{s}$ & & & & & & & 0,32 & & & & 0,3 & & & & & & & & & & & & 14 & & 0,319 & 341 \\
\hline & $\theta$ & & & & & & & & & & & & & & & & & & & & & & & & & & \\
\hline & 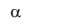 & & & & & 0,2 & 0 & 0,2 & & & 16 & 0 & & & & & 0, & 0,2 & & & & & & & & & \\
\hline & $n$ & & & & & & & & & & & & & & & & & & & & & & & & & & \\
\hline & $\mathrm{m}$ & 0,071 & 0,503 & 0,064 & 29,113 & 0,276 & 0,698 & 0,692 & 0,207 & 2,443 & 0,249 & 0,043 & 3,473 & 0,189 & 0,133 & 0,166 & 1,410 & 0,434 & 0,507 & 16,153 & 0,119 & 0,014 & 0,144 & 0,152 & 0,060 & 0,198 & .388 \\
\hline & $\begin{array}{l}R^{2} \\
F\end{array}$ & $\begin{array}{l}0,9751 \\
1377\end{array}$ & $\begin{array}{l}0,9160 \\
436\end{array}$ & $\begin{array}{l}0,9096 \\
403\end{array}$ & $\begin{array}{l}0,8791 \\
291\end{array}$ & $\begin{array}{l}0,8510 \\
229\end{array}$ & 0,9387 & 0,8889 & $\begin{array}{l}0,9836 \\
2393\end{array}$ & $\begin{array}{l}0,9684 \\
1225\end{array}$ & $\begin{array}{r}0,7834 \\
81\end{array}$ & $\begin{array}{l}0,9639 \\
1067\end{array}$ & $\begin{array}{l}0,9579 \\
910\end{array}$ & $\begin{array}{l}0,9907 \\
427\end{array}$ & $\begin{array}{l}0,9831 \\
2329\end{array}$ & $\begin{array}{c}0,9588 \\
930\end{array}$ & $\begin{array}{l}0,8686 \\
265\end{array}$ & $\begin{array}{r}0,8018 \\
131\end{array}$ & $\begin{array}{l}0,9356 \\
581\end{array}$ & $\begin{array}{r}0,9407 \\
257\end{array}$ & $\begin{array}{l}0,9891 \\
3207\end{array}$ & $\begin{array}{l}0,7568 \\
125\end{array}$ & 0,9763 & 0,9424 & 0,9607 & 0,7982 & 0,922 \\
\hline & Prob & $<0,0001$ & $\begin{array}{r}4,0,6 \\
<0,0001\end{array}$ & $\begin{array}{r}40,5001 \\
<0,000\end{array}$ & $\begin{array}{r}2,1,1 \\
<0,0001\end{array}$ & $\begin{array}{l}22,9 \\
0,0002\end{array}$ & $\begin{array}{r}6,2,2 \\
<0,0001\end{array}$ & $\begin{array}{r}32,0 \\
<0,0001\end{array}$ & $\begin{array}{r}20,0,3 \\
<0,0001\end{array}$ & $\begin{array}{l}12,5,5 \\
<0,0001\end{array}$ & $\begin{array}{c}8,1 \\
0,0190\end{array}$ & $\begin{array}{r}106, I \\
<0,0001\end{array}$ & $\begin{array}{c}91,0 \\
<0,0001\end{array}$ & $\begin{array}{r}42,1,6 \\
<0,0001\end{array}$ & $\begin{array}{r}232,9 \\
<0,0001\end{array}$ & $<0,0001$ & $\begin{array}{r}<, 0,0 \\
<0,0001\end{array}$ & $\begin{array}{l}1,1,1 \\
0,0031\end{array}$ & $\begin{array}{c}30,1 \\
<0,0001\end{array}$ & $\begin{array}{l}3,1 \\
0,0002\end{array}$ & $<0,0001$ & 0,0028 & 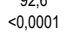 & $\begin{array}{l}0,0,5 \\
<0,0001\end{array}$ & $\begin{array}{r}3,9,9 \\
<0,0001\end{array}$ & $\begin{array}{r}40,9 \\
<0,0001\end{array}$ & \\
\hline & $\mathrm{N}$ & 10 & 21 & 21 & 21 & & 21 & 21 & 21 & & & & 21 & 21 & 21 & & 21 & 18 & 21 & & & & 14 & & 1 & 471 & 19,6 \\
\hline & $D_{F}$ & 0,008 & 0,014 & 0,012 & 0,015 & 0,026 & 0,010 & 0,017 & 0,006 & 0,009 & 0,026 & 0,009 & 0,009 & 0,006 & 0,007 & 0,008 & 0,015 & 0,027 & 0,0 & 0,013 & 0,006 & 0,018 & 0,017 & 0,015 & 0,009 & 0,021 & 0,013 \\
\hline & $\theta \mathrm{s}$ & 0 & 0,31 & 0,37 & 0,3 & 0,3 & 0,6 & 0,3 & 0,3 & 0 & 0 & 0,3 & 0,3 & 0,3 & 0,3 & 0,3 & 0,3 & 0,4 & 0,3 & & & 0,32 & & & & & 0,351 \\
\hline & $\theta \mathrm{r}$ & & & & & & & 0,1 & & & & & & & & & & & & & & & & & & & \\
\hline & & 0,5 & 0, & & 0,0 & & 0, & & & & & & 0,4 & & & & & & & & & & & & & & \\
\hline & n & 2,5 & 1,8 & 2 & 0,7 & 2,3 & 0,1 & 1,76 & 4,374 & 1,42 & & 7,4 & 1,3 & 3,8 & 3 & & 1,0 & 4,1 & & & & 18,8 & 6,061 & & & 2,3 & 703 \\
\hline & $\mathrm{m}$ & 0,257 & 0,390 & 0,309 & 5,346 & 0,381 & 0,510 & 0,539 & 0,101 & 0,538 & 0,086 & 0,061 & 0,257 & 0,114 & 0,152 & 0,592 & 8,732 & 0,062 & 0,857 & 8,068 & 0,033 & 0,020 & 0,070 & 0,061 & 0,258 & 0,196 & 1,158 \\
\hline & $\mathrm{R}^{\mathrm{R}}$ & 0,9 & 0,9 & 0,9 & 0,96 & & 0,9 & 0,8 & & 0,9 & 0,9 & 0,9 & 0,9 & 0,5 & 0,6 & & 0,8 & 0,5 & 0 & 0 & 0 & 0,5 & & & & & 年 \\
\hline & F & 8 & $\begin{array}{c}43,5 \\
<0001\end{array}$ & 55 & $\begin{array}{r}37,1 \\
<00001\end{array}$ & & $\begin{array}{r}61,2 \\
<001\end{array}$ & $\begin{array}{l}30,9 \\
<0001\end{array}$ & $\begin{array}{r}313,6 \\
<\end{array}$ & $\begin{array}{l}105,2 \\
<<002\end{array}$ & $\begin{array}{c}87,4 \\
<0001\end{array}$ & $\begin{array}{l}120,0 \\
<0,0\end{array}$ & $\begin{array}{l}168,0 \\
<0001\end{array}$ & $\begin{array}{r}177,3 \\
<<0\end{array}$ & 176 & 11 & $\begin{array}{c}28,7 \\
<0001\end{array}$ & $\begin{array}{l}101,4 \\
<1\end{array}$ & $\begin{array}{c}442,4 \\
<0001\end{array}$ & $\begin{array}{c}50,4 \\
<0001\end{array}$ & $\begin{array}{l}169,6 \\
<0,6\end{array}$ & $<00001$ & $<0001$ & $\begin{array}{c}132,4 \\
<0001\end{array}$ & $\begin{array}{l}131,0 \\
<0,0\end{array}$ & & 8,2 \\
\hline & +1 & 21 & 21 & 21 & 20 & 21 & 21 & 21 & 21 & 21 & 21 & 21 & 21 & 21 & 20 & 21 & 21 & 18 & 20 & 21 & 21 & 21 & 21 & 21 & 21 & 4908 & 20.8 \\
\hline & $D_{q}$ & 0,013 & 0,014 & 0,015 & 0,017 & 0,009 & 0.015 & 0.021 & 0,006 & 0.013 & 0.013 & 0.012 & 0.009 & 0,010 & 0.008 & 0,010 & 0,017 & 0,011 & 0,005 & 0.014 & 0,007 & 0,012 & 0,008 & 0.009 & 0.011 & 0,017 & 0.012 \\
\hline
\end{tabular}




\subsection{Atributos Físicos}

\subsubsection{Densidade do solo}

A densidade média do solo por camada variou muito pouco, não sendo possível identificar nenhuma tendência ao longo da transeção. $O$ coeficiente de variação ficou em torno de $3 \%$ em todas as camadas, confirmando a aparência homogênea do terreno onde fora instalado 0 experimento. Em relação à profundidade, foi possivel verificar diferença significativa pelo teste de Tukey, ao nível de probabilidade de $5 \%$, entre a primeira camada, que apresentou densidade média inferior a $1500 \mathrm{~kg} \mathrm{~m}^{-3}$, que as demais foram bem superiores, chegando a quase 1800 $\mathrm{kg} \mathrm{m}^{-3}$ na camada C. Esta camada juntamente com a $D$ apresentaram as maiores densidades para cada ponto, tendo a camada A o menor valor sempre. A Figura 13 exibe as médias por camada e geral para a densidade observada nas várias camadas.

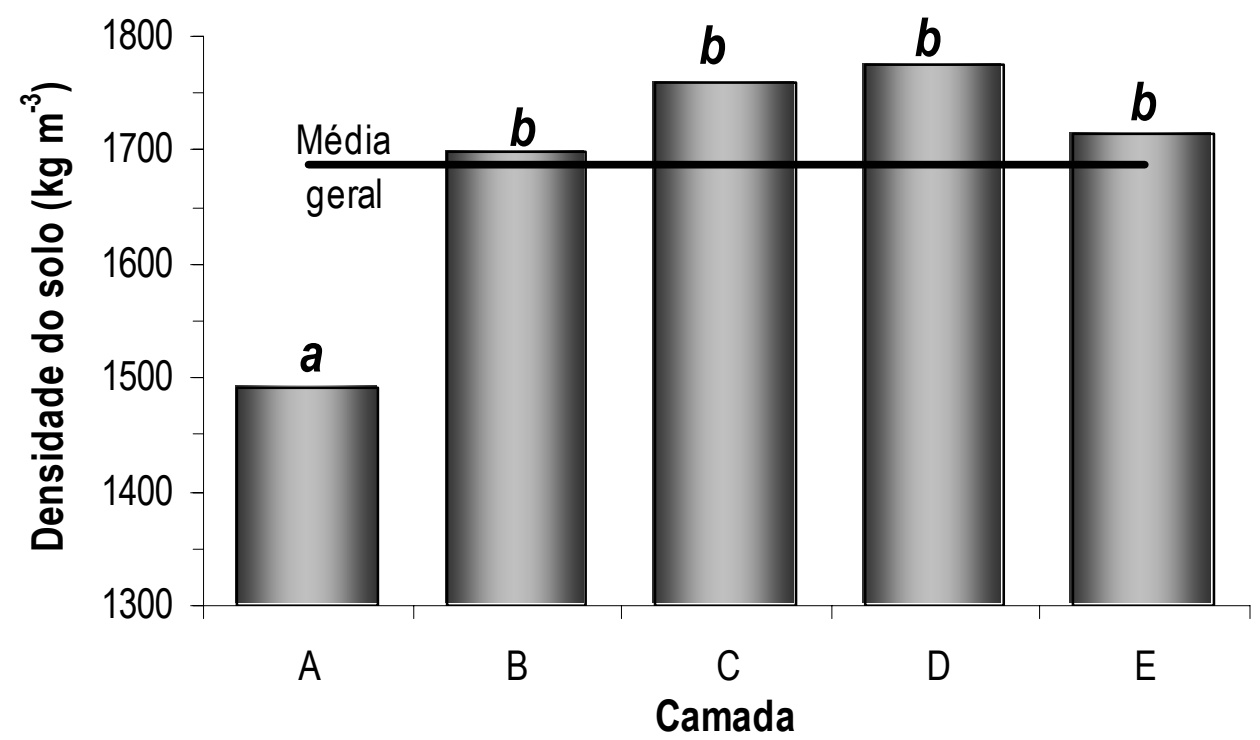

Figura 13 - Média das densidades do solo observadas para cada camada e média geral de todas as camadas. Barras marcadas com letras minúsculas iguais não diferiram, ao nível de probabilidade de 5\%, pelo teste de Tukey.

\subsubsection{Densidade dos sólidos}

Conforme esperado (Warrick \& Nielsen, 1980), a densidade dos sólidos, a semelhança da densidade do solo, não apresentou variações significativas ao longo da transeção, nem 
tendências. Os valores apresentaram baixa dispersão, com coeficiente de variação abaixo de $3 \%$ em média, chegando a 4,5\% na camada A. Entre as camadas não houve variações grandes e também não se verificou nenhuma tendência de aumento ou diminuição em função da profundidade. A camada B apresentou o menor valor de densidade dos sólidos, um pouco abaixo de $2.600 \mathrm{~kg} \mathrm{~m}^{-3}$, e na camada $\mathrm{E}$ a densidade atingiu cerca de $2.640 \mathrm{~kg} \mathrm{~m}^{-3}$ (Figura 14).

O padrão de variação da densidade dos sólidos não seguiu o padrão da densidade do solo, a correlação entre os dois conjuntos de dados ficou em torno de 0,20 na média, para as camadas B e D o coeficiente de correlação ultrapassou levemente o patamar de 0,40 , mas para as demais foi muito menor. Como a variabilidade da densidade dos sólidos foi muito baixa era de se esperar esta pequena semelhança com a densidade do solo, até porque não é necessariamente precedente a correlação elevada entre estas duas propriedades, pois a densidade dos sólidos depende apenas da composição da fase sólida e não da estrutura do solo.

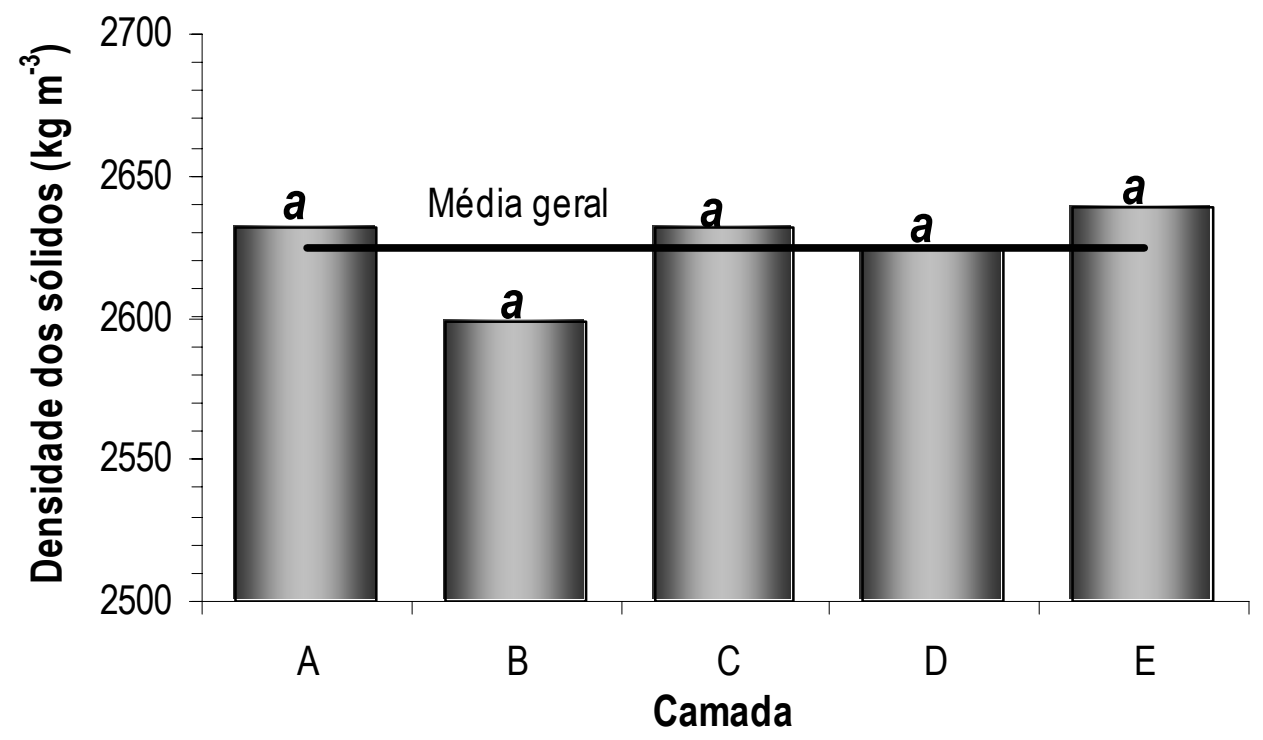

Figura 14 - Médias das densidade dos sólidos observadas ao longo da transeção por camada e média geral. Barras marcadas com letras minúsculas iguais não diferiram, ao nível de probabilidade de $5 \%$, pelo teste de Tukey.

\subsubsection{Granulometria}

Os teores de areia, argila e silte assim como as densidades, não apresentaram tendência definida ao longo da transeção. 0 solo mostrou-se bastante arenoso $\left(0,74 \mathrm{~kg} \mathrm{~kg}^{-1} \mathrm{de}\right.$ 
areia em média) variando em função da profundidade, ficando abaixo de $0,70 \mathrm{~kg} \mathrm{~kg}^{-1}$ apenas na camada E (Figura 15a). $O$ teor de argila apresentou comportamento aproximadamente constante ao longo da transeção, e também mostrou relação com a profundidade (Figura 15b), para ambos apenas a camada E diferiu significativamente, pelo teste de Tukey. Os teores de silte, por conseqüência, variaram pouco e sem exibir significância, fato comum em solos tropicais (Figura 15c).

O coeficiente de correlação entre 0 teor de argila e 0 de areia ficou em $-0,98$, mostrando a estreita, e inversa, relação entre os dois. Conseqüentemente a variação do teor de silte foi mais independente, a correlação deste teor foi de 0,70 com o teor de areia e de 0,60 com a argila. A Figura $15 \mathrm{~d}$ mostra as médias de cada teor ao longo da transeção. Nesta figura podese ver a pequena variação entre os pontos, com exceção da bateria 12, onde os teores de areia e argila se igualaram, comportamento também um pouco mais destacado, porém de padrão inverso, para as baterias 16 e 28. Estas variações foram mais sutis no teor de silte.
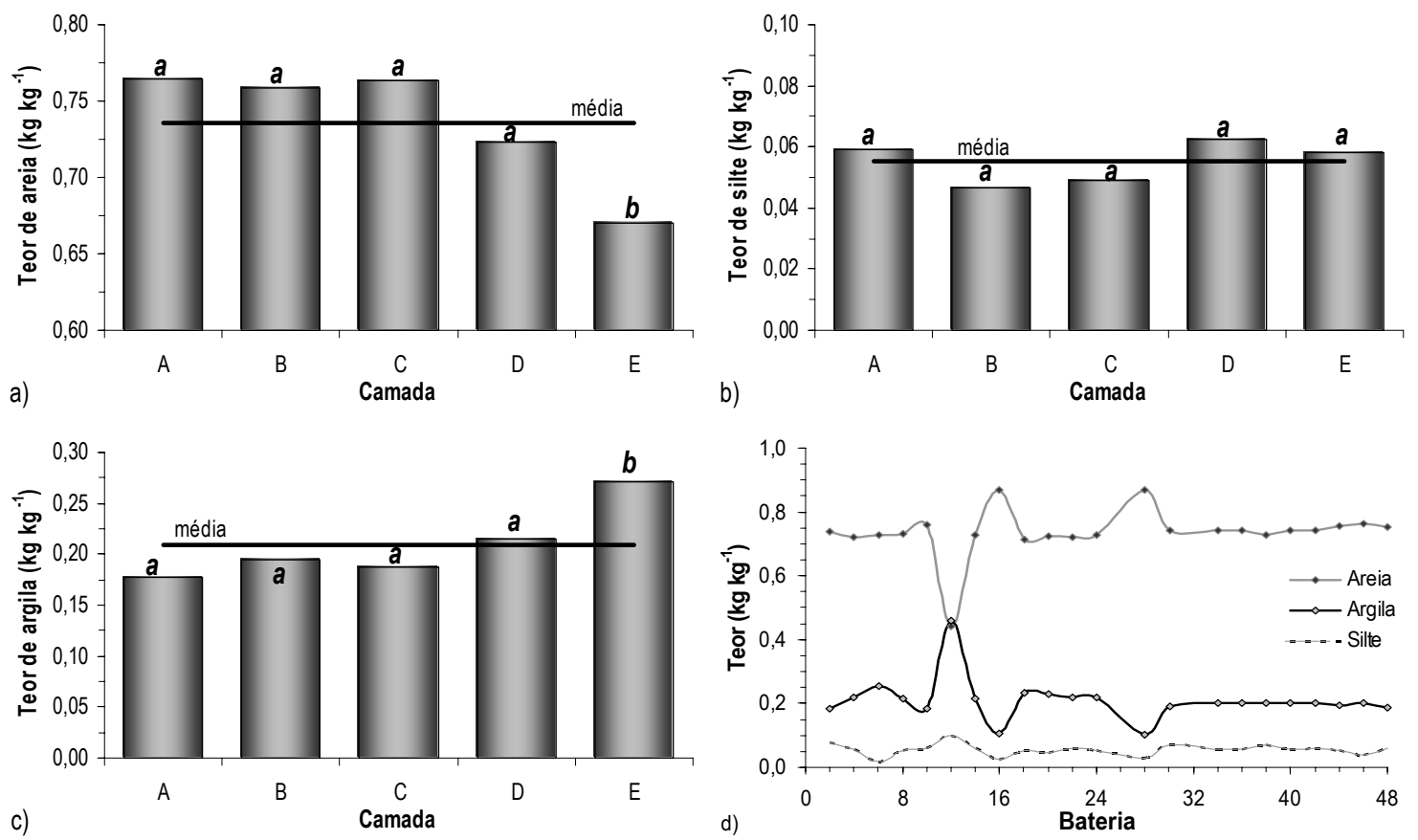

Figura 15 - Teores médios por camada para (a) areia, (b) argila e (c) silte, e (d) variação das médias ao longo da transeção. Barras marcadas com letras minúsculas iguais não diferiram, ao nivel de probabilidade de $5 \%$, pelo teste de Tukey. 


\subsection{CuRvas de CALIBRAÇÃo}

\subsubsection{Dados de Campo}

Foram coletados 10.421 pares de dados, compreendendo leituras simultâneas do tensiômetro (potencial matricial) e leituras do equipamento de TDR (tempo), sendo 5.704 do primeiro período (2000) e 4.717 do segundo período (2001). 0 número de pares não foi igual para todos os pontos porque alguns tensiômetros e/ou hastes do TDR apresentaram problemas operacionais. Para as baterias 27 e 30 esses problemas levaram à eliminação total destas bateria da análise. As leituras do TDR foram corrigidas para tempo real usando a equação ( 12 ) com os parâmetros da Tabela 2. 0 teor de água do solo foi obtido pelas curvas de retenção respectivas a cada ponto a partir do potencial matricial medido pelo tensiômetro.

A faixa de umidade observada variou bastante de ponto para ponto, tanto ao longo da transeção como em profundidade, assim como entre um período e outro. A faixa de umidade observada é importante pois se muito restrita pode dificultar a percepção de uma relação entre as variáveis, o que pôde ser verificado em especial nas camadas mais profundas. A Figura 16 mostra as amplitudes e médias dos valores de umidade e tempo observadas para o primeiro período. Nota-se grande variabilidade entre as amplitudes, diminuindo com a profundidade para a umidade e aumentando para a leitura do TDR, enquanto apresentaram variações mais homogêneas entre os vários pontos de uma mesma camada. A amplitude da umidade, como era de se esperar, diminuiu com 0 aumento da profundidade (Figura 16f) pois nas camadas mais profundas a umidade varia muito pouco. A média apresenta-se bastante constante, tendo um valor ligeiramente inferior na camada $C$, aumentando acima e abaixo. Esta tendência é semelhante para o segundo período (Figura 17), onde as amplitudes foram em média menores e sua variabilidade foi maior.

Um padrão de variação semelhante (amplitude menor e variabilidade maior) ocorreu para as leituras do TDR, porém as amplitudes foram muito mais homogêneas entre as camadas e a tendência que as médias das umidades seguem não foi acompanhada pelas leituras do TDR, não havendo um padrão muito bem definido. É interessante notar que as médias para a umidade foram praticamente iguais nos dois períodos, porém as leituras do TDR foram em média menores 
no segundo período, em aproximadamente $10 \%$. As variações das amplitudes das leituras e das umidades tornaram-se mais ajustadas no segundo período, ou seja, camadas com maior variabilidade das amplitudes na umidade correspondem a amplitudes mais variáveis das leituras do TDR, ao passo que no primeiro período esta correspondência não foi verificada. A camada $E$, por exemplo, apresentou-se bastante homogênea para umidade (Figura 16e) ao mesmo tempo que para o TDR essa foi uma das camadas mais heterogêneas (Figura 16k). 

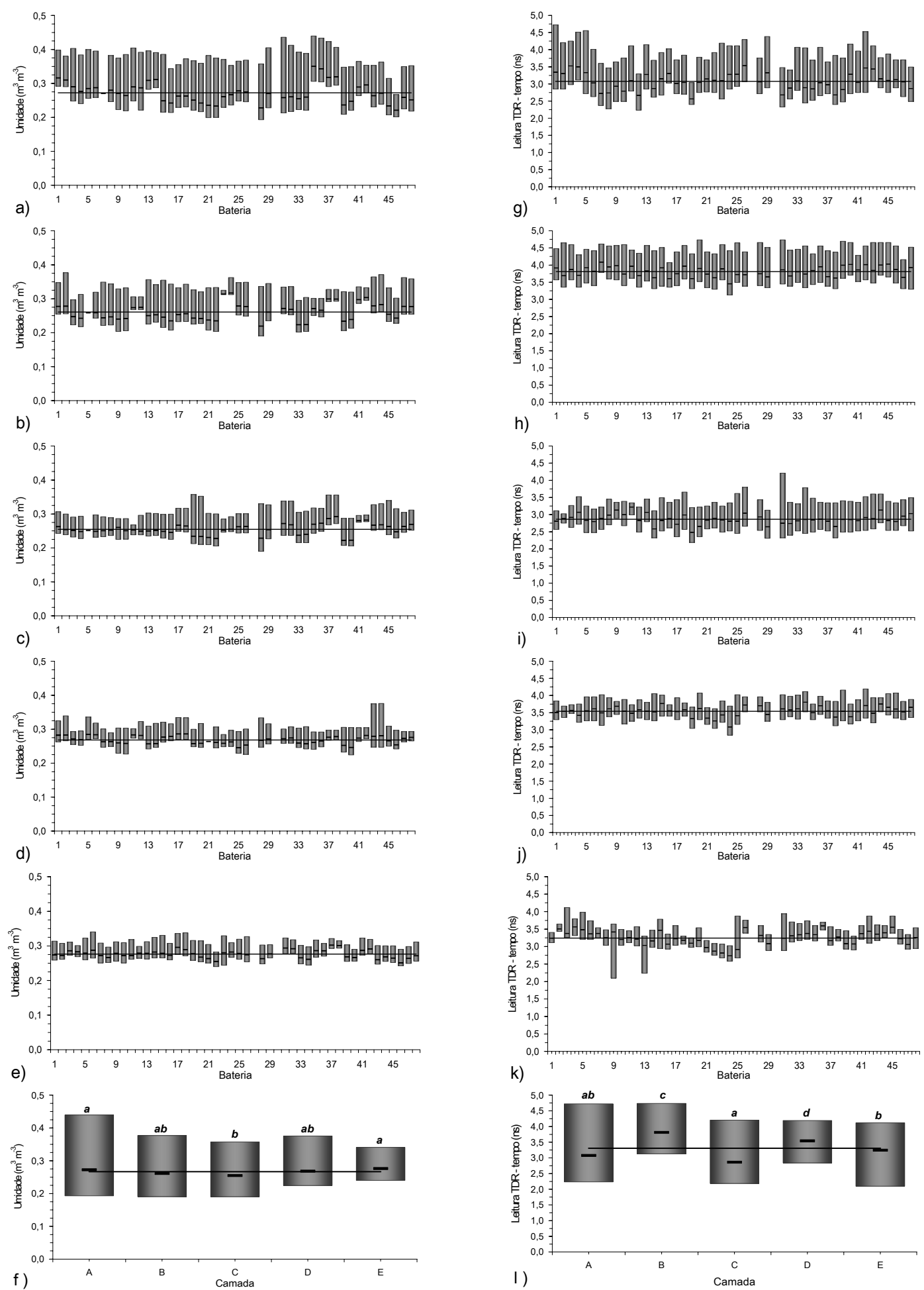

Figura 16 - Amplitudes e médias para a umidade e a leitura do TDR, no primeiro período de coleta de dados (2000). (a-e) Umidade nas camadas A a E, (f) umidade geral por camada; (g-k) leitura do TDR nas camadas A a E e (I) TDR geral por camada. Barras marcadas com letras minúsculas iguais não diferiram, ao nível de probabilidade de $5 \%$, pelo teste de Tukey. 

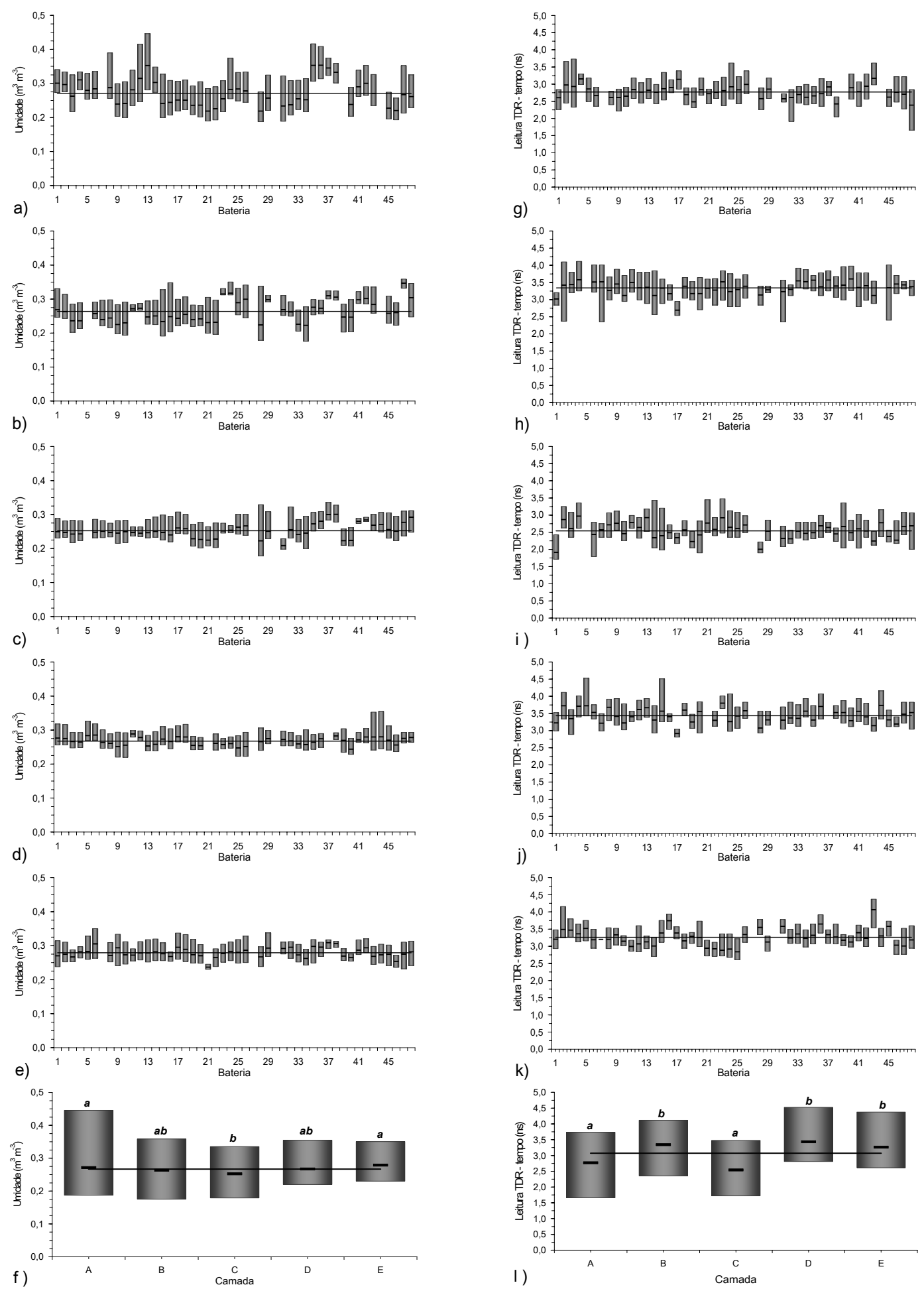

Figura 17 - Amplitudes e médias para a umidade e a leitura do TDR, no segundo período de coleta de dados (2001). (a-e) Umidade nas camadas A a E, (f) umidade geral por camada; ( $\mathrm{g}-\mathrm{k}$ ) leitura do TDR nas camadas A a E e (I) TDR geral por camada. Barras marcadas com letras minúsculas iguais não diferiram, ao nível de probabilidade de $5 \%$, pelo teste de Tukey. 
Além do aumento na variabilidade das amplitudes entre o primeiro e o segundo período, também percebe-se que estas variações foram aleatórias. Poderia ser esperado que pontos com maior amplitude no primeiro período também o fossem no segundo período, tendo em vista que o solo não foi mexido e que as condições de cobertura e clima foram semelhantes. A Tabela 4 mostra os valores dos coeficientes de correlação para as amplitudes da leitura do TDR e da umidade entre um período e outro. Para a umidade estes índices mostram-se maiores, com destaque para a camada $\mathrm{D}$, sendo muito baixa na camada $\mathrm{A}$ e intermediária nas demais. Pode-se concluir, considerando estes valores, que existe correlação entre os dois períodos. Por outro lado, analisando os valores das amplitudes para a leitura do TDR verifica-se correlação muito baixa, chegando a apresentar coeficientes negativos nas camadas $C$ e $E$, mostrando inconstância das medições pelo aparelho de TDR. Apesar destes valores baixos nota-se que correlações maiores na umidade também correspondem a índices maiores da leitura do TDR, porém seus baixos valores dificultam quaisquer especulações a respeito deste detalhe.

Seria razoável também esperar que as amplitudes da umidade e da leitura do TDR apresentassem correlação e que uma maior faixa de umidades observadas correspondesse a uma maior faixa nas leituras obtidas no TDR. Na Tabela 4 se encontram os valores dos índices de correlação entre as amplitudes da umidade e da leitura do TDR para cada período. Percebese uma quase total independência entre as amplitudes; o maior índice, para a camada C no primeiro período, é ainda muito baixo, mesmo sendo bastante superior aos demais. Sem analisar os valores em si, apenas suas amplitudes, em função dessas constatações já podem ser esperadas dificuldades no estabelecimento de uma boa relação entre as leituras do TDR e o teor de água no solo.

Tabela 4. Coeficientes de correlação das amplitudes da umidade $(A \theta)$ e das leituras do TDR (ATTDR) entre os dois períodos e entre as amplitudes da umidade e da leitura do TDR para $01^{\circ}$ período $\left(\theta-\mathrm{T}_{\mathrm{TDR} 1}\right)$ e $02^{\circ}$ período $\left(\theta-\mathrm{T}_{\mathrm{TDR} 2}\right)$.

\begin{tabular}{ccccc}
\hline Camada & A $\theta$ & ATTDR & $\theta-$ TTDR1 $_{1}$ & $\theta-$ T TDR2 \\
\hline A & 0,393 & 0,079 & $-0,112$ & 0,028 \\
B & 0,772 & 0,161 & 0,130 & 0,010 \\
C & 0,683 & $-0,082$ & 0,292 & $-0,207$ \\
D & 0,876 & 0,129 & $-0,023$ & 0,080 \\
E & 0,574 & $-0,029$ & 0,057 & 0,170 \\
\hline
\end{tabular}


Analisando as médias das umidades e das leituras verifica-se que houve também pequena correspondência entre elas (Figura $16 f$ e Figura 16l ou Figura 17f e Figura 17I). A Tabela 5 traz os coeficientes de correlação entre as médias das umidades e as médias das leituras do TDR para os dois períodos e no geral. Todos apresentaram-se bastante reduzidos, especialmente no primeiro período, chegando a ser negativo na camada B. Os maiores valores são encontrados quando se juntam os dados dos dois períodos e mesmo assim seus valores são muito baixos. Como a análise das médias pode ser considerada insuficiente para indicar a falta de relação entre umidade e a resposta do aparelho, na mesma Tabela 5 são apresentados os valores do coeficiente de correlação para cada camada considerando todos os pares de dados. Nota-se uma inversão da tendência geral exibida pelas médias, com o primeiro período apresentando coeficientes de correlação bem superiores aos do segundo e o conjunto completo ficando num patamar intermediário. Embora se perceba um aumento da relação entre os valores, eles ainda são reduzidos, e além disso variáveis no tempo. Não é possível afirmar, pois seriam necessários experimentos mais detalhados, mas há indícios de senescência do equipamento. $A$ diferença de resultados para o primeiro período é um indicativo de diferenças significativas entre as curvas de calibração dos vários segmentos das hastes.

Os baixos valores de correlação apresentados até aqui foram baseados na análise dos dados em conjuntos maiores ou em suas representações estatísticas, que, mesmo assim deveriam exibir alguma relação significativa. 0 passo seguinte foi a análise dos dados por bateria e por camada.

Tabela 5. Coeficientes de correlação entre a leitura do TDR e a umidade para cada camada, utilizando apenas as médias de cada ponto e com todos os dados.

\begin{tabular}{llccccc}
\hline \multirow{2}{*}{ Período } & \multicolumn{5}{c}{ Camada } \\
& & A & B & C & D & E \\
\hline \multirow{2}{*}{2000} & médias & 0,015 & $-0,111$ & 0,044 & 0,173 & 0,118 \\
& todos & 0,497 & 0,502 & 0,595 & 0,541 & 0,344 \\
\multirow{2}{*}{2001} & médias & 0,139 & 0,127 & 0,159 & 0,105 & 0,137 \\
& todos & 0,232 & 0,258 & 0,268 & 0,263 & 0,200 \\
& médias & 0,052 & 0,043 & 0,078 & 0,186 & 0,170 \\
& todos & 0,368 & 0,315 & 0,413 & 0,404 & 0,269 \\
\hline
\end{tabular}


Conforme já foi discutido, os valores das amplitudes observadas para umidade e para as leituras do TDR deveriam exibir alguma correlação, tendo em vista que se espera encontrar uma relação de causa-efeito entre umidade e o tempo do TDR, o que não se verificou. As médias também apresentaram-se pouco correlacionadas e os valores em si exibiram coeficientes melhores, mas ainda ruins. Uma outra questão a explorar ainda é o comportamento dos dados por ponto, e sua relação com pontos vizinhos.

Nas Tabelas dos Anexos A a F são apresentadas as médias, desvios padrão, 0 número de pares de dados e o intervalo de confiança para umidade e leitura do TDR em cada ponto para o primeiro e o segundo período, e para todos os dados, juntamente com o número de pontos que se apresentaram estatisticamente iguais e quanto isso representa em percentagem sobre o número total de possíveis comparações para cada ponto em cada camada.

Os valores apresentaram bastante variação. Como já foi comentado, a camada $C$ apresentou a menor média para umidade, corroborado pela leitura do TDR que, no entanto, apresentou médias maiores nas camadas $B$ e $D$ do que nas camadas $A$ e $E$, contrariando 0 observado pelo tensiômetro. Não pôde ser identificada nenhuma tendência ao longo da transeção para cada camada e a umidade apresentou-se com média aproximadamente constante e com desvios igualmente estáveis em qualquer ponto da transeção. A variabilidade, estimada pelo desvio padrão mostrou-se relativamente baixa e decrescente com a profundidade.

A umidade média foi praticamente igual para ambos os períodos, aumentando em apenas $0,5 \%$ em média, sendo $1,8 \%$ de acréscimo para a camada $A$ e decréscimo de 1,0\% para a camada C. A variabilidade reduziu-se em quase $10 \%$ no segundo período em relação ao primeiro, chegando a $23 \%$ para a camada A, aumentando em $18 \%$ na camada $E$. Para as leituras do TDR a média decresceu cerca de $7 \%$, com maior decréscimo na camada $B(12 \%)$ e pequeno aumento na camada $E(0,8 \%)$. A dispersão também foi reduzida chegando a ser $40 \%$ menor na camada A. A camada $E$ foi a única a apresentar aumento da dispersão das leituras do TDR, $12,5 \%$, na média, porém, houve decréscimo de $18 \%$ entre o segundo e o primeiro período.

O teste de semelhança, utilizando o intervalo de confiança com probabilidade de $95 \%$, comparando cada ponto com todos os outros da sua respectiva camada, revelou grande variação de comportamento. De um modo geral, as profundidades maiores apresentaram maior número 
de pontos semelhantes entre si para a umidade (Figura 18a), resultado da menor variação da umidade nessas camadas, o que já era esperado pela menor amplitude de variação observada na Figura 16 e na Figura 17. Por outro lado, as leituras do TDR exibiram comportamento diverso, tendo sua variabilidade aumentado com a profundidade. Observa-se assim um número decrescente de pontos semelhantes ao se aumentar a profundidade. A camada B foi a que apresentou mais semelhanças especialmente no primeiro período, bastante superior às verificadas para umidade (Figura 18). 0 segundo período de observação em geral apresentou as menores percentagens de pontos semelhantes, especialmente para o TDR, o que pode ser explicado pelo aumento da variabilidade neste período.
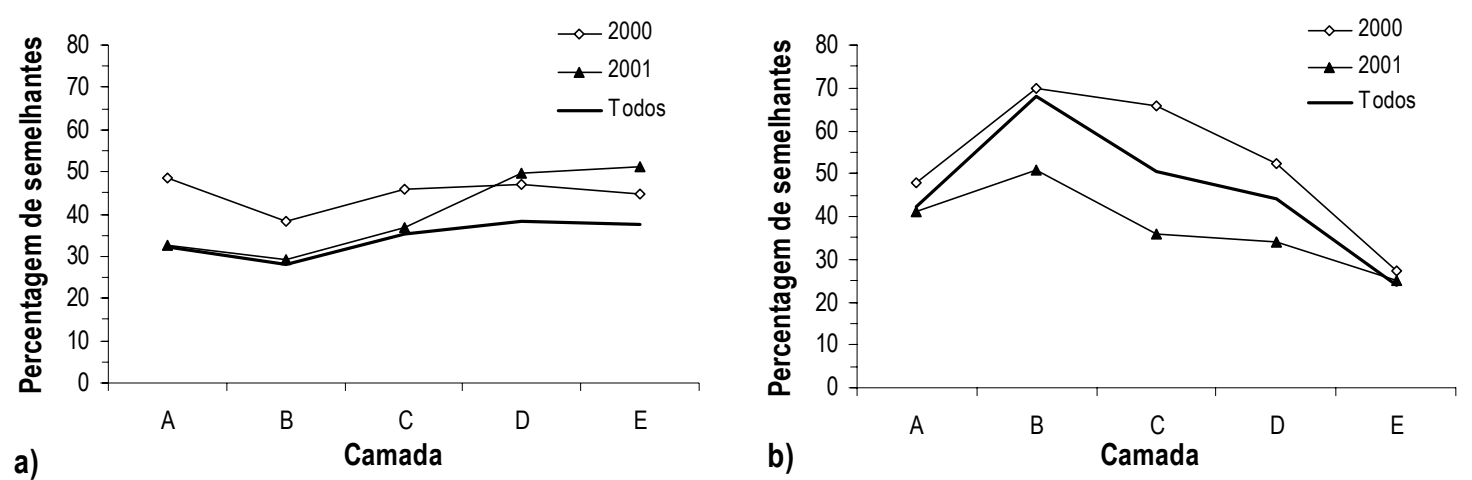

Figura 18 - Percentagem de pontos com umidade (a) e leitura do TDR (b) semelhantes na transeção, por camada e período.

A Figura 19 mostra a percentagem do número de pontos cuja análise de semelhança para as médias coincidiu para os dois períodos (SI). Em torno de $60 \%$ dos pontos para a umidade e $50 \%$ para a leitura do TDR mostraram-se semelhantes ou diferentes tanto para o primeiro como para o segundo período, ou seja, o comportamento foi igual nos dois períodos. A percentagem do número de pontos que se mostraram semelhantes entre si tanto no primeiro período quanto no segundo ( $C$ c) ficou em torno de $20 \%$ para ambos os conjuntos de dados (Figura 19), o que corresponde praticamente à metade dos pontos com análise coincidente para as umidades $\mathrm{e}$ cerca de um terço para o TDR. As variações foram maiores para a leitura do TDR, com extremos de mais de $30 \%$ na camada $B$ e apenas $7 \%$ na camada E. O que se pode verificar é que as leituras do TDR, que mostraram maior percentagem de semelhanças por período, não concordam da mesma forma entre períodos, exibindo variabilidade do comportamento no tempo. 


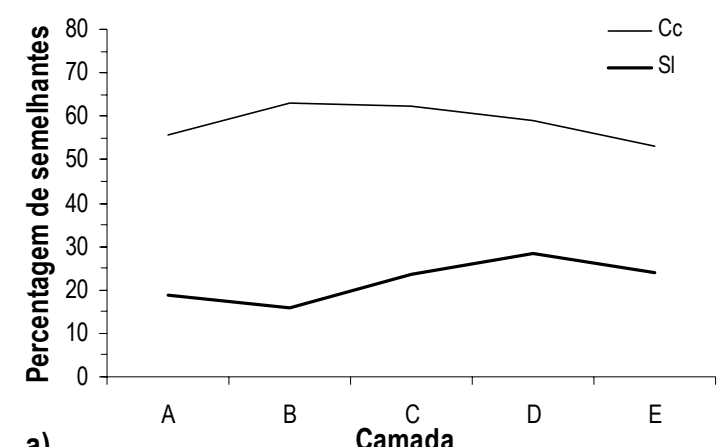

a)

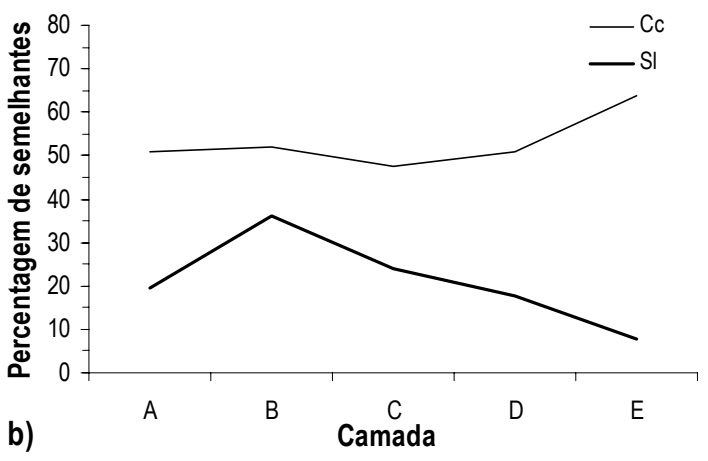

Figura 19 - Percentagem de pontos com resultados coincidentes da análise de semelhança das médias (Cc) e percentagem apenas dos pontos semelhantes nos dois períodos (SI), para umidade (a) e leitura do TDR (b), em função da profundidade.

Confeccionando uma tabela de correlações para a percentagem de pontos semelhantes entre os dois períodos, verifica-se que o comportamento geral para a umidade não variou muito entre os dois períodos, pois os coeficientes de correlação entre as duas seções de leitura, mostrados na Tabela 6, foram elevados, ou seja, pontos com grande número de semelhantes no primeiro período também o foram no segundo. Se o solo e as condições ambientais gerais variaram pouco, a umidade de cada ponto deveria seguir comportamento semelhante nos dois períodos, assim as semelhanças e as diferenças deveriam se repetir. $\mathrm{Na}$ mesma tabela verifica-se que, diferentemente da umidade, as leituras do TDR não apresentaram semelhanças correlacionadas entre os dois períodos, sendo razoável apenas para a camada $A$, chegando porém a ser negativa para as camadas $B$ e $D$, o que indica um comportamento pouco sistemático. O componente aleatório nas leituras do TDR parece mascarar, ou mesmo alterar, 0 comportamento normal esperado para estes dados.

A Tabela 6 complementa a análise da Figura 19, mostrando que, apesar do número similar de pontos com médias semelhantes, o padrão de variação dos dois conjuntos foi bastante diverso entre um período e outro. 
Tabela 6. Coeficiente de correlação para a percentagem de pontos semelhantes por camada entre dois períodos de observação.

\begin{tabular}{lccccc}
\hline & \multicolumn{5}{c}{ Camada } \\
& A & B & C & D & E \\
\hline Umidade & 0,862 & 0,712 & 0,824 & 0,625 & 0,716 \\
Tempo - TDR & 0,556 & $-0,200$ & 0,286 & $-0,014$ & 0,293 \\
\hline
\end{tabular}

A Tabela 7 exibe as semelhanças entre a umidade nos dois períodos, pela comparação de suas médias pelo intervalo de confiança de $95 \%$, onde se observa a grande correspondência entre os dois conjuntos de valores, com média acima de $90 \%$ dos pontos semelhantes; mesmo os valores estatisticamente diferentes possuem valores não muito díspares (pode-se também comparar as tabelas do Anexo A com o Anexo C). Já para os dados do tempo medido pelo aparelho de TDR a tendência é contrária. Apenas uma média de $30 \%$ dos pontos apresentaram-se estatisticamente semelhantes entre os dois períodos (Tabela 8). A camada B apresentou, assim como para a umidade, a menor percentagem, porém com o valor muito menor (9,1\% e 88,6\% respectivamente). É interessante notar que, para a leitura do TDR, a percentagem atingiu o máximo de $60 \%$ na camada $\mathrm{E}$, que é a que apresentou maior variabilidade em ambos os períodos e não mostrava correspondência para amplitude observada ou para semelhanças entre pontos. A pequena variação da média dos valores nesta camada entre os dois períodos e a amplitude relativamente grande em alguns pontos podem explicar este fato.

A relação entre as semelhanças para umidade e para as leituras do TDR entre os dois períodos apresentou-se restrita. Como para umidade a maioria dos pontos foi semelhante entre um período e outro, e para a leitura do TDR a maioria foi diferente, poderia ser esperado que a maioria dos pontos fosse divergente. Apenas 61 pontos foram semelhantes tanto para o TDR quanto para a umidade, o que representa todos os pontos semelhantes para a leitura do TDR, exceto cinco, grifados na Tabela 7. 
Tabela 7. Semelhança entre os valores de umidade por camada e bateria para os dois períodos (1-semelhante, 0 não semelhante, com IC de 95\%).

\begin{tabular}{|c|c|c|c|c|c|}
\hline \multirow{2}{*}{ Bateria } & \multicolumn{5}{|c|}{ Camadas } \\
\hline & $A$ & B & C & D & E \\
\hline 1 & 1 & 1 & 0 & 1 & 1 \\
\hline 2 & 1 & 1 & 1 & 1 & 1 \\
\hline 3 & 1 & 1 & 1 & 1 & 0 \\
\hline 4 & 1 & 1 & 1 & 1 & 1 \\
\hline 5 & 1 & - & - & 1 & 1 \\
\hline 6 & 1 & 1 & 1 & 1 & 1 \\
\hline 7 & - & 1 & 1 & 1 & - \\
\hline 8 & 1 & 1 & 1 & 1 & 1 \\
\hline 9 & 0 & 1 & 0 & 1 & 1 \\
\hline 10 & 1 & 1 & 1 & 1 & 1 \\
\hline 11 & 1 & 1 & 1 & 1 & 1 \\
\hline 12 & 1 & 1 & 1 & 1 & 1 \\
\hline 13 & 0 & 1 & 1 & 1 & 1 \\
\hline 14 & 1 & 1 & 1 & 1 & 1 \\
\hline 15 & 1 & 1 & 1 & 1 & 1 \\
\hline 16 & 1 & 1 & 1 & 0 & 1 \\
\hline 17 & 1 & 1 & 1 & 1 & 1 \\
\hline 18 & 1 & 1 & 1 & 1 & 1 \\
\hline 19 & 1 & 1 & 1 & 1 & 1 \\
\hline 20 & 1 & 1 & 1 & 1 & 1 \\
\hline 21 & 1 & 1 & 1 & - & 0 \\
\hline 22 & 1 & 1 & 1 & 1 & 1 \\
\hline 23 & 1 & 1 & 1 & 1 & 1 \\
\hline 24 & 1 & 1 & 1 & 1 & 1 \\
\hline 25 & 1 & 1 & 1 & 1 & 1 \\
\hline 26 & 1 & 0 & 1 & 1 & 1 \\
\hline 28 & 1 & 1 & 1 & 1 & 1 \\
\hline 29 & 1 & 0 & 1 & 1 & 0 \\
\hline 31 & 1 & 1 & 0 & 1 & 1 \\
\hline 32 & 1 & 1 & 1 & 1 & 1 \\
\hline 33 & 1 & 1 & 1 & 1 & 1 \\
\hline 34 & 1 & 1 & 1 & 1 & 1 \\
\hline 35 & 1 & 1 & 1 & 1 & 1 \\
\hline 36 & 1 & 1 & 1 & 1 & 1 \\
\hline 37 & 0 & 1 & 1 & - & 1 \\
\hline 38 & 1 & 1 & 1 & 1 & 1 \\
\hline 39 & - & 1 & 1 & 0 & 1 \\
\hline 40 & 1 & 1 & 1 & 1 & 1 \\
\hline 41 & 1 & 1 & 1 & 1 & 1 \\
\hline 42 & 1 & 1 & 1 & 1 & 1 \\
\hline 43 & 1 & 1 & 1 & 1 & 1 \\
\hline 44 & - & - & 1 & 1 & 1 \\
\hline 45 & 1 & 1 & 1 & 1 & 1 \\
\hline 46 & 1 & 0 & 1 & 1 & 1 \\
\hline 47 & 1 & 0 & 1 & 1 & 1 \\
\hline 48 & 0 & 0 & 0 & 1 & 1 \\
\hline Soma & 39 & 39 & 41 & 42 & 42 \\
\hline Total & 43 & 44 & 45 & 44 & 45 \\
\hline$\%$ & 90,7 & 88,6 & 91,1 & 95,5 & 93,3 \\
\hline
\end{tabular}

Tabela 8. Semelhança entre os valores da leitura do TDR por bateria e camada para os dois períodos (1-semelhante, 0-não semelhante, com IC de 95\%).

\begin{tabular}{cccccc}
\hline Bateria & \multicolumn{5}{c}{ Camadas } \\
& A & B & C & D & E \\
\hline 1 & 0 & 0 & 0 & 0 & 1 \\
2 & 0 & 1 & 1 & 0 & 1 \\
3 & 0 & 0 & 0 & 0 & 1 \\
4 & 0 & 1 & 1 & 0 & 0 \\
5 & 0 & - & - & 1 & 1 \\
6 & 0 & 0 & 0 & 1 & 0 \\
7 & - & 0 & 0 & 0 & - \\
8 & 1 & 0 & 0 & 1 & 1 \\
9 & 0 & 0 & 0 & 0 & 1 \\
10 & 1 & 0 & 0 & 0 & 1 \\
11 & 0 & 0 & 0 & 1 & 0 \\
12 & 1 & 0 & 0 & 1 & 0 \\
13 & 0 & 0 & 1 & 0 & 1 \\
14 & 1 & 0 & 0 & 0 & 0 \\
15 & 0 & 0 & 0 & 0 & 1 \\
16 & 0 & 0 & 0 & 0 & 0 \\
17 & 1 & 0 & 0 & 0 & 0 \\
18 & 0 & 0 & 0 & 1 & 1 \\
19 & 1 & 0 & 0 & 1 & 0 \\
20 & 0 & 0 & 0 & 1 & 1 \\
21 & 0 & 0 & 1 & - & 1 \\
22 & 0 & 0 & 0 & 1 & 1 \\
23 & 0 & 0 & 1 & 0 & 1 \\
24 & 0 & 1 & 1 & 0 & 0 \\
25 & 0 & 0 & 1 & 1 & 1 \\
26 & 0 & 0 & 0 & 0 & 0 \\
28 & 0 & 0 & 0 & 0 & 0 \\
29 & 0 & 0 & 1 & 1 & 1 \\
31 & 1 & 0 & 0 & 0 & 0 \\
32 & 0 & 0 & 0 & 0 & 1 \\
33 & 0 & 0 & 0 & 0 & 1 \\
34 & 0 & 0 & 0 & 0 & 0 \\
35 & 0 & 0 & 0 & 0 & 1 \\
36 & 0 & 0 & 0 & 1 & 1 \\
37 & 1 & 1 & 0 & - & 0 \\
38 & 0 & 0 & 0 & 0 & 1 \\
39 & - & 0 & 1 & 1 & 1 \\
40 & 0 & 0 & 0 & 1 & 1 \\
41 & 0 & 0 & 0 & 1 & 1 \\
42 & 0 & 0 & 0 & 0 & 0 \\
43 & 0 & 0 & 0 & 0 & 0 \\
44 & - & - & 0 & 1 & 0 \\
45 & 0 & 0 & 0 & 0 & 1 \\
46 & 0 & 0 & 0 & 0 & 0 \\
47 & 0 & 0 & 0 & 1 & 1 \\
48 & 0 & 0 & 0 & 1 & 1 \\
Soma & 8 & 4 & 9 & 18 & 27 \\
Total & 43 & 44 & 45 & 44 & 45 \\
$\%$ & 18,6 & 9,1 & 20,0 & 40,9 & 60,0 \\
\hline & & & & &
\end{tabular}


Para completar a análise de semelhanças dos dados foi encontrado o número de pontos semelhantes em função da distância que os separa. Cada ponto foi testado como todos os outros de sua respectiva camada. Levando-se em conta a distância que separa dois pontos quaisquer, esperar-se-ia que pontos mais próximos fossem em média mais semelhantes. Como 0 número total de comparações possíveis é maior para pontos mais próximos trabalhou-se então com a percentagem de ocorrências em relação ao número de possibilidades de comparação e apenas até a distância de $30 \mathrm{~m}$. Para a umidade, a tendência prevista pôde ser observada, embora em algumas camadas com pouca significância, tendo se apresentado semelhante tanto para o primeiro período (Figura 20), como para o segundo (Figura 21) e também para todos os dados em conjunto (Figura 22). Nota-se que o primeiro ponto dos gráficos, que corresponde à distância de $1 \mathrm{~m}$ entre os pontos comparados, apresenta uma percentagem elevada, maior que as outras (Figura 20). Para todos os dados em conjunto este detalhe é mais significativo (Figura 22) e para o segundo período este não é o ponto de maior percentagem para todas as camadas, mas também é elevado (Figura 21). Para os dados obtidos pelo TDR (Figuras 23 a 25) a mesma tendência não se verifica, até pelo contrário, o primeiro ponto apresenta valores inferiores aos pontos conseqüentes. A Figura 23 mostra o comportamento das leituras do TDR para o primeiro período, onde se vê, além da grande variação entre camadas, a ausência de tendência de diminuição da semelhança com o aumento da distância entre os pontos. Esta falta de tendência é repetida no segundo período, porém as variações entre camadas mostram-se mais sutis (Figura 24). O conjunto total de dados exibe o mesmo comportamento geral, com menores variações na percentagem por camada ao se aumentar a distância (Figura 25).

A diferença de comportamento para os dois conjuntos de dados é visível, com correlação muito baixa. 0 padrão exibido também reforça as evidências da existência de problemas para se encontrar uma relação entre umidade e as leituras do TDR. Isso se deve principalmente a problemas com os dados do TDR, pois é este conjunto que apresentou comportamento diverso, não correspondendo com padrões normalmente esperados ou com 0 padrão de variabilidade apresentado pelos dados de umidade. 


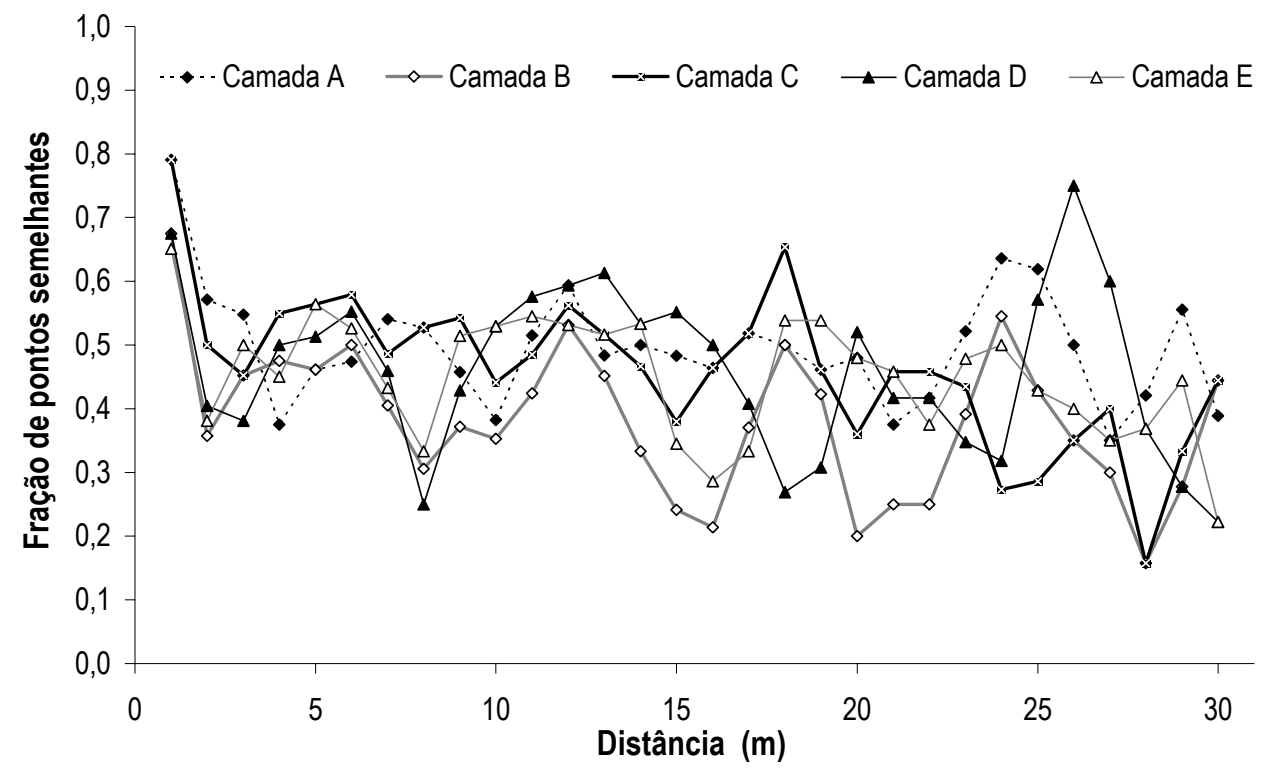

Figura 20 - Fração de pontos semelhantes em função da distância de comparação para umidade obtida por tensiometria, no primeiro período de observação (2000).

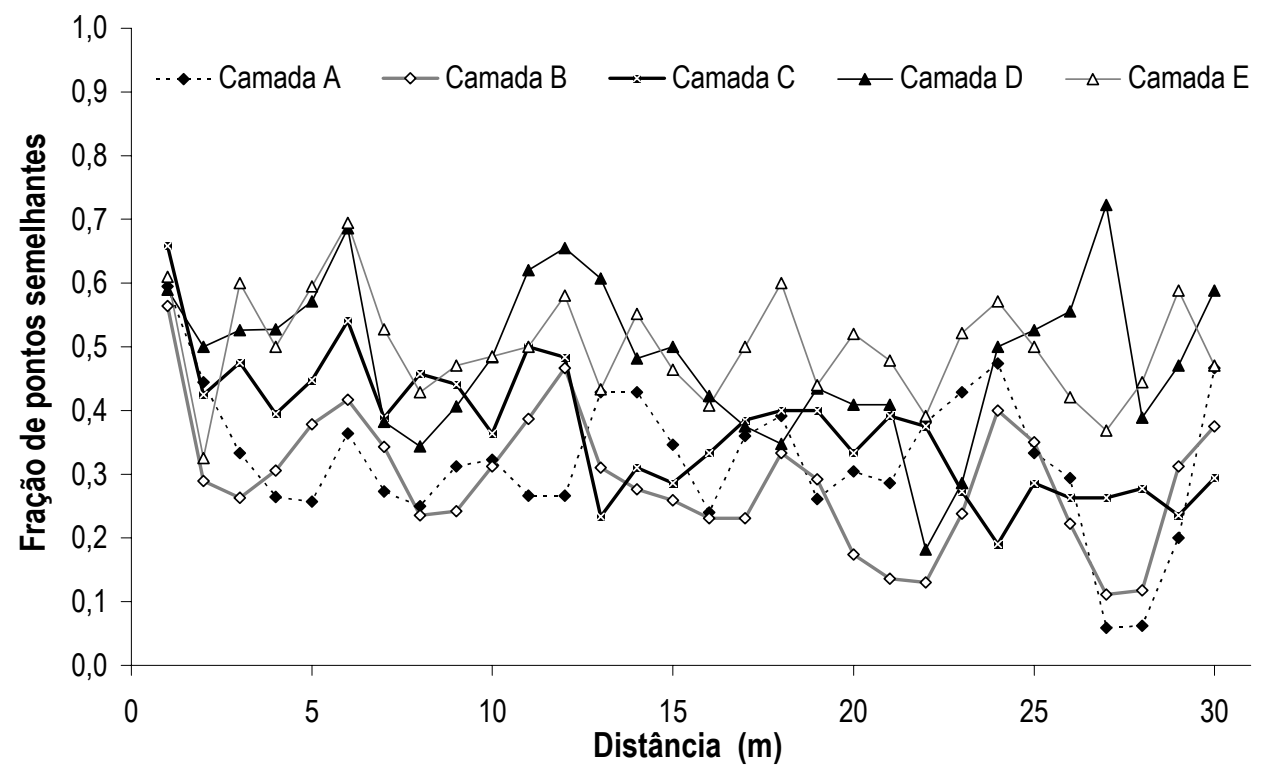

Figura 21 - Fração de pontos semelhantes em função da distância de comparação para umidade obtida por tensiometria, no segundo período de observação (2001). 


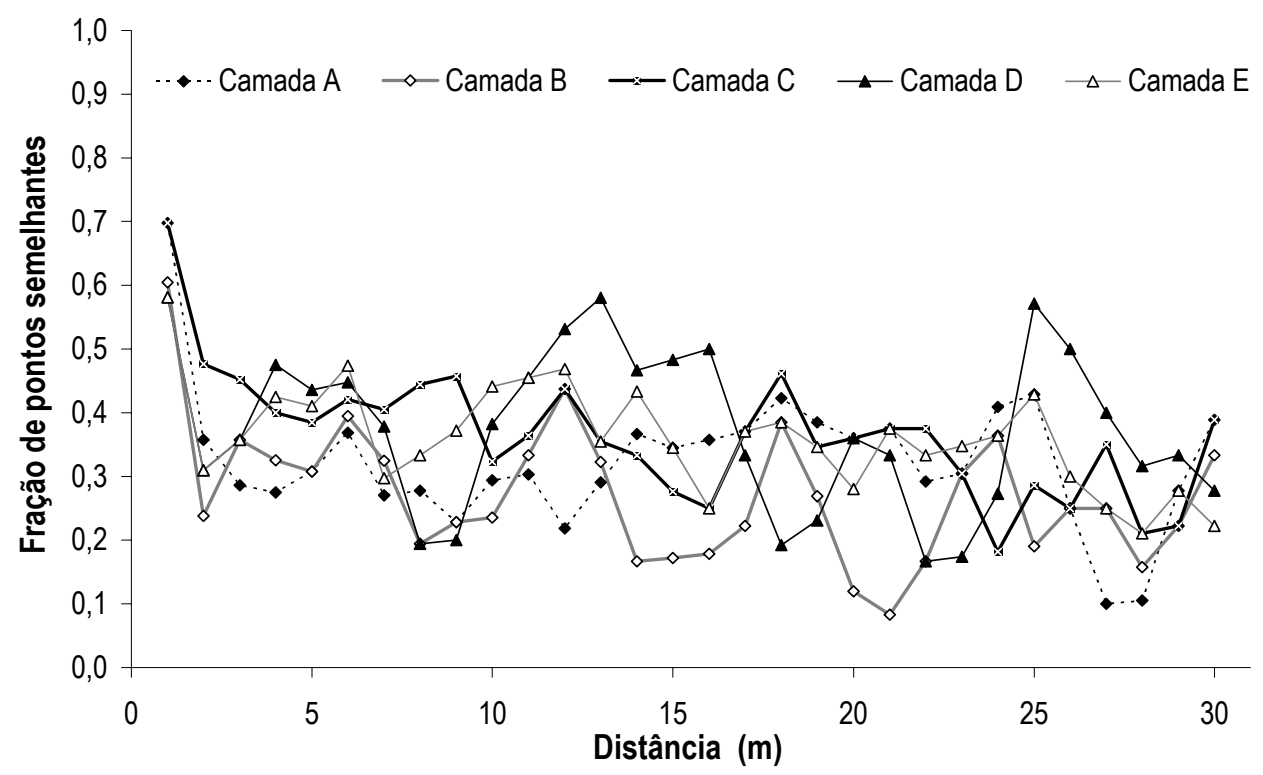

Figura 22 - Fração de pontos semelhantes em função da distância de comparação para umidade obtida por tensiometria, para todos os dados $(2000+2001)$.

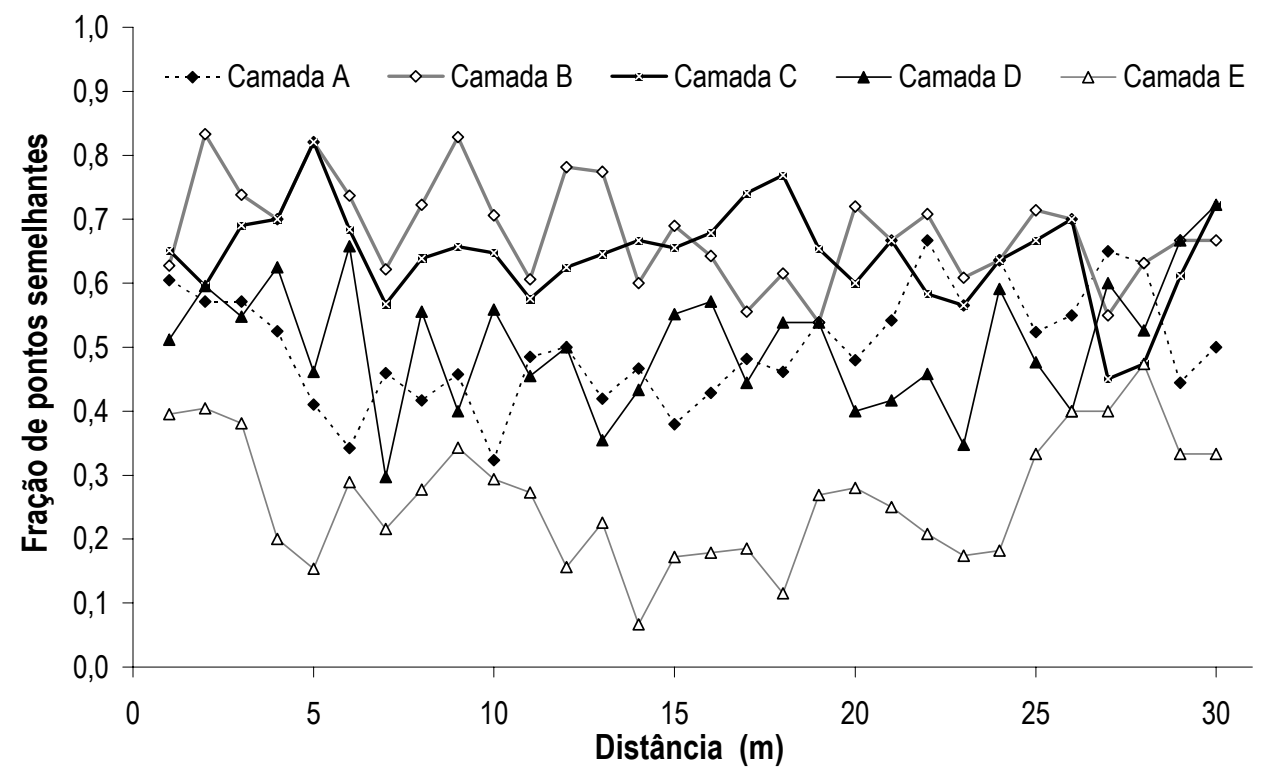

Figura 23 - Fração de pontos semelhantes em função da distância de comparação para leitura do TDR, no primeiro período de observação (2000). 


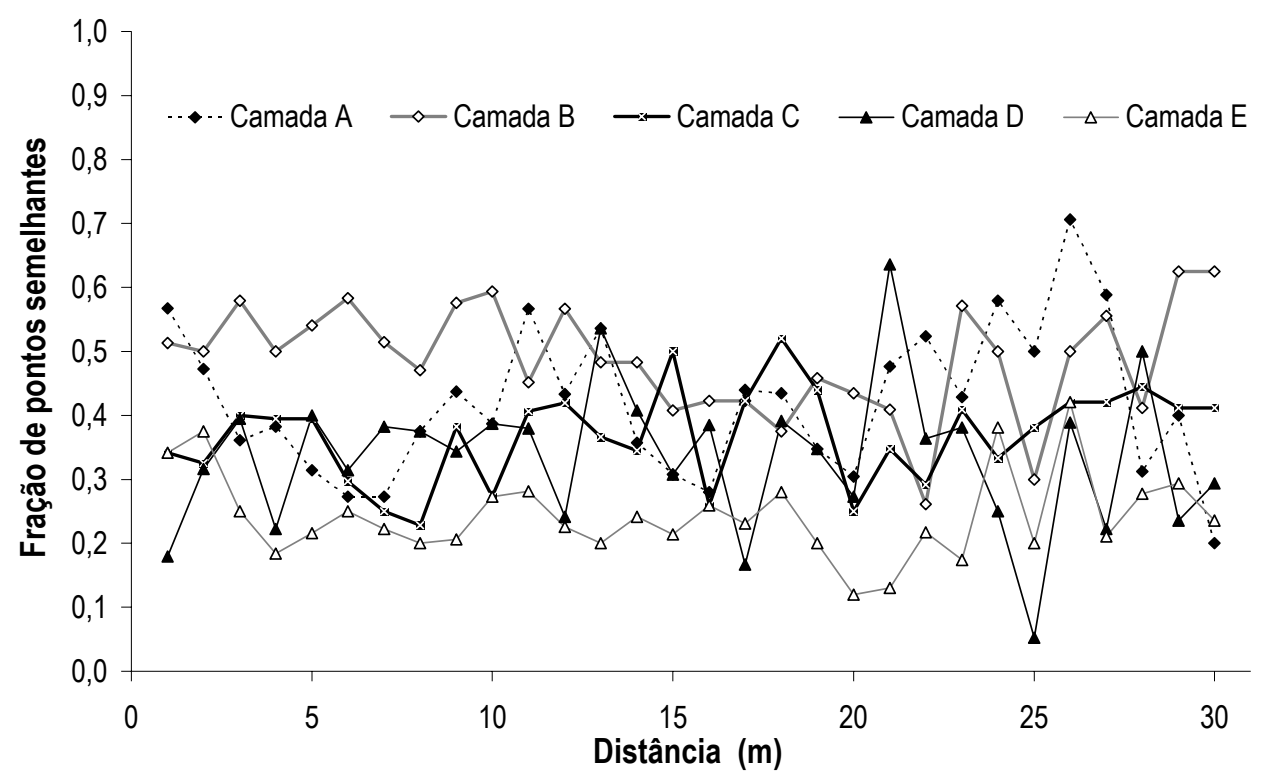

Figura 24 - Fração de pontos semelhantes em função da distância de comparação para leitura do TDR, no segundo período de observação (2001).

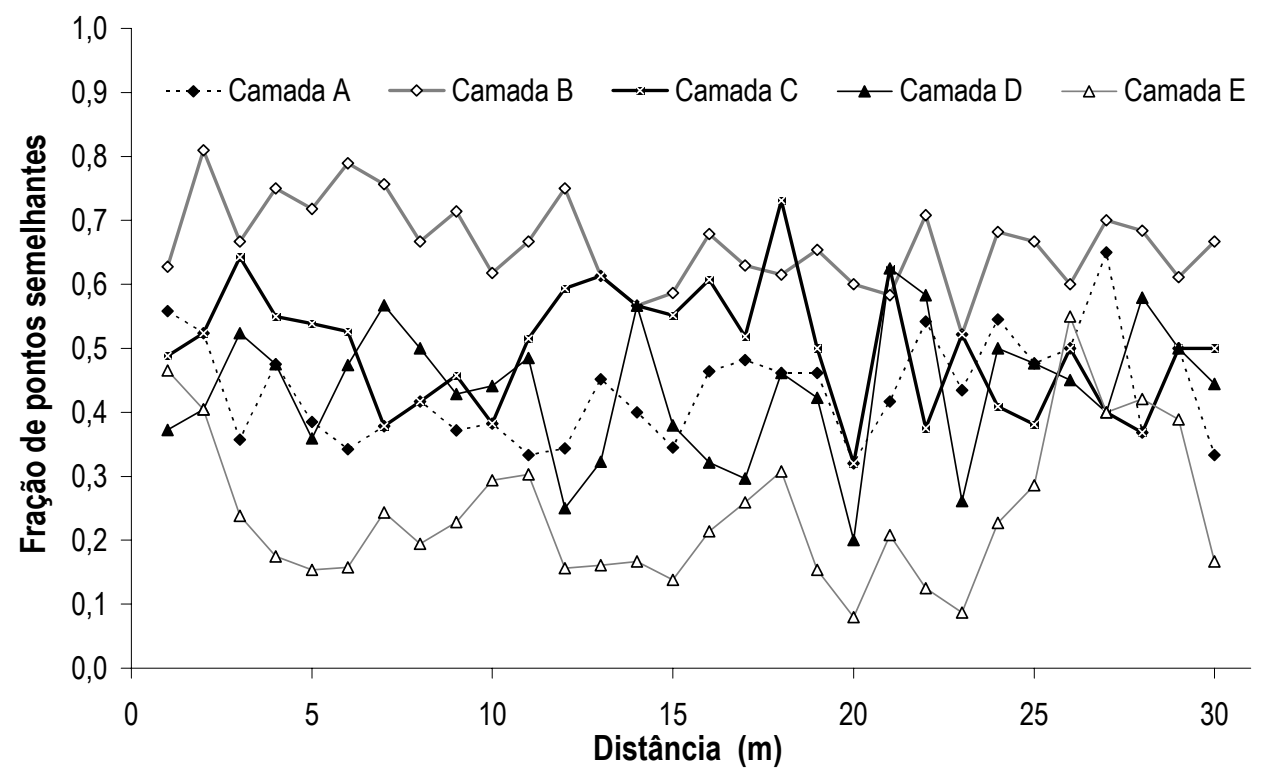

Figura 25 - Fração de pontos semelhantes em função da distância de comparação para leitura do TDR, para todos os dados $(2000+2001)$. 


\subsubsection{Ajuste das Equações de Calibração do TDR}

Não foi possível encontrar uma equação que se ajustasse satisfatoriamente a todos os dados em conjunto. A Figura 26 mostra o gráfico da relação da leitura do TDR e da umidade com os dados dos dois períodos de observação em conjunto, onde é visível a dispersão elevada dos pontos em torno da reta de regressão. 0 coeficiente de determinação da reta é 0,0803 , com erro médio esperado de $0,03 \mathrm{~m}^{3} \mathrm{~m}^{-3}$. De todo modo, apesar de a correlação entre as variáveis ter sido de apenas 0,283, a regressão mostrou-se altamente significativa $(F=910,3$ e prob. $<0,0001)$, 0 que evidencia que houve relação de causa-efeito entre as variáveis. Padrão muito semelhante foi encontrado para as regressões com os dados de cada período separadamente (Figura 28).

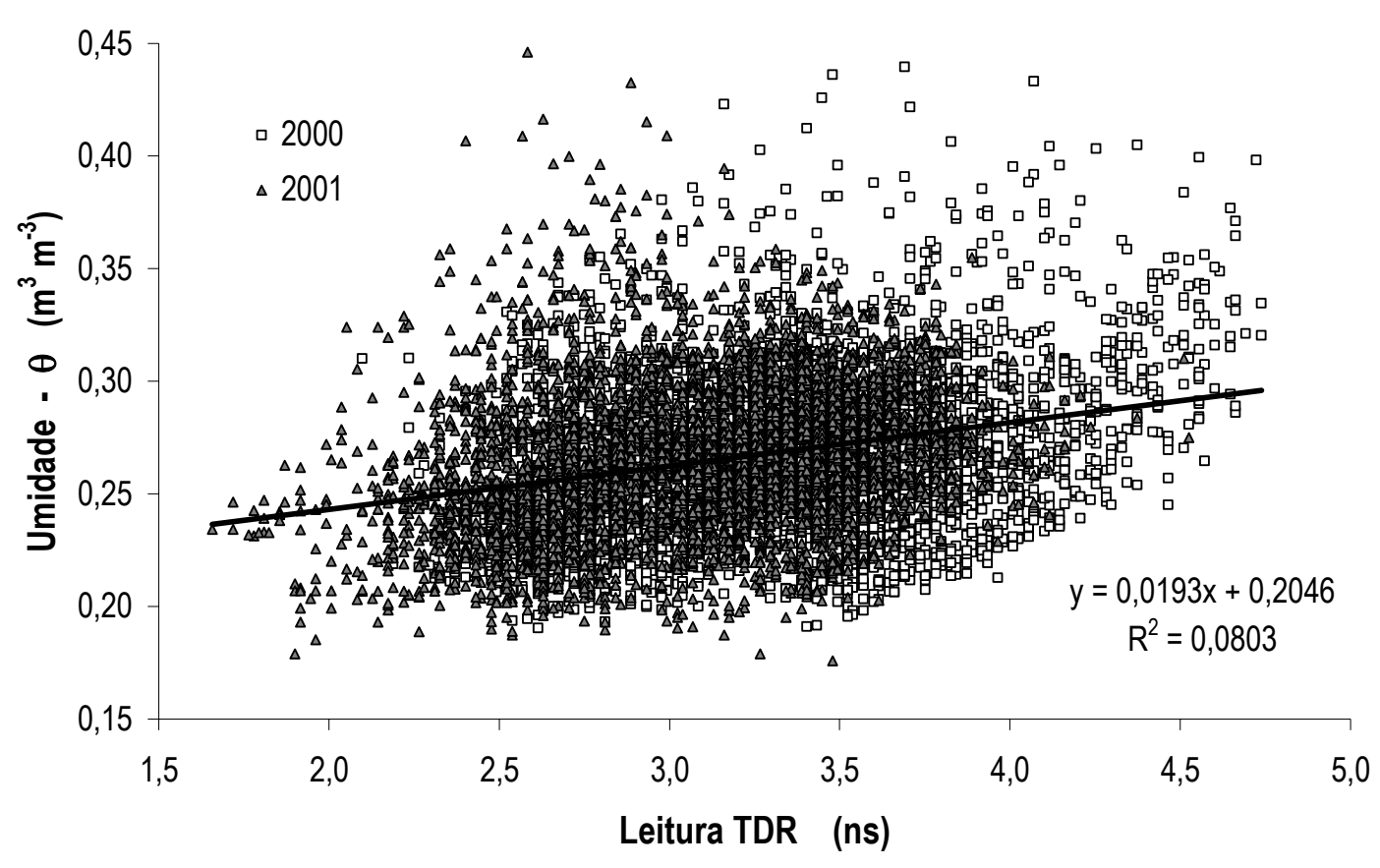

Figura 26 - Equação de calibração do TDR (modelo linear), ajustada a todos os pares de dados $\theta$-TTDR obtidos.

A relação causa-efeito encontrada, mesmo para regressões com dados por haste ou por camada separadas, revelou-se bem menor que as previstas pela equação do fabricante ou pela equação de Topp et al. (1980). Além de um coeficiente angular maior, o coeficiente linear destas equações mostrou-se muito menor do que os dados deste experimento exprimem (Figura 
27). Por conseguinte as estimativas da umidade pelos modelos de Topp et al. (1980) (eq. ( 9 )) ou do fabricante (eq. (14)) foram em geral menores que as observadas, sendo semelhantes ou superiores apenas para as camadas mais profundas e nos teores de água mais elevados. Estes resultados são particularmente interessantes pois, segundo a literatura (Dirksen \& Dasberg,1992; Ponizovsky, 1999), as curvas de calibração do TDR poderiam apresentar variações significativas em solos com alto teor de argila, acima de $0,50 \mathrm{~kg} \mathrm{~kg}^{-1}$, o que não foi o caso. Neste experimento o teor médio de argila do solo ficou abaixo de $0,20 \mathrm{~kg} \mathrm{~kg}^{-1}$, apenas na camada $E$ chegou próximo de $0,25 \mathrm{~kg} \mathrm{~kg}^{-1}$ (Figura 15). Sugerindo haver outros fatores, no solo ou no aparelho, que induziram estas variações na relação de calibração do TDR.

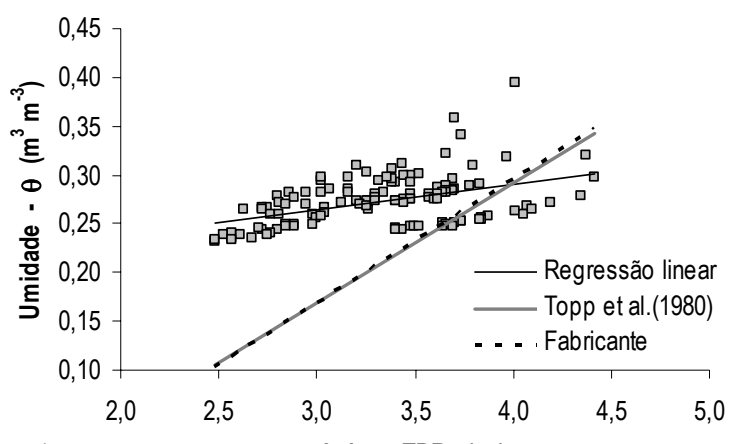

a)
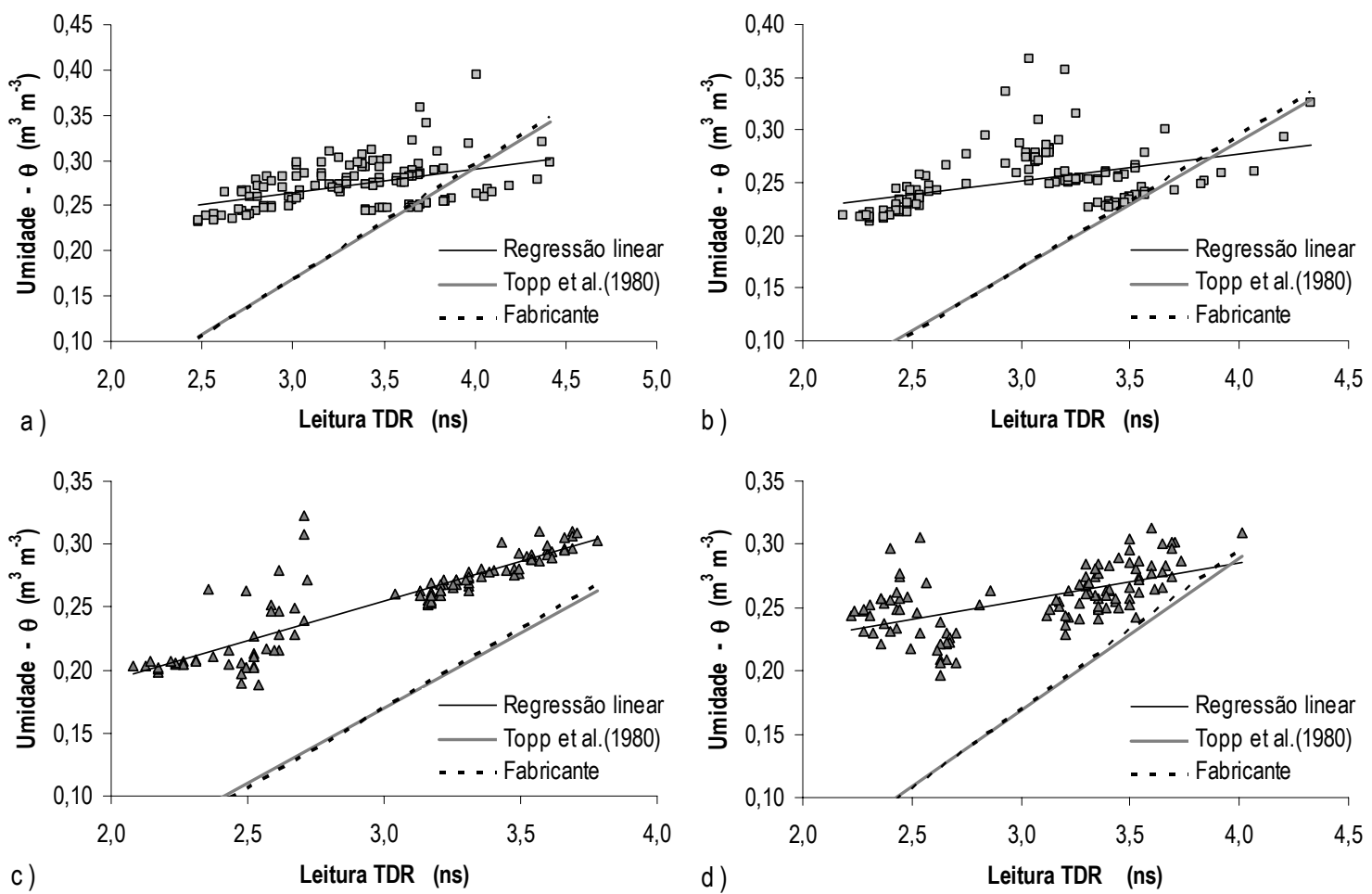

Figura 27 - Exemplos de curvas de calibração do TDR para os modelos das equações ( 9 ), ( 13 ) e ( 14 ), com os dados das hastes 6 (a) e 19 (b) do primeiro período, 31 (c) e 45 (d) do segundo período.

As regressões com modelos polinomiais não mostraram melhorias consideráveis em relação ao modelo linear. Equações polinomiais foram ajustadas aos dados, porém não proporcionaram coeficientes de determinação muito melhores e 0 erro esperado permaneceu 
praticamente inalterado. A Figura 28 mostra dois exemplos com todos os dados dos dois períodos separadamente, com as regressões lineares de cada um e a regressão polinomial com o melhor $\mathrm{R}^{2}$ encontrado, onde se pode verificar que a relação não é significativamente mais bem descrita por estes modelos do que pela regressão linear simples. Como este padrão repetiu-se para as demais análises, para simplificar a discussão serão apresentados apenas os resultados com a regressão linear simples.
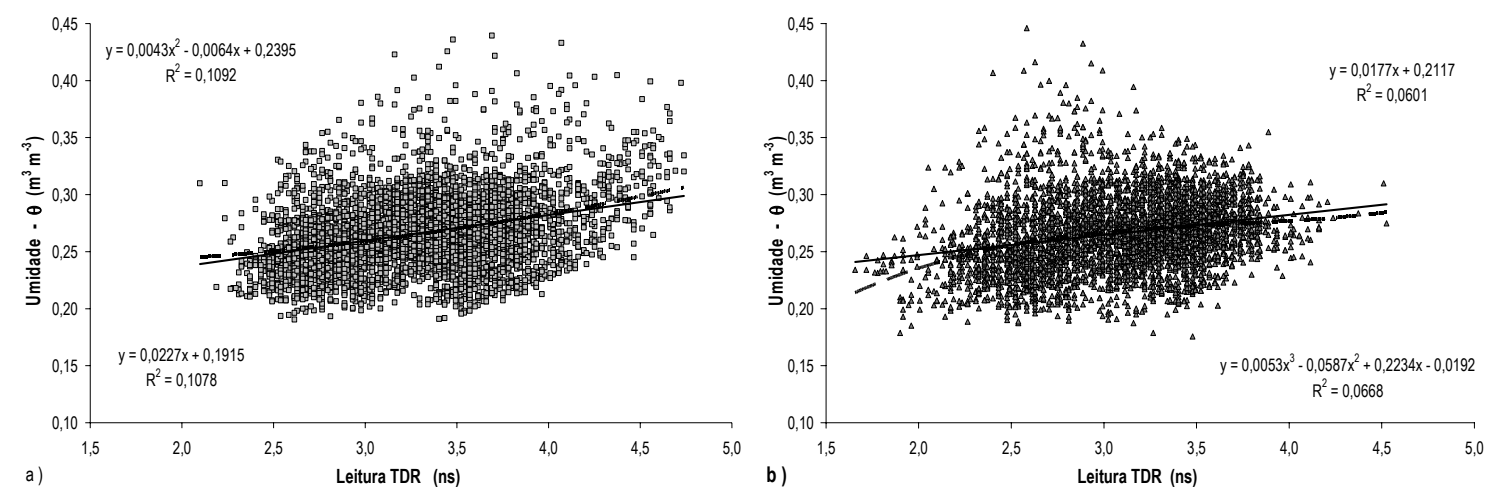

Figura 28- Equações de calibração do TDR e pares de dados $\theta-T_{\text {TDR }}$ observados para 0 primeiro período - 2000 (a) e para o segundo período - 2001 (b).

Aos dados de umidade provenientes do tensiômetro e curvas de retenção e das leituras do aparelho de TDR foram ajustadas equações seguindo o modelo linear, para cada haste, para cada camada e para cada segmento em particular. As curvas com os dados de conjuntos compostos, quer sejam provenientes de vários segmentos, varias hastes ou mesmo períodos, mostraram-se piores que para cada segmento e período específico.

Como o terreno utilizado apresentou-se bastante homogêneo, pode-se esperar que as variações dos atributos do solo sejam maiores em relação à profundidade do que ao longo da transeção. Assim as diferenças na calibração, caso fossem função apenas das características e propriedades do solo, deveriam se mostrar mais evidentes no perfil do solo. Ou seja, a dispersão dos pontos seria maior ao se juntarem os dados de todos os segmentos de cada haste do que ao se juntarem os dados por camada. No entanto esta expectativa foi contrariada pelos dados. 0 Anexo $\mathrm{G}$ mostra o resumo da regressão por camada, donde pode-se verificar que o desvio médio ficou acima de $0,025 \mathrm{~m}^{3} \mathrm{~m}^{-3}$, chegando a $0,028 \mathrm{~m}^{3} \mathrm{~m}^{-3}$ para os dados do segundo período $\mathrm{e}$ acima de $0,04 \mathrm{~m}^{3} \mathrm{~m}^{-3}$ nos três conjuntos de regressões na camada $A$. Para as regressões 
efetuadas por haste (Anexo $\mathrm{H}$ ) a média dos erros esperados ficou abaixo de $0,025 \mathrm{~m}^{3} \mathrm{~m}^{-3}$, não chegando a ultrapassar $0,04 \mathrm{~m}^{3} \mathrm{~m}^{-3}$ em nenhuma haste, com exceção da haste 13 no segundo período. Para uma melhor visualização as figuras dos Anexos $\mathrm{N}$ a $\mathrm{Q}$ exibem gráficos com exemplos da regressão por haste e por camada.

As tabelas dos Anexos I a M mostram os valores dos coeficientes linear, angular e de determinação, o desvio padrão da regressão, a estatística $F$ e sua respectiva probabilidade, dos ajustes do modelo linear aos dados por segmento de cada haste, para cada período de leitura e com todos os dados. É possível verificar que o desvio médio em torno das retas de calibração diminuiu, ficando na média em torno de $0,015 \mathrm{~m}^{3} \mathrm{~m}^{-3}$, porém bastante variável entre os pontos.

Esta precisão é semelhante à encontrada por Serrarens et al. (2000), que também identificaram um aumento da dispersão quando varias hastes foram consideradas em conjunto, praticamente dobrando o desvio padrão da regressão em relação à media dos desvios das curvas das hastes separadas, também usando modelos lineares.

A análise de correlação revelou que os coeficientes linear e angular das retas de calibração apresentaram-se altamente relacionados. A Tabela 9 exibe os coeficientes de correlação para os dois períodos e para todos os dados juntos. Todos os valores encontram-se acima de 0,90, com exceção dos da camada $C$ com todos os dados, que mesmo assim também foi elevado. Para simplificar a análise das curvas de calibração, tendo em vista estes resultados, considerou-se que o coeficiente angular representa suficientemente o modelo.

Tabela 9. Coeficientes de correlação entre os coeficientes angular e linear das retas ajustadas aos dados de umidade e leitura do TDR, para os dados coletados nos dois períodos e todos juntos.

\begin{tabular}{lccccc}
\hline \multirow{2}{*}{ Período } & \multicolumn{5}{c}{ Camada } \\
& A & B & C & D & E \\
\hline 2000 & $-0,932$ & $-0,983$ & $-0,976$ & $-0,994$ & $-0,990$ \\
2001 & $-0,974$ & $-0,983$ & $-0,983$ & $-0,994$ & $-0,987$ \\
$2000+2001$ & $-0,949$ & $-0,970$ & $-0,861$ & $-0,991$ & $-0,993$ \\
\hline
\end{tabular}


A análise das tabelas com os resultados das regressões permite verificar que, de uma maneira geral, o primeiro período apresentou desempenho melhor nas regressões. Praticamente todas as regressões para este período mostraram-se estatisticamente significativas: cerca de $98 \%$ dos pontos significativos com probabilidade de até $5 \%$ para o teste $\mathrm{F}$. Para 0 segundo período as regressões apresentaram-se significativas em número bem menor, cerca de $61 \%$ e para todos os dados em conjunto o percentual de significância ficou em aproximadamente $93 \%$. Entre as camadas houve pouca variação e não foi possível identificar nenhuma tendência. Apenas a camada $E$ mostrou-se com menor percentagem de ajustes significativos em relação às demais nos três conjuntos de regressões.

A análise dos coeficientes de determinação revelou resultados menos expressivos. Em torno de $18 \%$ dos ajustes exibiram $R^{2}$ superior a 0,80 e praticamente todos oriundos dos ajustes utilizando os dados do primeiro período de leitura apenas, onde $47 \%$ dos pontos apresentaram $\mathrm{R}^{2}$ igual ou superior a 0,80 , não chegando a $2 \%$ quando 0 ajuste foi feito com todos os dados. Neste caso cerca de $62 \%$ dos ajustes tiveram $R^{2}$ inferior a 0,50 e para o segundo período esta percentagem chegou a superar $78 \%$ dos ajustes. A Figura 29 mostra a distribuição dos coeficientes de determinação divididos em quatro categorias, para cada período e com todos os dados, onde é possível visualizar melhor as variações da qualidade dos ajustes da regressão linear.

A qualidade dos ajustes, estimada pelo coeficiente de determinação, também apresentou variações em função da profundidade (Figura 29). De um modo geral os ajustes se mostraram piores com 0 aumento da profundidade. Esta tendência foi bem evidente para os ajustes com os dados do primeiro período de leituras (Figura 29a) e um pouco menos para 0 segundo período (Figura 29b) e para as regressões com todos os dados em conjunto (Figura 29c). 0 fato de as amplitudes da variação de umidade decrescerem com a profundidade aliado aos baixos coeficientes de correlação entre os dois conjuntos de dados já davam indicativos de ajustes piores nas camadas mais profundas, como de fato foi verificado. 

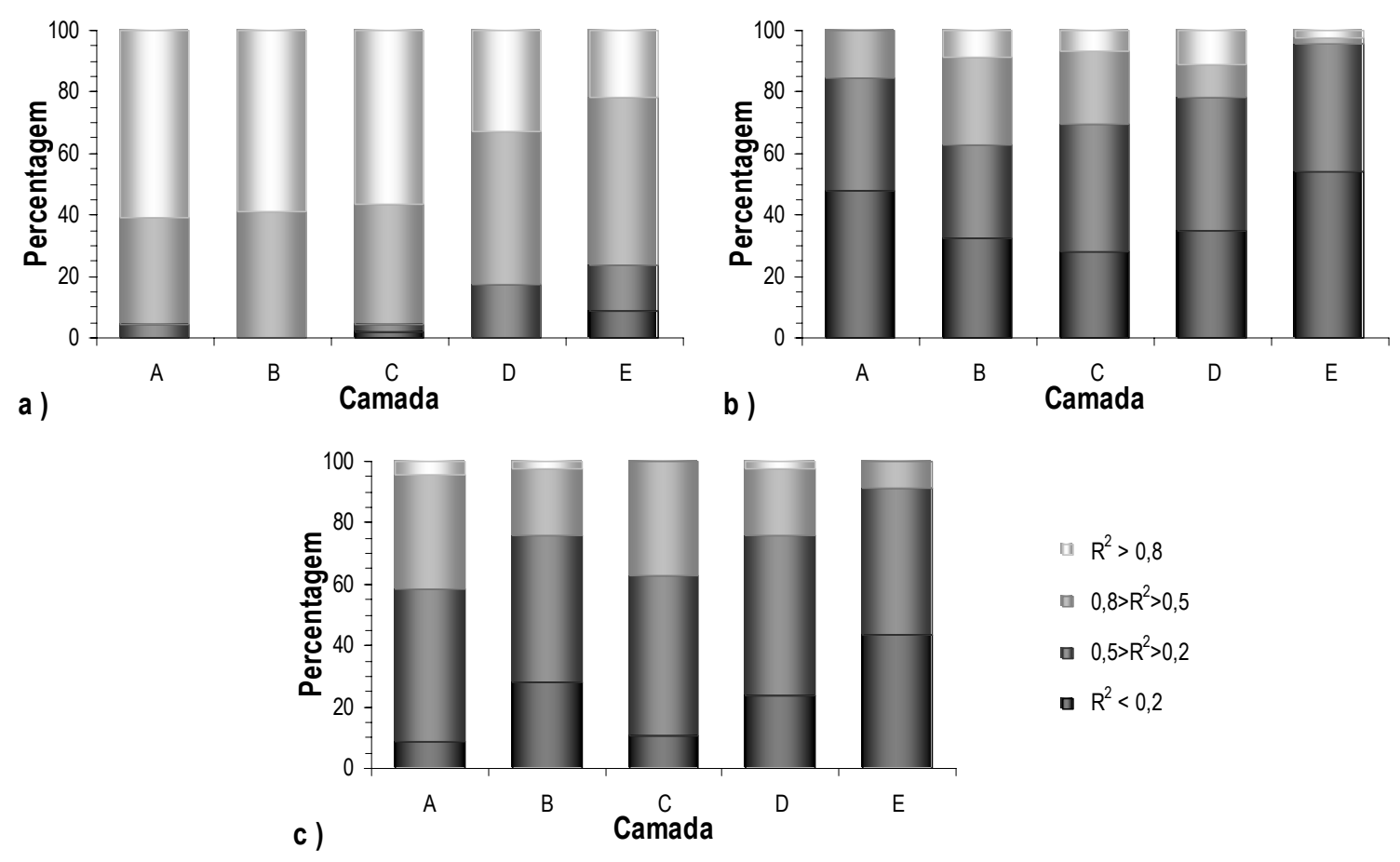

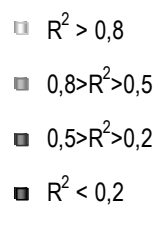

Figura 29 - Percentagem de equações de calibração com coeficientes de determinação da regressão linear em quatro classes por camada, para o primeiro período (a), segundo período (b) e todos os dados juntos (c).

A falta de correlação entre os dados coletados nos dois períodos também se reflete nos resultados de qualidade bem diferentes para os ajustes de calibração com o uso dos dados desses dois conjuntos. Juntando os dois conjuntos houve até a redução dos pontos com ajustes de qualidade superior a 0,8 para o coeficiente de determinação, o que indica que os ajustes devem ser diferentes entre os dois períodos. A correlação dos coeficientes angulares encontrados nos dois períodos mostra-se reduzida (Tabela 10), sendo quase nula para a camada E. A mesma tabela exibe os coeficientes de correlação entre os dois períodos para os coeficientes de determinação, onde se verificam valores mais baixos ainda. 0 que significa que a qualidade dos modelos não apresentou desempenho semelhante nos dois períodos. 
Tabela 10. Coeficientes de correlação para os coeficientes angular e de determinação das retas ajustadas aos dados de umidade e leitura do TDR, entre os dois períodos de observação.

\begin{tabular}{lccccc}
\hline & \multicolumn{5}{c}{ Camada } \\
& $\mathrm{A}$ & $\mathrm{B}$ & $\mathrm{C}$ & $\mathrm{D}$ & $\mathrm{E}$ \\
\hline $\mathrm{b}$ & 0,352 & 0,326 & 0,430 & 0,304 & $-0,0126$ \\
$\mathrm{R}^{2}$ & 0,196 & 0,076 & 0,247 & 0,244 & 0,238 \\
\hline
\end{tabular}

Os coeficientes angulares das retas de calibração, apesar de pouco correlacionados, mostraram-se semelhantes na maioria dos pontos nos dois períodos de observação. A Tabela 11 exibe o panorama dos pontos semelhantes entre um período e outro, ao nível de probabilidade de $95 \%$. Em média cerca de $82 \%$ dos pontos apresentaram-se semelhantes, sendo apenas $68,9 \%$ na camada $\mathrm{C}$ e chegando a $97,8 \%$ na camada $\mathrm{E}$. Os valores contraditórios entre a análise de correlação e a análise de semelhança devem ser abordados com cautela, pois revelam aspectos diferentes da análise geral das regressões.

As regressões não apresentaram qualidade muito boa, visto que os coeficientes de determinação foram em geral muito baixos e sem correlação definida. Isso se deve principalmente à dispersão elevada dos valores, que pode ser observada nos gráficos dos Anexos $\mathrm{N}$ a V. Para conjuntos com dispersão elevada é normal encontrar vários pontos em que as curvas de calibração não diferem estatisticamente, o que explica o grande número de pontos semelhantes entre um período e outro. A análise de semelhança tem sua importância reduzida nesses casos. A análise de correlação concorre para melhor interpretar o comportamento dos dados, assim, apesar de semelhantes ao serem comparados pelo valor médio do coeficiente angular, os dois períodos possuem padrões de variação do percentual explicado pela regressão completamente diferentes entre os dois períodos, não há correlação entre os conjuntos. Por este motivo as semelhanças estatísticas devem ser tratadas com prudência, e não tomadas como resultados absolutos.

A análise de semelhança efetuada entre as camadas também revelou grande número de pontos semelhantes. É interessante observar que o primeiro período de observações, que apresentou o maior número de pontos com retas de calibração significativas e com maiores coeficientes de determinação, apresentou um menor grau de semelhanças (Tabela 12). Apenas 
três pontos apresentaram curvas estatisticamente iguais em todas as camadas, ao passo que em nove pontos ao menos uma camada apresentou-se díspar das demais. Os resultados exibidos pelo segundo período, onde 24 pontos apresentaram curvas semelhantes em todas as camadas (Tabela 13), vêm corroborar o que foi discutido no parágrafo anterior, ou seja, as semelhanças entre as várias curvas são devidas muito mais à dispersão dos valores das leituras de umidade e tempo do TDR, do que a um comportamento de fato semelhante entre os vários pontos e segmentos. Também deve-se levar em conta que, além da dispersão maior, o segundo período apresenta amplitudes totais das leituras menores, reduzindo assim o percentual da variação geral explicável pela regressão e aumentando relativamente o intervalo de confiança, o que propicia mais facilmente as semelhanças. Ao juntarem-se os dois conjuntos de dados (Tabela 14) vê-se que o primeiro período é que define o comportamento geral deste novo conjunto. $O$ número de pontos com todas as camadas apresentando retas de calibração semelhantes, são seis, é bem mais próximo daquele apresentado pelos dados do primeiro período, havendo oito com pelo menos uma camada diferente das demais. 
Tabela 11. Semelhança entre os valores obtidos nos dois períodos dos coeficientes angulares das retas da regressão linear dos valores de umidade e leitura do TDR, por bateria e camada (1-semelhante, 0-não semelhante, com IC de 95\%).

\begin{tabular}{|c|c|c|c|c|c|}
\hline \multirow{2}{*}{ Bateria } & \multicolumn{5}{|c|}{ Camadas } \\
\hline & A & B & C & D & $\mathrm{E}$ \\
\hline 1 & 1 & 1 & 1 & 1 & 1 \\
\hline 2 & 1 & 0 & 0 & 1 & 1 \\
\hline 3 & 0 & 1 & 1 & 1 & 1 \\
\hline 4 & 1 & 1 & 1 & 1 & 1 \\
\hline 5 & 1 & - & - & 1 & 1 \\
\hline 6 & 1 & 1 & 0 & 1 & 1 \\
\hline 7 & - & 0 & 1 & 1 & - \\
\hline 8 & 1 & 1 & 1 & 1 & 1 \\
\hline 9 & 1 & 1 & 1 & 1 & 0 \\
\hline 10 & 1 & 1 & 1 & 1 & 1 \\
\hline 11 & 1 & 1 & 1 & 1 & 1 \\
\hline 12 & 1 & 1 & 1 & 1 & 1 \\
\hline 13 & 1 & 1 & 1 & 0 & 1 \\
\hline 14 & 0 & 0 & 0 & 0 & 1 \\
\hline 15 & 1 & 1 & 0 & 1 & 1 \\
\hline 16 & 0 & 1 & 1 & 1 & 1 \\
\hline 17 & 1 & 0 & 0 & 0 & 1 \\
\hline 18 & 1 & 1 & 0 & 1 & 1 \\
\hline 19 & 0 & 1 & 1 & 1 & 1 \\
\hline 20 & 1 & 1 & 0 & 1 & 1 \\
\hline 21 & 0 & 1 & 0 & - & 1 \\
\hline 22 & 1 & 1 & 1 & 1 & 1 \\
\hline 23 & 1 & 1 & 1 & 1 & 1 \\
\hline 24 & 1 & 1 & 1 & 0 & 1 \\
\hline 25 & 1 & 1 & 1 & 1 & 1 \\
\hline 26 & 1 & 1 & 1 & 1 & 1 \\
\hline 28 & 1 & 1 & 1 & 0 & 1 \\
\hline 29 & 1 & 1 & 1 & 0 & 1 \\
\hline 31 & 1 & 1 & 0 & 1 & 1 \\
\hline 32 & 0 & 1 & 0 & 1 & 1 \\
\hline 33 & 1 & 1 & 1 & 1 & 1 \\
\hline 34 & 1 & 1 & 1 & 1 & 1 \\
\hline 35 & 1 & 1 & 1 & 1 & 1 \\
\hline 36 & 1 & 1 & 1 & 0 & 1 \\
\hline 37 & 1 & 1 & 1 & - & 1 \\
\hline 38 & 0 & 1 & 1 & 1 & 1 \\
\hline 39 & . & 0 & 0 & 1 & 1 \\
\hline 40 & 1 & 1 & 1 & 0 & 1 \\
\hline 41 & 1 & 0 & 0 & 0 & 1 \\
\hline 42 & 1 & 1 & 1 & 1 & 1 \\
\hline 43 & 1 & 1 & 0 & 0 & 1 \\
\hline 44 & - & - & 1 & 0 & 1 \\
\hline 45 & 1 & 1 & 1 & 1 & 1 \\
\hline 46 & 1 & 1 & 0 & 1 & 1 \\
\hline 47 & 1 & 1 & 1 & 0 & 1 \\
\hline 48 & 1 & 1 & 1 & 1 & 1 \\
\hline Soma & 36 & 38 & 31 & 32 & 44 \\
\hline Total & 43 & 44 & 45 & 44 & 45 \\
\hline$\%$ & 83,7 & 86,4 & 68,9 & 72,7 & 97,8 \\
\hline
\end{tabular}


Tabela 12. Coeficientes angulares das retas da regressão linear dos valores de umidade e leitura do TDR por ponto para o primeiro período (2000). Valores seguidos de mesma letra, na linha, não diferem ao nível de probabilidade de $95 \%$.

\begin{tabular}{|c|c|c|c|c|c|c|c|c|c|c|}
\hline \multirow{2}{*}{ Bateria } & \multicolumn{10}{|c|}{ Camada } \\
\hline & A & & B & & $C$ & & $D$ & & $E$ & \\
\hline 1 & 0,057 & $a$ & 0,072 & $a$ & 0,082 & $a$ & 0,082 & $a$ & 0,052 & $a$ \\
\hline 2 & 0,055 & a & 0,069 & $a$ & 0,149 & $b$ & 0,106 & $a b$ & 0,084 & $a b$ \\
\hline 3 & 0,113 & $a$ & 0,068 & $a$ & 0,082 & $b$ & 0,072 & $a b$ & 0,018 & $a b$ \\
\hline 4 & 0,091 & a & 0,079 & $a b$ & 0,063 & $a$ & 0,066 & $a b$ & 0,021 & $b$ \\
\hline 5 & 0,081 & a & 0,045 & $b$ & 0,040 & $b$ & 0,059 & $a b$ & 0,013 & $b$ \\
\hline 6 & 0,089 & $a b$ & 0,051 & C & 0,066 & $\mathrm{ac}$ & 0,061 & $\mathrm{ac}$ & 0,031 & $b$ \\
\hline 7 & 0,106 & $a$ & 0,111 & $a$ & 0,057 & $b$ & 0,049 & $b$ & 0,038 & $a$ \\
\hline 8 & 0,090 & a & 0,093 & $a$ & 0,061 & $a$ & 0,055 & a & 0,022 & a \\
\hline 9 & 0,131 & a & 0,123 & a & 0,106 & a & 0,113 & $a$ & 0,021 & $b$ \\
\hline 10 & 0,122 & $a$ & 0,095 & $a$ & 0,094 & $a$ & 0,092 & $a$ & 0,031 & $a$ \\
\hline 11 & 0,104 & $a$ & 0,035 & $b$ & 0,029 & $b$ & 0,036 & $b$ & 0,033 & a \\
\hline 12 & 0,131 & $a$ & 0,026 & $b$ & 0,041 & $\mathrm{bc}$ & 0,062 & C & 0,013 & $c$ \\
\hline 13 & 0,083 & a & 0,086 & $a$ & 0,071 & $a$ & 0,096 & a & 0,033 & $b$ \\
\hline 14 & 0,092 & a & 0,079 & $a b$ & 0,064 & $b$ & 0,058 & $b$ & 0,017 & $a$ \\
\hline 15 & 0,111 & a & 0,101 & $a b$ & 0,070 & C & 0,054 & $b c$ & 0,024 & $b c$ \\
\hline 16 & 0,129 & $a$ & 0,142 & $a b$ & 0,099 & c & 0,104 & $a b c$ & 0,019 & $b c$ \\
\hline 17 & 0,122 & a & 0,075 & $b c$ & 0,061 & $b$ & 0,091 & $\mathrm{ac}$ & 0,027 & $\mathrm{ac}$ \\
\hline 18 & 0,123 & $a b$ & 0,080 & ac & 0,058 & c & 0,080 & $a b c$ & 0,089 & $b$ \\
\hline 19 & 0,210 & $a$ & 0,077 & $b$ & 0,121 & c & 0,054 & $b$ & 0,066 & $\mathrm{bc}$ \\
\hline 20 & 0,115 & a & 0,055 & $b$ & 0,112 & a & 0,052 & $b$ & 0,017 & $a$ \\
\hline 21 & 0,162 & $a$ & 0,092 & $b$ & 0,119 & $a b$ & 0,099 & $b$ & 0,034 & $a b$ \\
\hline 22 & 0,156 & $a$ & 0,110 & $a b$ & 0,089 & $b c$ & 0,080 & c & 0,024 & $a b c$ \\
\hline 23 & 0,098 & a & 0,008 & $b$ & 0,030 & c & 0,046 & C & 0,083 & $a b c$ \\
\hline 24 & 0,098 & $a$ & 0,029 & $b$ & 0,031 & $b$ & 0,059 & C & 0,034 & $a b c$ \\
\hline 25 & 0,093 & $a$ & 0,080 & $a b$ & 0,056 & c & 0,062 & $b c$ & 0,012 & $c$ \\
\hline 26 & 0,055 & $a b$ & 0,082 & $a b$ & 0,060 & $a$ & 0,129 & $b$ & 0,061 & $a b$ \\
\hline 28 & 0,129 & $a$ & 0,105 & $a$ & 0,130 & $a$ & 0,127 & a & 0,019 & $a$ \\
\hline 29 & 0,094 & a & 0,078 & $a b$ & 0,101 & $a$ & 0,090 & $a$ & 0,017 & $b$ \\
\hline 31 & 0,195 & $a$ & 0,052 & $b c$ & 0,073 & $b$ & 0,056 & $b c$ & 0,008 & c \\
\hline 32 & 0,196 & a & 0,074 & $b$ & 0,105 & c & 0,084 & $b$ & 0,012 & $b$ \\
\hline 33 & 0,123 & a & 0,069 & $b$ & 0,082 & $b$ & 0,036 & C & 0,017 & $b$ \\
\hline 34 & 0,120 & a & 0,069 & $b$ & 0,062 & $b$ & 0,065 & $b$ & 0,018 & $b$ \\
\hline 35 & 0,112 & $a$ & 0,057 & $b$ & 0,064 & $b c$ & 0,084 & $\mathrm{ac}$ & 0,019 & $b c$ \\
\hline 36 & 0,099 & $a$ & 0,050 & $b$ & 0,069 & c & 0,072 & $\mathrm{ac}$ & 0,045 & $a b c$ \\
\hline 37 & 0,093 & $a$ & 0,030 & $b$ & 0,081 & $a$ & 0,048 & C & 0,020 & $a b c$ \\
\hline 38 & 0,087 & $a$ & 0,027 & $b$ & 0,067 & $a$ & 0,034 & $b c$ & 0,018 & $\mathrm{ac}$ \\
\hline 39 & 0,103 & $a$ & 0,091 & $a b$ & 0,059 & C & 0,074 & $b c$ & 0,019 & $a$ \\
\hline 40 & 0,046 & a & 0,066 & $a$ & 0,061 & $a$ & 0,118 & $b$ & 0,018 & a \\
\hline 41 & 0,081 & a & 0,045 & $b$ & 0,019 & c & 0,054 & C & 0,020 & $a$ \\
\hline 42 & 0,046 & $a$ & 0,025 & $a b$ & 0,016 & $b$ & 0,022 & $b$ & 0,012 & a \\
\hline 43 & 0,095 & a & 0,072 & $a b$ & 0,063 & $b$ & 0,167 & C & 0,027 & $a b$ \\
\hline 44 & 0,127 & a & 0,088 & $b c$ & 0,069 & $b$ & 0,235 & $d$ & 0,033 & adc \\
\hline 45 & 0,088 & $a b$ & 0,084 & $a b$ & 0,109 & $a$ & 0,063 & $b$ & 0,019 & $b$ \\
\hline 46 & 0,057 & $a b$ & 0,062 & $a b$ & 0,091 & $b$ & 0,074 & $a b$ & 0,018 & $a b$ \\
\hline 47 & 0,096 & $a b$ & 0,111 & $a$ & 0,043 & c & 0,061 & $\mathrm{ac}$ & 0,026 & $a$ \\
\hline 48 & 0,117 & a & 0,073 & $a b$ & 0,056 & $b$ & 0,034 & $b$ & 0,028 & $a b$ \\
\hline
\end{tabular}


Tabela 13. Coeficientes angulares das retas da regressão linear dos valores de umidade e leitura do TDR por ponto para o segundo período (2001). Valores seguidos de mesma letra, na linha, não diferem ao nível de probabilidade de $95 \%$.

\begin{tabular}{|c|c|c|c|c|c|c|c|c|c|c|}
\hline \multirow{2}{*}{ Bateria } & \multicolumn{10}{|c|}{ Camada } \\
\hline & A & & B & & $C$ & & $D$ & & $E$ & \\
\hline 1 & 0,042 & $a$ & 0,102 & $a$ & 0,041 & $a$ & 0,038 & $a$ & 0,091 & $a$ \\
\hline 2 & 0,040 & $a$ & 0,029 & $a$ & 0,028 & a & 0,000 & a & 0,009 & $a$ \\
\hline 3 & 0,053 & $a b$ & 0,085 & $a b$ & 0,085 & $a$ & 0,014 & $b$ & 0,038 & $b$ \\
\hline 4 & 0,053 & $a b$ & 0,049 & $a$ & 0,046 & a & 0,042 & a & $-0,029$ & $b$ \\
\hline 5 & 0,063 & $a$ & - & & - & & 0,021 & a & 0,085 & $a$ \\
\hline 6 & 0,058 & a & 0,018 & $a$ & 0,031 & a & 0,058 & a & 0,023 & $a$ \\
\hline 7 & 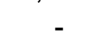 & & 0,037 & a & 0,099 & $b$ & 0,090 & $b$ & $f_{1}$ & \\
\hline 8 & 0,020 & $a$ & 0,092 & $a$ & 0,054 & a & 0,048 & a & 0,060 & $a$ \\
\hline 9 & 0,047 & $a$ & 0,081 & a & 0,089 & a & 0,075 & $a$ & 0,133 & $a$ \\
\hline 10 & 0,087 & a & 0,103 & a & 0,094 & a & 0,086 & $a$ & 0,060 & $a$ \\
\hline 11 & 0,122 & $a$ & 0,019 & $a b$ & 0,036 & $b$ & $-0,017$ & $b$ & 0,059 & $b$ \\
\hline 12 & 0,037 & $a$ & 0,017 & a & 0,029 & a & 0,027 & a & 0,045 & $a$ \\
\hline 13 & $-0,002$ & $a$ & 0,050 & $a$ & 0,023 & $a$ & $-0,014$ & a & 0,000 & $a$ \\
\hline 14 & 0,033 & $a$ & 0,039 & a & 0,009 & $a$ & $-0,006$ & a & 0,058 & $a$ \\
\hline 15 & 0,133 & $a$ & 0,092 & $a b$ & 0,002 & $b$ & 0,014 & $b$ & 0,026 & $b$ \\
\hline 16 & 0,205 & $a$ & 0,211 & $a$ & 0,139 & $a$ & 0,124 & $a b$ & 0,045 & $b$ \\
\hline 17 & 0,168 & $a$ & 0,177 & a & 0,158 & $a$ & 0,180 & $a$ & 0,042 & $a$ \\
\hline 18 & 0,022 & $a b$ & 0,061 & $a b$ & 0,113 & $a$ & 0,012 & $b$ & 0,066 & $a b$ \\
\hline 19 & 0,084 & $a$ & 0,085 & $a$ & 0,095 & a & 0,083 & a & 0,109 & $a$ \\
\hline 20 & 0,055 & $a$ & 0,033 & $a$ & 0,036 & $a$ & 0,030 & a & $-0,002$ & $a$ \\
\hline 21 & $-0,017$ & $a b$ & 0,020 & $a b$ & 0,042 & a & - & & $-0,001$ & $b$ \\
\hline 22 & 0,112 & $a$ & 0,103 & $a$ & 0,055 & $a$ & 0,052 & a & 0,038 & $a$ \\
\hline 23 & 0,039 & $a$ & 0,006 & $a$ & 0,008 & $a$ & 0,020 & a & 0,005 & $a$ \\
\hline 24 & 0,056 & $a$ & 0,013 & $a$ & 0,018 & a & 0,024 & $a$ & 0,039 & $a$ \\
\hline 25 & 0,111 & $a$ & 0,039 & $a$ & 0,057 & $a$ & 0,058 & a & 0,056 & $a$ \\
\hline 26 & 0,058 & $a$ & 0,097 & $a$ & 0,060 & a & 0,091 & a & 0,040 & $a$ \\
\hline 28 & 0,064 & a & 0,007 & a & 0,282 & $b$ & 0,030 & a & 0,062 & $a$ \\
\hline 29 & 0,122 & a & $-0,084$ & $a b$ & 0,057 & $a b$ & $-0,029$ & $b$ & 0,052 & $a b$ \\
\hline 31 & 0,343 & $a$ & 0,035 & $b c$ & 0,038 & $b$ & 0,067 & $\mathrm{~cd}$ & 0,096 & $d$ \\
\hline 32 & 0,030 & $a$ & 0,045 & $a$ & 0,199 & $b$ & 0,050 & a & 0,043 & $a$ \\
\hline 33 & 0,064 & $a b$ & 0,081 & $a b$ & 0,121 & $a$ & 0,055 & $b$ & 0,055 & $a b$ \\
\hline 34 & 0,110 & $a$ & 0,115 & $a$ & 0,076 & $a$ & 0,079 & a & 0,063 & $a$ \\
\hline 35 & 0,116 & a & 0,036 & a & 0,098 & a & 0,066 & a & 0,032 & $a$ \\
\hline 36 & 0,075 & $a$ & 0,055 & $a$ & 0,049 & a & 0,031 & a & 0,046 & $a$ \\
\hline 37 & 0,058 & $a b$ & 0,017 & a & 0,118 & $b$ & - & & 0,008 & $a b$ \\
\hline 38 & 0,015 & $a$ & 0,015 & $a$ & 0,022 & $a$ & 0,039 & a & 0,005 & $a$ \\
\hline 39 & - & & 0,032 & a & 0,003 & a & 0,052 & a & 0,049 & $a$ \\
\hline 40 & 0,037 & $a$ & 0,047 & a & 0,045 & a & 0,012 & a & 0,050 & $a$ \\
\hline 41 & 0,042 & $a b$ & 0,014 & $a b$ & 0,007 & $a$ & 0,008 & $a b$ & 0,054 & $b$ \\
\hline 42 & 0,074 & $a$ & 0,033 & $a b$ & 0,020 & $b$ & 0,040 & $a b$ & 0,005 & $a b$ \\
\hline 43 & 0,099 & $a b$ & 0,098 & $a b$ & 0,118 & a & 0,290 & $c$ & 0,028 & $b$ \\
\hline 44 & - & & - & & 0,028 & a & 0,038 & a & 0,040 & $a$ \\
\hline 45 & 0,005 & $a b$ & 0,057 & $a$ & 0,123 & $a b$ & 0,137 & $b$ & 0,076 & $a b$ \\
\hline 46 & 0,050 & $a$ & 0,036 & $a b$ & $-0,016$ & $a$ & 0,133 & $b$ & 0,026 & $a$ \\
\hline 47 & 0,115 & $a$ & $-0,119$ & $a b$ & 0,026 & $a b$ & 0,006 & $b$ & 0,014 & $a b$ \\
\hline 48 & 0,042 & $a b$ & 0,106 & $a b$ & 0,038 & $a b$ & 0,024 & a & 0,080 & b \\
\hline
\end{tabular}


Tabela 14. Coeficientes angulares das retas da regressão linear dos valores de umidade e leitura do TDR por ponto para todos os dados juntos $(2000+2001)$. Valores seguidos de mesma letra, na linha, não diferem ao nível de probabilidade de $95 \%$.

\begin{tabular}{|c|c|c|c|c|c|c|c|c|c|c|}
\hline \multirow{2}{*}{ Bateria } & \multicolumn{10}{|c|}{ Camada } \\
\hline & A & & B & & C & & D & & $E$ & \\
\hline 1 & 0,034 & $a$ & 0,020 & $a$ & 0,019 & $a$ & 0,039 & $a b$ & 0,098 & $b$ \\
\hline 2 & 0,048 & $a$ & 0,051 & $a$ & 0,050 & $a$ & $-0,003$ & $b$ & 0,014 & $a b$ \\
\hline 3 & 0,068 & $a$ & 0,050 & $a b$ & 0,060 & a & 0,024 & $b$ & 0,018 & $b$ \\
\hline 4 & 0,070 & a & 0,067 & $a$ & 0,055 & $a$ & 0,019 & $b$ & 0,011 & $b$ \\
\hline 5 & 0,052 & a & 0,042 & $a$ & 0,043 & $a$ & 0,032 & $a$ & 0,054 & a \\
\hline 6 & 0,059 & a & 0,033 & $a$ & 0,030 & $a$ & 0,054 & $a$ & 0,017 & $a$ \\
\hline 7 & 0,086 & a & 0,036 & $a$ & 0,033 & $a$ & 0,039 & a & 0,187 & $b$ \\
\hline 8 & 0,071 & a & 0,029 & $a$ & 0,043 & $a$ & 0,047 & $a$ & 0,064 & a \\
\hline 9 & 0,108 & a & 0,062 & $b$ & 0,059 & $b$ & 0,058 & $a b$ & 0,000 & C \\
\hline 10 & 0,117 & a & 0,049 & $b c$ & 0,027 & b & 0,048 & $b c$ & 0,090 & $\mathrm{ac}$ \\
\hline 11 & 0,093 & a & 0,015 & $b$ & 0,016 & $b$ & 0,021 & $b$ & 0,028 & $b$ \\
\hline 12 & 0,116 & a & 0,017 & $b$ & 0,035 & c & 0,043 & C & 0,040 & c \\
\hline 13 & 0,004 & $a b c$ & 0,048 & $b$ & 0,049 & $b$ & 0,030 & $a b c$ & $-0,001$ & C \\
\hline 14 & 0,074 & a & 0,038 & $b c$ & 0,025 & $b$ & 0,027 & $b c$ & 0,062 & $\mathrm{ac}$ \\
\hline 15 & 0,096 & a & 0,056 & $a b$ & 0,023 & $b$ & 0,028 & $b$ & 0,048 & $b$ \\
\hline 16 & 0,066 & a & 0,048 & $a$ & 0,055 & $a$ & 0,099 & $a$ & 0,000 & $b$ \\
\hline 17 & 0,107 & a & 0,020 & $b$ & 0,044 & C & 0,019 & $b$ & 0,051 & $a b c$ \\
\hline 18 & 0,073 & a & 0,029 & $b$ & 0,041 & $a b$ & 0,049 & $a b$ & 0,082 & $a b$ \\
\hline 19 & 0,159 & a & 0,045 & $b$ & 0,091 & $c$ & 0,061 & $b c$ & 0,022 & $b$ \\
\hline 20 & 0,087 & $a$ & 0,019 & $b$ & 0,071 & $\mathrm{ac}$ & 0,044 & C & 0,037 & $a b c$ \\
\hline 21 & 0,078 & $a b$ & 0,054 & $a$ & 0,074 & $a b$ & 0,099 & $b$ & 0,077 & $a b$ \\
\hline 22 & 0,092 & a & 0,074 & $a$ & 0,049 & $a$ & 0,069 & $a$ & 0,078 & $a$ \\
\hline 23 & 0,071 & a & 0,004 & $b$ & 0,018 & c & 0,015 & $b c$ & 0,011 & $a b c$ \\
\hline 24 & 0,042 & a & 0,021 & $a$ & 0,023 & $a$ & 0,029 & $a$ & 0,031 & a \\
\hline 25 & 0,046 & $a b$ & 0,028 & $a$ & 0,049 & $a b$ & 0,061 & $b$ & 0,047 & $a b$ \\
\hline 26 & 0,018 & a & 0,032 & $a b$ & 0,032 & $a$ & 0,086 & $b$ & 0,014 & a \\
\hline 28 & 0,064 & a & 0,030 & $a b$ & 0,032 & $a b$ & 0,016 & $b$ & 0,049 & $a b$ \\
\hline 29 & 0,072 & $a$ & 0,055 & $b$ & 0,086 & C & 0,026 & $b$ & 0,059 & b \\
\hline 31 & 0,211 & a & 0,023 & $b$ & 0,094 & C & 0,034 & $b$ & 0,025 & $b$ \\
\hline 32 & 0,117 & $a$ & 0,046 & $b$ & 0,076 & $\mathrm{ac}$ & 0,057 & $b c$ & 0,055 & $b c$ \\
\hline 33 & 0,070 & $a$ & 0,051 & $a b$ & 0,053 & $a b$ & 0,029 & $b$ & 0,074 & $a$ \\
\hline 34 & 0,098 & a & 0,065 & $b$ & 0,045 & $b$ & 0,045 & $b$ & 0,054 & b \\
\hline 35 & 0,092 & $a$ & 0,032 & $b$ & 0,041 & $b$ & 0,047 & $b$ & 0,051 & $a b$ \\
\hline 36 & 0,061 & a & 0,015 & $b$ & 0,049 & $a$ & 0,047 & $a$ & 0,070 & a \\
\hline 37 & 0,072 & $a b$ & 0,022 & $a$ & 0,058 & $b$ & 0,042 & $a b$ & 0,036 & $a b$ \\
\hline 38 & 0,040 & $a b$ & 0,014 & $a$ & 0,046 & b & 0,034 & $b$ & 0,018 & $a b$ \\
\hline 39 & 0,103 & a & 0,021 & $b$ & 0,026 & $b$ & 0,066 & $c$ & 0,074 & $\mathrm{ac}$ \\
\hline 40 & 0,038 & $a b$ & 0,029 & $a$ & 0,035 & $a$ & 0,076 & $b$ & 0,058 & $a b$ \\
\hline 41 & 0,054 & $a b$ & 0,013 & $\mathrm{~cd}$ & 0,012 & $b$ & 0,033 & ac & 0,081 & $b$ \\
\hline 42 & 0,029 & a & 0,013 & $a b$ & 0,009 & $b$ & 0,020 & $a b$ & 0,024 & $a b$ \\
\hline 43 & 0,060 & $a b$ & 0,023 & $b c$ & 0,020 & c & 0,092 & $a$ & 0,018 & $c$ \\
\hline 44 & 0,127 & $a$ & 0,088 & $b$ & 0,029 & $c$ & 0,114 & $a b$ & 0,047 & $b c$ \\
\hline 45 & 0,039 & $a b$ & 0,024 & $a$ & 0,050 & $a b$ & 0,029 & $a$ & 0,076 & b \\
\hline 46 & 0,032 & a & 0,013 & $a$ & 0,020 & $a$ & 0,025 & a & 0,025 & a \\
\hline 47 & 0,061 & a & 0,072 & $a b$ & 0,010 & $b$ & 0,028 & $a b$ & 0,036 & $a b$ \\
\hline 48 & 0,027 & $a b$ & 0,001 & $a$ & 0,012 & a & 0,022 & a & 0,064 & b \\
\hline
\end{tabular}


A análise de semelhanças entre os coeficientes angulares obtidos para cada ponto, por camada, revelou comportamento análogo ao que já vem sendo exposto. A Tabela 15 exibe os resultados desta análise. Observa-se um número grande de pontos semelhantes, em torno de $60 \%$ para o primeiro período e $80 \%$ para o segundo, concordando com os resultados anteriores. Para o conjunto de todos os dados os resultados foram intermediários. Nota-se que novamente a camada $\mathrm{E}$ apresentou o maior número de semelhanças, com as camadas intermediárias apresentando menores percentagens e a camada $\mathrm{A}$ um pouco maior.

A percentagem de pontos que se apresentaram semelhantes nos dois períodos simultaneamente ficou em torno de $40 \%$. Sendo maior para a camada E, onde cerca de $60 \%$ dos pontos se mostrou estatisticamente igual tanto no primeiro como no segundo período.

Tabela 15. Resultados da análise de semelhança entre os coeficientes angulares para cada camada e período.

\begin{tabular}{|c|c|c|c|c|c|}
\hline & Camada & $\begin{array}{c}\text { Total de } \\
\text { combinações }\end{array}$ & $\begin{array}{c}\text { Total de } \\
\text { semelhantes }\end{array}$ & $\begin{array}{l}\text { Total de não } \\
\text { semelhantes }\end{array}$ & $\begin{array}{l}\text { Percentagem de } \\
\text { semelhantes }\end{array}$ \\
\hline \multirow{6}{*}{ ষ্ণ } & A & 1.035 & 654 & 381 & 63,2 \\
\hline & B & 1.035 & 500 & 535 & 48,3 \\
\hline & C & 1.035 & 543 & 492 & 52,5 \\
\hline & D & 1.035 & 691 & 344 & 66,8 \\
\hline & $E$ & 1.035 & 698 & 337 & 67,4 \\
\hline & Total & 5.175 & 3.086 & 2.089 & 59,6 \\
\hline \multirow{6}{*}{ চ্ণ } & A & 903 & 798 & 105 & 88,4 \\
\hline & B & 946 & 769 & 177 & 81,3 \\
\hline & C & 990 & 649 & 341 & 65,6 \\
\hline & D & 946 & 695 & 251 & 73,5 \\
\hline & $E$ & 990 & 936 & 54 & 94,5 \\
\hline & Total & 4.775 & 3.847 & 928 & 80,6 \\
\hline \multirow{6}{*}{$\begin{array}{l}\bar{\delta} \\
\text { N } \\
\text { +े } \\
\text { 이 }\end{array}$} & A & 1.035 & 713 & 322 & 68,9 \\
\hline & B & 1.035 & 727 & 308 & 70,2 \\
\hline & C & 1.035 & 697 & 338 & 67,3 \\
\hline & D & 1.035 & 742 & 293 & 71,7 \\
\hline & $E$ & 1.035 & 809 & 226 & 78,2 \\
\hline & Total & 5.175 & 3.688 & 1.487 & 71,3 \\
\hline
\end{tabular}


As semelhanças entre pontos, como já discutido anteriormente, não seguem um padrão sistemático. A análise das semelhanças em função das distâncias entre os pontos corrobora esta constatação, não apresentando um padrão definido (Figuras 30, 31 e 32).

Basicamente poderiam ser esperados dois padrões para as semelhanças das curvas de calibração em função da distância que as separa: se as equações fossem iguais em todos os pontos e independentes da variabilidade dos atributos físicos do solo, não se deveria perceber nenhuma tendência ao longo da transeção e a percentagem de curvas semelhantes para todas as distâncias deveria ser elevada; por outro lado se alguma tendência pudesse ser identificada haveria indicativos de correlação da calibração com uma característica ou propriedade do solo e então um decréscimo da percentagem de curvas semelhantes em função da distância poderia ser esperado, pois pontos próximos tenderiam a ser mais semelhantes que pontos mais distanciados.

Os dados do primeiro período exibem tendências, ainda que fracas, seguindo a segunda proposição. A fração de pontos semelhantes decai em função da distância, especialmente para as três primeiras camadas. A camada A mostra esta tendência ao longo de toda a transeção, ao passo que nas camadas B e C este padrão é verificado para distancias pequenas, até $10 \mathrm{~m}$. Destarte há indicativos de dependência espacial para este período.

No segundo período, a camada A manteve o mesmo padrão que para o primeiro período, enquanto nas camadas $B, C$ e $D$ a tendência de diminuição da percentagem de pontos semelhantes é percebida até distâncias em torno de $5 \mathrm{~m}$. 0 número reduzido de pontos e uma tendência muito sutil não permitem, ou dificultam, maiores inferências acerca da variabilidade espacial das curvas de calibração, e isoladamente impedem quaisquer especulações sobre sua possível dependência espacial e a relação como os atributos do solo. Esta dificuldade é reforçada pelo fato de que a camada $E$ no segundo período em especial, mas também no primeiro junto com a camada $\mathrm{D}$, apresenta padrão de variação segundo a proposição de independência. Este padrão também pode ser notado ao se juntarem os dois conjuntos nas camadas B, D e E. 


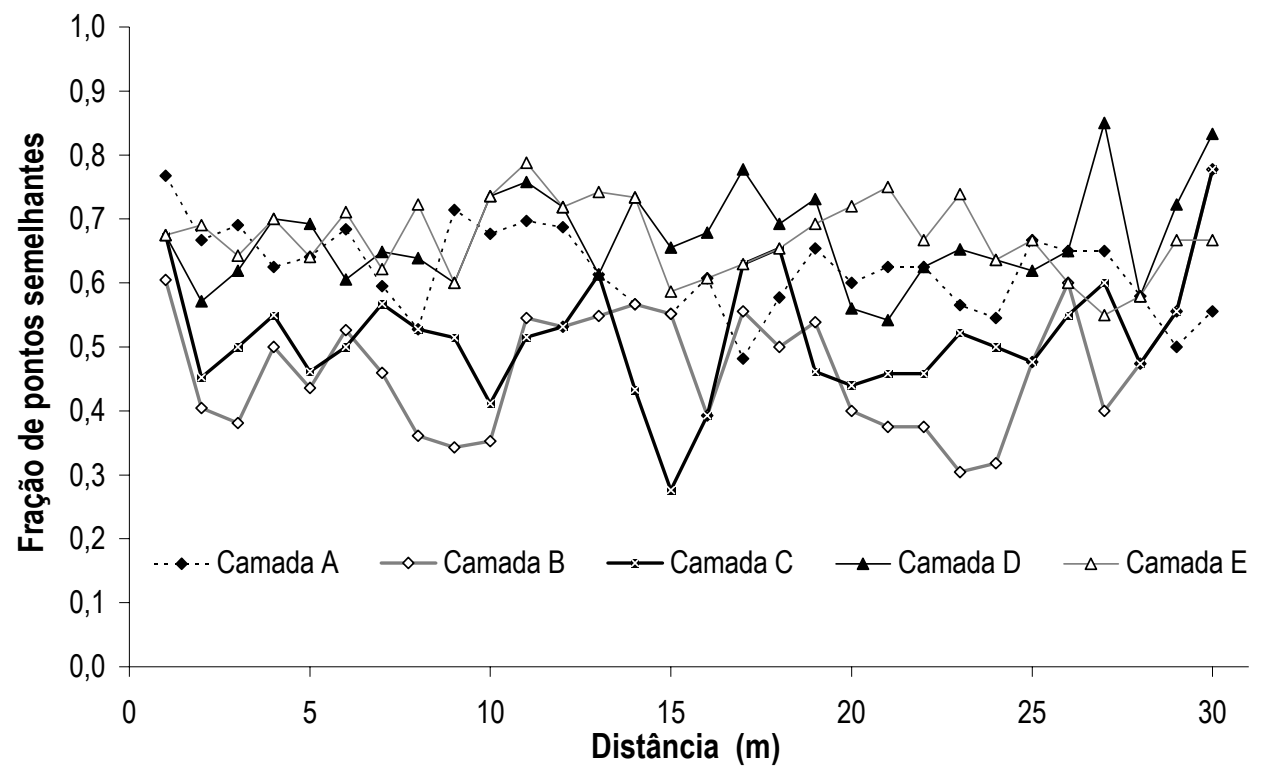

Figura 30 - Fração de pontos semelhantes em função da distância de comparação para 0 coeficiente angular da regressão tempo TDR $\times$ umidade, para o primeiro período (2000).

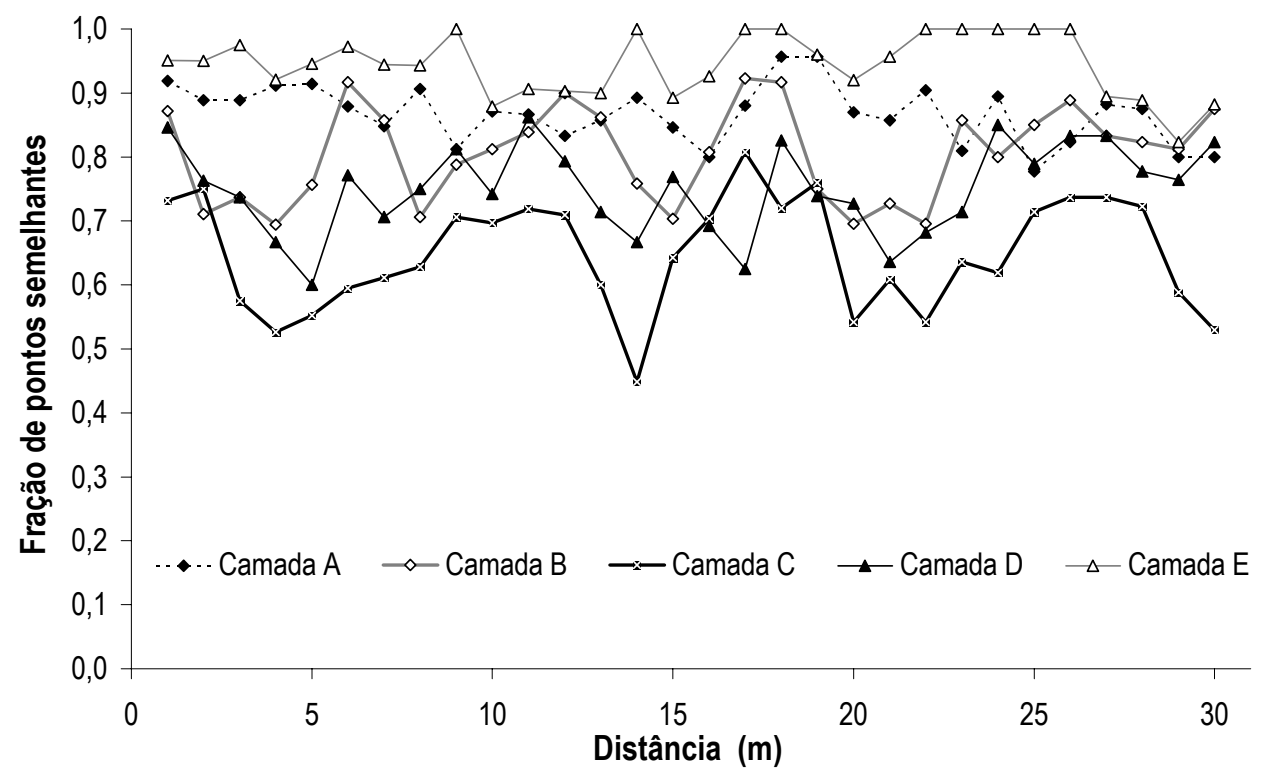

Figura 31 - Fração de pontos semelhantes em função da distância de comparação para coeficiente angular da regressão tempo TDR×umidade, para o segundo período (2001). 


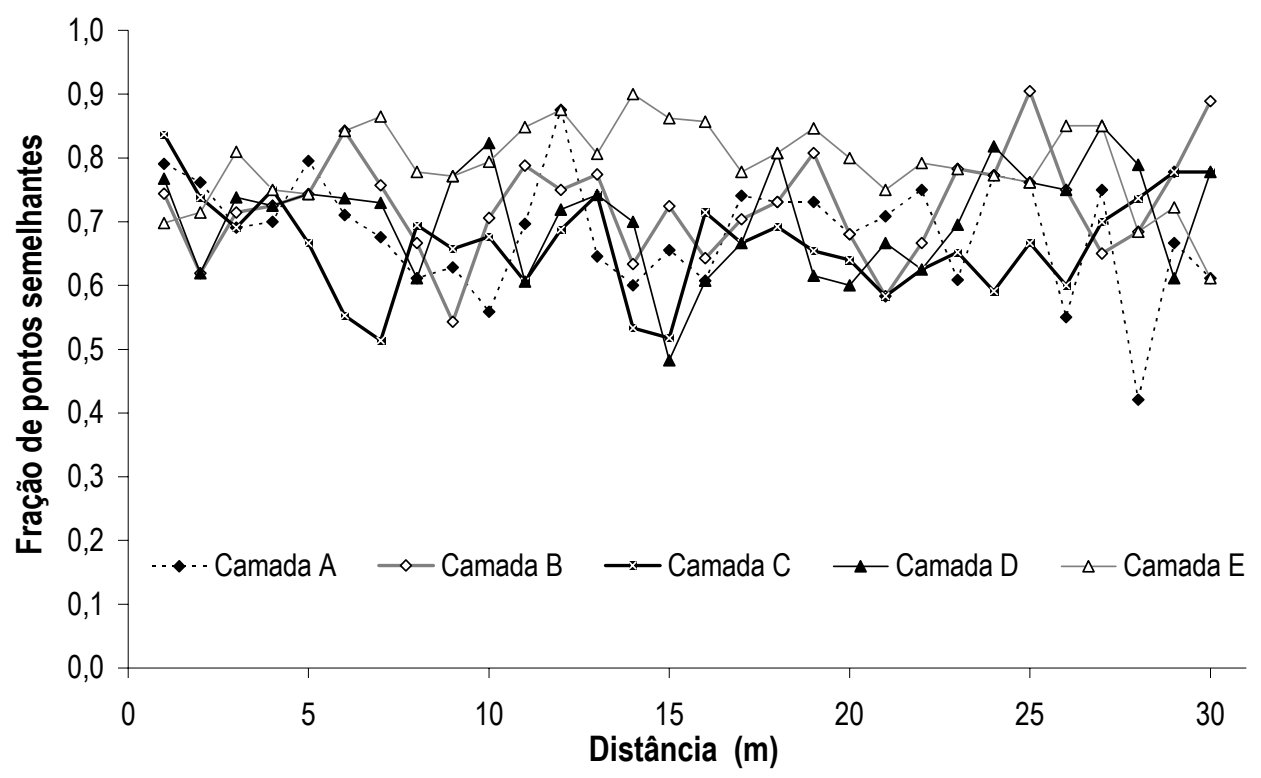

Figura 32 - Fração de pontos semelhantes em função da distância de comparação para coeficiente angular da regressão tempo TDR×umidade, para os dados dos dois períodos $(2000+2001)$.

Os resultados para a calibração no campo deste modelo de TDR, até aqui apresentados, demonstram a disparidade de comportamento entre diferentes hastes ou mesmo em diferentes segmentos de uma mesma haste. Resultados também negativos são reportados na literatura (Dasberg et al., 1995; Serrarens et al., 2000), sendo atribuídos a problemas com a alteração da densidade do solo por ocasião da instalação das hastes no solo. Dasberg et al. (1995) estimaram o raio do cilindro de influência das hastes deste modelo de TDR, segundo os quais este seria inferior a 1 centímetro. Sendo assim, a compactação do solo (diminuição da porosidade) ou a abertura de fendas (aumento do espaço poroso) pode alterar sensivelmente 0 teor volumétrico da água no solo nas proximidades das hastes, comprometendo a representatividade da leitura do TDR. Este fato poderia explicar o elevado grau de variabilidade entre curvas encontrado, especialmente para o primeiro período, apesar de as hastes terem sido instaladas cerca de 60 dias antes das leituras e ter sido efetuada forte irrigação na véspera do início dos experimentos. A explicação também perde credibilidade ao considerarmos o segundo período de observações, pois após mais de um ano no campo sob chuva e sol, o contato das hastes com o solo deveria ter melhorado, ao contrário do que foi observado. Porém, o aumento 
da dispersão dos dados prejudica qualquer conclusão a respeito da melhora, mesmo tendo mais pontos semelhantes.

O fato de as leituras do TDR terem mostrado aumento da dispersão em relação à umidade do solo gera outro problema. Há indicativos da senescência das hastes, dos cabos ou conectores que ficaram um ano e meio no campo. Este fato é particularmente importante e estudos mais dirigidos devem ser feitos. Garantir a estabilidade temporal das medições é fundamental pois uma das principais vantagens do TDR seria a tomada de leituras da umidade no campo ao longo do tempo sem grande necessidade de manutenção.

\subsubsection{Atributos do Solo e a Calibração}

Apesar dos indícios de variação espacial, a relação da leitura do TDR e a umidade do solo, representada pelas retas de calibração não exibiu correlação bem definida com os atributos físicos determinados neste experimento. A correlação entre 0 coeficiente angular das retas e a densidade do solo apresentou comportamento diverso entre camadas diferentes (Tabela 16). As camadas C e D, que apresentaram maior densidade, também mostraram coeficientes de correlação superiores às demais nos dois períodos e para todos os dados, ao passo que para as camadas B e E o coeficiente ficou muito reduzido. A camada A apresentou correlação intermediária às demais. Para a densidade dos sólidos as camadas B e D exibiram coeficientes de correlação superior às outras.

Os valores de correlação com a densidade do solo e dos sólidos parecem concordar com a literatura, onde a função de calibração seria pouco dependente da densidade. 0 coeficiente de correlação maior para camadas com densidades maiores poderia indicar uma interação mais significativa da calibração do TDR com a densidade quando esta for elevada, mas estudos mais detalhados deveriam ser feitos para comprovar isto. 
Tabela 16. Coeficientes de correlação entre 0 coeficiente angular das retas de calibração e alguns atributos físicos do solo, analisados para os dois anos de observação em separado e em conjunto.

\begin{tabular}{|c|c|c|c|c|c|c|}
\hline Período & Camada & $\begin{array}{c}\text { Densidade } \\
\text { do solo }\end{array}$ & $\begin{array}{l}\text { Densidade } \\
\text { dos sólidos }\end{array}$ & $\begin{array}{c}\text { Teor de } \\
\text { areia }\end{array}$ & $\begin{array}{c}\text { Teor de } \\
\text { silte }\end{array}$ & $\begin{array}{c}\text { Teor de } \\
\text { argila }\end{array}$ \\
\hline \multirow{5}{*}{ চ্̀ } & A & $-0,209$ & $-0,025$ & $-0,027$ & 0,030 & 0,024 \\
\hline & B & $-0,180$ & $-0,238$ & 0,511 & 0,045 & $-0,550$ \\
\hline & C & $-0,405$ & 0,111 & 0,336 & $-0,144$ & $-0,320$ \\
\hline & $D$ & $-0,546$ & $-0,493$ & 0,239 & $-0,107$ & $-0,247$ \\
\hline & $E$ & $-0,156$ & $-0,271$ & $-0,001$ & $-0,223$ & 0,071 \\
\hline \multirow{5}{*}{ চ্ণ } & A & $-0,140$ & $-0,013$ & 0,177 & $-0,142$ & $-0,181$ \\
\hline & B & $-0,081$ & 0,116 & 0,263 & $-0,054$ & $-0,263$ \\
\hline & $C$ & $-0,290$ & 0,019 & 0,266 & $-0,228$ & $-0,220$ \\
\hline & $D$ & $-0,407$ & $-0,194$ & 0,205 & $-0,305$ & $-0,146$ \\
\hline & $E$ & $-0,086$ & $-0,002$ & 0,003 & $-0,175$ & 0,052 \\
\hline \multirow{5}{*}{$\begin{array}{l}\bar{\delta} \\
\text { i } \\
+ \\
\stackrel{ }{\circ}\end{array}$} & A & $-0,191$ & $-0,212$ & $-0,214$ & 0,134 & 0,218 \\
\hline & B & $-0,029$ & $-0,103$ & 0,247 & $-0,065$ & $-0,209$ \\
\hline & $C$ & $-0,380$ & $-0,012$ & 0,008 & $-0,070$ & 0,012 \\
\hline & D & $-0,366$ & $-0,274$ & 0,143 & $-0,169$ & $-0,114$ \\
\hline & $E$ & 0,072 & $-0,159$ & $-0,003$ & $-0,104$ & 0,036 \\
\hline
\end{tabular}

A análise de correlação entre 0 coeficiente angular das retas de calibração e os componentes da granulometria também apresentou resultados irregulares. Todos os coeficientes foram baixos, atingindo pouco mais de 0,50 para a camada B no primeiro período tanto para argila como para a areia, com sinal contrário, como era de se esperar pois estes teores mostraram correlação estreita e inversa. Não foi possível identificar nenhuma tendência definida. Para os dois períodos em separado as camadas intermediárias exibiram correlação maior que as camadas extremas, porém com todos os dados reunidos os coeficientes reduziram-se, e na camada $\mathrm{C}$ chegou a praticamente zero.

O padrão das semelhanças em função da distância entre pontos e a análise de correlação da calibração com os atributos do solo não exibiram as correspondências que podiam ser esperadas. A camada A, que mostrou tendências com padrão que sugere dependência 
espacial da calibração (Figuras 30 a 32), exibiu coeficientes de correlação bastante baixos, ou ainda contradizentes, entre um período e outro. Este padrão de contrariedade foi observado para as demais camadas, sendo a falta de correspondência das correlações entre um período e outro um dos principais problemas (Tabela 16). A camada D, que apresenta coeficientes de correlação relativamente altos para alguns atributos, não exibiu nenhum padrão definido de variação espacial. A camada C talvez possa ser considerada como a que apresenta 0 comportamento mais próximo do esperado, já que exibiu tendência de diminuição das semelhanças em função do aumento da distância entre pontos e também índices de correlação elevados em relação às demais camadas, com alguns atributos do solo.

Como se observa na Tabela 16, apesar de alguns coeficientes de correlação se apresentarem relativamente altos, os valores absolutos são bastante reduzidos. Este detalhe é importante, pois qualquer conclusão é deturpada pelos baixos valores de correlação. Aliando-se a isto, o fato de muitas curvas de calibração apresentarem dispersão elevada, reduzindo a legitimidade da análise de semelhanças, também implica em incertezas demasiadamente grandes que impedem inferências seguras a respeito de seu padrão de comportamento. Por outro lado, o fato de alguns pontos apresentarem, ao menos parcialmente, o padrão previsto impede o descarte das hipóteses levantadas. Sugere-se que uma pesquisa mais profunda seja efetuada. 


\section{CONCLUSÕES}

Com base nos resultados expostos e discutidos neste trabalho foi possível chegar-se às seguintes conclusões:

1 Os estudos de calibração de equipamentos no campo são um expediente determinante na definição da aplicabilidade da técnica do TDR para uso em escala e no campo;

20 uso da tensiometria, apesar de trabalhoso, é viável como referência em experimentos de calibração ou validação no campo, de equipamentos para medição de umidade do solo;

3 O tipo de TDR estudado, embora apresente várias vantagens em relação aos demais, tem seu uso no campo inviabilizado devido à grande variabilidade da relação das suas respostas com o conteúdo de água do solo;

4 A variação das respostas do equipamento em função do tempo de permanência no campo das hastes exibiu padrões de senescência das mesmas.

5 Os indícios de variabilidade espacial e relação de dependência com atributos do solo não puderam ser confirmados devido à grande dispersão do conjunto de dados obtidos. 
ANEXOS 
Anexo A. Umidade média $\left(\theta_{\mathrm{m}}\right)$, Desvio padrão $(\mathrm{Dp})$, número de observações $(\mathrm{n})$, intervalo de confiança a $95 \%$ de probabilidade para a média (IC95\%), número de pontos concordantes $(\mathrm{nC})$ e sua percentagem $(\% \mathrm{C})$ por camada para os dados do primeiro período de observações (2000).

\begin{tabular}{|c|c|c|c|c|c|c|c|c|c|c|c|c|c|c|c|c|c|c|c|c|c|c|c|c|c|c|c|c|c|c|}
\hline \multirow{2}{*}{ Bat. } & \multicolumn{6}{|c|}{ Camada A } & \multicolumn{6}{|c|}{ Camada B } & \multicolumn{6}{|c|}{ Camada C } & \multicolumn{6}{|c|}{ Camada D } & \multicolumn{6}{|c|}{ Camada E } \\
\hline & $\theta_{\mathrm{m}}$ & Dp & $\mathrm{n}$ & $\mathrm{IC}_{95 \%}$ & $\mathrm{nC}$ & $\% C$ & $\theta_{\mathrm{m}}$ & Dp & $\mathrm{n}$ & $\mathrm{I}_{95 \%}$ & $\mathrm{nC}$ & $\% C$ & $\theta_{\mathrm{m}}$ & $\mathrm{Dp}$ & $n$ & $\mathrm{I}_{95 \%}$ & $\mathrm{nC}$ & $\% \mathrm{C}$ & $\theta_{\mathrm{m}}$ & Dp & $\mathrm{n}$ & $\mathrm{I}_{95 \%}$ & $\mathrm{nC}$ & $\% C$ & $\theta_{\mathrm{m}}$ & Dp & $\mathrm{n}$ & & $\mathrm{nC}$ & \\
\hline 1 & 0,316 & 0,0243 & 25 & 0,0095 & 6 & 13,3 & 0,277 & 0,0213 & 23 & 0,0087 & 14 & 31,1 & 0,263 & 0,0135 & 24 & 0,0054 & 21 & 46,7 & 0,282 & 0,0134 & 25 & 0,0052 & 18 & 40,0 & 0,274 & 0,0140 & 25 & 0,0072 & 29 & 64,4 \\
\hline 2 & 0,310 & 0,0205 & 25 & 0,0080 & 9 & 20,0 & 0,278 & 0,0264 & 25 & 0,0103 & 14 & 31,1 & 0,254 & 0,0139 & 24 & 0,0055 & 27 & 60,0 & 0,283 & 0,0153 & 25 & 0,0060 & 18 & 40,0 & 0,272 & 0,0121 & 25 & 0,0062 & 27 & \\
\hline 3 & 0,290 & 0427 & 25 & 0,0168 & 28 & 62,2 & 0,247 & 0,0212 & 24 & 0,0085 & 22 & 48,9 & 252 & 0,0152 & 24 & 0,0061 & 30 & 66,7 & 0,271 & 0,0083 & 24 & 0,0033 & 17 & 37,8 & 0286 & 0,0099 & 25 & 0,0051 & 19 & \\
\hline 4 & 0,276 & 0356 & 25 & 0,0140 & 28 & 62,2 & 0,242 & 0,0246 & 25 & 0,0097 & 24 & 53,3 & , 248 & 0,0161 & 24 & 0,0064 & 24 & 53,3 & 0,269 & 0,0101 & 24 & 0,0040 & 20 & 44,4 & 0,283 & 0,0091 & 25 & 0,0047 & 19 & 42, \\
\hline 5 & 0,285 & 0,0325 & 25 & 0,0127 & 24 & 53,3 & 258 & 0,0168 & 25 & 0,0066 & 18 & 40,0 & 251 & 0,0119 & 23 & 0,0049 & 23 & 51,1 & 0,285 & 0,0144 & 24 & 0,0058 & 15 & 33,3 & 0,279 & 0,0135 & 25 & 0,0070 & 25 & 556 \\
\hline 6 & 0,287 & 0319 & 25 & 0,0125 & 22 & 48,9 & 259 & 0,0178 & 25 & 0,0070 & 19 & 42,2 & 249 & 0,0159 & 24 & 0,0063 & 24 & 53,3 & 0,283 & 0,0113 & 24 & 0,0045 & 15 & 33,3 & 0,288 & 0,0178 & 24 & 0,0093 & 21 & 46,7 \\
\hline 7 & 0,270 & 0362 & 25 & 0,0142 & 28 & 62,2 & 0,244 & 0,0302 & 25 & 0,0118 & 24 & 53,3 & 250 & 0,0136 & 24 & 0,0054 & 26 & 57,8 & 0,263 & 0,0135 & 25 & 0,0053 & 26 & 57,8 & 0,272 & 0,0144 & 25 & 0,0074 & 28 & \\
\hline 8 & 0,280 & 0322 & 25 & 0126 & 25 & 55,6 & 46 & 294 & 25 & 0,0115 & 22 & 48 & 252 & 0133 & 24 & 0,0053 & 26 & 57, & 263 & 0,0110 & 24 & DOM & & 55 & On & 0,0114 & &, 0059 & & \\
\hline 9 & 0,271 & 0,0411 & 25 & 0,0161 & 31 & 68,9 & 40 & 3447 & 25 & 0,0136 & 25 & 55 & 60 & 0,0159 & 24 & 0,0064 & 32 & 71 & 260 & 0,0193 & 25 & 0075 & 26 & 57,8 & 0,279 & 0,0145 & 25 & 0,0074 & 27 & 6 \\
\hline 10 & 0,264 & 0,0420 & 25 & 0,0164 & 33 & 73,3 & 242 & 0,0338 & 25 & 0,0133 & 25 & 55,6 & 51 & 0,0180 & 24 & 0,0072 & 30 & 66,7 & 58 & 0,0181 & 25 & 0,0071 & 23 & 51,1 & 0,272 & 0,0155 & 25 & 0,0080 & 28 & \\
\hline 11 & 0,289 & 0,0387 & 25 & 0,0152 & 25 & 55,6 & 0,274 & 0,0088 & 25 & 0,0034 & 14 & 31,1 & 253 & 0,0073 & 24 & 0,0029 & 21 & 46,7 & 0,283 & 0,0058 & 25 & 0,0023 & 13 & 28,9 & 0,272 & 0,0125 & 25 & 0,0064 & 27 & \\
\hline 12 & 0,287 & 0402 & 25 & 158 & 27 & 60,0 & 274 & 0,0091 & 25 & 0,0036 & 14 & 31 , & 249 & 0,0128 & 25 & 0,0050 & 24 & 52 & & 0,0117 & 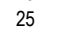 & 0,0046 & 10 & s & - & 0,0083 & 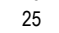 & 0,0043 & & \\
\hline 14 & 0,311 & 0,0248 & 25 & 0,0097 & 9 & 20,0 & 53 & 0,0256 & 25 & 0,0100 & 24 & 53,3 & 51 & 0,0157 & 23 & 0,0064 & 30 & 66,7 & 58 & 0,0158 & 25 & 062 & 22 & 48,9 & 0,282 & 0,0160 & 25 & 0,0082 & 27 & \\
\hline 15 & 0,248 & 0,0395 & 25 & 0,0155 & 27 & 60,0 & 246 & 0,0370 & 25 & 0,0145 & 27 & 60,0 & 248 & 0,0193 & 24 & 0,0077 & 26 & 57,8 & 0,277 & 0,0151 & 25 & 0,0059 & 23 & 51,1 & 0,279 & 0,0154 & 25 & 0,0080 & 28 & \\
\hline 16 & 0,242 & 0337 & 25 & 0,0132 & 23 & 51,1 & 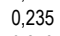 & 0,0347 & 25 & 0,0136 & 22 & 48, & 46 & 0,0211 & 25 & 0,0083 & 25 & 5 & 279 & 0,0123 & 24 & 0,0049 & 22 & 48 & 0273 & 0,0118 & 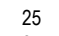 & 0,0061 & & \\
\hline 17 & 0,262 & 302 & 25 & & 28 & & & & & & 24 & & & 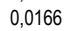 & 25 & & & & & & & & & & & & & & & \\
\hline 18 & 0,263 & 0,0335 & 25 & 0,0131 & 30 & $\begin{array}{l}66,7 \\
66,7\end{array}$ & 56 & 0,0250 & 25 & 0,0098 & 25 & 55, & 64 & 0,0175 & 25 & 0,0069 & 20 & 44 & 86 & 0143 & 23 & 0059 & 13 & 28, & 0,289 & 0,0149 & 24 & $\begin{array}{l}0,0078 \\
\end{array}$ & 18 & \\
\hline 19 & 0,250 & 0,0354 & 25 & 0,0139 & 27 & 60,0 & 43 & 0,0227 & 25 & 0,0089 & 22 & 48,9 & 234 & 0,0333 & 25 & 0,0131 & 22 & 48,9 & 58 & 111 & 24 & 0045 & 21 & 46,7 & 0,277 & 0,0113 & 24 & 0,0060 & 24 & \\
\hline 20 & 0,242 & 0,0324 & 25 & 0,0127 & 22 & 48,9 & 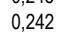 & 0,0210 & 25 & 0,0082 & 20 & 44,4 & 34 & 0,0316 & 25 & 0,0124 & 20 & 44, & $=$ & 0,0155 & 25 & 061 & 开 & 48,9 & 0,267 & 0,0147 & , & 0,0076 & & \\
\hline 21 & & & 25 & & 21 & & & & & & 3 & 51 & & & 25 & & & & & & & & & & & & & 0,0073 & & \\
\hline 22 & 0,233 & 0,0414 & 25 & 0,0162 & 18 & 40,0 & & 0,0334 & 25 & 0,0131 & 22 & 48 & & 0,0228 & 24 & 0,0091 & 8 & 17 & & 3 & 24 & 57 & 24 & & & 0,0 & 25 & 0062 & & \\
\hline 23 & 0,261 & 0,0352 & 25 & 0,0138 & 32 & 71,1 & 14 & 0,0029 & 23 & 0,0012 & 1 & 2,2 &, 252 & 0,0087 & 24 & 0,0035 & 22 & 48, & 258 & 0,0087 & 25 & 0,0034 & 21 & 46,7 & 0,280 & 0,0219 & 25 & 0,0113 & 30 & \\
\hline 24 & 0,266 & 0,0299 & 25 & 0,0117 & 28 & 62,2 & & 0,0116 & 25 & 0,0046 & 1 & 2,2 & & 0,0100 & 25 & 0,0039 & 25 & 55 & & 0, & 25 & & 24 & 53,3 & & 0,0100 & rot & 0,0052 & 年 & \\
\hline 25 & 0,278 & 0,0295 & 25 & & 25 & 55 & & & 25 & & 14 & 31 & & $a$ & 25 & & 27 & & & & & & . & & & & 5 & & & \\
\hline 29 & 0,270 & 0,0419 & 25 & 64 & 30 & 66 & & 0, & 25 & 0,0 & 31 & 68 & & 0,0276 & 25 & 8 & 36 & 80 & & & 24 & & r & & & & 24 & 0,0041 & & \\
\hline 31 & 0,258 & 年 & 25 & & 34 & & & & 24 & & 17 & & & & 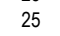 & & & & & & & & & & & & & 0059 & & \\
\hline 32 & 0,2 & & 2 & & 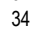 & & & & & & 2 & & & & & & & & & & & & & & & & & 0056 & & \\
\hline 33 & 0,254 & 0,0410 & 25 & 0, & 29 & 64 & & $0, \quad$ & 25 & 0,0 & 10 & & & 0,022 & 25 & & 20 & & & & 25 & 7 & 21 & & & $0, c$ & 5 & 0,0075 & & \\
\hline 34 & 0,259 & 0,0411 & 25 & & 32 & 71 & & 0, & 25 & & 12 & 26 & & 0,02 & 25 & 3 & 24 & 5 & & & 24 & & 22 & 48 & & 0,0 & 25 & 0,0065 & 5 & \\
\hline 35 & 0,350 & 0,0 & 25 & & 1 & 2 & & & 2 & & 16 & & & & 2 & & 15 & & & & 25 & & 24 & & & & 25 & & & \\
\hline 36 & 0,343 & 0,03 & 25 & & 2 & & & & - & & 22 & 48 & & 0,0 & 2 & & 17 & & & & & & & & & & 25 & 0046 & & \\
\hline 37 & 0, & & 25 & & 6 & 13 & & & & & 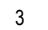 & & & & 2 & & & & & & & & & & & & & 0039 & & \\
\hline 38 & 0,3 & 0,02 & 25 & & 6 & 13 & & & 2 & & 3 & 0 & & & 2 & & 3 & & & & & & 21 & & & & 5 & 30 & & \\
\hline 39 & & & 25 & & 18 & 40 & & & 25 & & 21 & 46 & & 0,0 & 2 & & 7 & & & & 25 & & 20 & & & & 25 & 0,0069 & 5 & \\
\hline 40 & 0,247 & 0,0288 & 25 & 0 & 24 & 53 & & & 25 & & 22 & 48 & & 0,0205 & 25 & & 1 & & & 0 & 25 & & & & & 12 & 25 & $\begin{array}{l}0,0047\end{array}$ & & \\
\hline 4 & 0, & 0,025 & 25 & & 16 & & & & 25 & & (1) & r & & 0,00 & 25 & & 5 & & & & & & & & & & 5 & 0065 & & \\
\hline 42 & 0,2 & 0,022 & 25 & & 13 & & & & 2 & & 3 & 6 & & 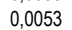 & 2 & & 6 & & & & & & & & & & 5 & 58 & & \\
\hline 43 & & & 25 & & 28 & & & & 25 & & 14 & & & & 2 & & 15 & & & & 2 & & 34 & & & & 25 & & 13 & \\
\hline 44 & 0,271 & 0,0299 & 25 & $0, c$ & 27 & 60 & & 0, & 25 & & 14 & 31 & & 0,0197 & 25 & 0,6 & 15 & 3 & & 5 & 25 & 7 & 32 & 71 & 0,268 & $0, c$ & 25 & 0,0061 & 24 & \\
\hline 45 & 0,233 & 0,025 & 25 & & 14 & & & & - & & 2 & 53 & & 0,02 & 25 & & 32 & & & & & & & & & & 25 & 0063 & 19 & \\
\hline 46 & 0,2 & & 2 & & 5 & & & & & & & & & & & & & & & & & & & & & & & 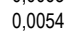 & & \\
\hline 47 & & & 2 & & 28 & & & & 2 & & 14 & & & & 2 & & 21 & & & & & & & & & & 25 & & 20 & \\
\hline 48 & 0,252 & 0,0343 & 25 & 0,0134 & 27 & 60,0 & $0,2 \pi 7$ & 0,0268 & 25 & , vivo & 14 & 31,1 & 0,209 & 0,0172 & 20 & 0,0068 & & 0,0 & 0,210 & 0,0087 & 20 & 0,0032 & 10 & 40,0 & 0,271 & 0,0151 & 20 & 0,0078 & 20 & \\
\hline ral & 0,272 & 0,0337 & 1150 & 0,0132 & 1004 & 48,5 & 0,261 & 228 & 1143 & 0089 & 796 & 38,5 & 0.255 & 0,0190 & 1132 & 0,0075 & 948 & 45,8 & 0,268 & 0,0145 & 1133 & 0,0057 & 976 & 47,1 & 0,276 & 0,0128 & 1146 & 0,0066 & 928 & 44, \\
\hline
\end{tabular}


Anexo B. Leitura média do TDR, ( $\left.T_{T D R}\right)$, Desvio padrão (Dp), número de observações ( $\left.\mathrm{n}\right)$, intervalo de confiança a 95\% de probabilidade para a média (IC95\%), número de pontos concordantes $(\mathrm{nC})$ e sua percentagem $(\% \mathrm{C})$ por camada para os dados do primeiro período de observações (2000).

\begin{tabular}{|c|c|c|c|c|c|c|c|c|c|c|c|c|c|c|c|c|c|c|c|c|c|c|c|c|c|c|c|c|c|c|c|}
\hline \multirow{2}{*}{ Bat. } & \multicolumn{6}{|c|}{ Camada A } & \multirow{2}{*}{\multicolumn{7}{|c|}{ Camada B }} & \multicolumn{6}{|c|}{ Camada C } & \multicolumn{6}{|c|}{ Camada D } & \multicolumn{6}{|c|}{ Camada E } \\
\hline & TTDR & $\mathrm{Dp}$ & $n$ & IC95\% & $\mathrm{nC}$ & $\% \mathrm{C}$ & & & & & & & & TTOR & Dp & $\mathrm{n}$ & IC95\% & $\mathrm{nC}$ & $\% C$ & TTDR & $\mathrm{Dp}$ & $\mathrm{n}$ & $\mid C_{95 \%}$ & $\mathrm{nC}$ & $\% \mathrm{C}$ & $\mathrm{T}_{\mathrm{TDR}}$ & $\mathrm{Dp}$ & $\mathrm{n}$ & IC95\% & $\mathrm{nC}$ & $\% \mathrm{C}$ \\
\hline 1 & 3,343 & 0,3746 & 25 & 0,1468 & 22 & 48,9 & 3,915 & 0,2459 & 23 & 0,1005 & 34 & 75,6 & & 2,809 & 0,1350 & 24 & 0,0540 & 31 & 68,9 & 3,503 & 0,1274 & 25 & 0,0499 & 28 & 62,2 & 3,235 & 0,0852 & 25 & 0,0334 & 14 & 31,1 \\
\hline 2 & 3,304 & 0,3216 & 25 & 0,1261 & 21 & 46,7 & 3,690 & 0,3553 & 25 & 0,1393 & 35 & 77,8 & & 2,883 & 0,0738 & 24 & 0,0295 & 31 & 68,9 & 3,534 & 0,0698 & 25 & 0,0274 & 26 & 57,8 & 3,502 & 0,0570 & 25 & 0,0223 & 7 & 15,6 \\
\hline 3 & 3,527 & 0,3333 & 25 & 0,1306 & 12 & 26,7 & 3,873 & 0,2823 & 24 & 0,1129 & 37 & 82,2 & & 2,917 & 0,1673 & 24 & 0,0669 & 35 & 77,8 & 3,561 & 0,0684 & 24 & 0,0274 & 25 & 55,6 & 3,372 & 0,1653 & 25 & 0,0648 & 16 & 35,6 \\
\hline 4 & 3,497 & 0,3762 & 25 & 0,1475 & 13 & 28,9 & 3,700 & 0,2971 & 25 & 0,1164 & 34 & 75,6 & & 3,066 & 0,2311 & 24 & 0,0925 & 15 & 33,3 & 3,419 & 0,1341 & 24 & 0,0536 & 17 & 37,8 & 3,559 & 0,1145 & 25 & 0,0449 & 7 & 15,6 \\
\hline 5 & 3,328 & 0,3786 & 25 & 0,1484 & 22 & 48,9 & 3,924 & 0,3108 & 25 & 0,1218 & 35 & 77,8 & & 2,831 & 0,2434 & 23 & 0,0995 & 37 & 82,2 & 3,551 & 0,2013 & 24 & 0,0805 & 32 & 71,1 & 3,479 & 0,2548 & 25 & 0,0999 & 17 & 37,8 \\
\hline 6 & 3,029 & 0,3340 & 25 & 0,1309 & 26 & 57,8 & 3,820 & 0,3064 & 25 & 0,1201 & 42 & 93,3 & & 2,794 & 0,2112 & 24 & 0,0845 & 34 & 75,6 & 3,611 & 0,1529 & 24 & 0,0612 & 31 & 68,9 & 3,362 & 0,1187 & 24 & 0,0475 & 15 & 33,3 \\
\hline 7 & 2,724 & 0,3268 & 25 & 0,1281 & 13 & 28,9 & 4,085 & 0,2427 & 25 & 0,0951 & 17 & 37,8 & & 2,888 & 0,1919 & 24 & 0,0768 & 35 & 77,8 & 3,493 & 0,2579 & 25 & 0,1011 & 32 & 733 & 372 & 0,0821 & 25 & 0,0322 & 14 & 31,1 \\
\hline 8 & 2,735 & 0,2739 & 25 & 0,1074 & 12 & 26,7 & 3,947 & 0,2687 & 25 & 0,1053 & 30 & 66,7 & & 2,985 & 0,1868 & 24 & 0,0747 & 28 & 62,2 & 3,612 & 0,1449 & 24 & 0,0580 & 29 & 64,4 & 3,250 & 0,1152 & 25 & 0,0452 & 16 & 35,6 \\
\hline 9 & 2,932 & 0,2672 & 25 & 0,1047 & 25 & 55,6 & 3,982 & 0,2581 & 25 & 0,1012 & 25 & 55,6 & & 3,130 & 0,1203 & 24 & 0,0481 & 6 & 13,3 & 3,685 & 0,1010 & 25 & 0,0396 & 14 & 31,1 & 3,416 & 0,2861 & 25 & 0,1122 & 20 & 44,4 \\
\hline 10 & 2,789 & 0,2766 & 25 & 0,1084 & 13 & 28,9 & 3,740 & 0,2948 & 25 & 0,1155 & 35 & 77,8 & & 2,997 & 0,1832 & 24 & 0,0733 & 25 & 55,6 & 3,542 & 0,1677 & 25 & 0,0657 & 31 & 68,9 & 3,201 & 0,1132 & 25 & 0,0444 & 13 & 28,9 \\
\hline 11 & 3,095 & 0,3537 & 25 & 0,1386 & 32 & 71,1 & 3,965 & 0,2188 & 25 & 0,0858 & 25 & 55,6 & & 3,218 & 0,0796 & 24 & 0,0319 & 1 & 2,2 & 3,482 & 0,1325 & 25 & 0,0519 & 28 & 62,2 & 3,253 & 0,0876 & 25 & 0,0344 & 14 & 31,1 \\
\hline 12 & 2,667 & 0,2420 & 25 & 0,0949 & 9 & 20 & & 0,3038 & 25 & 0,1191 & 33 & & & 2,829 & 0,2411 & 25 & 0,0945 & 37 & 08 & 3,583 & 0,1516 & & 0,0594 & & & & 85 & & 13 & r & 31,1 \\
\hline 13 & 3,277 & 0,3185 & 25 & 0,1248 & 26 & 57 & 3,828 & 0,3394 & 25 & 0,1330 & 42 & 93 & & 3,063 & 0,1931 & 24 & 0,0773 & 13 & 28,9 & 3,543 & 0,1342 & 24 & 0,0537 & 30 & 66,7 & 3,031 & 0,1888 & 25 & $\begin{array}{l}0,0740 \\
\end{array}$ & 9 & 20,0 \\
\hline 14 & 2,867 & 0,2621 & 25 & 0,1028 & 23 & 51,1 & 3,630 & 0,3081 & 25 & 0,1208 & 25 & 55,6 & & 2,581 & 0,2346 & 23 & 0,0959 & 7 & 15,6 & 3,523 & 0,2336 & 25 & 0,0916 & 34 & 75,6 & 3,162 & 0,1584 & 25 & 0,0621 & 18 & 40,0 \\
\hline 15 & 3,148 & 0,3071 & 25 & 0,1204 & 27 & 60,0 & 3,918 & 0,3157 & 25 & 0,1238 & 35 & 77,8 & & 2,829 & 0,2717 & 24 & 0,1087 & 37 & 82,2 & 3,763 & 0,1941 & 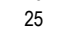 & 0,0761 & 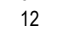 & 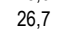 & 3,464 & 0,1900 & 25 & 0,0745 & 16 & 35,6 \\
\hline 16 & 3,306 & 0,2562 & 25 & 0,1004 & 20 & 4 & & 0,2218 & 25 & 0,0869 & 19 & 42 & & 2,882 & 0,2085 & 25 & 0,0817 & 35 & 77 & 3,5 & 0,0903 & 24 & 0,0361 & 26 & & & 0,1099 & & 0,0431 & 8 & 17,8 \\
\hline 17 & 3,012 & 0,2220 & 25 & 0,0870 & 24 & 53 & 3,745 & 0,2620 & 25 & 0,1027 & 35 & 77,8 & & 2,716 & 0,2666 & 25 & 0,1045 & 31 & 68,9 & 3,528 & 0,1369 & 25 & 0,0537 & 28 & 62,2 & 220 &, 1386 & 25 & 0,0543 & 15 & 33,3 \\
\hline 18 & 3,042 & 0,2500 & 25 & 0,0980 & 25 & 55,6 & 3,967 & 0,2661 & 25 & 0,1043 & 27 & 60,0 & & 2,986 & 0,2887 & 25 & 0,1131 & 36 & 80,0 & 3,587 & 0,1097 & 23 & 0,0448 & 27 & 60,0 & 3,180 & 0,0515 & 24 & 0,0206 & 9 & 20,0 \\
\hline 19 & 2,565 & 0,1611 & 25 & 0,0631 & 4 & 8,9 & 3,601 & 0,2763 & 25 & 0,1083 & 23 & 51,1 & & 2,483 & 0,2578 & 25 & 0,1010 & 4 & 8,9 & 3,327 & 0,1550 & 24 & 0,0620 & 8 & 17,8 & 3,094 & 0,0629 & 24 & 0,0252 & 7 & 15,6 \\
\hline 20 & 3,047 & 0,2540 & 25 & 0,0996 & 25 & 55,6 & 3, & 0,3494 & 25 & 0,1370 & 38 & 84 & & 2, & 0,2500 & 25 & 0,0980 & 23 & 51 & $\begin{array}{l}3,621 \\
3,621\end{array}$ & 0,2406 & 2 & 0,0943 & 3 & & 74 & 0,1243 & 25 & 0,0487 & 14 & 31,1 \\
\hline 21 & 3,144 & 0,2393 & 25 & 0,0938 & 26 & 57 & 3,735 & 0,3103 & 25 & 0,1216 & 35 & 77 & & 2,839 & 0,1788 & 25 & 0,0701 & 32 & 71, & 38 & 0,1346 & 25 & 0,0528 & 8 & 17 & 70 & 0,0881 & 25 & 0,0345 & 2 & 4,4 \\
\hline 22 & 3,107 & 0,2419 & 25 & 0,0948 & 27 & 60,0 & 3,628 & 0,2955 & 25 & 0,1158 & 25 & 55,6 & & 2,891 & 0,2344 & 24 & 0,0938 & 36 & 80,0 & 3,256 & 0,1655 & 24 & 0,0662 & 5 & 11,1 & 2,867 & 0,0977 & 25 & 0,0383 & 2 & $\begin{array}{l}7,4 \\
4,4\end{array}$ \\
\hline 23 & 3,091 & 0,3274 & 25 & 0,1283 & 31 & 68,9 & 3, & 0,2958 & 23 & 0,1209 & 38 & 84,4 & & 2,842 & 0,2282 & 24 & 0,0913 & 36 & 80,0 & 3,432 & 0,1754 & 25 & 0,0687 & 21 & 46,7 & 2,813 & 0,1106 & 25 & 0,0433 & 3 & 6,7 \\
\hline 24 & 3,278 & 0,2859 & 25 & 0,1121 & 22 & 48,9 & & 0,3490 & 25 & 0,1368 & 12 & 26 , & & 2,809 & 0,2410 & 25 & 0,0945 & 34 & 75 & 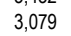 & 0,1773 & 2 & 0,0695 & 2 & & & 0,0992 & 25 & 0,0389 & 1 & 2,2 \\
\hline 25 & 3,2 & 0,3002 & 25 & & 24 & & & & 25 & 0,11 & 34 & & & & & 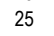 & & 3 & & & & 2 & & & & & & & & 6 & 13,3 \\
\hline 26 & 3,536 & 0,2585 & 25 & 0,1013 & 7 & 15,6 & 3,720 & 0,2656 & 25 & 0,1041 & 33 & 73 & & 3,040 & 0,2477 & 25 & 0,0971 & 21 & 46 , & 3,720 & 0,1263 & 25 & 0,0495 & 14 & 31, & 3,542 & 0,1166 & 25 & 0,0457 & 8 & 17,8 \\
\hline 28 & 3,059 & 0,2784 & 25 & 0,1091 & 29 & 64,4 & 3, & 0,3180 & 24 & 0,1272 & 36 & 80, & & 2,932 & 0,2976 & 25 & 0,1167 & 38 & 84 & 3,699 & 0,1451 & 24 & 0,0581 & 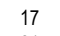 & 37, & 3,316 & 0,1235 & 25 & 0,0484 & 19 & 42,2 \\
\hline 29 & 3,325 & 0,4080 & 25 & 0,1599 & 25 & 55 & & 0,3342 & 25 & 0,1310 & 30 & 66 & & 2, & 0,2544 & 25 & 0,0997 & 21 & 46 & 3 & 0,1522 & 24 & 0,0609 & 21 & & & 0,1222 & 24 & 0,0489 & 9 & 20,0 \\
\hline 31 & 2,681 & & 25 & 0,0942 & 10 & 22 & & 0,3343 & 2. & 0,13 & . & & & & & 25 & & 35 & & & & 2 & & 3 & & & & 2 & & 22 & 48,9 \\
\hline 32 & 2,880 & 0,2182 & 25 & 0,0855 & 21 & 46 & & 0,2809 & 25 & 0,1101 & 30 & 66 & & 2,736 & 0,3053 & 25 & 0,1197 & 33 & 73 & 3,579 & 0,1620 & 2 & 0,0635 & 30 & & 77 & 0,1429 & &, 0560 & 20 & 44,4 \\
\hline 33 & 3,089 & 0,3219 & 25 & 0,12 & 31 & 68 & & 0,2869 & 0 & 0,1124 & 41 & 91 & & 2,8 & 0,2568 & 25 & & 35 & 77 & 3,612 & 0,2315 & 2 & 0,0908 & 33 & 73 & 35 & 0,1489 & 25 & 0,0584 & 20 & 44,4 \\
\hline 34 & 2,889 & 0,3266 & 25 & 0,1 & 26 & 57 & & 0,3474 & 25 & 0,13 & 37 & 82 & & 2 & & 25 & & 40 & 88 & & 0,2004 & 24 & 0,0802 & 6 & 13 & & 0,1402 & 25 & 0,0549 & 15 & 33,3 \\
\hline 35 & 2,855 & 0,2781 & 25 & 0,1090 & 24 & 53 & & 0,2 & 25 & 0,1 & 40 & 88 & & & & 25 & & 38 & 8 & & 0,1536 & 25 & 0,0602 & 3 & 68 & 10 & 0,1294 & 25 & 0,0507 & 18 & 40,0 \\
\hline 36 & 3,037 & 0,3341 & 25 & 0,1310 & 29 & 64 & & 0,3064 & 25 & 0, & 32 & 71 & & & & 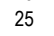 & & 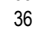 & & & 0,1464 & 2 & & & & & 0,0639 & & 51 & 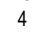 & 8,9 \\
\hline 37 & 2,975 & 0,2297 & 25 & 0,0 & 25 & 5 & & 0,2 & 25 & & 30 & 66 & & 2,808 & & 2 & & 3 & & & 0,1612 & 2 & & & & & 0,1146 & & 0,0449 & 13 & 28,9 \\
\hline 38 & 2,6 & & 25 & & 11 & 2 & & 0,2 & 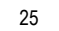 & & 24 & 53 & & & & 25 & & 27 & & & & 25 & & 14 & & & & 2 & 0,0336 & 13 & 28,9 \\
\hline 39 & 2,836 & & 25 & 0,1 & 22 & & & 0,3025 & 25 & 0,1 & & & & & & 25 & & 37 & & & 0,2600 & 2 & 0,1019 & 3 & & & 0,1150 & 25 & & 9 & 20,0 \\
\hline 40 & 3,282 & 0,3670 & 25 & 0,1439 & 28 & 62 & & 0,3015 & 25 & 0,1182 & 25 & 55 & & $\begin{array}{l}2,850 \\
2,850\end{array}$ & 0,2904 & 25 & 0,1138 & . & 84 & 9 & 0,1753 & 2 & 0,0687 & 1 & 31 & 73 & 0,1133 & 25 &, 0444 & 7 & 15,6 \\
\hline 41 & 3,0 & 0,2984 & 25 & 0,11 & 26 & 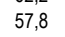 & & 0,23 & . & & 3 & & & & & 25 & & 3 & & & & & & & & & & & & 14 & 31,1 \\
\hline 42 & 3,4 & & 25 & & 13 & 2 & & & 2 & & 2 & 55 & & & & 2 & & 37 & & & & 2 & & 2 & & & & & & 15 & 3 \\
\hline 43 & 3,435 & & 25 & & 13 & & & 0,35 & 25 & 0,1 & 42 & 93 & & 2, & & 25 & & 38 & & & 0,2123 & 25 & 0,0 & 31 & & 54 & 0,1228 & 25 & $0, C$ & 16 & 35,6 \\
\hline 44 & 3,149 & 0,2260 & 25 & 0,0886 & 26 & 57 & 4,0 & 0,2964 & 25 & 0,1 & 25 & 55,6 & & 3, & 0,24 & 25 & 0,0959 & 11 & & 3, & 0,1261 & 25 & 0, & 10 & 22, & 93 & 0,0790 & 25 & 0,0310 & 14 & 31,1 \\
\hline 45 & 3,10 & & 25 & 0,10 & 28 & 62 & & 0,27 & 25 & & 24 & & & 2,8 & & 2 & & 34 & & & & 2 & & & & & & & 72 & 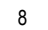 & 8 \\
\hline 46 & 3,1 & & 25 & 0,0 & 27 & 60 & & 0,2 & 2 & & 3 & 82 & $\#$ & 27 & & 2 & & 3 & 75 & & & 2 & & 3 & & & & & 28 & 16 & 6 \\
\hline 47 & 3,060 & 0,2692 & 25 & 0,1055 & 27 & 60, & & 0,2372 & 25 & 0,0930 & 25 & 55,6 & & & & 25 & & 36 & & & 0,1390 & 25 & 0,0545 & 29 & & 3,057 & 0,1022 & 25 & 0,0400 & 7 & 15,6 \\
\hline 48 & 2,866 & 0,2194 & 25 & 0,0860 & 18 & 40,0 & 3,924 & 0,2929 & 25 & 0,1148 & Ju & 77,8 & $\#$ & 3,026 & 0,2684 & 25 & 0,1052 & 26 & 57,8 & 3,653 & 0,1539 & 25 & 0,0603 & 25 & 55,6 & 3,253 & 0,1562 & 25 & 0,0612 & 20 & 44,4 \\
\hline Geral & 3,076 & 0,2902 & 1150 & 0,1138 & 990 & 47,8 & 3,814 & 0,2919 & 1143 & 0,1148 & 1446 & 69,9 & & 2,864 & 0,2430 & 1132 & 0,0959 & 1360 & 65,7 & 3,542 & 0,1670 & 1133 & 0,0659 & 1084 & 52,4 & 3,245 & 0,1301 & 1146 & 0,0511 & 564 & 27,2 \\
\hline
\end{tabular}


Anexo C. Umidade média $\left(\theta_{\mathrm{m}}\right)$, Desvio padrão (Dp), número de observações $(\mathrm{n})$, intervalo de confiança a $95 \%$ de probabilidade para a média (IC95\%), número de pontos concordantes $(\mathrm{nC})$ e sua percentagem $(\% \mathrm{C})$ por camada para os dados do segundo período de observações (2001).

\begin{tabular}{|c|c|c|c|c|c|c|c|c|c|c|c|c|c|c|c|c|c|c|c|c|c|c|c|c|c|c|c|c|c|c|}
\hline \multirow{2}{*}{ Bat. } & \multicolumn{6}{|c|}{ Camada A } & \multicolumn{6}{|c|}{ Camada B } & \multicolumn{6}{|c|}{ Camada C } & \multicolumn{6}{|c|}{ Camada D } & \multicolumn{6}{|c|}{ Camada E } \\
\hline & $\theta_{\mathrm{m}}$ & $\mathrm{Dp}$ & $\mathrm{n}$ & & $\mathrm{nC}$ & $\% C$ & $\theta_{\mathrm{m}}$ & Dp & $\mathrm{n}$ & $\mathrm{I}_{95 \%}$ & $\mathrm{nC}$ & $\% \mathrm{C}$ & $\theta_{\mathrm{m}}$ & Dp & & $I_{95 \%}$ & $\mathrm{nC}$ & $\% \mathrm{C}$ & $\theta_{\mathrm{m}}$ & Dp & & $\mathrm{I}_{95 \%}$ & $\mathrm{nC}$ & $\% \mathrm{C}$ & $\theta_{\mathrm{m}}$ & Dp & & $\mathrm{I}_{95 \%}$ & $\mathrm{nC}$ & $\% C$ \\
\hline 1 & 0,300 & 0,0192 & 22 & 0,0080 & 11 & 26,2 & 0,268 & 0,0211 & 22 & 0,0088 & 13 & 30,2 & 0,249 & 0,0155 & 22 & 0,0065 & 24 & 54,5 & 0,276 & 0,0172 & 20 & 0,0075 & 26 & 60,5 & 0,270 & 0,0230 & 22 & 0,0096 & 29 & 65,9 \\
\hline 2 & 0,297 & 0150 & 21 & 064 & 11 & 262 & 0263 & 0,0174 & 22 & 0,0073 & 12 & 27,9 & 0,247 & 0,0125 & 22 & 0,0052 & 23 & 523 & 275 & 0,0150 & 22 & 0,0063 & 26 & & & 0,0172 & 22 & 0,0072 & 31 & \\
\hline 3 & 0,263 & 0278 & 21 & 119 & 18 & 42,9 & 0,236 & 0,0217 & 22 & 0,0091 & 19 & 44,2 & 243 & 0,0177 & 22 & 0,0074 & 23 & 52,3 & 266 & 0,0115 & 22 & 0,0048 & 26 & 60, & 0,267 & 0,0094 & 22 & 0,0039 & 21 & 47,7 \\
\hline 4 & 0,310 & 0,0227 & 4 & 223 & 13 & 31,0 & 0,236 & 0,0197 & 22 & 0,0082 & 19 & 44,2 & 0,243 & 0,0157 & 22 & 0,0066 & 23 & 52,3 & 264 & 0,0115 & 22 & 0,0048 & 26 & 60, & 282 & 0,0101 & 18 & 0,0047 & 24 & 54,5 \\
\hline 5 & 0,279 & 0,0198 & 22 & 083 & 11 & 26,2 & & & & & & & & & & & & & 0,283 & 0,0145 & 22 & 0,0060 & 18 & 41,9 & 283 & 0,0192 & 22 & 0,0080 & 30 & 682 \\
\hline 6 & 0,284 & 0,0225 & 22 & 0,0094 & 13 & 31,0 & 0,257 & 0,0134 & 22 & 0,0056 & 14 & 32,6 & 0,248 & 0,0148 & 22 & 0,0062 & 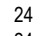 & 54,5 & 0,285 & 0,0125 & 22 & 0,0052 & 13 & 30,2 & 0,305 & 0,0271 & 21 & 0,0116 & 12 & 27,3 \\
\hline 7 & & & & & & & 0,240 & 0,0195 & 22 & 0,0081 & 19 & 44,2 & 0,250 & 0,0136 & 22 & 0,0057 & 24 & 54,5 & 0,264 & 0,0143 & 19 & 0,0064 & 31 & 72 & & & & & & \\
\hline 8 & 0,287 & 0,0317 & 20 & 0139 & 16 & 38,1 & 0,244 & 0,0212 & 22 & 0,0089 & 20 & 46,5 & 47 & 0,0112 & 22 & 0,0047 & 22 & 50,0 & 0,261 & 0,0117 & 22 & 0,0049 & 22 & 51,2 & 0,271 & 0,0158 & 22 & 0,0066 & 29 & 0, \\
\hline 9 & 0,239 & 0,0254 & 22 & 0,0106 & 17 & 40,5 & 0,225 & 0,0219 & 22 & 0,0092 & 12 & 27,9 & 0,245 & 0,0196 & 22 & 0,0082 & 25 & 56,8 & 0,252 & 0,0204 & 22 & 0,0085 & 20 & 46,5 & 0,294 & 0,0302 & 22 & 0,0126 & 26 & 591 \\
\hline 10 & 0,241 & 0,0279 & 22 & 0116 & 20 & 47,6 & 0,230 & 0,0250 & 22 & 0,0105 & 18 & 41,9 & 0,250 & 0,0190 & 22 & 0,0080 & 25 & 56,8 & 0,256 & 0,0219 & 22 & 0,0091 & 24 & 55,8 & 0,273 & 0,0185 & 22 & 0,0077 & 30 & 68,2 \\
\hline 11 & 0,281 & 0267 & 21 & 114 & 15 & 35,7 & & 0,0042 & 22 & 0,0017 & 6 & $14, \mathrm{C}$ & & 0,0064 & 2 & 0,0027 & 21 & 77 & & 100 & 10 & 0,0036 & & & & 000 & 2 & 0040 & 25 & \\
\hline 13 & 0,353 & 0,0504 & 14 & 0,0264 & 6 & 14,3 & 0,247 & 0,0174 & 21 & 0,0074 & 20 & 46,5 & & 0,0138 & 22 & 0,0058 & 23 & 52,3 & 53 & 0,0128 & 22 & 0,0053 & 16 & 37,2 & 278 & 0,0197 & 22 & 0082 & 32 & 72,7 \\
\hline 14 & 0,303 & 0,0202 & 22 & 085 & 8 & 19,0 & 0,250 & 0,0191 & 20 & 0,0084 & 19 & 44,2 & 50 & 0,0151 & 21 & 0,0065 & 25 & 56,8 & 258 & 0,0143 & 21 & 0,0061 & 23 & 53,5 & 282 & 0,0186 & 22 &, 0078 & 29 & 650 \\
\hline 15 & 0,242 & 0346 & 22 & & 21 & & & 0037 & 22 & 0.0157 & 20 & 46 & & 0,0203 & & 0,0085 & (2) & & & 0.01 & 22 & 0,0061 & & & & & 22 & 0063 & 1 & \\
\hline 16 & 0,244 & 0,0273 & 22 & 114 & 19 & 45 & 18 & 0,0367 & 21 & 11 & 25 & 58 & & 207 & 22 & 0 & 25 & 56 & & 0,01 & 22 & & 30 & & & & 2 & 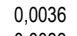 & 1 & \\
\hline 17 & 0,251 & 0,0240 & 22 & 100 & 18 & 42,9 & 0,243 & 0,0206 & 22 & 0,0086 & 20 & 46, & & 0,0168 & 22 & 0,0070 & 20 & 45,5 & 0,280 & 0,0131 & 22 & 0,0055 & 19 & 44 & 295 & 0,0211 & 22 & 0088 & 19 & 43,2 \\
\hline 18 & 0,251 & 0,0231 & 22 & 097 & 17 & 40,5 & 0,254 & 0,0196 & 22 & 0,0082 & 16 & 37,2 & 58 & 0,0150 & 22 & 0,0063 & 20 & 45 & 0,279 & 0,0146 & 22 & 0,0061 & 20 & 46 & 889 & 0,0211 & 22 & 0,0088 & 26 & \\
\hline 19 & 0,236 & 0,0218 & 22 & 091 & 16 & 38,1 & 0,239 & 0,0160 & 22 & 0,0067 & 17 & 39, & & 0,0195 & & 0,0081 & 11 & 25 & 0,25 & 0,0109 & 2 & 0,0045 & 17 & 39 & & 0, & 2 & 0077 & 21 & 7 \\
\hline 20 & & & & & 19 & & & & 2 & & 17 & & & & & & & & & 0,0 & & 0,0042 & 10 & & & & & 065 & & \\
\hline 21 & 0,219 & 0249 & 2 & 104 & 11 & 26 & & 0,0266 & 22 & 0,0111 & 18 & 41, & & 143 & 2 & 0,0060 & 6 & 13 & & & - & - & 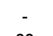 & - & 37 & 37 & 22 & 0016 & 0 & 0,0 \\
\hline 22 & 0,225 & 0,0265 & 2 & 111 & 13 & 31 & & 0,0251 & 21 & 0,0107 & 19 & 44,2 & & 0,0172 & 22 & 0,0072 & 9 & $2 C$ & 0,261 & 0,0116 & 22 & 0,0048 & 22 & 51, & & $0, C$ & 22 & 0061 & 21 & 47,7 \\
\hline 23 & 0,254 & 0,0242 & 2 & & 18 & 42 & & 0,0049 & 19 & 0,0022 & 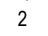 & 4,7 & & 0,0075 & 1 & 0,0036 & 23 & & & 0,0081 & 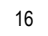 & 0,0040 & 20 & & & & 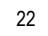 & 0062 & 31 & 0.5 \\
\hline 24 & 0,282 & & 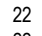 & & 17 & & & & & & 2 & 4,7 & & & & & 18 & & & & & & & & & & & & & \\
\hline 25 & 0,283 & 0237 & 22 & 199 & 14 & 33 & & 0,0199 & 22 & 0,0083 & 6 & 14 & & & & & Th & & & 0,0 & 2 & 0,0070 & 11 & & & & & 0073 & &, 2 \\
\hline 29 & 0,257 & & 22 & & 18 & & & & 3 & & 8 & & & & & & ת & & & & 1 & & & & & & 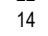 & & & \\
\hline 31 & 0,2 & & 2 & & 1 & & & & & & 11 & & & & & & & & & & & & & & & & & 046 & & \\
\hline 32 & 0,2 & 0,0268 & 22 & & 10 & 45 & & 0, & 22 & , & 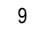 & & & & & & 28 & 63 & & 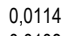 & 2 & 0,0048 & 25 & 58 & & 8 & 2 & 045 & 11 & 25,0 \\
\hline 33 & 0,2 & 0,021 & 2 & & 17 & 40 & & & 22 & & 10 & & & & & & 24 & & & 3 & & 0,0045 & 22 & & & & 22 & 069 & 29 & \\
\hline 34 & & 0,0 & 2 & & 18 & 42 & & & & & & & & & & & 29 & & & & & & 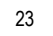 & & & & 0 & 57 & 19 & \\
\hline 35 & 0, & 0,027 & 2 & & 3 & 7 & & & & & 6 & & & & & & & & & 0,0 & & 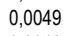 & & & & & & 0072 & 13 & \\
\hline 36 & 0, & 0,024 & 22 & & 3 & 7, & & & 22 & & 8 & 18 & & & & & 6 & 13 & 0,274 & 0,0099 & 2 & 0,0042 & ¿2 & 51 & & 0,01 & 2 & 0045 & 11 & \\
\hline 37 & 0,345 & 0,015 & 22 & & 4 & 9, & & & 22 & & 4 & 9, & & & & & 2 & & & & & & & & & & 2 & 24 & 2 & \\
\hline 38 & 0,333 & 0,0167 & 22 & 0,0070 & 4 & 9,5 & & & 22 & & 5 & & & & & & & & & & & & 13 & & & & 2 & 21 & 5 & \\
\hline 39 & & & & & & & & 0,0 & 22 & & 20 & & & & & & & & & ת م & 2 & & 31 & & & & 2 & 041 & 23 & \\
\hline $4 c$ & 0, & 021 & 22 & & 16 & & & & & & 2 & & & & & & & & & & & & & & & & & 026 & & \\
\hline 4 & & & & & 14 & & & & 2 & & & & & & & & 3 & & & & & & 19 & & & & 1 & & 1 & \\
\hline 42 & 0,300 & 0,0232 & 2 & & 11 & & & & 22 & & 6 & 14 & & & 1 & & 3 & & & 0,0 & 2 & 0,0043 & 18 & & & & 22 & 052 & 15 & \\
\hline 43 & 0,271 & 0,0232 & 22 & 0,0097 & 15 & 35,7 & 0,284 & 0,0195 & 21 & 0,0084 & 7 & 16 & & & & & & & & & & & & & & & 2 & 0662 & 6 & \\
\hline 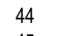 & & & & & 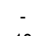 & . & & & 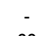 & & - & & & & & & & & & & & & & & & & & 068 & & \\
\hline 45 & 0,2 & 0,0189 & 2 & 0,00 & 13 & 3 & & & 22 & 0,0087 & 1 & & & & & & 26 & & & & & & & & & & 2 & 067 & Ju & \\
\hline 46 & & & 2 & & 7 & & & & 21 & & 15 & & & & & & 25 & & & & & & 20 & & & & 22 & 039 & 1 & \\
\hline 47 & 0,267 & 0,0371 & 22 & 0,0155 & 20 & 47,6 & 0 & 0,0136 & 3 & 0,0153 & 0 & 0, & 0, & 0,0 & 22 & 0,0 & 9 & 20, & 0,275 & 0,0085 & 22 & 0,0036 & 20 & 46, & 5 & 31 & 22 & 0,0080 & 33 & 75,0 \\
\hline 48 & 0,261 & 0,0265 & 23 & 0,0108 & 16 & 38,1 & 0,304 & 0,0320 & 22 & 0,0134 & io & 23,3 & 0,292 & 0,0189 & -1 & 0,0081 & , & 11,4 & 0,218 & 0,0079 & 22 & 0,0033 & 10 & 41,9 & 0,282 & 0,0182 & 23 & 0,0075 & 29 & 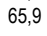 \\
\hline Geral & 0,271 & 0,0256 & 915 & 0,0111 & 590 & 32,7 & 0,263 & 0,0182 & 919 & 0,0080 & 552 & 29,2 & 0,252 & 0,0154 & 967 & 0,0065 & 728 & 36,8 & 0,267 & 0,0136 & 937 & 0,0058 & 942 & 49,8 & 0,279 & 0,0151 & 972 & 0,0064 & 1012 & 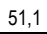 \\
\hline
\end{tabular}


Anexo D. Leitura média do TDR, ( $\left.T_{T D R}\right)$, Desvio padrão (Dp), número de observações ( $n$ ), intervalo de confiança a 95\% de probabilidade para a média (IC95\%), número de pontos concordantes $(\mathrm{nC})$ e sua percentagem $(\% \mathrm{C})$ por camada para os dados do segundo período de observações (2001).

\begin{tabular}{|c|c|c|c|c|c|c|c|c|c|c|c|c|c|c|c|c|c|c|c|c|c|c|c|c|c|c|c|c|c|c|}
\hline \multirow{2}{*}{ Bat. } & \multirow{2}{*}{\multicolumn{6}{|c|}{ Camada A }} & \multicolumn{6}{|c|}{ Camada B } & \multicolumn{6}{|c|}{ Camada C } & \multicolumn{6}{|c|}{ Camada D } & \multicolumn{6}{|c|}{ Camada E } \\
\hline & & & $\mathrm{n}$ & & & $\% C$ & $\mathrm{~T}_{\mathrm{TDR}}$ & $\mathrm{Dp}$ & $\mathrm{n}$ & IC95\% & $\mathrm{nC}$ & $\% C$ & TTDR & $\mathrm{Dp}$ & $\mathrm{n}$ & $\mathrm{C}_{95 \%}$ & $\mathrm{nC}$ & $\% \mathrm{C}$ & TTOR & $\mathrm{Dp}$ & $\mathrm{n}$ & IC95\% & $\mathrm{nC}$ & $\% C$ & $T_{T D R}$ & $\mathrm{Dp}$ & $n$ & $\mathrm{I}_{95 \%}$ & $\mathrm{nC}$ & $\% C$ \\
\hline 1 & 2,603 & 0,1611 & 22 & 0,0673 & 16 & 38,1 & 3,021 & 0,1046 & 22 & 0,0437 & 0 & 7,0 & 1,912 & 0,1539 & 22 & 0,0643 & 1 & 2,3 & 3,226 & 0,1387 & 20 & 0,0608 & 14 & 32,6 & 3,201 & 0,1307 & 22 & 0,0546 & 17 & 38,6 \\
\hline 2 & 2,977 & 0,2670 & 21 & 0,1142 & 18 & 42,9 & 3,423 & 0,3437 & 22 & 0,1436 & 34 & 79,1 & 2,870 & 0,1722 & 22 & 0,0719 & 8 & 18,2 & 3,726 & 0,2127 & 22 & 0,0889 & 11 & 25,6 & 3,488 & 0,2027 & 22 & 0,0847 & 11 & 25,0 \\
\hline 3 & 2,931 & 0,3153 & 21 & 0,1349 & 22 & 52,4 & 3,439 & 0,1624 & 22 & 0,0679 & 27 & 62,8 & 2,607 & 0,1972 & 22 & 0,0824 & 24 & 54,5 & 3,350 & 0,1724 & 22 & 0,0721 & 20 & 46,5 & 3,468 & 0,1311 & 22 & 0,0548 & 8 & 18,2 \\
\hline 4 & 3,152 & 0,1297 & 4 & 0,1271 & 6 & 14,3 & 3,579 & 0,2414 & 22 & 0,1009 & 16 & 37,2 & 2,970 & 0,2178 & 22 & 0,0910 & 3 & 6,8 & 3,710 & 0,1764 & 22 & 0,0737 & 11 & 25,6 & 3,362 & 0,1394 & 18 & 0,0644 & 14 & 31,8 \\
\hline 5 & 2,857 & 0,1740 & 22 & 0,0727 & 22 & 52,4 & . & . & & & - & - & - & . & 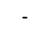 & & - & . & 3,724 & 0,2282 & 22 & 0,0953 & 12 & 27,9 & 3,518 & 0,1507 & 22 & 0,0630 & 5 & 11,4 \\
\hline 6 & 2,663 & 0,1477 & 22 & 0,0617 & 20 & 47,6 & 3,511 & 0,1793 & 22 & 0,0749 & 24 & 55,8 & 2,438 & 0,2873 & 22 & 0,1200 & 24 & 54,5 & 3,528 & 0,1297 & 22 & 0,0542 & 13 & 30,2 & 3,187 & 0,1437 & 21 & 0,0615 & 15 & 34,1 \\
\hline 7 & & & & & . & & 3,520 & 0,3079 & 22 & 0,1286 & 27 & 62,8 & 2,573 & 0,1091 & 22 & 0,0456 & 20 & 45,5 & 3,216 & 0,1415 & 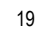 & 0,0636 & 14 & 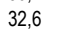 & & & & & & \\
\hline 8 & 2,614 & 0,1151 & 20 & 0,0504 & 14 & 33,3 & 3,267 & 0,1504 & 22 & 0,0628 & 23 & 53,5 & 2,718 & 0,1584 & 22 & 0,0662 & 15 & 34,1 & 3,678 & 0,1399 & 22 & 0,0585 & 12 & 27, & 3,201 & 0,1572 & 22 & 0,0657 & 18 & 40,9 \\
\hline 9 & 2,614 & 0,1522 & 22 & 0,0636 & 15 & 35,7 & 3,453 & 0,1610 & 22 & 0,0673 & 26 & 60,5 & 2,761 & 0,1502 & 22 & 0,0628 & 15 & 34,1 & 3,411 & 0,1873 & 22 & 0,0783 & 22 & 51,2 & 3,334 & 0,1150 & 22 & 0,0480 & 13 & 29,5 \\
\hline 10 & 2,650 & 0,1789 & 22 & 0,0748 & 20 & 47,6 & 3,119 & 0,1914 & 22 & 0,0800 & 11 & 25,6 & 2,461 & 0,1495 & 22 & 0,0625 & 16 & 36,4 & 3,223 & 0,1611 & 22 & 0,0673 & 15 & 34,9 & 3,145 & 0,0764 & 22 & 0,0319 & 12 & 27,3 \\
\hline 11 & 2,838 & 0,1513 & 21 & 0,0647 & 21 & 50,0 & 501 & 0,1546 & 22 & 0,0646 & 24 & 55,8 & 2,782 & 0,1063 & 22 & 0,0444 & 10 & 22,7 & 3,403 & 0,0867 & 10 & 0,0538 & 18 & 41,9 & 992 & 0,0908 & 22 &, 0379 & 7 & 15,9 \\
\hline 12 & 2,769 & 0,1564 & 22 & 0,0654 & 23 & 54 & & 0,2264 & 22 & 0,0946 & 30 & 69,8 & 26 & 0,1564 & 22 & 0,0654 & 20 & 45 & 3615 & 0,1606 & 22 & 0,0671 & 18 & & & 穴 & & 33 & 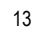 & 29,5 \\
\hline 13 & 2,822 & 0,1630 & 14 & 0,0854 & 24 & 57,1 & 3,356 & 0,2517 & 21 & 0,1077 & 31 & 72,1 & 2,925 & 0,1533 & 22 & 0,0641 & 5 & 11,4 & 3,668 & 0,1354 & 22 & 0,0566 & 14 & 32 & 127 & 0,1180 & 22 & 0,0493 & 12 & 27,3 \\
\hline 14 & 2,761 & 0,1849 & 22 & 0,0773 & 24 & 57,1 & 3,118 & 0,3088 & 20 & 0,1353 & 17 & 39,5 & 2,339 & 0,3211 & 21 & 0,1373 & 18 & 40,9 & 3,308 & 0,1987 & 21 & 0,0850 & 20 & 46,5 & 3,005 & 0,1564 & 22 & 0,0654 & 8 & 18,2 \\
\hline 15 & 2,865 & 0,2080 & 22 & 0,0869 & 22 & 52,4 & 32 & 0,2041 & 22 & 0,0853 & 28 & 65,1 & 2,399 & 0,2975 & 22 & 0,1243 & 22 & 50,0 & 3,566 & 0,2589 & ? & 0,1082 & - & 48,8 & 387 & 0,1224 & 22 & 0,0512 & 11 & 25,0 \\
\hline 16 & 2,900 & 0,1119 & 22 & 0,0468 & 16 & 38,1 & 74 & 0,1325 & 21 & 0,0567 & 12 & 27,9 & 2,486 & 0,1252 & 22 & 0,0523 & 19 & 43 & 3,404 & 0,0667 & 22 & 0,0279 & 10 & 23 & 4 & 11 & & 0,0464 & 0 & 0,0 \\
\hline 17 & 3,140 & 0,1230 & 22 & 0,0514 & 3 & 7,1 & 2,694 & 0,1089 & 22 & 0,0455 & 0 & 0,0 & 2,342 & 0,0835 & 22 & 0,0349 & 8 & 18,2 & 2,913 & 0,0622 & 22 & 0,0260 & 0 & 0, & 86 & 0891 & 22 & 0,0372 & 11 & 25,0 \\
\hline 18 & 2,692 & 0,1241 & 22 & 0,0519 & 20 & 47,6 & 3,388 & 0,1699 & 22 & 0,0710 & 28 & 65,1 & 2,568 & 0,1147 & 22 & 0,0479 & 22 & 50,0 & 3,599 & 0,0957 & 22 & 0,0400 & 16 & 37,2 & 156 & 0,1397 & 22 & 0,0584 & 15 & 34,1 \\
\hline 19 & 2,484 & 0,1472 & 22 & 0,0615 & 6 & 14,3 & 77 & 0,1461 & 22 & 0,0611 & 13 & 30,2 & 2,232 & 0,1343 & 22 & 0,0561 & 6 & 13,6 & 3,253 & 0,1056 & 22 & 0,0441 & 14 & 32,6 & 288 & 0,0803 & 22 & 0,0335 & 14 & 31,8 \\
\hline 20 & 2,838 & 0,1347 & 22 & $\begin{array}{l}0,0563 \\
\end{array}$ & 21 & 50,0 & 3,176 & 0,1749 & 22 & 0,0731 & 16 & 37,2 & 2,422 & 0,2222 & 22 & $\begin{array}{l}0,0929 \\
\text { a }\end{array}$ & 17 & 38 & $\begin{array}{l}3,5504 \\
\text { S, }\end{array}$ & 0,1952 & 22 & $\begin{array}{l}0,0816\end{array}$ & 17 & 39,5 & 3,253 & 30 & & 0,0765 & 20 & 45,5 \\
\hline 21 & 2,720 & 0,1282 & 22 & 0,0536 & 20 & 47,6 & 3,330 & 0,1511 & 22 & 0,0631 & 24 & 55,8 & 7771 & 0,2274 & 22 & 0,0950 & 17 & 38,6 & & & & & & & & 50 & 24 &, 0455 & - & 18,2 \\
\hline 22 & 2,760 & 0,1350 & 22 & 0,0564 & 21 & 50,0 & $\begin{array}{l}3,274 \\
\text { s. }\end{array}$ & 0,1723 & 21 & 0,0737 & 25 & 58,1 & 2,582 & 0,1456 & 22 & 0,0608 & 22 & 50,0 & 3,300 & 0,1226 & 22 & 0,0513 & 18 & 41,9 & 2,927 & 0,1153 & 22 & 0,0482 & 8 & 18,2 \\
\hline 23 & 2,808 & 0,1965 & 22 & 0,0821 & 24 & 57,1 & 17 & 0,2475 & 19 & 0,1113 & 26 & 60,5 & 2,924 & 0,2742 & 17 & 0,1303 & 8 & 18,2 & 3,801 & 0,1168 & 16 & 0,0572 & r & 11,6 & 2,883 & 0,1285 & 22 & 0,0537 & 4 & 9,1 \\
\hline 24 & 2,923 & 0,2360 & 22 & 0,0986 & 19 & 45,2 & & 0,2274 & 22 & 0,0950 & 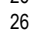 & 60,5 & 264 & 0,2029 & 22 & 0,0848 & 20 & 45 & 3,263 & 0,2392 & To & 0,0999 & 20 & & 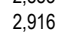 & 48 & & 0,0605 & 8 & 18,2 \\
\hline 25 & 2,834 & 0,1654 & 22 & 0,0691 & 22 & 52 & & 0,2200 & 22 & 0 & 27 & 62 & & & 22 & & 25 & . & & 0,1868 & & & 23 & & & & & 57 & 4 & 9,1 \\
\hline 26 & 2,988 & 0,1666 & 22 & 0,0696 & 10 & 23,8 & 3,389 & 0,1743 & 22 & 0,0728 & 28 & 65 & 2,712 & 0,1216 & 22 & 0,0508 & 15 & 34,1 & 3,577 & 0,1191 & 22 & 0,0498 & 14 & 32,6 & 343 & 0,1456 & 22 & 0,0608 & 15 & 34,1 \\
\hline 28 & 2,576 & 0,1497 & 22 & 0,0625 & 13 & 31,0 & & 0,1389 & 22 & 0,0581 & 9 & 20 & 2,005 & 0,0926 & 22 & 0,0387 & 1 & 2,3 & 3,074 & 0,1419 & - & 0,0593 & 1 & 2,3 & 549 & 0879 & 22 & 0,0367 & 5 & 11,4 \\
\hline 29 & 2,852 & 0,1579 & 22 & 0,0660 & 21 & 50,0 & & 0,0927 & 3 & 0,1049 & 30 & 69 & & 0,1636 & 22 & 0,0684 & 23 & 52 & 3,312 & 0,1615 & 10 & 0,0746 & 19 & 44 & & 58 & 14 & 0,0711 & 16 & 36,4 \\
\hline 31 & 2,574 & & 22 & $0, C$ & 11 & 26 & & 0,2295 & 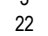 & , & (1) & 60 & & & 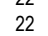 & & 11 & & & 0,1685 & re & & (10 & & & & 2 & 0,0420 & 5 & 11,4 \\
\hline 32 & 2,609 & 0,1869 & 22 & 0,0781 & 17 & 40, & & 0,0855 & 22 & 0,0357 & 19 & 44 & 2,U12 & 0,1122 & 22 & 0,0469 & 10 & 22 & 3,370 & 0,1280 & 22 & 0,0535 & 10 & 37 & & 0903 & & 0377 & 13 & 29,5 \\
\hline 33 & 2,695 & 0,1592 & 22 & 0,0665 & 21 & 50 & & 0,1414 & 22 & 0,059 & 16 & 37 & & 0,1 & 22 & 0, & 20 & 45 & 3,354 & 0,1534 & 22 & 0,0641 & 18 & 41 & 3,359 & 09 & 22 & 0,0631 & 14 & 31,8 \\
\hline 34 & 2,617 & 0,1559 & 22 & 0,0652 & 15 & 35 & & 0,1405 & 24 & 0,0 & 17 & 39 & & & 15 & & 21 & $4 \pi$ & 3, & 0,1289 & 22 & 0,0539 & 12 & & 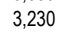 & & 22 & 0,0546 & 17 & 38,6 \\
\hline 35 & 2,657 & 0, & 22 & 0,0575 & 20 & 47 & & 0,0974 & 2 & 0,04 & 11 & 25 & & & 22 & 0, & 19 & 4 & 3,310 & 0,1227 & 22 & 0,0513 & 18 & 41 , & 319 & 0,1417 & 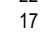 & 0,0673 & 17 & 38,6 \\
\hline 36 & 2,719 & 0,1771 & 22 & 0,0740 & 26 & 61, & & 0,1793 & 2 & 0, & 28 & 65 & & & 2 & & 18 & 70 & 3,704 & 0,2019 & 22 & 0,0844 & 13 & 30,2 & 50 & 00 & 2 & 0,0460 & 2 & 4,5 \\
\hline 37 & 2,916 & 0,1022 & 22 & 0,0427 & 16 & 38,1 & & 0,171 & 24 & 0, & 15 & 3 & & & 2 & & 15 & & & & & & & & & 20 & & 0,0343 & 12 & 27,3 \\
\hline 38 & 2,422 & 0,1712 & 22 & 0,0715 & 2 & 4,8 & & 0,13 & 22 & 0,0 & 24 & 55 & & & 22 & & 14 & 3 & 3, & 0,07 & 22 & 0,0 & 12 & 27 & & & 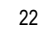 & 0,0641 & 18 & 40,9 \\
\hline 39 & & & & & & & & 0,2342 & 22 & 0,09 & 32 & 74 & & & 22 & & 28 & & & 0,1953 & 22 & 0,0816 & 15 & & 3,175 & 14 & & 0,0382 & 15 & 34,1 \\
\hline 40 & 2,894 & 0,1815 & 22 & 0,0759 & 19 & 45,2 & 3,6 & $\begin{array}{l}0,1929 \\
0\end{array}$ & 22 & 0,0806 & 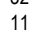 & 25 & 2,487 & 0,1 & 22 & 0, & 19 & 43 & 3,2 & 0,1444 & 2 & 0,0618 & 10 & & 23 & 39 & 2 & 0,0350 & 11 & 25,0 \\
\hline 41 & 2,783 & 年 & 21 & 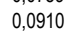 & 27 & 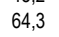 & & 0,23 & 2 & & 28 & & & & & & 29 & & & & & & & & & & & 0,0482 & & 25,0 \\
\hline 42 & $\begin{array}{l}2,1 \\
2,9\end{array}$ & 0, & 22 & $0, c$ & 17 & 40 & & 0,2 & 2 & & 31 & & & & 14 & & 24 & & & & & & 19 & & & & & 0,05 & 16 & 4 \\
\hline 43 & 3,169 & 0,1487 & 22 & 0,0621 & 2 & 4,8 & 3,120 & 0,1439 & 21 & 0,0616 & 10 & 23,3 & & & 22 & & 0 & & & 0,1 & 22 & 0,0427 & 6 & 14 & 4,064 & 75 & 22 & 0,0658 & 0 & 0,0 \\
\hline 44 & - & & & & 2 & - & & & 21 & &. & 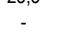 & 2,776 & 0,2166 & 22 & 0,0905 & 17 & $3 \varepsilon$ & 36 & 0,1699 & 22 & 0,0710 & 9 & 20,9 & 33 & 19 & 22 & 0,0509 & 17 & 38,6 \\
\hline 45 & 2,619 & 1169 & 22 & 0,048 & 15 & 35,7 & & 0,2721 & 22 & 0,1137 & 31 & 72 & & & 22 & & 10 & & & & & & 18 & & & & & 35 & 5 & 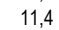 \\
\hline 46 & 2,76 & & 22 & 0, & 23 & 54 & & 0,131 & 21 & 0, & 24 & 55 & & & 22 & & 0 & & & & 2 & & 7 & & & 99 & & 1758 & 10 & 7 \\
\hline 47 & 2,706 & 311 & 22 & 0,0968 & 28 & 66,7 & & 0,1077 & 3 & & 34 & 79, & & 0,16 & 22 & & 19 & & & & 24 & 0,0705 & 10 & & 3,00 & 0,1621 & 《L & 0,0680 & 8 & 18,2 \\
\hline 48 & 2,387 & 0,2843 & 23 & 0,1162 & 2 & 4,8 & 3,377 & 0,1044 & 22 & 0,0436 & 22 & 51,2 & 2,687 & 0,2295 & 21 & 0,0981 & 20 & 45,5 & 3,526 & 0,2090 & 22 & 0,0873 & 16 & 37,2 & 3,182 & 0,1549 & 23 & 0,0633 & 15 & 34,1 \\
\hline Geral & 2,770 & 0,1679 & 915 & 0,0725 & 744 & 41,2 & 3,342 & 0,1808 & 919 & 0,0793 & 964 & 51,0 & 2,543 & 0,1697 & 967 & 0,0721 & 712 & 36,0 & 3,435 & 0,1514 & 937 & 0,0643 & 644 & 34,0 & 3,264 & 0,1285 & 972 & 0,0544 & 498 & 25,2 \\
\hline
\end{tabular}


Anexo E. Umidade média $\left(\theta_{\mathrm{m}}\right)$, Desvio padrão (Dp), número de observações (n), intervalo de confiança a 95\% de probabilidade para a média (IC95\%), número de pontos concordantes (nC) e sua percentagem $(\% \mathrm{C})$ por camada para todos os dados observados.

\begin{tabular}{|c|c|c|c|c|c|c|c|c|c|c|c|c|c|c|c|c|c|c|c|c|c|c|c|c|c|c|c|c|c|c|}
\hline \multirow{2}{*}{ Bat. } & \multicolumn{6}{|c|}{ Cama } & \multicolumn{6}{|c|}{ Camada } & \multicolumn{6}{|c|}{ Ca } & \multicolumn{6}{|c|}{$\mathrm{Ca}$} & \\
\hline & $\theta_{\mathrm{m}}$ & Dp & $\mathrm{n}$ & $\mid C_{95 \%}$ & $\mathrm{nC}$ & $\% \mathrm{C}$ & $\theta_{\mathrm{m}}$ & $\mathrm{Dp}$ & n & $\mathrm{I}_{95 \%}$ & $\mathrm{nC}$ & $\%$ & $\theta_{\mathrm{m}}$ & $\mathrm{Dp}$ & $\mathrm{n}$ & $\mathrm{IC}_{95 \%}$ & $\mathrm{nC}$ & $\%$ & $\theta_{\mathrm{m}}$ & Dp & $\mathrm{n}$ & & $\mathrm{nC}$ & $\% C$ & $\theta_{\mathrm{m}}$ & Dp & $\mathrm{n}$ & $I_{95 \%}$ & c. & (n) \\
\hline 1 & 0,309 & 0,0232 & 47 & 0,0066 & 5 & 11,1 & 0,273 & 0,0215 & 45 & 0,0063 & 12 & 26,7 & 0,256 & 0,0158 & 46 & 0,0046 & 23 & 51,1 & 0,280 & 0,0153 & 45 & 0,0045 & 19 & 42,2 & 0,272 & 0,0187 & 47 & 0,0053 & 26 & 57,8 \\
\hline 2 & 0,304 & 192 & 46 & 0,0056 & 4 & 8,9 & 0,271 & 0,0237 & 47 & 0,0068 & 13 & 28,9 & 0,251 & 0,0135 & 46 & 0,0039 & 23 & 51,1 & 0,279 & 0,0155 & 47 & 0,0044 & 19 & 42,2 & 0,273 & 0,0146 & 47 & 0,0042 & 23 & 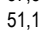 \\
\hline 3 & 0,277 & 388 & 46 & 0,0112 & 17 & 37,8 & 42 & 0,0219 & 46 & 0,0063 & 17 & 37,8 & & 169 & 46 & 0,0049 & 22 & 48,9 & 269 & 0,0102 & 46 & 0,0030 & 17 & 378 & 0,277 & 0,0136 & 47 & 0,0039 & 25 & \\
\hline 4 & 0,281 & 358 & 29 & 0130 & 16 & 35,6 & 239 & 0,0225 & 47 & 0,0064 & 17 & 37,8 & 246 & 0159 & 46 &, 0046 & 20 & 44,4 & 0,267 & 0,0109 & 46 & 0,0032 & 17 & 37,8 & 0,282 & ,0094 & 43 & 0,0028 & & \\
\hline 5 & 0,282 & 771 & 47 & 0,0078 & 12 & 26,7 & 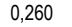 & 180 & 26 & 0,0069 & 13 & 28 & 53 & 138 & 24 & 0,0055 & 25 & 55,6 & 84 & 0,0143 & 46 & 0,0041 & 12 & , & 0,281 & 0,0163 & 47 & 0,0047 & & \\
\hline 6 & 0,286 & 277 & 47 & 0,0079 & 13 & 28,9 & 58 & 0,0157 & 47 & 0,0045 & 9 & 20,0 & 48 & 0152 & 46 & 0,0044 & 22 & 48,9 & 84 & 0,0118 & 46 & 0,0034 & 11 & 24,4 & 0,296 & 0,0240 & 45 & 0,0070 & 10 & 22 \\
\hline 7 & 0,275 & 0,0445 & 26 & 0,0171 & 26 & 57,8 & 42 & 0,0256 & 47 & 0,0073 & 18 & 40,0 & 50 & 0,0134 & 46 & 0,0039 & 23 & 51,1 & 63 & 0,0137 & 44 & 0,0040 & 19 & 422 & 0,275 & 0,0190 & 27 & 0,0072 & 29 & \\
\hline 8 & 0,283 & 319 & 45 & 0,0093 & 15 & 33,3 & 15 & 0,0257 & 47 & 0,0073 & 20 & 44,4 & 50 & 0125 & 46 & 0,0036 & 21 & 46 , & & 0,0113 & 46 & 0033 & 10 & & & 0,0137 & 17 & , ,0039 & & \\
\hline 9 & 0,256 & 378 & 47 & 108 & 22 & 48,9 & 33 & 01 & 47 & 36 & 17 & 37 & 53 & 1 & 46 & 0,0055 & 25 & 55 & & 200 & 47 & 057 & 20 & & 0 & 0,0241 & 47 & 0,0069 & & \\
\hline 10 & 0,253 & 0375 & 47 & 0,0107 & 20 & 44,4 & & 0,0303 & 47 & 0,0087 & 19 & 42,2 & & 83 & 46 & 0,0053 & 24 & 53 & & 0,0197 & 47 & 056 & 18 & 40,0 & 0,272 & 0,0168 & 47 & 0,0048 & 25 & \\
\hline 11 & 0,286 & 0,0337 & 46 & 0,0097 & 13 & 28,9 & 73 & 0,0070 & 47 & 0,0020 & 10 & 22,2 & 50 & 0,0074 & 46 & 0,0021 & 21 & 46,7 & 84 & 0,0063 & 35 & 0021 & 10 & 22,2 & 0,272 & 0,0111 & 47 & 0,0032 & 21 & \\
\hline 12 & 0,300 & 464 & 47 & 0,0133 & 14 & 31.1 & 77 & 0,0074 & 4 & 00021 & 10 & 22,2 & 247 & 0,0107 & 47 & 0.0031 & 20 & 44, & & 0,0102 & 77 & 0029 & & & 0279 & 0,0114 & & 0,0033 & & \\
\hline 14 & 0,307 & 0,0229 & 47 & 0,0065 & 5 & 11,1 & & 27 & 45 & 66 & 18 & 40 & & 3 & 44 & 0,0045 & 23 & 51 & & 150 & 46 & 43 & 18 & 40,0 & & 71 & . & 0,0049 & & 11 \\
\hline 15 & 0,245 & 0,0370 & 47 & 0,0106 & 20 & 44,4 & 40 & 0,0374 & 47 & 0,0107 & 22 & 48,9 & & 0,0195 & 46 & 0,0056 & 23 & 51, & & 148 & 47 & 042 & 21 & 67 & 0,278 & 0,0151 & 47 & 0,0043 & 23 & \\
\hline 16 & 0,243 & 0,0305 & 47 & 0,0087 & 18 & 40,0 & 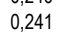 & 0,0359 & 46 & 0,0104 & 20 & 44,4 & 43 & 0,0208 & 47 & 0,0060 & 22 & 48 , & & 0,0161 & 46 & 046 & 19 & 42,2 & 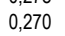 & 0,0106 & th & 0,0030 & & \\
\hline 17 & & & 47 & & 19 & & & & & & 20 & & & & 47 & & 11 & & & & & & & & & & & & & \\
\hline 18 & 0,257 & 294 & 47 & 884 & 20 & 44,4 & & 24 & 47 & 64 & 14 & 31 & & 165 & 47 & 0,0047 & 13 & & & & 45 & 43 & 14 & & & & 6 & 0052 & & \\
\hline 19 & 0,244 & 304 & 47 & 0,0087 & 18 & 40,0 & & 0198 & 47 & & 17 & 37,8 & & 0276 & 47 & 0,0079 & 10 & 22, & & 10 & 46 & 032 & 16 & 35, & 75 & 0,0151 & 46 & 0,0044 & 27 & \\
\hline 20 & 0,239 & 297 & 47 & 85 & 16 & 35,6 & 242 & 182 & 47 & 52 & 17 & 37,8 & & 261 & 47 & 0,0075 & 10 & 22, & & 33 & 47 & 38 & 17 & 37 & 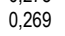 & 0,0150 & 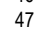 & 0,0043 & & \\
\hline 21 & & & 47 & & 12 & & & & & & 18 & & & & 47 & & & & & & & & & & & & & & & \\
\hline 22 & 0,229 & 351 & 47 & & 12 & 26 & & 6 & 46 & & 17 & & & & 46 & & 7 & & & & & & & & & & & & & \\
\hline 23 & 0,258 & 304 & 47 & 87 & 21 & 46,7 & & 39 & 42 & & 1 & 2,2 & & 081 & 41 & 0,0025 & 22 & 48, & & 0884 & 41 & 26 & 17 & 37 & 8 & 0,0188 & 47 & 0,0054 & 25 & \\
\hline 24 & 0,274 & 308 & 47 & & 17 & 37,8 & & 0,01 & 47 & & 1 & 2,2 & & 0,0082 & 47 & & 19 & 42 & & & 47 & & 19 & & & & . & & & \\
\hline 25 & & & 47 & & 14 & & & & & & 7 & & & & 17 & & 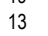 & & & & +1 & & & & & & & & & \\
\hline 29 & 0,2 & 364 & 47 & & 21 & 46 & & & 28 & & 19 & 42 & & 0,02 & 47 & & 26 & & & & 42 & & 10 & & & & & & & \\
\hline 31 & & & 47 & & 23 & & & & & & 12 & & & & 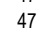 & & & & & & & & & & & & & & & \\
\hline 27 & & & 47 & & 22 & & & & & & 10 & & & & & & & & & & & & & & & & & & & \\
\hline 33 & 0,25 & & 47 & & 20 & & & & 4 & & 7 & & & & 47 & & & & & & & & & & & & & & & \\
\hline 34 & 0,25 & 0 & 47 & & 21 & 46 & & & 47 & & 7 & & & & 40 & & 23 & & & & & & 18 & & & & & 37 & & \\
\hline 35 & & & 47 & & 1 & 2 & & & 47 & & 11 & & & & 47 & & 11 & & & & 47 & & & & & & & & & \\
\hline 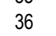 & & & 47 & & 1 & 2, & & & & & 11 & 24 & & & 47 & & & & & & & & & & & & & & & \\
\hline 37 & & & 47 & & 2 & 4, & & & & & & & & & & & & & & & & & & & & & & & & \\
\hline 38 & 0,3 & & 47 & & 2 & 4 & & & & & 3 & & & & 47 & & & & & & & & 13 & & & & & & & \\
\hline 39 & & & 25 & & 20 & & & & 47 & & 17 & & & & 47 & & & & & & 47 & & $\angle 2$ & & & & & & & \\
\hline 40 & 0,2 & 77 & 47 & & 18 & 40 & & & 47 & & 18 & & & 0,0 & 47 & & & & & & 46 & & & & & & & 23 & & \\
\hline 11 & & 0221 & 46 & & 11 & & & & & & 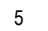 & & & & & & & & & & & & & & & & & 33 & & \\
\hline 42 & & & 47 & & 10 & 22 & & & 4 & & & & & & & & & & & & & & & & & & & & & \\
\hline 10 & & & 47 & & 20 & & & & & & 12 & & & & 4 & & & & & & & & 2 & & & & & & & \\
\hline 44 & 0,2 & 9 & 25 & & 23 & 51 & & & 25 & & 13 & 28 & & & 47 & & 11 & & & & 47 & & 4 & & & 0, & 47 & 40 & 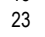 & \\
\hline 45 & 0,2 & & 47 & & 11 & & & & & & 12 & & & & & & & & & & & & & & & & & & & \\
\hline 46 & & & 47 & & 5 & & & & & & & & & & & & & & & & & & & & & & & & & \\
\hline 47 & & & $4 I$ & & 19 & & & & 2 & & 14 & & & & 47 & & 1 & & & & & & 16 & & & & & & & \\
\hline 18 & 0,256 & 0,0309 & 48 & 0, & 20 & 44,4 & 0,290 & 0,0320 & 47 & 0,0092 & 6 & 13,3 & $0, \angle 00$ & 0,0212 & 40 & 0,0061 & & 13,3 & 0,271 & 0,0080 & 41 & 0,0023 & 10 & 35,6 & 0,276 & 0,0174 & 40 & 0,0049 & & \\
\hline & & & & & & & & & & & & & & & & & & & & & & & & & & & & & & \\
\hline
\end{tabular}


Anexo F. Leitura média do TDR, (TTDR), Desvio padrão (Dp), número de observações (n), intervalo de confiança a 95\% de probabilidade para a média $(\mathrm{IC} 95 \%)$, número de pontos concordantes $(\mathrm{nC})$ e sua percentagem $(\% \mathrm{C})$ por camada para todos os dados observados.

\begin{tabular}{|c|c|c|c|c|c|c|c|c|c|c|c|c|c|c|c|c|c|c|c|c|c|c|c|c|c|c|c|c|c|c|}
\hline \multirow{2}{*}{ Bat. } & \multicolumn{6}{|c|}{ Camada A } & \multicolumn{6}{|c|}{ Camada B } & \multicolumn{6}{|c|}{ Camada C } & \multicolumn{6}{|c|}{ Camada D } & \multicolumn{6}{|c|}{ Camada E } \\
\hline & $T_{T D R}$ & Dp & $n$ & $C_{95 \%}$ & $\mathrm{nC}$ & $\% C$ & $\mathrm{~T}_{\mathrm{TDR}}$ & Dp & $n$ & ICagers & $\mathrm{nC}$ & $\% \mathrm{C}$ & TTRR & $\mathrm{Dp}$ & $n$ & ICos & $\mathrm{nC}$ & C & TTRB & Dp & $n$ & 10 & $\mathrm{nC}$ & $c$ & $\mathrm{~T}_{\mathrm{T} D R}$ & $\mathrm{Dp}$ & $\mathrm{n}$ & $\mathrm{I}_{95 \%}$ & $\mathrm{nC}$ & \\
\hline 1 & 2,997 & 0,4736 & 47 & 0,1354 & 30 & 66,7 & 3,478 & 0,4896 & 45 & 0,1431 & 38 & 84,4 & 2,380 & 0,4749 & 46 & 0,1372 & 10 & 22,2 & 3,380 & 0,1911 & 45 & 0,0558 & 20 & $\begin{array}{l}44,4 \\
\end{array}$ & 3,219 & 0,1090 & 47 & 0,0312 & 11 & 24,4 \\
\hline 2 & 3,155 & 375 & 46 & 0,0975 & 16 & 35,6 & 565 & 0,3713 & 47 & 0,1061 & 39 & 86,7 & 877 & 0,1291 & 46 & 0,0373 & 13 & 28,9 & 3,624 & 0,1804 & 47 & 0,0516 & 19 & 42,2 & 3,496 & 0,1432 & 47 & 0,0409 & 9 & 20,0 \\
\hline 3 & 3,255 & 398 & 46 & 0,1271 & 14 & 31,1 & 65 & 177 & 46 & 0,0918 & 35 & 778 & 69 & 0,2388 & 46 & 0690 & 26 & 578 & 460 & 0,1665 & 46 & 0,0481 & 24 & 533 & 3,417 & 0,1562 & 47 & 0,0447 & 14 & 11. \\
\hline 4 & 3,450 & 712 & 29 & 1351 & 4 & 8,9 & 14 & 2763 & 47 & 0,0790 & 35 & 77,8 & 20 & 0,2276 & 46 & 065 & 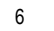 & 13,3 & 558 &, 2129 & 46 & 0615 & 26 & & 77 & 0,1582 & 43 & 0,0473 & & \\
\hline 5 & 3,108 & 808 & 47 & 1089 & 22 & 48,9 & 18 & 058 & 26 & 1175 & 10 & 22,2 & 335 & 0,2390 & 24 & 0956 & 27 & 60,0 & 634 & 0,2295 & 46 & 0,0663 & 19 & 42, & 3,497 & 0,2112 & 47 & 0,0604 & 10 & \\
\hline 6 & 2,858 & 0,3196 & 47 & 0,0914 & 25 & 55,6 & 76 & 966 & 47 & 0,0848 & 33 & 73,3 & 24 & 3060 & 46 & 0884 & 29 & 64 & 572 & 0,1468 & 46 & 0,0424 & 22 & 48 & 3,281 & 0,1566 & 45 & 0,0458 & 16 & 35 \\
\hline 7 & 2,712 & 3264 & 26 & 1255 & 19 & 42,2 & 21 & 940 & 47 & 0,1126 & 24 & 53,3 & 37 & 0,2229 & 46 & 0644 & 27 & 60,0 & 373 & 0,2546 & 44 & 0,0752 & 21 & 46,7 & 3,381 & 0,0854 & 27 & 0,0322 & 13 & \\
\hline 8 & 2,681 & 2243 & 45 & 0655 & 12 & 7 & 28 & 0,4069 & 47 & 0,1163 & 39 & 86,7 & 357 & 0,2185 & 46 & 0631 & 22 & 48,9 & 644 & 0,1448 & 46 & 0,0419 & 17 & 37, & 3,227 & 0,1372 & 47 & 0,0392 & 13 & \\
\hline 9 & 2,784 & 712 & 47 & 775 & 18 & & & 121 & 47 & 081 & 31 & & & 2297 & 46 & 0664 & 11 & & 567 & ,2011 & 47 & 75 & 26 & & & & 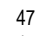 & & & \\
\hline 10 & 2,724 & 438 & 47 & 697 & 14 & & & 999 & 47 & 143 & 26 & & & 3174 & 46 & 17 & 30 & & 93 & 0,2289 & 47 & 0,0654 & 22 & 48, & 75 & 0,1008 & 47 & 0,0288 & 10 & 22 \\
\hline 11 & 2,978 & 3059 & 46 & 0,0884 & 27 & 60,0 & 18 & 0,3014 & 47 & 0,0862 & 28 & 62,2 & 10 & 0,2388 & 46 & 0690 & 7 & 5,6 & 60 & 0,1253 & 35 & 0,0415 & 23 & 51 & 31 & 0,1585 & 47 & 0,0453 & 12 & \\
\hline 12 & 2,714 & 0,2107 & 47 & 0,0602 & 13 & 28,9 & 28 & 0,3197 & 47 & 0,0914 & 36 & 80,0 & 41 & 0,2247 & 47 & 0,0642 & 27 & 60,0 & 598 & 0,1550 & 47 & 0,0443 & 20 & 44 & 3,145 & 0,1711 & 47 & 0,0489 & 14 & \\
\hline 14 & 2,817 & 331 & 47 & 366 & 22 & & & 100 & 45 & 1165 & 21 & & & 017 & 44 & 91 & 14 & & & 16 & 46 & 98 & 24 & 53 & & 748 & 47 & 1500 & 8 & \\
\hline 15 & 3,016 & 0,2991 & 47 & 0,0855 & 27 & 60,0 & & 981 & 47 & 138 & 38 & 84,4 & & 0,3551 & 46 & 026 & 30 & & 71 & 0,2453 & 47 & 701 & 18 & 40 & 128 & 0,1649 & 47 & 0,0471 & 14 & \\
\hline 16 & 3,116 & 0,2863 & 47 & 0818 & 17 & 37,8 & & 836 & 46 & 0,0819 & 18 & 40,0 & 97 & 0,2640 & 47 & 0755 & 31 & 68,9 & 182 & 0,1094 & 46 & 0,0316 & 21 & 46 , & 3,385 & 0,3580 & 47 & 0,1023 & 21 & \\
\hline 17 & 3,072 & 0,1917 & 47 & 548 & 17 & & & 678 & 47 & 623 & & & & 0 & 47 & 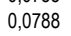 & 17 & & & 0,3282 & 47 & 38 & . & & & & 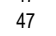 & 0,0411 & & \\
\hline 18 & & & 47 & & 23 & & & & 47 & & & & & & 47 & & & & & & & & & & & & 6 & & & \\
\hline 19 & 2,527 & 584 & 47 & 0,0453 & ? & 4, & & 3090 & 47 & 883 & 18 & 40 & & 0,2428 & 47 & 0694 & 3 & 6,7 & & 0,1374 & 46 & 0,0397 & 9 & 20 & & 0,1212 & 46 & 0,0350 & r & 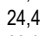 \\
\hline 20 & 2,949 & 2304 & 47 & 0,0659 & 23 & 51,1 & & 0,4589 & 47 & 0,1312 & 40 & 88,9 & 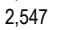 & 0,2629 & 47 & 0752 & 18 & 40,0 & 0 & 0,2208 & 47 & 0,0631 & 24 & 53 & 1 & 0,1579 & 47 & 0,0452 & 13 & \\
\hline 21 & 2,946 & 0,2884 & 47 & 0,0825 & 25 & 55 & & 0,3200 & 47 & , & 37 & & & 0,2036 & 47 & 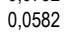 & 25 & & & 0,1346 & 25 & 0,0528 & 14 & & & & 7 & 0,0281 & & \\
\hline 22 & & & 47 & & 2 & & & & 46 & & & & & & & & & & & & & & & & & & & & & \\
\hline 23 & 2,959 & 065 & 47 & 0876 & 26 & & & 297 & 42 & 997 & 32 & & & 0,2484 & 41 & 00 & 22 & & & 20 & 41 & 30 & 25 & & & & 47 & 0352 & & \\
\hline 24 & 3,112 & 162 & 47 & 0,0904 & 18 & 4 & & 158 & 47 & 0,0903 & 14 & & & 0,2367 & 47 & 7 & 26 & 57, & - & 0,2262 & 47 & 0647 & 1 & 2 & 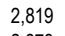 & 0,1523 & 47 & 0,0435 & 2 & \\
\hline 25 & 3,073 & 326 & 47 & 0,0951 & 24 & & & & 47 & 952 & 35 & & & 0,27 & 47 & & 30 & & & 0,22 & 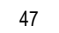 & & 21 & & & & 47 & & & 8,9 \\
\hline 29 & 3, & 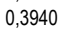 & 47 & & 23 & & & & 28 & & 39 & & & 0,6 & 47 & & 20 & & & 0,16 & 4 & 9 & 18 & & & 71 & 38 & 0,0404 & & \\
\hline 31 & & 15 & 47 & & 8 & & & & 46 & & 40 & & & 0, & 47 & & 2 & & & 0,2 & 4 & 6 & 26 & & & & 47 & & & \\
\hline 32 & & 0 & 47 & & 18 & & & & 47 & & & & & & & & & & & & & & & & & & & 356 & & \\
\hline 33 & & & 47 & & 2 & & & & 4 & & & & & & & & & & & & & & & & & & & (1) & & \\
\hline 34 & 2,7 & 0,2924 & 47 & & 19 & & & & 47 & & 3 & & & 0, & $4 C$ & & 36 & & & 0,2 & 4 & & 13 & & & & $4 T$ & 437 & & \\
\hline 35 & & - & 47 & & 11 & & & & 47 & & 29 & & & & 47 & & 32 & & & & 4 & & 19 & & & & 42 & 03 & & \\
\hline 36 & & & 47 & & 24 & & & & 47 & & & & & & 47 & & & & & & & & & & & & 7 & & & \\
\hline 37 & & & 47 & & . & & & & 47 & & & & & & & & & & & & & & & & & & & 376 & & t,4 \\
\hline 0 & & & 47 & & 5 & & & & 4 & & & & & & & & & & & & & & & & & & & & & \\
\hline 39 & & & 25 & & 27 & & & & 4 & & & & & & & & & & & & 4 & & & & & & 47 & & 0 & \\
\hline 40 & & & 47 & & 21 & & & & 47 & & & & & & 47 & & 3 & & & & 4 & & 14 & & & & 47 & 93 & 8 & \\
\hline 41 & 2, & 0,2920 & 46 & 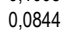 & 25 & & & & 46 & & & & & & 46 & & & & & 0,1 & 4 & & & & & & 46 & 3315 & & \\
\hline 42 & & & 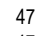 & & 16 & & & & 47 & & & & & & & & & & & & & & & & & & & 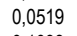 & & \\
\hline 43 & & & $4 t$ & & 5 & & & & 4 & & 4 & & & & & & & & & & & & iv & & & & & & & \\
\hline 44 & & & 25 & & 15 & & & & 25 & & & & & & & & & & & & 4 & & 3 & & & & 47 & & 14 & \\
\hline 45 & 2,8 & 0,31 & 47 & ? & 24 & & & 0,4 & 47 & . & 35 & 1 & & 0,2 & 47 & & 27 & & & 0,2 & 47 & 1 & 28 & & & 6 & 47 & & 4 & \\
\hline 70 & & 0,2815 & 47 & & 26 & & & & 46 & & & & & & & & & & & & & & & & & & & 78 & 12 &, 7 \\
\hline 47 & & & 47 & & 24 & & & & & & & & & & & & & & & & & & & & & & & & & \\
\hline 48 & 2,636 &,, 3476 & 48 & 0,0983 & 12 & $\angle 0, t$ & 0,000 & $0,354 I$ & 41 & 0,1014 & 36 & 00,0 & & 0,3018 & & $8 / 2$ & & & & , & 47 & & & is & (10 & 1581 & 48 & 0447 & 15 & \\
\hline Elat & 41 & $29 / 4$ & & 819 & $8 / 4$ & 2,4 & & 100 & J03 & 19 & & & 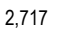 & 98 & 100 & & & & 472 & , & 2014 & & & & & & & & & \\
\hline
\end{tabular}


Anexo G. Valores dos coeficientes linear (a), angular (b) e de determinação $\left(R^{2}\right)$, o desvio padrão da regressão (DPR), a estatística $F$ e sua respectiva probabilidade, para os ajustes do modelo linear nos dois períodos de observação e todos juntos para os dados agrupados por camada e com todas as camadas em conjunto.

\begin{tabular}{|c|c|c|c|c|c|c|c|c|c|c|c|c|c|c|c|c|c|c|}
\hline \multirow{2}{*}{ Camada } & \multicolumn{6}{|c|}{2000} & \multicolumn{6}{|c|}{2001} & \multicolumn{6}{|c|}{$2000+2001$} \\
\hline & a & b & $\mathrm{R}^{2}$ & DPR & $\mathrm{F}$ & Prob. & a & b & $\mathrm{R}^{2}$ & DPR & $\mathrm{F}$ & Prob. & a & b & $\mathrm{R}^{2}$ & DPR & $\mathrm{F}$ & Prob. \\
\hline A & 0,092 & 0,059 & 0,247 & 0,039 & 376,5 & $<0,0001$ & 0,150 & 0,043 & 0,054 & 0,044 & 52,1 & $<0,0001$ & 0,137 & 0,046 & 0,135 & 0,042 & 322,4 & $<0,0001$ \\
\hline B & 0,061 & 0,052 & 0,252 & 0,029 & 384,1 & $<0,0001$ & 0,147 & 0,034 & 0,066 & 0,033 & 65,1 & $<0,0001$ & 0,159 & 0,028 & 0,099 & 0,032 & 227,0 & $<0,0001$ \\
\hline c & 0,101 & 0,054 & 0,354 & 0,021 & 618,9 & $<0,0001$ & 0,189 & 0,025 & 0,074 & 0,025 & 76,9 & $<0,0001$ & 0,164 & 0,033 & 0,171 & 0,024 & 432,0 & $<0,0001$ \\
\hline D & 0,100 & 0,047 & 0,293 & 0,016 & 469,1 & $<0,0001$ & 0,202 & 0,019 & 0,069 & 0,017 & 69,5 & $<0,0001$ & 0,158 & 0,031 & 0,163 & 0,017 & 403,3 & $<0,0001$ \\
\hline $\mathrm{E}$ & 0,196 & 0,025 & 0,118 & 0,016 & 153,1 & $<0,0001$ & 0,229 & 0,015 & 0,040 & 0,021 & 40,4 & $<0,0001$ & 0,212 & 0,020 & 0,072 & 0,018 & 165,3 & $<0,0001$ \\
\hline Média & 0,110 & 0,047 & 0,253 & 0,024 & 400,3 & & 0,183 & 0,027 & 0,061 & 0,028 & 60,8 & & 0,166 & 0,032 & 0,128 & 0,027 & 310,0 & \\
\hline Todas & 0,192 & 0,023 & 0,108 & 0,029 & 688,8 & $<0,0001$ & 0,212 & 0,018 & 0,060 & 0,031 & 301,7 & $<0,0001$ & 0,205 & 0,019 & 0,080 & 0,030 & 910,3 & $<0,0001$ \\
\hline
\end{tabular}


Anexo H. Coeficientes linear (a), angular (b) e de determinação $\left(R^{2}\right)$, o desvio padrão da regressão (DPR), a estatística $F$ e sua respectiva probabilidade, para os ajustes do modelo linear nos dois períodos de observação e todos juntos para os dados agrupados por haste com todas as camadas em conjunto.

\begin{tabular}{|c|c|c|c|c|c|c|c|c|c|c|c|c|c|c|c|c|c|c|}
\hline \multirow[t]{2}{*}{ Bateria } & \multicolumn{6}{|c|}{2000} & \multicolumn{6}{|c|}{2001} & \multicolumn{6}{|c|}{$2000+2001$} \\
\hline & a & b & $\mathrm{R}^{2}$ & DPR & $\mathrm{F}$ & Prob. & a & b & $\mathrm{R}^{2}$ & DPR & $\mathrm{F}$ & Prob. & a & b & $R^{2}$ & DPR & $\mathrm{F}$ & Prob. \\
\hline 1 & 0,189 & 0,0278 & 0,2096 & 0,0225 & 31,81 & $<0,0001$ & 0,230 & 0,0152 & 0,0959 & 0,0242 & 11,24 & 0,0011 & 0,218 & 0,0196 & 0,1728 & 0,0234 & 47,64 & $<0,0001$ \\
\hline 2 & 0,145 & 0,0399 & 0,2998 & 0,0215 & 52,23 & $<0,0001$ & 0,227 & 0,0133 & 0,0587 & 0,0216 & 6,67 & 0,0112 & 0,187 & 0,0265 & 0,1700 & 0,0223 & 47,33 & $<0,0001$ \\
\hline 3 & 0,166 & 0,0301 & 0,1590 & 0,0265 & 22,68 & $<0,0001$ & 0,186 & 0,0217 & 0,1442 & 0,0209 & 18,02 & $<0,0001$ & 0,166 & 0,0291 & 0,1980 & 0,0242 & 56,54 & $<0,0001$ \\
\hline 4 & 0,085 & $\begin{array}{l}0,0519 \\
\end{array}$ & 0,4046 & 0,0206 & 82,23 & $<0,0001$ & 0,206 & 0,0152 & 0,0422 & 0,0252 & 3,78 & 0,0550 & 0,138 & 0,0360 & 0,2107 & 0,0234 & 55,79 & $<0,0001$ \\
\hline 5 & 0,176 & 0,0279 & 0,2799 & 0,0203 & 46,65 & $<0,0001$ & 0,238 & 0,0130 & 0,0940 & 0,0169 & 6,84 & 0,0110 & 0,200 & 0,0222 & 0,1915 & 0,0201 & 44,52 & $<0,0001$ \\
\hline 6 & 0,188 & 0,0255 & 0,1946 & 0,0232 & 29,00 & $<0,0001$ & 0,224 & 0,0167 & 0,0848 & 0,0267 & 9,92 & 0,0021 & 0,214 & 0,0187 & 0,1138 & 0,0252 & 29,40 & $<0,0001$ \\
\hline 7 & 0,237 & 0,0070 & 0,0211 & 0,0256 & 2,63 & 0,1077 & 0,254 & 0,000 & 0,000 & 0,029 & 0,003 & 0,955 & 0,239 & 0,0058 & 0,0126 & 0,0268 & 2,40 & 0,1226 \\
\hline 8 & 0,261 & 0,0002 & 0,0000 & 0,0245 & 0,00 & 0,9725 & 0,270 & $-0,003$ & 0,002 & 0,025 & 0,227 & 0,6348 & 0,265 & $-0,0010$ & 0,0003 & 0,0246 & 0,07 & 0,7869 \\
\hline 9 & 0,255 & 0,0019 & 0,0008 & 0,0300 & 0,10 & 0,7577 & 0,177 & 0,0239 & 0,0785 & 0,0317 & 9,20 & 0,0030 & 0,211 & 0,0139 & 0,0376 & 0,0312 & 9,05 & 0,0029 \\
\hline 10 & 0,202 & 0,0169 & 0,0568 & 0,0284 & 7,35 & 0,0077 & 0,168 & 0,0280 & 0,1297 & 0,0249 & 16,10 & 0,0001 & 0,188 & 0,0213 & 0,0983 & 0,0268 & 25,30 & $<0,0001$ \\
\hline 11 & $\begin{array}{l}0,194 \\
0\end{array}$ & 0,0235 & 0,1479 & 0,0209 & 21,17 & $<0,0001$ & 0,191 & 0,0255 & 0,1773 & 0,0176 & 20,48 & $<0,0001$ & 0,200 & 0,0223 & 0,1621 & 0,0195 & 42,35 & $<0,0001$ \\
\hline 12 & 0,214 & 0,0189 & 0,1314 & 0,0224 & 18,60 & $<0,0001$ & 0,253 & 0,0080 & 0,0100 & 0,0321 & 1,09 & 0,2997 & 0,232 & 0,0138 & 0,0456 & 0,0275 & 11,14 & 0,0010 \\
\hline 13 & 0,226 & 0,0129 & 0,0251 & 0,0314 & 3,11 & 0,0802 & 0,402 & $-0,0413$ & 0,1117 & 0,0403 & 12,45 & 0,0006 & 0,296 & $-0,0081$ & 0,0069 & 0,0369 & 1,54 & 0,2161 \\
\hline 14 & 0,250 & 0,0068 & 0,0104 & 0,0304 & 1,27 & 0,2614 & 0,251 & 0,0061 & 0,0085 & 0,0270 & 0,89 & 0,3481 & 0,250 & 0,0066 & 0,0109 & 0,0287 & 2,50 & 0,1156 \\
\hline 15 & 0,143 & 0,0341 & 0,2739 & 0,0264 & 46,03 & $<0,0001$ & 0,176 & 0,0251 & 0,1506 & 0,0288 & 19,14 & $<0,0001$ & 0,164 & 0,0285 & 0,2128 & 0,0276 & 62,72 & $<0,0001$ \\
\hline 16 & 0,135 & $\begin{array}{l}0,0365 \\
0\end{array}$ & $\begin{array}{l}0,1646 \\
0\end{array}$ & 0,0276 & 24,04 & $<0,0001$ & 0,151 & $\begin{array}{l}0,0324 \\
\end{array}$ & 0,3074 & 0,0218 & 47,50 & $<0,0001$ & 0,147 & 0,0333 & 0,2176 & $\begin{array}{l}0,0251 \\
\end{array}$ & 64,24 & $<0,0001$ \\
\hline 17 & 0,210 & 0,0193 & 0,1003 & 0,0245 & 13,72 & 0,0003 & 0,161 & 0,0362 & 0,2495 & 0,0236 & 35,90 & $<0,0001$ & 0,192 & 0,0251 & 0,1705 & 0,0242 & 47,89 & $<0,0001$ \\
\hline 18 & 0,217 & 0,0162 & 0,0745 & 0,0249 & 9,65 & 0,0024 & 0,197 & 0,0226 & 0,1554 & 0,0222 & 19,87 & $<0,0001$ & 0,208 & 0,0190 & 0,1147 & 0,0236 & 29,79 & $<0,0001$ \\
\hline 19 & 0,176 & 0,0255 & 0,1794 & 0,0262 & 26,45 & $<0,0001$ & 0,152 & 0,0326 & 0,4021 & 0,0183 & 72,64 & $<0,0001$ & 0,164 & 0,0290 & 0,2665 & 0,0228 & 83,92 & $<0,0001$ \\
\hline 20 & 0,163 & 0,0260 & 0,2378 & 0,0236 & 38,38 & $<0,0001$ & 0,154 & 0,0300 & 0,3071 & 0,0194 & 47,87 & $<0,0001$ & 0,163 & 0,0267 & 0,2616 & 0,0217 & 82,56 & $<0,0001$ \\
\hline 21 & 0,137 & 0,0340 & 0,1643 & 0,0288 & 24,18 & $<0,0001$ & 0,174 & 0,0181 & 0,0648 & 0,0199 & 5,96 & 0,0167 & 0,132 & 0,0345 & 0,1902 & 0,0260 & 49,56 & $<0,0001$ \\
\hline 22 & 0,117 & 0,0396 & 0,2200 & 0,0265 & 34,12 & $<0,0001$ & 0,130 & 0,0378 & 0,2086 & 0,0233 & 28,20 & $<0,0001$ & 0,131 & $\begin{array}{l}0,0362 \\
\end{array}$ & 0,2003 & 0,0252 & 57,59 & $<0,0001$ \\
\hline 23 & 0,144 & 0,0401 & 0,4038 & 0,0227 & 81,27 & $<0,0001$ & 0,205 & 0,0210 & 0,1115 & 0,0260 & 11,80 & 0,0009 & 0,169 & 0,0322 & 0,2625 & 0,0245 & 76,88 & $<0,0001$ \\
\hline 24 & 0,128 & 0,0484 & 0,4137 & 0,0211 & 86,80 & $<0,0001$ & 0,163 & 0,0387 & 0,1934 & 0,0247 & 25,89 & $<0,0001$ & 0,145 & 0,0436 & 0,2971 & 0,0230 & 98,47 & $<0,0001$ \\
\hline 25 & 0,175 & $\begin{array}{l}0,0291 \\
\end{array}$ & 0,2640 & 0,0212 & 44,13 & $<0,0001$ & 0,246 & 0,0087 & 0,0169 & 0,0241 & 1,85 & 0,1763 & 0,213 & 0,0184 & 0,0989 & 0,0233 & 25,57 & $<0,0001$ \\
\hline 26 & 0,155 & 0,0323 & 0,1879 & 0,0221 & 28,46 & $<0,0001$ & 0,231 & 0,0142 & 0,0327 & 0,0266 & 3,65 & 0,0587 & 0,222 & 0,0149 & 0,0449 & 0,0253 & 10,94 & 0,0011 \\
\hline 28 & 0,064 & 0,0530 & 0,3353 & 0,0306 & 61,02 & $<0,0001$ & 0,152 & 0,0307 & 0,2209 & 0,0317 & 30,62 & $<0,0001$ & 0,140 & 0,0321 & 0,2205 & 0,0323 & 65,36 & $<0,0001$ \\
\hline 29 & 0,142 & 0,0384 & 0,3763 & 0,0221 & 73,00 & $<0,0001$ & 0,132 & 0,0461 & 0,3321 & 0,0223 & 38,28 & $<0,0001$ & 0,156 & 0,0356 & 0,3114 & 0,0228 & 90,43 & $<0,0001$ \\
\hline 31 & 0,186 & 0,0272 & 0,2163 & 0,0284 & 33,39 & $<0,0001$ & 0,066 & 0,0629 & 0,7763 & 0,0170 & $\begin{array}{l}374,72\end{array}$ & $<0,0001$ & 0,127 & 0,0442 & 0,4583 & 0,0258 & 195,42 & $<0,0001$ \\
\hline $\begin{array}{l}32 \\
32\end{array}$ & 0,157 & 0,0357 & 0,2675 & 0,0260 & 44,92 & $<0,0001$ & 0,175 & 0,0300 & 0,2556 & 0,0228 & 37,09 & $<0,0001$ & 0,166 & 0,0330 & $\begin{array}{l}0,2785 \\
0\end{array}$ & 0,0245 & $\begin{array}{l}89,92 \\
\end{array}$ & $<0,0001$ \\
\hline 33 & 0,169 & 0,0237 & 0,1298 & 0,0268 & 18,35 & $<0,0001$ & 0,225 & 0,0084 & 0,0255 & 0,0226 & 2,82 & 0,0958 & 0,202 & 0,0146 & 0,0631 & 0,0253 & 15,70 & $<0,0001$ \\
\hline 34 & 0,174 & 0,0223 & 0,1442 & 0,0274 & 20,56 & $<0,0001$ & 0,238 & 0,0031 & 0,0035 & 0,0246 & 0,36 & 0,5502 & 0,204 & 0,0137 & 0,0624 & 0,0265 & 14,98 & 0,0001 \\
\hline 35 & 0,330 & $-0,0129$ & 0,0228 & 0,0379 & 2,87 & 0,0925 & 0,364 & $-0,0234$ & 0,0792 & 0,0357 & 8,86 & 0,0036 & 0,346 & $-0,0179$ & 0,0475 & 0,0368 & 11,36 & 0,0009 \\
\hline 36 & 0,313 & $-0,0078$ & 0,0110 & 0,0355 & 1,35 & 0,2471 & 0,375 & $-0,0248$ & 0,1230 & 0,0316 & 15,15 & 0,0002 & 0,347 & $-0,0169$ & 0,0553 & 0,0339 & 13,58 & 0,0003 \\
\hline 37 & 0,267 & 0,0090 & 0,0255 & 0,0221 & 3,21 & 0,0755 & 0,324 & $-0,0027$ & 0,0024 & 0,0210 & 0,21 & 0,6450 & 0,301 & 0,0010 & 0,0002 & 0,0237 & 0,05 & 0,8183 \\
\hline 38 & 0,281 & 0,0054 & 0,0142 & 0,0208 & 1,77 & 0,1858 & 0,363 & $\begin{array}{c}-0,0192 \\
\end{array}$ & 0,2497 & 0,0166 & 35,93 & $<0,0001$ & 0,326 & $-0,0079$ & 0,0343 & 0,0201 & 8,27 & 0,0044 \\
\hline 39 & 0,167 & 0,0231 & 0,1743 & 0,0261 & 25,97 & $<0,0001$ & 0,133 & 0,0373 & 0,3701 & 0,0197 & 50,54 & $<0,0001$ & 0,161 & 0,0265 & 0,2099 & 0,0244 & 56,05 & $<0,0001$ \\
\hline 40 & 0,179 & 0,0198 & 0,1330 & 0,0240 & 18,87 & $<0,0001$ & 0,169 & 0,024 & 0,222 & 0,018 & 30,492 & $<0,0001$ & 0,179 & 0,0202 & 0,1562 & 0,0217 & 42,96 & $<0,0001$ \\
\hline 41 & 0,215 & 0,0211 & 0,2939 & 0,0141 & 51,20 & $<0,0001$ & 0,277 & 0,0025 & 0,0061 & 0,0139 & 0,64 & 0,4273 & 0,246 & 0,0122 & 0,1187 & 0,0145 & 30,69 & $<0,0001$ \\
\hline 42 & 0,211 & 0,0226 & 0,5062 & 0,0106 & 126,10 & $<0,0001$ & 0,253 & 0,0124 & 0,0667 & 0,0162 & 7,14 & 0,0088 & 0,238 & 0,0158 & 0,2088 & 0,0141 & 59,39 & $<0,0001$ \\
\hline 43 & 0,123 & 0,0431 & 0,4019 & 0,0211 & 82,65 & $<0,0001$ & 0,259 & 0,0048 & 0,0166 & 0,0220 & 1,81 & 0,1817 & 0,220 & 0,0158 & 0,1059 & 0,0237 & 27,48 & $<0,0001$ \\
\hline 44 & 0,134 & 0,0401 & 0,3503 & 0,0220 & 66,31 & $<0,0001$ & 0,232 & 0,0129 & 0,0697 & 0,0204 & 4,80 & 0,0322 & 0,179 & 0,0279 & 0,2209 & 0,0223 & 53,59 & $<0,0001$ \\
\hline 45 & 0,180 & 0,0223 & 0,1975 & 0,0215 & 30,26 & $<0,0001$ & 0,168 & 0,029 & 0,332 & 0,020 & 53,617 & $<0,0001$ & 0,186 & 0.0217 & 0,2160 & 0,0215 & 64,20 & $<0,0001$ \\
\hline 46 & 0,168 & $\begin{array}{l}0,0226 \\
\end{array}$ & 0,2281 & 0,0183 & 36,05 & $<0,0001$ & 0,200 & 0,0162 & 0,1099 & 0,0198 & $\begin{array}{l}13,09 \\
\end{array}$ & 0,0005 & 0,200 & 0,0144 & 0,1059 & 0,0199 & 27,25 & $<0,0001$ \\
\hline 47 & 0,124 & 0,0442 & 0,4654 & 0,0165 & 107,08 & $<0,0001$ & 0,209 & 0,0224 & 0,1013 & 0,0253 & 10,03 & 0,0021 & 0,189 & 0,0261 & 0,1652 & 0,0226 & 42,36 & $<0,0001$ \\
\hline 48 & 0,162 & 0,0320 & 0,3708 & 0,0189 & 72,49 & $<0,0001$ & 0,216 & 0,0222 & 0,1648 & 0,0240 & 21,50 & $<0,0001$ & 0,213 & $\begin{array}{l}0,0197 \\
\end{array}$ & 0,1384 & 0,0241 & 37,59 & $<0,0001$ \\
\hline Média & 0,183 & 0,0252 & 0,2019 & 0,0242 & 35,95 & & 0,216 & 0,0164 & 0,1471 & 0,0237 & 25,54 & & 0,204 & 0,0196 & 0,1510 & 0,0246 & 43,75 & \\
\hline
\end{tabular}


Anexo I. Coeficientes linear (a), angular (b) e de determinação (R2), o desvio padrão da regressão (DPR), a estatística $F$ e sua respectiva probabilidade, para os ajustes do modelo linear nos dois períodos de observação e todos juntos aos dados da camada A.

\begin{tabular}{|c|c|c|c|c|c|c|c|c|c|c|c|c|c|c|c|c|c|c|}
\hline \multirow[t]{2}{*}{ Bateria } & \multicolumn{6}{|c|}{2000} & \multicolumn{6}{|c|}{2001} & \multicolumn{6}{|c|}{$2000+2001$} \\
\hline & a & b & $\mathrm{R}^{2}$ & DPR & $\mathrm{F}$ & Prob. & $\mathrm{a}$ & b & $R^{2}$ & DPR & $\mathrm{F}$ & Prob. & $\mathrm{a}$ & b & $\mathrm{R}^{2}$ & DPR & $\mathrm{F}$ & Prob. \\
\hline 1 & 0,125 & 0,0570 & 0,7723 & 0,0118 & 78,02 & $<0,0001$ & 0,192 & 0,0418 & 0,1227 & 0,0184 & 2,80 & 0,1100 & 0,208 & 0,0337 & 0,4755 & 0,0170 & 40,80 & $<0,0001$ \\
\hline 2 & 0,128 & 0,0551 & 0,7465 & 0,0105 & 67,74 & $<0,0001$ & 0,177 & 0,0401 & 0,5066 & 0,0108 & 19,51 & 0,0003 & 0,154 & 0,0476 & 0,6961 & 0,0107 & 100,80 & $<0,0001$ \\
\hline 3 & $-0,109$ & 0,1130 & 0,7770 & 0,0206 & 80,13 & $<0,0001$ & 0,109 & 0,0525 & 0,3543 & 0,0229 & 10,42 & 0,0044 & 0,056 & 0,0680 & 0,5934 & 0,0251 & 64,23 & $<0,0001$ \\
\hline 4 & $-0,041$ & 0,0906 & 0,9161 & 0,0105 & 251,19 & $<0,0001$ & 0,144 & 0,0527 & 0,0905 & 0,0265 & 0,20 & 0,6991 & 0,039 & 0,0700 & 0,5261 & 0,0251 & 29,97 & $<0,0001$ \\
\hline 5 & 0,015 & 0,0810 & 0,8930 & 0,0108 & $\begin{array}{l}191,99 \\
\end{array}$ & $<0,0001$ & 0,098 & 0,0635 & 0,3118 & 0,0168 & 9,06 & 0,0069 & 0,120 & 0,0523 & 0,5394 & 0,0186 & 52,70 & $<0,0001$ \\
\hline 6 & 0,018 & 0,0887 & 0,8633 & 0,0120 & 145,22 & $<0,0001$ & 0,130 & 0,0577 & 0,1427 & 0,0214 & 3,33 & 0,0831 & 0,117 & 0,0589 & 0,4633 & 0,0205 & 38,84 & $<0,0001$ \\
\hline 7 & $-0,018$ & 0,1059 & 0,9117 & 0,0110 & 237,38 & $<0,0001$ & , IUU & 0,0011 & $0,1+12 T$ & 0,0217 & - & & 0,042 & 0,0860 & 0,3975 & 0,0353 & 15,84 & 0,0006 \\
\hline 8 & 0,034 & 0,0900 & 0,5847 & 0,0212 & 32,38 & $<0,0001$ & 0,235 & 0,020 & 0,005 & 0,033 & 0,095 & 0,761 & 0,093 & 0,0708 & 0,2481 & 0,0280 & $\begin{array}{l}14,04 \\
14,19\end{array}$ & 0,0005 \\
\hline 9 & $-0,115$ & 0,1315 & 0,7296 & 0,0218 & 62,05 & $<0,0001$ & 0,116 & 0,047 & 0,080 & 0,025 & 1,729 & 0,2034 & $-0,044$ & 0,1078 & 0,5990 & 0,0242 & 67,22 & $<0,0001$ \\
\hline 10 & $-0,075$ & 0,1217 & 0,6439 & 0,0256 & 41,59 & $<0,0001$ & 0,009 & 0,0874 & 0,3147 & 0,0236 & 9,18 & 0,0066 & $-0,066$ & 0,1170 & 0,5773 & 0,0247 & 61,46 & $<0,0001$ \\
\hline 11 & $-0,034$ & 0,1043 & 0,9075 & 0,0120 & 225,73 & $<0,0001$ & $-0,065$ & 0,1219 & 0,4768 & 0,0198 & 17,32 & 0,0005 & 0,007 & 0,0934 & 0,7196 & 0,0180 & 112,89 & $<0,0001$ \\
\hline 12 & $\begin{array}{l}-0,064 \\
-0,04\end{array}$ & 0,1314 & 0,6249 & 0,0252 & 38,32 & $<0,0001$ & 0,213 & 0,0366 & 0,0135 & 0,0501 & 0,27 & 0,6067 & $-0,015$ & 0,1160 & 0,2779 & 0,0398 & 17,32 & 0,0001 \\
\hline 13 & 0,038 & 0,0826 & 0,8738 & 0,0102 & 159,22 & $<0,0001$ & 0,358 & $-0,0021$ & 0,0000 & 0,0525 & 0,00 & 0,9815 & 0,311 & 0,0044 & 0,0013 & 0,0433 & 0,05 & 0,8273 \\
\hline 14 & 0,046 & 0,0923 & 0,9557 & 0,0053 & 495,60 & $<0,0001$ & 0,212 & 0,0326 & 0,0891 & 0,0198 & 1,96 & 0,1771 & 0,097 & 0,0744 & 0,5745 & 0,0151 & 60,75 & $<0,0001$ \\
\hline 15 & $-0,100$ & 0,1106 & 0,7399 & 0,0206 & 65,42 & $<0,0001$ & $-0,138$ & 0,1327 & 0,6359 & 0,0214 & 34,92 & $<0,0001$ & $-0,043$ & 0,0956 & 0,5960 & 0,0238 & 66,39 & $<0,0001$ \\
\hline 16 & $-0,184$ & 0,1290 & 0,9633 & 0,0066 & 604,02 & $<0,0001$ & $-0,351$ & 0,2050 & 0,7058 & 0,0152 & 47,97 & $<0,0001$ & 0,038 & 0,0658 & 0.3799 & 0,0243 & 27,57 & $<0,0001$ \\
\hline 17 & $-0,106$ & 0,1222 & 0,8083 & 0,0135 & 96,98 & $<0,0001$ & $\begin{array}{l}-0,276 \\
-0,\end{array}$ & $\begin{array}{l}0,1679 \\
0\end{array}$ & 0,7379 & 0,0126 & 56,31 & $<0,0001$ & $-0,073$ & 0,1072 & 0,5489 & 0,0188 & 54,75 & $<0,0001$ \\
\hline 18 & $-0,112$ & 0,1231 & 0,8422 & 0,0136 & 122,76 & $<0,0001$ & 0,193 & 0,0217 & 0,0136 & 0,0235 & 0,27 & 0,6059 & 0,046 & 0,0733 & 0,4409 & 0,0222 & 35,49 & $<0,0001$ \\
\hline 19 & $-0,289$ & 0,2105 & 0,9182 & 0,0103 & 258,33 & $<0,0001$ & 0,027 & 0,0839 & 0,3213 & 0,0184 & 9,47 & 0,0059 & $\begin{array}{l}-0,158 \\
-0,10\end{array}$ & 0,1587 & 0,6831 & 0,0173 & 97,02 & $<0,0001$ \\
\hline 20 & $-0,107$ & 0,1147 & 0,8083 & 0,0145 & 96,98 & $<0,0001$ & 0,079 & 0,0553 & 0,0786 & 0,0262 & 1,71 & 0,2063 & $-0,018$ & 0,0872 & 0,4592 & 0,0220 & 38,21 & $<0,0001$ \\
\hline 21 & $-0,273$ & 0,1616 & 0,7509 & 0,0228 & 69,32 & $<0,0001$ & 0,266 & $\begin{array}{l}-0,0175 \\
\end{array}$ & 0,0081 & 0,0254 & 0,16 & 0,6904 & $-0,002$ & 0,0780 & 0,3633 & 0,0301 & 25,68 & $<0,0001$ \\
\hline 22 & $\begin{array}{l}-0,270 \\
-0,252\end{array}$ & 0,1561 & 0,8308 & 0,0174 & $\begin{array}{l}0,0,02 \\
112,94\end{array}$ & $<0,0001$ & $\begin{array}{r}-0,080 \\
-0,085\end{array}$ & 0,1123 & 0,3281 & $\begin{array}{l}0,0222 \\
0,022\end{array}$ & $\begin{array}{l}0,710 \\
9,77\end{array}$ & $\begin{array}{l}0,0004 \\
0,0053\end{array}$ & $\begin{array}{l}-0,002 \\
-0,041\end{array}$ & 0,0918 & 0,4764 & 0,0257 & $\begin{array}{l}20,00 \\
40,94\end{array}$ & $<0,0001$ \\
\hline 23 & $-0,042$ & $\begin{array}{l}0,0980 \\
0\end{array}$ & $\begin{array}{l}0,8297 \\
0\end{array}$ & $\begin{array}{l}0,0148 \\
0\end{array}$ & $\begin{array}{l}112,04 \\
112,05\end{array}$ & $<0,0001$ & 0,145 & 0,0390 & 0,1002 & 0,0236 & $\begin{array}{l}2,11 \\
2,23\end{array}$ & 0,1513 & 0,049 & 0,0706 & 0,5057 & 0,0216 & 46,05 & $<0,0001$ \\
\hline 24 & $-0,054$ & 0,0978 & 0,8743 & 0,0108 & 160,02 & $<0,0001$ & 0,117 & 0,0565 & 0,1952 & 0,0277 & 4,85 & 0,0395 & 0,144 & 0,0416 & 0,1831 & 0,0281 & 10,09 & 0,0027 \\
\hline 25 & $-0,028$ & 0,0930 & 0,8980 & 0,0096 & 202,52 & $<0,0001$ & $-0,032$ & 0,1111 & 0,6000 & 0,0154 & 30,01 & $<0,0001$ & 0,139 & 0,0461 & 0,3269 & 0,0222 & 21,86 & $<0,0001$ \\
\hline 26 & 0,080 & 0,0551 & 0,2325 & 0,0264 & 6,97 & 0,0146 & 0,104 & 0,0581 & 0,1624 & 0,0225 & 3,88 & 0,0629 & 0,217 & 0,0181 & 0,0565 & 0,0264 & 2,69 & 0,1077 \\
\hline 28 & $-0,167$ & 0,1292 & 0,8515 & 0,0153 & 131,89 & $<0,0001$ & 0,053 & 0,0643 & 0,1972 & 0,0199 & 4,91 & 0,0384 & 0,043 & 0,0638 & 0,4351 & 0,0244 & 34,66 & $<0,0001$ \\
\hline 29 & $-0,043$ & 0,0940 & 0,8389 & 0,0172 & 119,73 & $<0,0001$ & $\begin{array}{l}-0,090 \\
-\end{array}$ & 0,1215 & 0,4584 & 0,0214 & 16,93 & 0,0005 & 0,041 & 0,0718 & 0,6034 & 0,0232 & 68,48 & $<0,0001$ \\
\hline 31 & $-0,265$ & 0,1952 & 0,7797 & 0,0255 & 81,39 & $<0,0001$ & $-0,650$ & 0,3433 & 0,5876 & 0,0247 & 28,50 & $<0,0001$ & $-0,308$ & 0,2109 & 0,7115 & 0,0259 & 110,96 & $<0,0001$ \\
\hline 32 & $-0,305$ & 0,1961 & 0,7897 & 0,0226 & 86,35 & $<0,0001$ & 0,159 & 0,0299 & 0,0435 & 0,0269 & 0,91 & 0,3519 & $-0,072$ & 0,1167 & 0,4837 & 0,0297 & 42,15 & $<0,0001$ \\
\hline 33 & $-0,125$ & 0,1228 & 0,9290 & 0,0112 & 300,87 & $<0,0001$ & 0,081 & 0,0645 & 0,2246 & $\begin{array}{l}0,0195 \\
0,010\end{array}$ & 5,79 & 0,0259 & 0,050 & 0,0702 & $\begin{array}{l}0,4750 \\
0,470\end{array}$ & 0,0242 & 40,71 & $<0,0001$ \\
\hline 34 & $-0,086$ & 0,1196 & 0,9016 & 0,0132 & 210,81 & $<0,0001$ & $\begin{array}{l}-0,037 \\
-\end{array}$ & 0,1102 & 0,4360 & 0,0200 & 15,46 & 0,0008 & $-0,016$ & 0,0984 & 0,6856 & 0,0197 & 98,13 & $<0,0001$ \\
\hline 35 & 0,029 & 0,1125 & 0,8642 & 0,0127 & 146,39 & $<0,0001$ & 0,045 & 0,1157 & 0,3416 & 0,0226 & 10,38 & 0,0043 & 0,098 & 0,0918 & 0,5345 & 0,0210 & 51,67 & $<0,0001$ \\
\hline 36 & 0,041 & 0,0993 & 0,8820 & 0,0124 & 171,95 & $<0,0001$ & 0,150 & 0,0749 & 0,3043 & 0,0206 & 8,75 & 0,0078 & 0,171 & 0,0611 & 0,3894 & 0,0243 & 28,70 & $<0,0001$ \\
\hline 37 & 0,042 & 0,0925 & 0,5355 & 0,0202 & 26,51 & $<0,0001$ & 0,177 & 0,0578 & 0,1433 & 0,0148 & 3,35 & 0,0823 & 0,117 & 0,0725 & 0,2348 & 0,0241 & 13,81 & 0,0006 \\
\hline $\begin{array}{l}11 \\
38\end{array}$ & $\begin{array}{l}0,087 \\
0,087\end{array}$ & 0,0868 & 0,8418 & 0,0107 & 122,35 & $<0,0001$ & 0,296 & 0,0154 & 0,0247 & $\begin{array}{l}0,0169 \\
0,0\end{array}$ & 0,51 & 0,4850 & 0,222 & 0,0405 & $\begin{array}{l}0,2155 \\
0\end{array}$ & 0,0208 & 12,36 & 0,0010 \\
\hline 39 & $-0,056$ & 0,1031 & 0,9312 & 0,0088 & 311,18 & $<0,0001$ & & - & & & (1, & & $-0,056$ & 0,1031 & 0,9312 & 0,0088 & 311,18 & $<0,0001$ \\
\hline 40 & 0,096 & 0,0463 & 0,3474 & 0,0238 & 12,24 & 0,0019 & 0,132 & 0,0366 & 0,0992 & 0,0205 & 2,20 & 0,1533 & 0,125 & 0,0382 & 0,2735 & 0,0221 & 16,94 & 0,0002 \\
\hline 41 & 0,042 & 0,0811 & 0,9283 & 0,0069 & 297,59 & $<0,0001$ & 0,172 & 0,0424 & 0,2411 & 0,0164 & 6,04 & 0,0238 & 0,130 & 0,0544 & 0,5192 & 0,0155 & 47,52 & $<0,0001$ \\
\hline 42 & 0,134 & 0,0465 & 0,8757 & 0,0080 & 161,97 & $<0,0001$ & 0,083 & 0,074 & 0,467 & 0,017 & 17,549 & 0,000 & 0,203 & 0,0293 & 0,3318 & 0,0186 & 22,34 & $<0,0001$ \\
\hline 43 & $-0,064$ & 0,0954 & 0,7473 & 0,0142 & 68,02 & $<0,0001$ & $-0,043$ & 0,099 & 0,404 & 0,018 & 13,570 & 0,0015 & 0,068 & 0,0600 & 0,3333 & 0,0212 & 22,49 & $<0,0001$ \\
\hline 44 & $-0,128$ & 0,1269 & 0,9207 & 0,0086 & 266,86 & $<0,0001$ & - &, 000 & , TUT & 0,0 & 70,010 & our & $-0,128$ & 0,1269 & 0,9207 & 0,0086 & 266,86 & $<0,0001$ \\
\hline 45 & $-0,041$ & 0,0884 & 0,8586 & 0,0096 & 139,71 & $<0,0001$ & 0,215 & 0,0046 & 0,0008 & 0,0194 & 0,02 & 0,9012 & 0,118 & 0,0391 & 0,3112 & 0,0188 & 20,33 & $<0,0001$ \\
\hline 46 & 0,043 & 0,0569 & 0,6896 & 0,0095 & 51.10 & $<0,0001$ & 0,082 & 0,0499 & 0,3265 & 0,0127 & 9,70 & 0,0055 & 0,126 & 0,0321 & 0,3252 & 0,0132 & 21,69 & $<0,0001$ \\
\hline 47 & $\begin{array}{l}0,037 \\
-0,047\end{array}$ & 0,0965 & 0,6483 & 0,0195 & 42,40 & $<0,0001$ & $\begin{array}{l}-0,043 \\
-\end{array}$ & 0,1146 & 0,5110 & 0,0266 & 20,90 & 0,0002 & 0,087 & 0,0606 & 0,2907 & 0,0294 & 18,44 & $<0,0001$ \\
\hline 48 & $-0,084$ & 0,1173 & 0,5637 & 0,0231 & 29,72 & $<0,0001$ & 0,160 & 0,0423 & 0,2064 & 0,0242 & 5,46 & 0,0294 & 0,184 & 0,0273 & 0,0944 & 0,0297 & 4,79 & 0,0337 \\
\hline Média & $-0,052$ & 0.1070 & 0,7918 & 0,0148 & 147,69 & 0,0083 & 0,068 & 0,0730 & 0,2654 & 0,0223 & 10,43 & 0,1749 & 0,057 & 0.0740 & 0,4524 & 0,0228 & 52,13 & 0,0212 \\
\hline
\end{tabular}


Anexo J. Coeficientes linear (a), angular (b) e de determinação (R2), o desvio padrão da regressão (DPR), a estatística $F$ e sua respectiva probabilidade, para os ajustes do modelo linear nos dois períodos de observação e todos juntos aos dados da camada B.

\begin{tabular}{|c|c|c|c|c|c|c|c|c|c|c|c|c|c|c|c|c|c|c|}
\hline \multirow[t]{2}{*}{ Bateria } & \multicolumn{6}{|c|}{2000} & \multicolumn{6}{|c|}{2001} & \multicolumn{6}{|c|}{$2000+2001$} \\
\hline & a & b & R2 & DPR & $\mathrm{F}$ & Prob. & $\mathrm{a}$ & b & R2 & DPR & $\mathrm{F}$ & Prob. & a & b & R2 & DPR & $\mathrm{F}$ & Prob. \\
\hline 1 & $-0,003$ & 0,0715 & 0,6845 & 0,0122 & 45,57 & $<0,0001$ & $-0,039$ & 0,1018 & 0,2543 & 0,0187 & 6,82 & 0,0167 & 0,203 & 0,0201 & 0,2095 & 0,0193 & 11,40 & 0,0016 \\
\hline 2 & 0,024 & 0,0688 & 0,8566 & 0,0102 & 137,34 & $<0,0001$ & 0,165 & 0,0285 & 0,3152 & 0,0148 & 9,21 & 0,0065 & 0,088 & 0,0514 & 0,6502 & 0,0142 & 83,66 & $<0,0001$ \\
\hline 3 & $\begin{array}{l}-0,016 \\
-0,04\end{array}$ & 0,0679 & 0,8166 & 0,0093 & 97,95 & $<0,0001$ & $\begin{array}{l}-0,055 \\
-\end{array}$ & 0,0847 & 0,4030 & 0,0171 & $\begin{array}{l},, 21 \\
13,50\end{array}$ & 0,0015 & 0,058 & 0,0500 & 0,5249 & 0,0153 & $\begin{array}{l}48,61 \\
48,0\end{array}$ & $<0,0001$ \\
\hline 4 & $\begin{array}{l}-0,048 \\
-0,0\end{array}$ & 0,0786 & 0,8972 & 0,0081 & 200,67 & $<0,0001$ & 0,061 & 0,0490 & 0,3598 & 0,0162 & 11,24 & 0,0032 & $\begin{array}{l}-0,005 \\
-\end{array}$ & 0,0670 & 0,6792 & 0,0129 & 95,29 & $<0,0001$ \\
\hline 5 & 0,083 & 0,0445 & 0,6797 & 0,0097 & 48,80 & $<0,0001$ & & - & - & - & - & 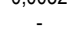 & 0,095 & 0,0420 & 0,5082 & 0,0129 & 24,80 & $<0,0001$ \\
\hline 6 & 0,065 & 0,0508 & 0,7686 & 0,0087 & 76,38 & $<0,0001$ & 0,194 & 0,0180 & 0,0578 & 0,0134 & 1,23 & 0,2809 & 0,138 & 0,0325 & 0,3768 & 0,0126 & 27,21 & $<0,0001$ \\
\hline 7 & $-0,208$ & 0,1106 & 0,7890 & 0,0142 & 85,99 & $<0,0001$ & 0,111 & 0,0365 & 0,3330 & 0,0163 & 9,98 & 0,0049 & 0,104 & 0,0360 & 0,3068 & 0,0215 & 19,91 & $<0,0001$ \\
\hline 8 & $-0,122$ & 0,0933 & 0,7281 & 0,0157 & $\begin{array}{l}01,60 \\
61,60\end{array}$ & $<0,0001$ & $\begin{array}{l}-0,057 \\
-\end{array}$ & 0,092 & 0,427 & 0,016 & $\begin{array}{l}14,878 \\
14.878\end{array}$ & 0,0010 & 0,139 & 0,0292 & 0,2143 & 0,0230 & 12,28 & 0,0010 \\
\hline 9 & $-0,249$ & 0,1229 & 0,8368 & 0,0143 & 117,97 & $<0,0001$ & $-0,054$ & 0,0808 & 0,3519 & 0,0181 & 10,86 & 0,0036 & 0,003 & 0,0616 & 0,4939 & 0,0216 & 43,92 & $<0,0001$ \\
\hline 10 & $-0,115$ & 0,0954 & 0 & 0,0192 & 51,40 & $<0,0001$ & $\begin{array}{l}-0,090 \\
-0,00\end{array}$ & 0,1027 & 0,6153 & 0,0159 & $\begin{array}{l}31,99 \\
31\end{array}$ & $<0,0001$ & 0,066 & 0,0492 & 0,4222 & 0,0233 & 32,88 & $<0,0001$ \\
\hline 11 & 0,137 & 0,0346 & 0,7400 & 0,0046 & 65,45 & $<0,0001$ & 0,205 & 0,0190 & 0,5002 & 0,0030 & 20,01 & 0,0002 & 0,217 & 0,0148 & 0,4032 & 0,0055 & 30,40 & $<0,0001$ \\
\hline 12 & 0,177 & 0,0262 & 0,7615 & 0,0046 & 73,44 & $<0,0001$ & 0,217 & 0,0168 & 0,5978 & 0,0032 & 29,73 & $<0,0001$ & 0,213 & 0,0173 & 0,5560 & 0,0050 & 56,35 & $<0,0001$ \\
\hline 13 & $-0,080$ & 0,0862 & 0,8570 & 0,0122 & 137,83 & $<0,0001$ & 0,079 & 0,0500 & 0,5252 & 0,0123 & 21,02 & 0,0002 & 0,074 & 0,0483 & 0,5106 & 0,0183 & 45,91 & $<0,0001$ \\
\hline 14 & $-0,035$ & 0,0792 & 0,9114 & 0,0078 & 236,50 & $<0,0001$ & 0,128 & 0,0392 & 0,4017 & 0,0152 & 12,08 & 0,0027 & 0,123 & 0,0378 & 0,4421 & 0,0171 & 34,07 & $<0,0001$ \\
\hline 15 & $-0,149$ & 0,1009 & 0,7423 & 0,0192 & 66,25 & $<0,0001$ & $-0,072$ & 0,0915 & 0,2468 & 0,0334 & 6,55 & 0,0187 & 0,036 & 0,0559 & 0,3547 & 0,0304 & 24,73 & $<0,0001$ \\
\hline 16 & $-0,277$ & 0,1422 & 0,8271 & 0,0147 & 110,04 & $<0,0001$ & $-0,422$ & 0,2113 & 0,5839 & 0,0243 & 26,66 & $<0,0001$ & 0,076 & 0,0484 & 0,1466 & 0,0335 & 7,56 & 0,0086 \\
\hline 17 & $-0,026$ & $\begin{array}{l}0,0746 \\
0\end{array}$ & 0,7975 & 0,0101 & 90,57 & $<0,0001$ & $\begin{array}{l}-0,234 \\
-0,23\end{array}$ & 0,1772 & 0,8801 & 0,0073 & $\begin{array}{l}146,82 \\
140\end{array}$ & $<0,0001$ & 0,185 & 0,0195 & 0,2627 & 0,0188 & 16,03 & $\begin{array}{l}0,0002 \\
\end{array}$ \\
\hline 18 & $-0,062$ & 0,0802 & 0,7298 & 0,0133 & 62,12 & $<0,0001$ & 0,048 & 0,0608 & 0,2789 & 0,0170 & 7,74 & 0,0115 & 0,147 & 0,0293 & 0,2329 & 0,0198 & 13,66 & 0,0006 \\
\hline 19 & $-0,033$ & 0,0766 & 0,8663 & 0,0085 & 149,02 & $<0,0001$ & $\begin{array}{r}-0,032 \\
\end{array}$ & 0,0855 & 0,6089 & 0,0103 & $\begin{array}{l}3,14 \\
31,13\end{array}$ & $<0,0001$ & 0,088 & 0,0450 & 0,4950 & 0,0142 & 44,10 & $<0,0001$ \\
\hline 20 & 0,028 & 0,0548 & 0,8280 & 0,0089 & 110,73 & $<0,0001$ & 0,138 & 0,0326 & 0,1477 & 0,0141 & 3,46 & 0,0774 & 0,174 & 0,0189 & 0,2266 & 0,0162 & 13,19 & 0,0007 \\
\hline 21 & $\begin{array}{l}-0,108 \\
\end{array}$ & 0,0924 & 0,7797 & 0,0156 & 81,42 & $<0,0001$ & 0,165 & 0,0198 & 0,0127 & 0,0271 & 0,26 & 0,6179 & 0,043 & 0,0538 & 0,3359 & 0,0245 & 22,76 & $<0,0001$ \\
\hline 22 & $\begin{array}{l}-0,100 \\
-0,166\end{array}$ & $\begin{array}{l}0,1104 \\
0,1\end{array}$ & 0,9529 & 0,0074 & $\begin{array}{r}0,42 \\
465,64\end{array}$ & $<0,0001$ & $\begin{array}{l}-0,107 \\
\end{array}$ & 0,1034 & 0,5027 & 0,0182 & $\begin{array}{l}0,20 \\
19,21\end{array}$ & 0,0003 & $\begin{array}{c}-0,024 \\
-0,024\end{array}$ & 0,0741 & 0,5720 & $\begin{array}{l}0,0140 \\
0,0196\end{array}$ & $\begin{array}{l}22,10 \\
58,82\end{array}$ & $<0,0001$ \\
\hline 23 & 0,281 & 0,0084 & 0,7316 & $\begin{array}{l}0,0015 \\
0\end{array}$ & 57,23 & $<0,0001$ & 0,293 & $\begin{array}{l}0,0063 \\
0,03\end{array}$ & 0,1002 & 0,0048 & 1,89 & 0,1867 & 0,299 & 0,0041 & 0,1211 & 0,0037 & 5,51 & 0,0239 \\
\hline 24 & 0,218 & 0,0287 & 0,7432 & 0,0060 & 66,56 & $<0,0001$ & 0,275 & 0,0129 & 0,1099 & 0,0086 & 2,47 & 0,1317 & 0,246 & 0,0212 & 0,4205 & 0,0079 & 32,66 & $<0,0001$ \\
\hline 25 & $-0,020$ & 0,0803 & 0,9013 & 0,0077 & 210,06 & $<0,0001$ & 0,161 & 0,0391 & 0,1856 & 0,0184 & 4,56 & 0,0453 & 0,186 & 0,0277 & 0,1680 & 0,0207 & 9,09 & 0,0042 \\
\hline 26 & $-0,028$ & 0,0821 & 0,7313 & 0,0135 & 62,60 & $<0,0001$ & $-0,030$ & 0,0972 & 0,4659 & 0,0186 & 17,44 & 0,0005 & 0,174 & 0,0319 & 0,1076 & 0,0261 & 5,42 & 0,0244 \\
\hline $\begin{array}{l}20 \\
28\end{array}$ & $\begin{array}{l}-0,0<0 \\
-0,172\end{array}$ & 0,1046 & 0,9597 & 0,0070 & $\begin{array}{r}0,00 \\
523,72\end{array}$ & $<0,0001$ & 0,201 & 0,0074 & $\begin{array}{l}0,0039 \\
0,0006\end{array}$ & 0,0423 & $\begin{array}{l}0,014 \\
0,01\end{array}$ & 0,9124 & 0,117 & 0,0303 & 0,1032 & 0,0357 & $\begin{array}{l}3,4 L \\
5,06\end{array}$ & $\begin{array}{l}0,0244 \\
0,0295\end{array}$ \\
\hline 29 & $-0,025$ & 0,0779 & 0,8892 & 0,0094 & 184,62 & $<0,0001$ & 0,573 & $-0,0836$ & 0,5714 & 0,0095 & 1,33 & 0,4544 & 0,064 & 0,0555 & 0,4211 & 0,0223 & 18,91 & 0,0002 \\
\hline 31 & 0,070 & 0,0521 & $\begin{array}{l}0,8740 \\
0\end{array}$ & $\begin{array}{l}0,0068 \\
0\end{array}$ & $\begin{array}{r}152,02 \\
152,58\end{array}$ & $<0,0001$ & 0,156 & 0,0349 & 0,2867 & 0,0129 & 8,04 & $\begin{array}{l}0,04442 \\
0,0102\end{array}$ & 0,188 & 0,0232 & $\begin{array}{l}0,3472 \\
0\end{array}$ & 0,0137 & 23,40 & $<0,0001$ \\
\hline 32 & $-0,004$ & 0,0740 & 0,9183 & 0,0063 & 258,63 & $<0,0001$ & 0,113 & 0,0450 & 0,1273 & 0,0103 & 2,92 & 0,1031 & 0,103 & 0,0463 & 0,5720 & 0,0116 & 60,14 & $<0,0001$ \\
\hline 33 & $\begin{array}{l}-0,004 \\
-0,039\end{array}$ & 0,0691 & 0,8408 & $\begin{array}{l}0,0088 \\
0\end{array}$ & $\begin{array}{l}121,45 \\
\end{array}$ & $<0,0001$ & $\begin{array}{r}-0,061 \\
\end{array}$ & $\begin{array}{l}0,0809 \\
0,080\end{array}$ & 0,6199 & 0,0092 & $\begin{array}{l}2,02 \\
32,62\end{array}$ & $<0,0001$ & 0,035 & 0,0514 & 0,5307 & 0,0128 & 50,89 & $<0,0001$ \\
\hline 34 & $-0,036$ & 0,0694 & 0,9212 & 0,0072 & 268,96 & $<0,0001$ & $\begin{array}{l}-0,181 \\
\end{array}$ & 0,1146 & 0,5905 & 0,0137 & 28,84 & $<0,0001$ & $-0,013$ & 0,0649 & 0,6694 & 0,0134 & 91,10 & $<0,0001$ \\
\hline 35 & 0,054 & 0,0566 & 0,9770 & 0,0023 & 978,56 & $<0,0001$ & 0,147 & 0,0361 & 0,0972 & 0,0110 & 2,15 & 0,1579 & 0,156 & 0,0316 & 0,3242 & 0,0112 & 21,59 & $<0,0001$ \\
\hline 36 & $\begin{array}{l}0,054 \\
0,068\end{array}$ & 0,0501 & 0,9534 & 0,0035 & $\begin{array}{l}410,00 \\
470,53\end{array}$ & $<0,0001$ & 0,087 & 0,0552 & 0,7481 & 0,0059 & $\begin{array}{l}2,10 \\
59,41\end{array}$ & $<0,0001$ & 0,213 & 0,0153 & $\begin{array}{l}0,1715 \\
0\end{array}$ & 0,0130 & $\begin{array}{l}2,0,39 \\
9,31\end{array}$ & 0,0038 \\
\hline 37 & 0,190 & 0,0297 & 0,9524 & 0,0020 & 460,59 & $<0,0001$ & 0,247 & 0,0174 & 0,2168 & 0,0058 & 5,53 & 0,0290 & 0,225 & 0,0219 & 0,3268 & 0,0078 & 21,85 & $<0,0001$ \\
\hline $\begin{array}{l}31 \\
38\end{array}$ & 0,201 & 0,0271 & 0,9101 & 0,0025 & 232,87 & $<0,0001$ & $\begin{array}{l}0,251 \\
0,255\end{array}$ & $\begin{array}{l}0,0148 \\
0\end{array}$ & 0,1002 & 0,0061 & 2,23 & 0,1512 & 0,253 & 0,0140 & 0,1967 & 0,0073 & 11,02 & 0,0018 \\
\hline 39 & $\begin{array}{l}0,001 \\
-0,129\end{array}$ & 0,0907 & 0,9142 & 0,0086 & 244,96 & $<0,0001$ & 0,139 & 0,0316 & 0,1413 & $\begin{array}{l}0,0187 \\
0\end{array}$ & $\begin{array}{l}2,20 \\
3,29\end{array}$ & 0,0847 & 0,163 & 0,0206 & 0,1010 & 0,0245 & 5,06 & 0,0295 \\
\hline 40 & $-0,028$ & 0,0664 & 0,7029 & 0,0133 & 54,40 & $<0,0001$ & 0,076 & 0,047 & 0,168 & 0,021 & $\begin{array}{l}0,027 \\
4,027\end{array}$ & 0,0585 & 0,131 & 0,0291 & 0,1705 & 0,0214 & $\begin{array}{l}0,00 \\
9,25\end{array}$ & 0,0039 \\
\hline 41 & 0,124 & 0,0450 & 0,7437 & 0,0064 & 66,75 & $<0,0001$ & 0,251 & 0,0139 & 0,1335 & 0,0084 & 2,93 & 0,1034 & 0,249 & 0,0135 & 0,1861 & 0,0098 & 10,06 & 0,0028 \\
\hline 42 & 0,204 & 0,0248 & 0,6167 & 0,0054 & 37,01 & $<0,0001$ & 0,189 & 0,0332 & 0,3285 & 0,0103 & 9,78 & $\begin{array}{l}0,0053 \\
\end{array}$ & 0,255 & 0,0127 & 0,2283 & 0,0092 & 13,31 & 0,0007 \\
\hline $\begin{array}{l}42 \\
43\end{array}$ & $\begin{array}{l}0,204 \\
0,003\end{array}$ & $\begin{array}{l}0,0717 \\
0,0710\end{array}$ & $\begin{array}{l}0,8938 \\
0,893\end{array}$ & $\begin{array}{r}, 0 \\
0,0089 \\
0\end{array}$ & $\begin{array}{c}J, 01 \\
193,61\end{array}$ & $<0,0001$ & $\begin{array}{r}-0,021 \\
-0,021\end{array}$ & 0,0977 & 0,5170 & 0,0139 & $\begin{array}{l}9,10 \\
20,34\end{array}$ & 0,0002 & $\begin{array}{l}0,200 \\
0,202\end{array}$ & 0,0225 & $\begin{array}{l},, 2203 \\
0,1913\end{array}$ & 0,0214 & 10,41 & 0,0024 \\
\hline 44 & $-0,069$ & 0,0879 & 0,8751 & 0,0100 & $\begin{array}{l}161,20 \\
\text { S }\end{array}$ & $<0,0001$ & - & - & - & 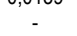 & - & - & $\begin{array}{l}-0,069 \\
\end{array}$ & 0,0879 & 0,8751 & 0,0100 & 161,20 & $<0,0001$ \\
\hline 45 & $-0,083$ & 0,0837 & 0,8720 & 0,0092 & 156,68 & $<0,0001$ & 0,066 & 0,0572 & 0,5650 & 0,0140 & 25,98 & $<0,0001$ & 0,166 & 0,0242 & 0,2140 & 0,0206 & $\begin{array}{l}101,20 \\
12,25\end{array}$ & 0,0011 \\
\hline 46 & 0,005 & 0,0616 & 0,8948 & 0,0063 & 195,62 & $<0,0001$ & 0,135 & 0,036 & 0,055 & 0,020 & 1,113 & 0,3047 & 0,202 & 0,0133 & 0,0385 & 0,0210 & 1,76 & 0,1910 \\
\hline 47 & $\begin{array}{l}0,128 \\
-0,10\end{array}$ & 0,1112 & 0,8670 & 0,0106 & 149,95 & $<0,0001$ & 0,755 & $-0,1191$ & 0,8952 & 0,0062 & 8,54 & $\begin{array}{l}0,2099 \\
0\end{array}$ & 0,025 & 0,0718 & 0,2378 & 0,0308 & 8,11 & 0,0085 \\
\hline 48 & $-0,011$ & 0,0734 & 0,6435 & 0,0163 & 41,52 & $<0,0001$ & $-0,055$ & 0,1061 & 0,1200 & 0,0308 & 2,73 & 0,1143 & 0,287 & 0,0006 & 0,0000 & 0,0324 & 0,00 & 0,9645 \\
\hline Média & $-0,012$ & 0,0715 & 0,8232 & 0,0093 & 172,25 & 0.0004 & 0,094 & 0.0519 & 0,3533 & 0,0148 & 15,51 & 0.1749 & 0,133 & 0,0356 & 0,3402 & 0.0176 & 29,67 & 0.0212 \\
\hline
\end{tabular}


Anexo K. Coeficientes linear (a), angular (b) e de determinação (R2), o desvio padrão da regressão (DPR), a estatística F e sua respectiva probabilidade, para os ajustes do modelo linear nos dois períodos de observação e todos juntos aos dados da camada C.

\begin{tabular}{|c|c|c|c|c|c|c|c|c|c|c|c|c|c|c|c|c|c|c|}
\hline \multirow[t]{2}{*}{ Bateria } & \multicolumn{6}{|c|}{2000} & \multirow{2}{*}{\multicolumn{6}{|c|}{$\mathrm{R}^{2} \quad 2001$ DPR }} & \multicolumn{6}{|c|}{$2000+2001$} \\
\hline & a & b & $\mathrm{R}^{2}$ & DPR & $\mathrm{F}$ & Prob. & & & & & & & a & b & $\mathrm{R}^{2}$ & DPR & $\mathrm{F}$ & Prob. \\
\hline 1 & 0,031 & 0,0824 & 0,6776 & 0,0078 & 46,24 & $<0,0001$ & 0,171 & 0,0412 & 0,1668 & 0,0145 & 4,00 & 0,0591 & 0,212 & 0,0188 & 0,3191 & 0,0132 & 20,62 & $<0,0001$ \\
\hline 2 & $-0,176$ & 0,1491 & 0,6313 & 0,0086 & 37,67 & $<0,0001$ & 0,166 & 0,0283 & 0,1532 & 0,0117 & 3,62 & 0,0717 & 0,108 & 0,0497 & 0,2270 & 0,0120 & 12,92 & 0,0008 \\
\hline 3 & 0,013 & 0,0817 & 0,8060 & 0,0069 & 91,39 & $<0,0001$ & 0,022 & 0,0847 & 0,8932 & 0,0059 & 167,22 & $<0,0001$ & 0,081 & 0,0599 & 0,7186 & 0,0091 & 112,33 & $<0,0001$ \\
\hline 4 & 0,055 & 0,0630 & 0,8226 & 0,0069 & 102,00 & $<0,0001$ & 0,106 & 0,0463 & 0,4093 & 0,0124 & 13,86 & 0,0013 & 0,078 & 0,0554 & 0,6255 & 0,0099 & 73,50 & $<0,0001$ \\
\hline 5 & 0,137 & 0,0403 & 0,6786 & 0,0069 & 44,34 & $<0,0001$ & & & & & & & 0,132 & 0,0427 & 0,5447 & 0,0095 & 26,32 & $<0,0001$ \\
\hline 6 & 0,063 & 0,0662 & 0,7789 & 0,0076 & 77,52 & $<0,0001$ & 0,172 & 0,0312 & 0,3655 & 0,0121 & 11,52 & 0,0029 & 0,171 & 0,0296 & 0,3542 & 0,0124 & 24,13 & $<0,0001$ \\
\hline 7 & 0,086 & 0,0570 & 0,6500 & 0,0082 & 40,86 & $<0,0001$ & $-0,004$ & 0,0989 & 0,6286 & 0,0085 & 33,85 & $<0,0001$ & 0,161 & 0,0328 & 0,2959 & 0,0114 & 18,49 & $<0,0001$ \\
\hline 8 & 0,071 & 0,0606 & 0,7200 & 0,0072 & 56,56 & $<0,0001$ & 0,100 & 0,054 & 0,584 & 0,007 & 28,130 & $<0,0001$ & 0,126 & 0,0432 & 0,5712 & 0,0083 & 58,61 & $<0,0001$ \\
\hline 9 & $-0,070$ & 0,1056 & 0,6403 & 0,0097 & 39,16 & $<0,0001$ & $-0,001$ & 0,0893 & 0,4656 & 0,0147 & 17,43 & 0,0005 & 0,079 & 0,0591 & 0,5050 & 0,0136 & 44,89 & $<0,0001$ \\
\hline 10 & $-0,030$ & 0,0937 & 0,9081 & 0,0056 & 217,48 & $<0,0001$ & 0,019 & 0,0935 & 0,5393 & 0,0132 & 23,41 & $<0,0001$ & 0,176 & 0,0270 & 0,2193 & 0,0164 & 12,36 & 0,0010 \\
\hline 11 & 0,158 & 0,0294 & 0,1032 & 0,0070 & 2,53 & 0,1258 & 0,146 & 0,0362 & 0,3574 & 0,0053 & 11,12 & 0,0033 & 0,201 & 0,0163 & 0,2756 & 0,0064 & 16,74 & 0,0002 \\
\hline 12 & 0,132 & 0,0412 & 0,6004 & 0,0083 & 34,56 & $<0,0001$ & 0,168 & 0,0290 & 0,3918 & 0,0058 & 12,88 & 0,0018 & 0,150 & 0,0353 & 0,5491 & 0,0073 & 54,79 & $<0,0001$ \\
\hline 13 & 0,032 & $\begin{array}{l}0,0711 \\
0\end{array}$ & $\begin{array}{l}, 0 \\
0,7529\end{array}$ & 0,0080 & $\begin{array}{l}3,00 \\
67,04\end{array}$ & $<0,0001$ & 0,178 & 0,0233 & 0 & $\begin{array}{l}0,0137 \\
0,0\end{array}$ & $\begin{array}{l}12,000 \\
1,44\end{array}$ & 0,2448 & 0,100 & 0,0494 & $\begin{array}{l}0,3883 \\
0,3883\end{array}$ & 0,0117 & $\begin{array}{l}37,19 \\
27,93\end{array}$ & $<0,0001$ \\
\hline 14 & 0,087 & 0,0638 & 0,9050 & $\begin{array}{l}0,0050 \\
0\end{array}$ & 200,15 & $<0,0001$ & 0,229 & $\begin{array}{l}0,0089 \\
0\end{array}$ & $\begin{array}{l}0,0359 \\
0\end{array}$ & 0,0152 & $\begin{array}{l}1,44 \\
0,71\end{array}$ & $\begin{array}{l}0,4105 \\
0,4105\end{array}$ & 0,189 & $\begin{array}{l}0,0252 \\
0\end{array}$ & 0,2474 & 0,0134 & 13,80 & 0,0006 \\
\hline 15 & 0,050 & 0,0700 & 0,9751 & 0,0031 & 861,35 & $<0,0001$ & 0,242 & 0,0020 & 0,0009 & 0,0208 & 0,02 & 0,8958 & 0,189 & 0,0226 & $\begin{array}{l}0,174 \\
0,1693\end{array}$ & 0,0180 & 8,97 & 0,0045 \\
\hline 16 & $\begin{array}{l}-0,039 \\
\end{array}$ & 0,0987 & 0,9540 & 0,0046 & 476,95 & $<0,0001$ & $-0,106$ & 0,1390 & 0,7104 & 0,0114 & 49,07 & $<0,0001$ & 0,096 & 0,0546 & 0,4790 & 0,0152 & 41,37 & $<0,0001$ \\
\hline 17 & 0,103 & 0,0605 & 0,9392 & 0,0042 & 355,25 & $<0,0001$ & $-0,111$ & 0,1585 & 0,6237 & 0,0105 & 33,16 & $<0,0001$ & 0,151 & 0,0444 & 0,5283 & 0,0117 & 50,40 & $<0,0001$ \\
\hline 18 & 0,092 & 0,0577 & 0,9029 & 0,0056 & 213,78 & $<0,0001$ & $-0,032$ & 0,1129 & 0,7415 & 0,0078 & 57,36 & $<0,0001$ & 0,148 & 0,0408 & 0,5723 & 0,0109 & 60,21 & $<0,0001$ \\
\hline 19 & $\begin{array}{l}-0,067 \\
-\end{array}$ & 0,1215 & 0,8843 & 0,0116 & 175,75 & $<0,0001$ & 0,018 & 0,0946 & 0,4263 & 0,0151 & 14,86 & 0,0010 & 0,017 & 0,0907 & 0,6380 & 0,0168 & 79,31 & $<0,0001$ \\
\hline 20 & $-0,064$ & 0,1120 & 0,7860 & 0,0149 & 84,47 & $<0,0001$ & 0,139 & 0,0363 & 0,1983 & 0,0166 & 4,95 & 0,0378 & 0,050 & 0,0707 & 0,5064 & 0,0186 & 46,16 & $<0,0001$ \\
\hline 21 & $-0,106$ & 0,1186 & 0,7920 & 0,0111 & 87,57 & $<0,0001$ & 0,108 & 0,0421 & 0,4491 & 0,0109 & 16,30 & 0,0006 & 0,019 & 0,0743 & 0,5729 & 0,0132 & 60,37 & $<0,0001$ \\
\hline 22 & $-0,028$ & 0,0886 & 0,8305 & 0,0096 & $\begin{array}{l}107,79 \\
\end{array}$ & $<0,0001$ & 0,086 & 0,0550 & $\begin{array}{l}0,2163 \\
0,21\end{array}$ & 0,0156 & 5,52 & 0,0292 & 0,094 & 0,0489 & 0,3686 & $\begin{array}{l}0,0161 \\
0\end{array}$ & 25,69 & $<0,0001$ \\
\hline 23 & 0,168 & 0,0295 & 0,6061 & 0,0056 & 33,85 & $<0,0001$ & 0,229 & 0,0079 & 0,0823 & 0,0074 & 1,34 & 0,2644 & 0,200 & 0,0180 & 0,3060 & 0,0068 & 17,20 & 0,0002 \\
\hline 24 & 0,169 & 0,0306 & 0,5393 & 0,0070 & 26,92 & $<0,0001$ & 0,205 & 0,0184 & 0,4531 & 0,0042 & $\begin{array}{l}1,07 \\
16,57\end{array}$ & 0,0006 & 0,191 & 0,0233 & 0,4543 & 0,0061 & 37,46 & $<0,0001$ \\
\hline 25 & 0,104 & 0,0564 & 0,9387 & 0,0043 & 352,06 & $<0,0001$ & 0,114 & 0,0569 & 0,6128 & 0,0098 & 31,65 & $<0,0001$ & 0,129 & 0,0491 & 0,6921 & 0,0090 & 101,14 & $<0,0001$ \\
\hline 26 & 0,080 & 0,0601 & 0,7370 & 0,0091 & 64,44 & $<0,0001$ & 0,103 & 0,0600 & 0,1916 & 0,0154 & 4,74 & 0,0416 & 0,173 & 0,0316 & 0,2306 & 0,0150 & 13,49 & 0,0006 \\
\hline 28 & $\begin{array}{l}-0,153 \\
-0,0\end{array}$ & $\begin{array}{l}0,1301 \\
0\end{array}$ & 0,8170 & $\begin{array}{l}0,0187 \\
0\end{array}$ & $\begin{array}{l}102,74 \\
102\end{array}$ & $<0,0001$ & $-0,343$ & 0,2822 & 0,4777 & 0,0280 & $\begin{array}{l}4,14 \\
18,29\end{array}$ & 0,0004 & 0,146 & 0,0319 & 0,1685 & 0,0371 & 9,12 & 0,0042 \\
\hline 29 & $-0,015$ & 0,1014 & 0,8726 & 0,0101 & 157,50 & $<0,0001$ & 0,106 & 0,0570 & 0,1814 & 0,0203 & 4,43 & 0,0481 & 0,030 & 0,0856 & 0,5825 & 0,0163 & 62,80 & $<0,0001$ \\
\hline 31 & 0,071 & 0,0732 & 0,8159 & 0,0145 & 101,93 & $<0,0001$ & 0,120 & 0,0381 & 0,7111 & 0,0043 & 49,24 & $<0,0001$ & 0,003 & 0,0938 & 0,7930 & 0,0185 & 172,43 & $<0,0001$ \\
\hline 32 & $-0,019$ & 0,1049 & 0,9866 & 0,0038 & 1694,32 & $<0,0001$ & $-0,205$ & 0,1994 & 0,7738 & 0,0124 & 68,42 & $<0,0001$ & 0,070 & 0,0756 & 0,6535 & 0,0176 & 84,88 & $<0,0001$ \\
\hline 33 & 0,007 & 0,0815 & 0,8926 & 0,0074 & 191,16 & $<0,0001$ & $\begin{array}{l}-0,066 \\
-0,20\end{array}$ & 0,1214 & 0,7598 & 0,0088 & 63,26 & $<0,0001$ & 0,096 & 0,0533 & 0,4424 & 0,0151 & 35,71 & $<0,0001$ \\
\hline 34 & 0,062 & 0,0624 & $\begin{array}{l}0,02809 \\
0,9689\end{array}$ & $\begin{array}{l}0,0047 \\
0\end{array}$ & 717,64 & $<0,0001$ & $\begin{array}{c}0,050 \\
0,059\end{array}$ & $\begin{array}{l}1 \\
0,0757\end{array}$ & 0,2679 & $\begin{array}{l}, 000 \\
0,0214\end{array}$ & $\begin{array}{c}0.0,20 \\
4,76\end{array}$ & 0,0482 & 0,120 & 0,0451 & $\begin{array}{l}, 4424 \\
0,4829\end{array}$ & 0,0184 & $\begin{array}{l}35,11 \\
35,48\end{array}$ & $<0,0001$ \\
\hline 35 & 0,088 & 0,0639 & 0,9624 & 0,0040 & 587,92 & $<0,0001$ & 0,029 & 0,0979 & 0,8180 & 0,0066 & 89,91 & $<0,0001$ & 0,160 & 0,0413 & 0,4889 & 0,0128 & 43,04 & $<0,0001$ \\
\hline 36 & 0,074 & 0,0695 & 0,9420 & 0,0047 & 373,37 & $<0,0001$ & 0,150 & 0,0486 & 0,4461 & 0,0097 & 16,11 & 0,0007 & 0,139 & 0,0492 & 0,5124 & 0,0118 & 47,29 & $<0,0001$ \\
\hline 37 & 0,061 & 0,0805 & 0,8470 & 0,0089 & 127,35 & $<0,0001$ & $-0,013$ & 0,1184 & 0,4882 & 0,0104 & 19,08 & 0,0003 & 0,136 & 0,0575 & 0,3699 & 0,0160 & 26,42 & $<0,0001$ \\
\hline 38 & 0,114 & 0,0671 & 0,8865 & 0,0074 & 179,68 & $<0,0001$ & 0,247 & 0,0220 & $\begin{array}{l}0,0331 \\
0\end{array}$ & 0,0135 & 0,68 & 0,4179 & 0,179 & 0,0459 & 0,3897 & 0,0147 & 28,73 & $<0,0001$ \\
\hline 39 & 0,052 & 0,0594 & 0,7434 & 0,0102 & 66,64 & $<0,0001$ & 0,214 & 0,0032 & 0,0068 & 0,0130 & 0,14 & $\begin{array}{l}0,7153 \\
\end{array}$ & 0,150 & 0,0262 & 0,2492 & 0,0145 & 14,94 & 0,0004 \\
\hline 40 & 0,048 & 0,0613 & 0,7554 & 0,0103 & $\begin{array}{l}31,02 \\
\end{array}$ & $<0,0001$ & 0,112 & 0,045 & 0,262 & 0,012 & 7,119 & 0,0148 & 0,129 & 0,0351 & 0,3576 & $\begin{array}{l}0,0142 \\
0\end{array}$ & 25,05 & $<0,0001$ \\
\hline 41 & 0,225 & 0,0194 & 0,8992 & 0,0018 & 205,21 & $<0,0001$ & 0,261 & 0,0071 & 0,2654 & 0,0030 & 6,86 & 0,0169 & 0,246 & 0,0123 & 0,5559 & 0,0031 & 55,07 & $<0,0001$ \\
\hline 42 & 0,234 & 0,0165 & 0,8969 & 0,0017 & 200,16 & $<0,0001$ & 0,232 & 0,0202 & 0,4462 & 0,0032 & 9,67 & 0,0090 & 0,256 & 0,0095 & 0,3596 & 0,0040 & 20,77 & $<0,0001$ \\
\hline $\begin{array}{l}42 \\
43\end{array}$ & $\begin{array}{l}0,204 \\
0,085\end{array}$ & 0,0632 & $\begin{array}{l}0,9218 \\
0,9218\end{array}$ & 0,0053 & 271,09 & $<0,0001$ & 0,004 & 0,1178 & $\begin{array}{l}\text {, } \\
0,797027\end{array}$ & $\begin{array}{l}0,0059 \\
0,000\end{array}$ & $\begin{array}{l}9,01 \\
78,88\end{array}$ & $\begin{array}{r}<0,0001 \\
<0\end{array}$ & 0,216 & 0,0201 & $\begin{array}{l}, 2332 \\
0,2332\end{array}$ & $\begin{array}{l}0,0140 \\
0,0142\end{array}$ & $\begin{array}{l}2, r 1 \\
13,69\end{array}$ & 0,0006 \\
\hline 44 & 0,051 & 0,0693 & 0,7382 & 0,0103 & 64,85 & $<0,0001$ & 0,193 & 0,0280 & 0,2058 & 0,0122 & 5,18 & 0,0339 & 0,182 & 0,0294 & 0,2557 & 0,0148 & 15,46 & 0,0003 \\
\hline 45 & $-0,044$ & 0,1089 & 0,8940 & 0,0082 & 193,88 & $<0,0001$ & $-0,038$ & 0,123 & 0,391 & 0.015 & 12,826 & 0,0019 & 0,129 & 0,0500 & 0,4068 & 0,0172 & 30,86 & $<0,0001$ \\
\hline 46 & $-0,006$ & 0,0907 & 0,9298 & 0,0063 & 304,68 & $<0,0001$ & 0,287 & $-0,0160$ & 0,0158 & 0,0179 & 0,32 & 0,5767 & 0,197 & 0,0204 & 0,1099 & 0,0196 & 5,55 & 0,0229 \\
\hline 47 & 0,137 & 0,0429 & 0,4083 & 0,0130 & 15,87 & 0,0006 & 0,207 & 0,0262 & 0,0474 & 0,0198 & 1,00 & 0,3303 & 0,242 & 0,0100 & 0,0177 & 0,0193 & 0,81 & 0,3729 \\
\hline 48 & 0,100 & 0,0558 & 0,7553 & 0,0087 & 71,00 & $<0,0001$ & 0,191 & 0,0378 & 0,2113 & 0,0172 & 5,09 & 0,0360 & 0,246 & 0,0116 & 0,0272 & 0,0211 & 1,23 & 0,2734 \\
\hline Média & 0,048 & 0,0724 & 0,7933 & 0,0077 & 208,60 & 0,0004 & 0,094 & 0,0645 & 0,3860 & 0,0120 & 22,80 & 0,1749 & 0,141 & 0,0417 & 0,4090 & 0,0137 & 38,88 & 0,0212 \\
\hline
\end{tabular}


Anexo L. Coeficientes linear (a), angular (b) e de determinação (R2), o desvio padrão da regressão (DPR), a estatística $\mathrm{F}$ e sua respectiva probabilidade, para os ajustes do modelo linear nos dois períodos de observação e todos juntos aos dados da camada $\mathrm{D}$.

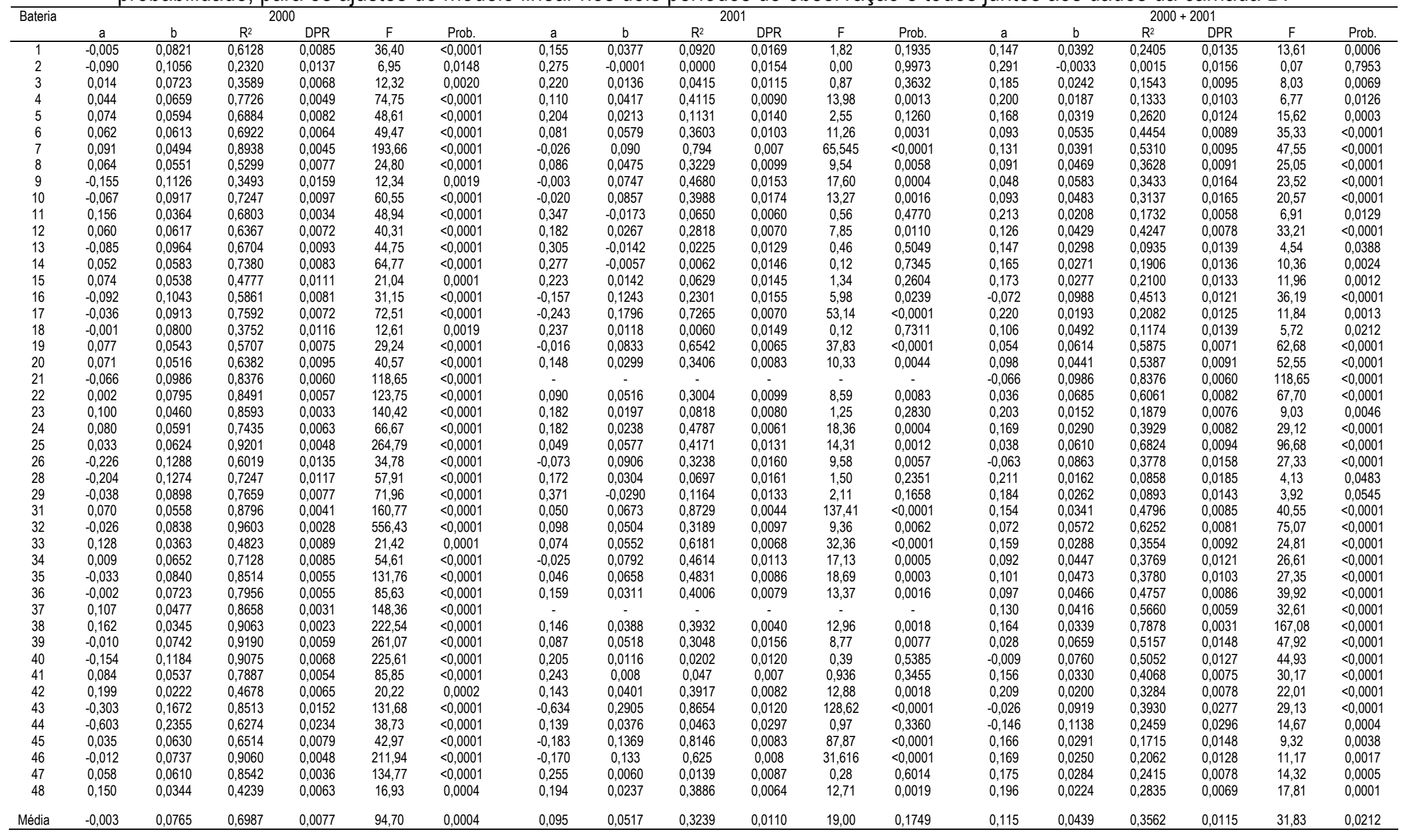


Anexo M. Coeficientes linear (a), angular (b) e de determinação (R2), o desvio padrão da regressão (DPR), a estatística F e sua respectiva probabilidade, para os ajustes do modelo linear nos dois períodos de observação e todos juntos aos dados da camada $\mathrm{E}$.

\begin{tabular}{|c|c|c|c|c|c|c|c|c|c|c|c|c|c|c|c|c|c|c|}
\hline \multirow[t]{2}{*}{ Bateria } & \multicolumn{6}{|c|}{2000} & \multirow{2}{*}{\multicolumn{6}{|c|}{$\mathrm{R}^{2} 2001$}} & \multicolumn{6}{|c|}{$2000+2001$} \\
\hline & a & b & $R^{2}$ & DPR & $\mathrm{F}$ & Prob. & & & & & & & a & b & $\mathrm{R}^{2}$ & DPR & $\mathrm{F}$ & Prob. \\
\hline 1 & $-0,082$ & 0,1099 & 0,4478 & 0,0106 & 18,65 & 0,0003 & $-0,023$ & 0,0915 & 0,2693 & 0,0202 & 7,37 & 0,0133 & $-0,043$ & 0,0979 & 0,3267 & 0,0155 & 21,83 & $<0,0001$ \\
\hline 2 & 0,026 & 0,0704 & 0,1106 & 0,0116 & 2,86 & 0,1043 & 0,242 & 0,0092 & 0,0118 & 0,0175 & 0,24 & 0,6298 & 0,225 & 0,0139 & 0,0186 & 0,0146 & 0,85 & 0,3605 \\
\hline 3 & 0,141 & 0,0429 & 0,5169 & 0,0070 & $\begin{array}{l}24,61 \\
24,61\end{array}$ & $<0,0001$ & 0,135 & 0,0380 & 0,2804 & 0,0082 & $\begin{array}{l}0,24 \\
7,79\end{array}$ & 0,0113 & 0,214 & 0,0183 & 0,0445 & 0,0134 & 2,10 & 0,1544 \\
\hline 4 & 0,065 & 0,0612 & 0,5968 & 0,0059 & 34,05 & $<0,0001$ & 0,378 & $-0,0286$ & 0,1562 & 0,0096 & 2,96 & 0,1045 & 0,243 & 0,0113 & 0,0360 & 0,0094 & 1,53 & 0,2230 \\
\hline 5 & 0,127 & 0,0438 & 0,6802 & 0,0078 & 48,91 & $<0,0001$ & $-0,016$ & 0,0849 & 0,4465 & 0,0146 & 16,13 & 0,0007 & 0,093 & 0,0538 & 0,4846 & 0,0118 & 42,32 & $<0,0001$ \\
\hline 6 & $-0,156$ & 0,1319 & 0,7768 & 0,0086 & 76,58 & $<0,0001$ & 0,230 & 0,0235 & 0,0155 & 0,0276 & 0,30 & 0,5907 & 0,241 & 0,0166 & 0,0117 & 0,0242 & 0,51 & 0,4790 \\
\hline 7 & $-0,235$ & 0,1503 & 0,7380 & 0,0075 & 64,78 & $<0,0001$ & & $0,0<0 u$ & & & & & $-0,356$ & 0,1867 & 0,7036 & 0,0105 & 59,36 & $<0,0001$ \\
\hline 8 & $-0,009$ & 0,0847 & 0,7270 & 0,0061 & $\begin{array}{l}61,24 \\
61,24\end{array}$ & $<0,0001$ & 0,079 & 0,060 & 0,356 & 0,013 & 11,071 & 0,0034 & $\begin{array}{l}0,062 \\
0,002\end{array}$ & 0,0640 & 0,4081 & 0,0107 & $\begin{array}{l}31,02 \\
31,02\end{array}$ & $<0,0001$ \\
\hline 9 & 0,317 & $-0,0112$ & 0,0487 & 0,0144 & 1,18 & 0,2889 & $\begin{array}{l}-0,150 \\
-\end{array}$ & 0,1330 & 0,2560 & 0,0267 & 6,88 & 0,0163 & 0,285 & 0,0003 & 0,0000 & 0,0244 & 0,00 & 0,9872 \\
\hline 10 & $-0,098$ & 0,1156 & 0,7131 & 0,0085 & 57,18 & $<0,0001$ & 0,083 & 0,0603 & 0,0620 & 0,0183 & 1,32 & 0,2638 & $-0,014$ & 0,0902 & 0,2931 & 0,0143 & 18,66 & $<0,0001$ \\
\hline 11 & $-0,115$ & 0,1190 & 0,6976 & 0,0070 & 53,06 & $<0,0001$ & 0,097 & 0,0586 & 0,3041 & 0,0082 & 8,74 & 0,0078 & 0,184 & 0,0281 & 0,1600 & 0,0103 & 8,57 & 0,0053 \\
\hline 12 & 0,112 & 0,0520 & 0,7484 & 0,0043 & 68,41 & $<0,0001$ & 0,140 & 0,0451 & 0,3054 & $\begin{array}{l}0,0122 \\
0\end{array}$ & 8,79 & 0,0076 & 0,153 & 0,0400 & 0,3611 & 0,0092 & 25,44 & $<0,0001$ \\
\hline 13 & 0,283 & $-0,0014$ & 0,0003 & 0,0151 & 0,01 & 0,9306 & 0,280 & $-0,0005$ & 0,0000 & 0,0201 & 0,00 & 0,9895 & 0,283 & $\begin{array}{r}-0,0013 \\
\end{array}$ & 0,0002 & 0,0172 & $\begin{array}{c}0,01 \\
0,01\end{array}$ & 0,9312 \\
\hline 14 & $\begin{array}{l}-0,010 \\
-0,010\end{array}$ & 0,0923 & 0,8384 & 0,0066 & 119,34 & $<0,0001$ & 0,108 & 0,0577 & 0,2353 & 0,0167 & 6,15 & 0,0221 & $\begin{array}{l}0,000 \\
0,092\end{array}$ & $\begin{array}{l}0,0615 \\
0,0\end{array}$ & 0 & 0,0134 & $\begin{array}{l}0,61 \\
29,61\end{array}$ & $<0,0001$ \\
\hline 15 & 0,081 & 0,0570 & 0,4919 & 0,0112 & 22,27 & $<0,0001$ & 0,188 & 0,0260 & 0,0451 & 0,0150 & 0,95 & 0,3425 & 0,113 & 0,0479 & 0,2730 & 0,0130 & 16,90 & 0,0002 \\
\hline 16 & $-0,028$ & 0,0981 & 0,8303 & 0,0050 & 112,57 & $<0,0001$ & 0,101 & 0,0446 & 0,3287 & 0,0073 & 9,79 & 0,0053 & 0,269 & 0,0003 & 0,0001 & 0,0108 & 0,00 & 0,9459 \\
\hline 17 & $\begin{array}{l}-0,008 \\
-\end{array}$ & 0,0945 & 0,6937 & 0,0089 & 52,08 & $<0,0001$ & 0,152 & 0,0422 & 0,0316 & 0,0213 & 0,65 & 0,4284 & 0,126 & 0,0513 & 0,1630 & 0,0169 & 8,76 & 0,0049 \\
\hline 18 & $-0,362$ & 0,2046 & 0,4992 & 0,0108 & 21,93 & 0,0001 & 0,082 & 0,0658 & 0,1897 & 0,0195 & 4,68 & 0,0427 & 0,028 & 0,0824 & $\begin{array}{l},, 2240 \\
0,2241\end{array}$ & 0,0160 & $\begin{array}{l}0,10 \\
12,71\end{array}$ & $\begin{array}{l}0,0049 \\
0.0009\end{array}$ \\
\hline 19 & $\begin{array}{l}-0,022 \\
-\end{array}$ & 0,0967 & 0,2888 & 0,0098 & 8,93 & 0,0068 & $\begin{array}{l}-0,085 \\
-\end{array}$ & 0,1089 & 0,2265 & 0,0166 & $\begin{array}{l}5,86 \\
5,86\end{array}$ & 0,0252 & 0,204 & 0,0223 & 0,0323 & 0,0150 & 1,47 & 0,2322 \\
\hline 20 & $-0,086$ & 0,1112 & 0,8835 & 0,0051 & 174,40 & $<0,0001$ & 0,276 & $-0,0016$ & 0,0004 & 0,0159 & 0,01 & 0,9316 & 0,148 & 0,0375 & 0,1556 & 0,0139 & 8,29 & 0,0061 \\
\hline 21 & $\begin{array}{l}-0,147 \\
\end{array}$ & 0,1383 & 0,7444 & 0,0073 & 66,98 & $<0,0001$ & 0,239 & $-0,0009$ & 0,0007 & 0,0038 & 0,01 & 0,9070 & 0,023 & 0,0771 & 0,1979 & 0,0154 & 11,10 & 0,0017 \\
\hline 22 & $\begin{array}{l}-0,141 \\
-0,057\end{array}$ & 0,1087 & $\begin{array}{l}0,7894 \\
0,7895\end{array}$ & 0,0056 & $\begin{array}{l}0,90 \\
86,24\end{array}$ & $<0,0001$ & 0,153 & 0,0384 & 0,0923 & 0,0142 & 2,03 & 0,1694 & 0,035 & 0,0777 & 0,3645 & 0,0113 & 25,81 & $<0,0001$ \\
\hline 23 & 0,198 & 0,0293 & 0,0218 & 0,0221 & $\begin{array}{c}0,51 \\
0,51\end{array}$ & 0,4812 & 0,263 & $\begin{array}{l}0,0049 \\
0\end{array}$ & 0,0018 & 0,0151 & 0,04 & $\begin{array}{l}0,8509 \\
0\end{array}$ & 0,248 & 0,0106 & 0,0049 & 0,0189 & $\begin{array}{l}0,22 \\
0,10\end{array}$ & 0,6418 \\
\hline 24 & 0,115 & 0,0611 & 0,3643 & 0,0082 & 13,18 & 0,0014 & 0,170 & 0,0387 & 0,1472 & 0,0138 & $\begin{array}{l}3,04 \\
3,45\end{array}$ & 0.0779 & 0,195 & 0,0312 & 0,1507 & 0.0114 & $\begin{array}{l}0,22 \\
7,98\end{array}$ & 0,0070 \\
\hline 25 & 0,142 & 0,0467 & 0,7410 & 0,0080 & 65,80 & $<0,0001$ & 0,121 & 0,0563 & 0,3382 & 0,0146 & 10,22 & 0,0045 & 0,144 & 0,0470 & 0,4888 & 0,0118 & 43,04 & $<0,0001$ \\
\hline 26 & $-0,032$ & 0,0865 & 0,2642 & 0,0172 & 8,26 & 0,0086 & 0,152 & 0,0403 & 0,0671 & 0,0224 & 1,44 & 0,2445 & 0,231 & 0,0142 & 0,0114 & 0,0219 & 0,52 & 0,4749 \\
\hline $\begin{array}{l}20 \\
28\end{array}$ & $\begin{array}{l}-0,052 \\
-0,073\end{array}$ & $\begin{array}{l}0,1012 \\
0,100\end{array}$ & $\begin{array}{l}0,2024 \\
0,8293\end{array}$ & 0,0058 & $\begin{array}{c}0,06 \\
111,76\end{array}$ & $<0,0001$ & 0,048 & $\begin{array}{l}0,0616 \\
0,06\end{array}$ & 0,1211 & 0,0150 & $\begin{array}{l}1,44 \\
2,75\end{array}$ & $\begin{array}{l}0,1126 \\
0,1126\end{array}$ & $\begin{array}{l}0,095 \\
0,005\end{array}$ & 0,0495 & 0,2914 & 0,0124 & $\begin{array}{l}0,02 \\
18,50\end{array}$ & $\begin{array}{r}\quad, 4,49 \\
<0,0001\end{array}$ \\
\hline 29 & 0,124 & 0,0495 & 0,6121 & 0,0049 & 34,72 & $<0,0001$ & 0,131 & 0,0517 & 0,1221 & 0,0196 & 1,67 & 0,2206 & 0,101 & 0,0587 & 0,2332 & 0,0137 & 10,95 & 0,0021 \\
\hline 31 & 0,145 & 0,0459 & 0,8565 & 0,0045 & $\begin{array}{l}337,27 \\
137\end{array}$ & $<0,0001$ & $\begin{array}{l}-0,053 \\
-\end{array}$ & 0,0964 & 0,7885 & 0,0051 & 74,58 & $<0,0001$ & $\begin{array}{l}0,209 \\
0\end{array}$ & 0,0247 & 0,3050 & 0,0094 & 19,75 & $<0,0001$ \\
\hline 32 & 0,058 & 0,0708 & 0,8571 & 0,0042 & $\begin{array}{l}137,93 \\
\end{array}$ & $<0,0001$ & 0,157 & 0,0425 & 0,1261 & 0,0104 & 2,88 & 0,1049 & 0,113 & 0,0551 & 0,3982 & 0,0085 & 29,77 & $<0,0001$ \\
\hline 33 & $\begin{array}{l}-0,030 \\
-\end{array}$ & 0,0886 & 0,8281 & 0,0061 & $\begin{array}{l}110,76 \\
0\end{array}$ & $<0,0001$ & 0,088 & $\begin{array}{l}0,0549 \\
0\end{array}$ & 0,2490 & 0,0147 & $\begin{array}{l}2,00 \\
6,63\end{array}$ & 0,0181 & 0,020 & 0,0742 & 0,4874 & 0,0114 & $\begin{array}{l}2,11 \\
42,79\end{array}$ & $<0,0001$ \\
\hline 34 & $-0,010$ & 0,0804 & 0,7898 & 0,0059 & 86,43 & $<0,0001$ & 0,059 & 0,0630 & 0,3701 & 0,0110 & $\begin{array}{l}11,75 \\
11,0\end{array}$ & 0,0027 & 0,082 & 0,0544 & $\begin{array}{l}0,4014 \\
0,4120\end{array}$ & 0,0100 & 31,53 & $<0,0001$ \\
\hline 35 & 0,043 & 0,0728 & 0,7155 & 0,0061 & 57,84 & $<0,0001$ & 0,192 & 0,0318 & 0,0887 & 0,0149 & 1,46 & 0,2458 & 0,122 & 0,0507 & 0,2325 & 0,0124 & $\begin{array}{l}12,12 \\
12,\end{array}$ & 0,0012 \\
\hline $\begin{array}{l}30 \\
36\end{array}$ & $\begin{array}{l}-0,047 \\
-047\end{array}$ & 0,0926 & 0,4321 & 0,0069 & $\begin{array}{l}3,04 \\
17,50\end{array}$ & 0,0004 & 0,128 & 0,0460 & $\begin{array}{l},, 2234 \\
0,2234\end{array}$ & 0,0097 & $\begin{array}{l}1,40 \\
5,75\end{array}$ & $\begin{array}{l}0,450 \\
0,0263\end{array}$ & $\begin{array}{l}1,038 \\
0,038\end{array}$ & 0,0698 & 0 & 0,0088 & 24,49 & $<0,0001$ \\
\hline 37 & 0,154 & 0,0469 & 0,5045 & 0,0054 & 23,42 & $<0,0001$ & 0,281 & 0,0083 & 0,0138 & 0,0059 & 0,28 & 0,6025 & 0,188 & 0,0363 & 0,4063 & 0,0058 & 30,80 & $<0,0001$ \\
\hline 38 & 0,123 & 0,0544 & 0,6232 & $\begin{array}{l}0,0037 \\
0\end{array}$ & 38,03 & $<0,0001$ & 0,290 & 0,0047 & 0,0203 & 0,0051 & 0,42 & 0,5266 & $\begin{array}{l}0,245 \\
0\end{array}$ & 0,0179 & $\begin{array}{l}0,1269 \\
0,1209\end{array}$ & 0,0057 & 6,54 & 0,0140 \\
\hline 39 & $-0,065$ & 0,1081 & $\begin{array}{l}0,8579 \\
0\end{array}$ & 0,0052 & 138,81 & $<0,0001$ & 0,115 & 0,0486 & 0,2061 & 0,0089 & $\begin{array}{l}0,42 \\
5,19\end{array}$ & 0,0338 & $\begin{array}{l}0,038 \\
0,038\end{array}$ & 0,0739 & 0,5126 & 0,0083 & $\begin{array}{l}0,04 \\
47,33\end{array}$ & $<0,0001$ \\
\hline 40 & 0,053 & 0,0695 & 0,7301 & 0,0049 & 62,22 & $<0,0001$ & 0,109 & 0,050 & 0,467 & 0,005 & 17,506 & 0,0005 & $\begin{array}{l}0,0006 \\
0,086\end{array}$ & 0,0580 & 0,5720 & 0,0052 & 60,13 & $<0,0001$ \\
\hline 41 & $-0,076$ & 0,1076 & 0,8318 & 0,0053 & 113,76 & $<0,0001$ & 0,104 & 0,0538 & 0,3413 & 0,0086 & 9,85 & 0,0054 & 0,014 & 0,0806 & 0,5821 & 0,0075 & 61,28 & $<0,0001$ \\
\hline 42 & 0,084 & 0,0602 & 0,8140 & 0,0049 & 100,67 & $<0,0001$ & 0,277 & 0,0050 & 0,0028 & 0,0128 & 0,06 & 0,8148 & 0,211 & 0,0245 & 0,1431 & 0,0110 & 7,51 & 0,0088 \\
\hline $\begin{array}{l}42 \\
43\end{array}$ & $\begin{array}{r}0,004 \\
-0,050\end{array}$ & $\begin{array}{l}0,0024 \\
0,0924\end{array}$ & $\begin{array}{l}0,06140 \\
0,6813\end{array}$ & $\begin{array}{l}0,0049 \\
0,0079\end{array}$ & 49,18 & $<0,0001$ & $\begin{array}{l}0,217 \\
0,156\end{array}$ & 0,0276 & 0,0847 & 0,0146 & $\begin{array}{l}0,00 \\
1,85\end{array}$ & $\begin{array}{l}0,0140 \\
0,1890\end{array}$ & $\begin{array}{l}0,111 \\
0.199\end{array}$ & $\begin{array}{l}0,0175 \\
0,0177\end{array}$ & $\begin{array}{l}, 1431 \\
0,2100\end{array}$ & 0,0133 & $\begin{array}{l}1,51 \\
11,96\end{array}$ & 0,0012 \\
\hline 44 & $-0,165$ & 0,1276 & 0,7291 & 0,0063 & 61,91 & $<0,0001$ & 0,142 & 0,0396 & 0,0886 & 0,0159 & 1,94 & 0,1784 & 0,113 & 0,0471 & 0,1350 & 0,0133 & 7,02 & 0,0111 \\
\hline 45 & 0,016 & 0,0701 & 0,7070 & 0,0067 & 55,49 & $<0,0001$ & 0,003 & 0,076 & 0,239 & 0,014 & 6,284 & 0,0209 & 0,000 & 0,0755 & 0,4188 & 0,0115 & $\begin{array}{l}1,02 \\
32,43\end{array}$ & $<0,0001$ \\
\hline 46 & 0,042 & 0,0647 & 0,6909 & 0,0060 & 51,41 & $<0,0001$ & 0,176 & 0,0257 & 0,1476 & 0,0089 & 3,46 & 0,0775 & 0,174 & 0,0251 & 0,1758 & 0,0092 & 9,60 & 0,0033 \\
\hline 47 & $\begin{array}{r}0,094 \\
-0,090\end{array}$ & 0,1156 & 0,7811 & 0,0064 & $\begin{array}{l}82,08 \\
82,41\end{array}$ & $<0,0001$ & 0,234 & 0,0138 & 0,0138 & 0,0195 & $\begin{array}{l}0,40 \\
0,28\end{array}$ & 0,6022 & 0,160 & 0,0361 & 0,0806 & 0,0166 & 3,94 & $\begin{array}{l}0,0532 \\
0\end{array}$ \\
\hline 48 & 0,041 & 0,0707 & 0,5331 & 0,0106 & 26,26 & $<0,0001$ & 0,027 & 0,0803 & 0,4645 & 0,0137 & 18,22 & 0,0003 & 0,072 & 0,0635 & 0,3349 & 0,0143 & 23,16 & $<0,0001$ \\
\hline Média & 0,009 & 0,0823 & 0,6230 & 0,0078 & 60,03 & 0,0004 & 0,135 & 0,0439 & 0,1855 & 0,0139 & 6.44 & 0.1749 & 0.124 & 0,0473 & 0,2548 & 0.0127 & 18,92 & 0.0212 \\
\hline
\end{tabular}



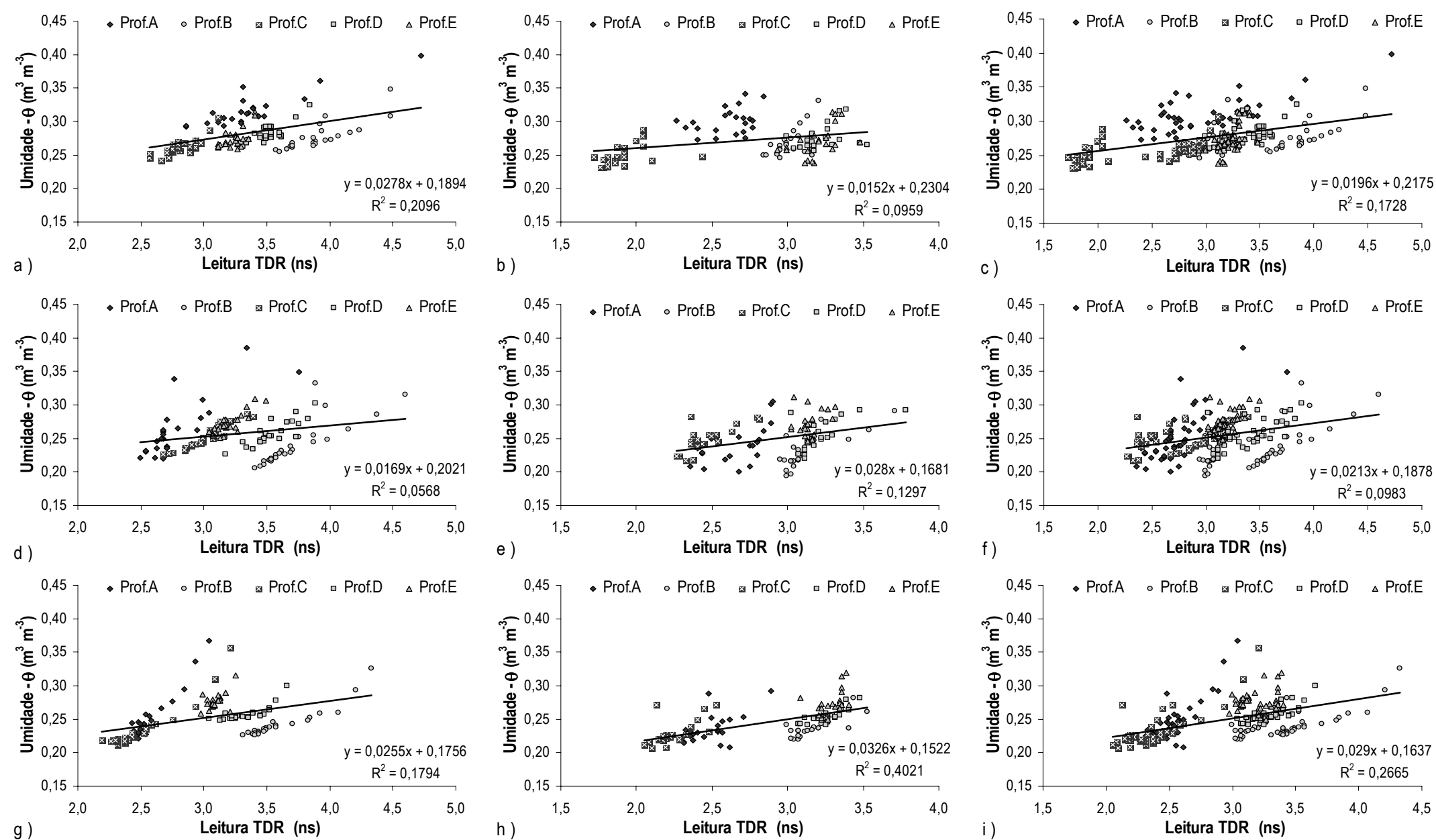

Anexo $\mathrm{N}$ - Exemplos de curvas de calibração para os dados agrupados por haste. A primeira coluna corresponde ao primeiro período, a segunda ao segundo período e a terceira coluna com todos os dados em conjunto. Primeira linha corresponde à bateria 1 , a segunda à 10 e a terceira à 19. Dados da camada $\mathrm{A}(\diamond)$, camada $\mathrm{B}(\bigcirc)$, Camada $\mathrm{C}(\boldsymbol{\nabla})$, camada $\mathrm{D}(\square)$ e camada $\mathrm{E}(\Delta)$. 

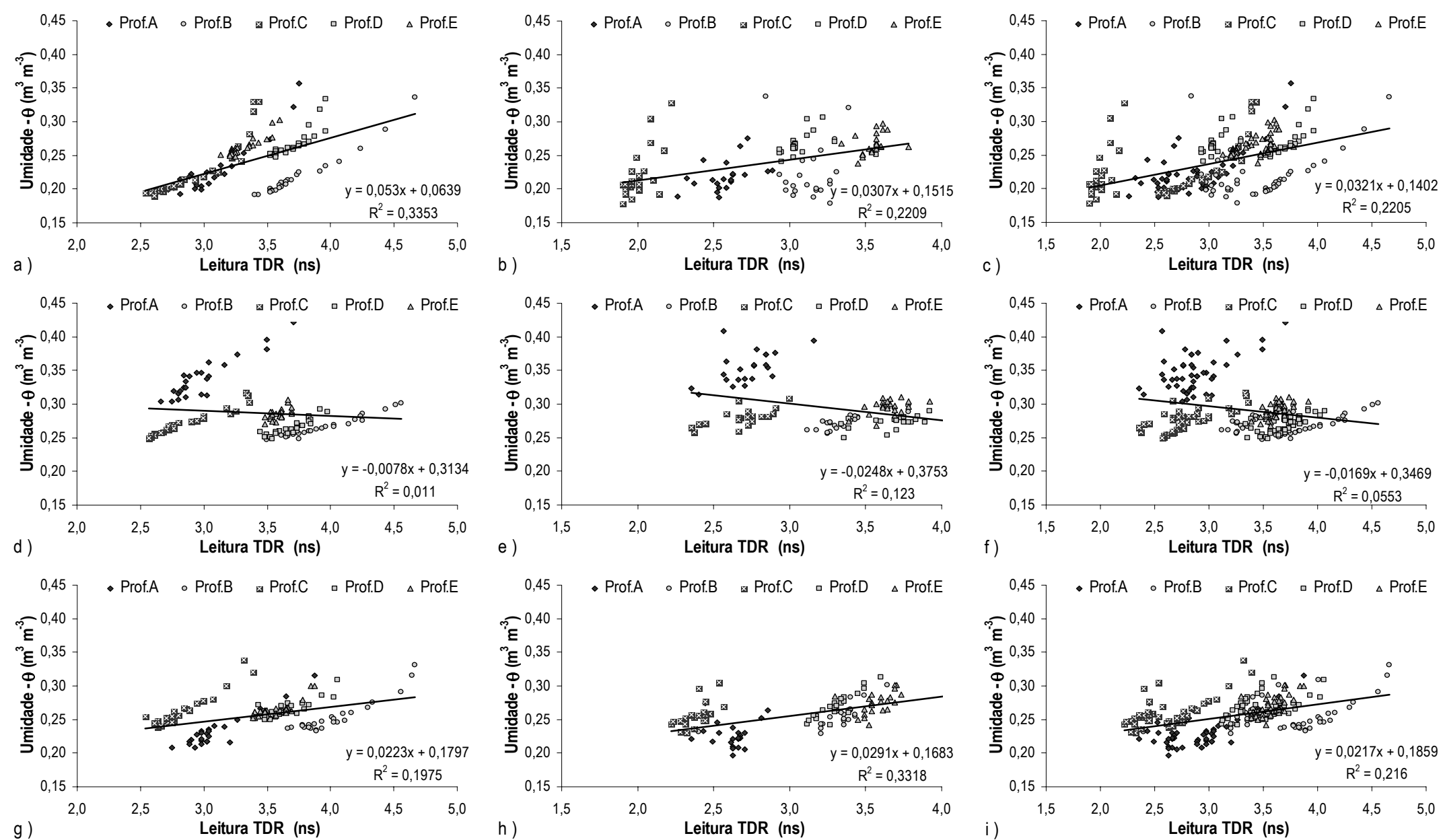

Anexo 0 - Exemplos de equações de calibração para os dados agrupados por haste. A primeira coluna corresponde ao primeiro período, a segunda ao segundo período e a terceira coluna com todos os dados em conjunto. Primeira linha corresponde à bateria 28, a segunda à 36 e a terceira à 45 . Dados da camada $A(\diamond)$, camada B $(\odot)$, Camada C $(\mathbf{X})$, camada $D(\square)$ e camada $E(\Delta)$. 

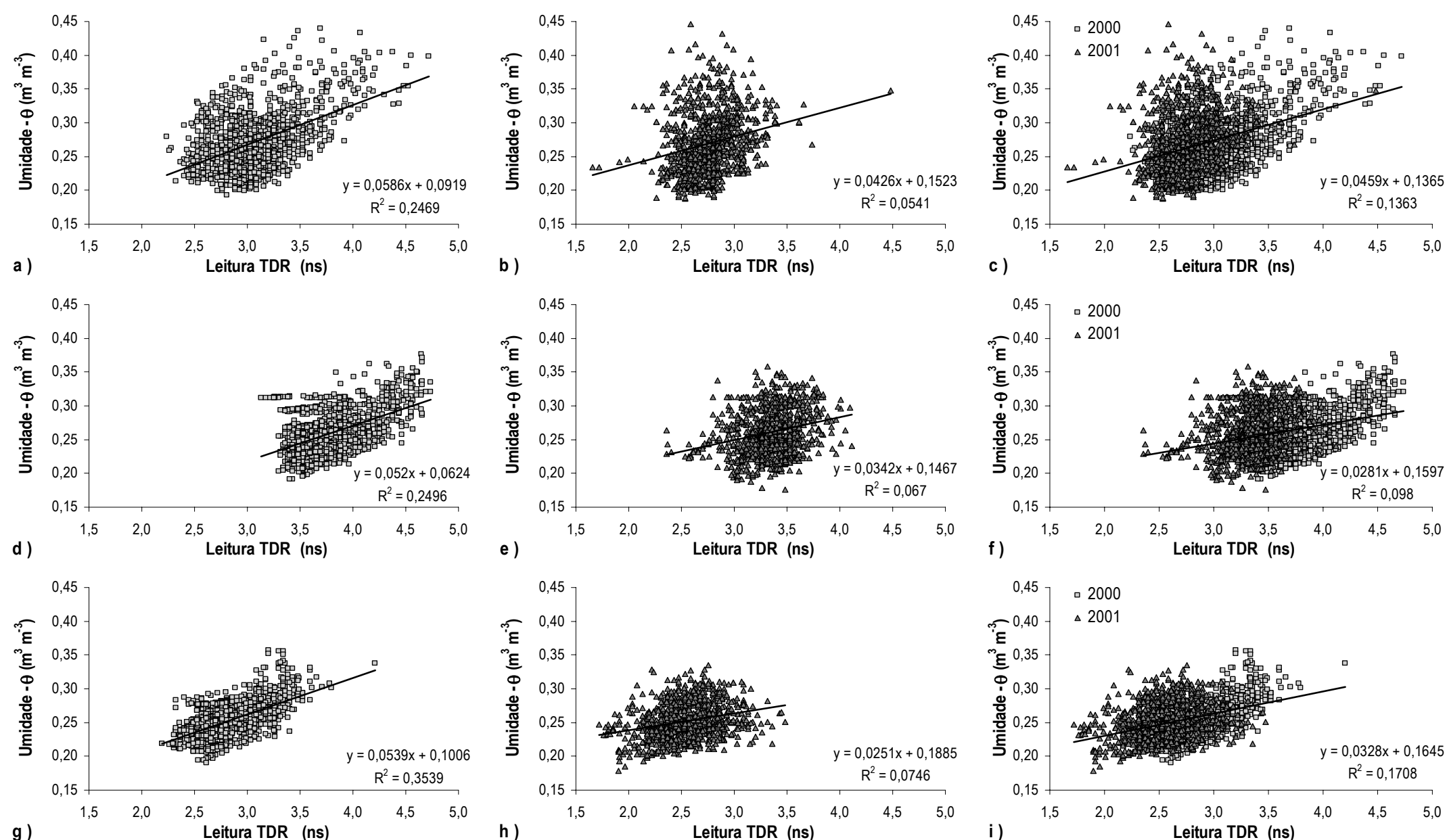

Anexo P - Equações de calibração e dados observados agrupados por camada. A primeira coluna corresponde ao primeiro período, a segunda ao segundo período e a terceira coluna com todos os dados em conjunto. Primeira linha corresponde à camada $A$, a segunda à $B$ e a terceira à $C$. 

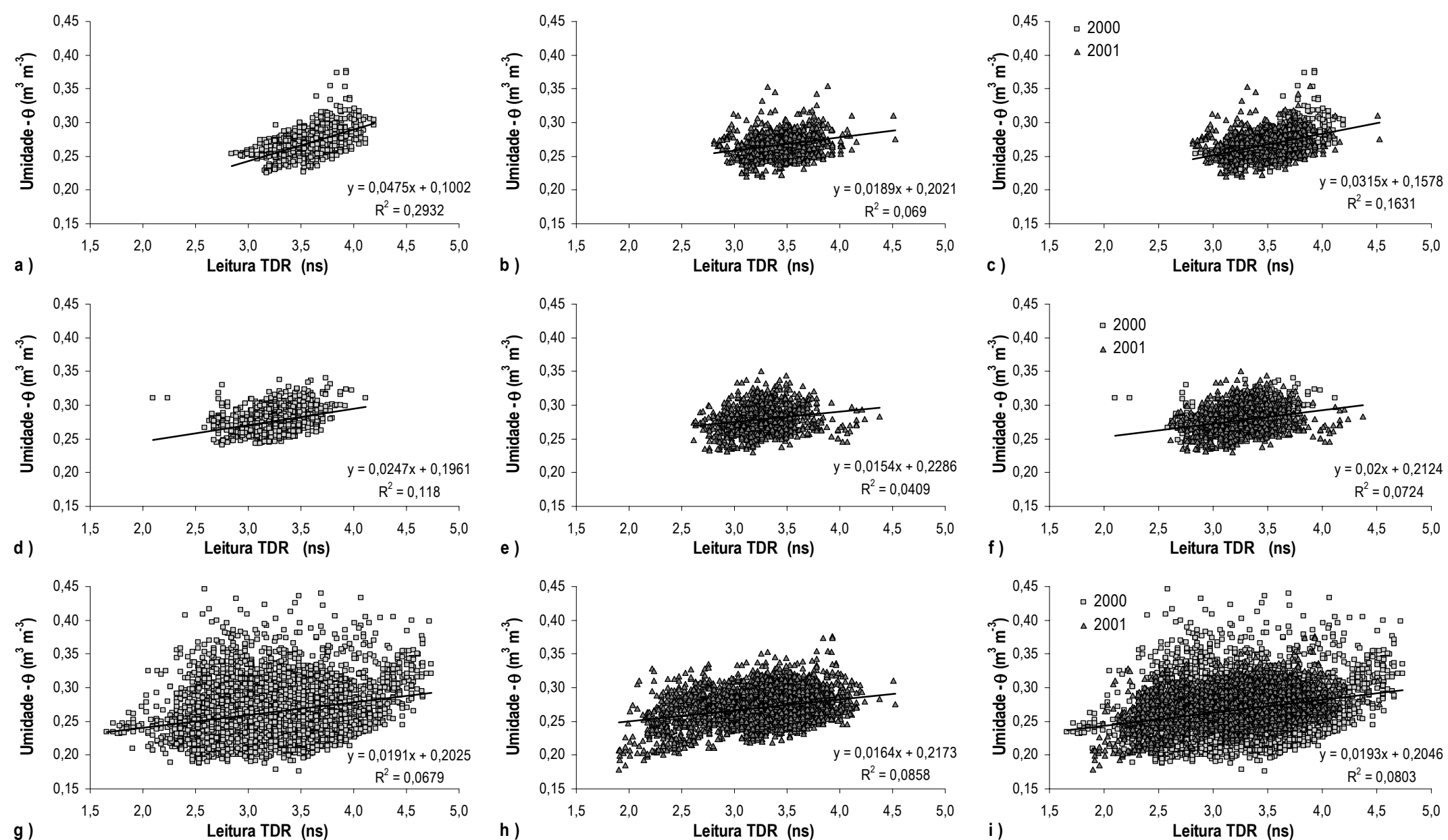

Anexo $Q$ - Equações de calibração e dados observados agrupados por camada. A primeira coluna corresponde ao primeiro período, a segunda ao segundo e a terceira coluna com todos os dados em conjunto. Primeira linha corresponde à camada $\mathrm{D}$, a segunda à $\mathrm{E} e$ a terceira à todas juntas. 


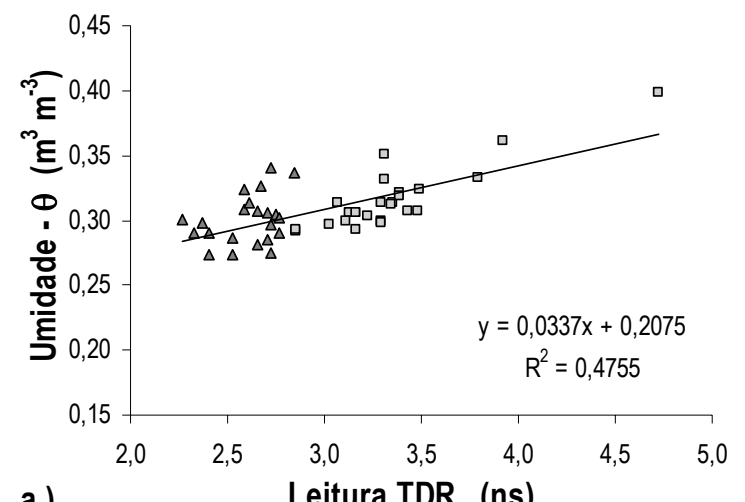

a)
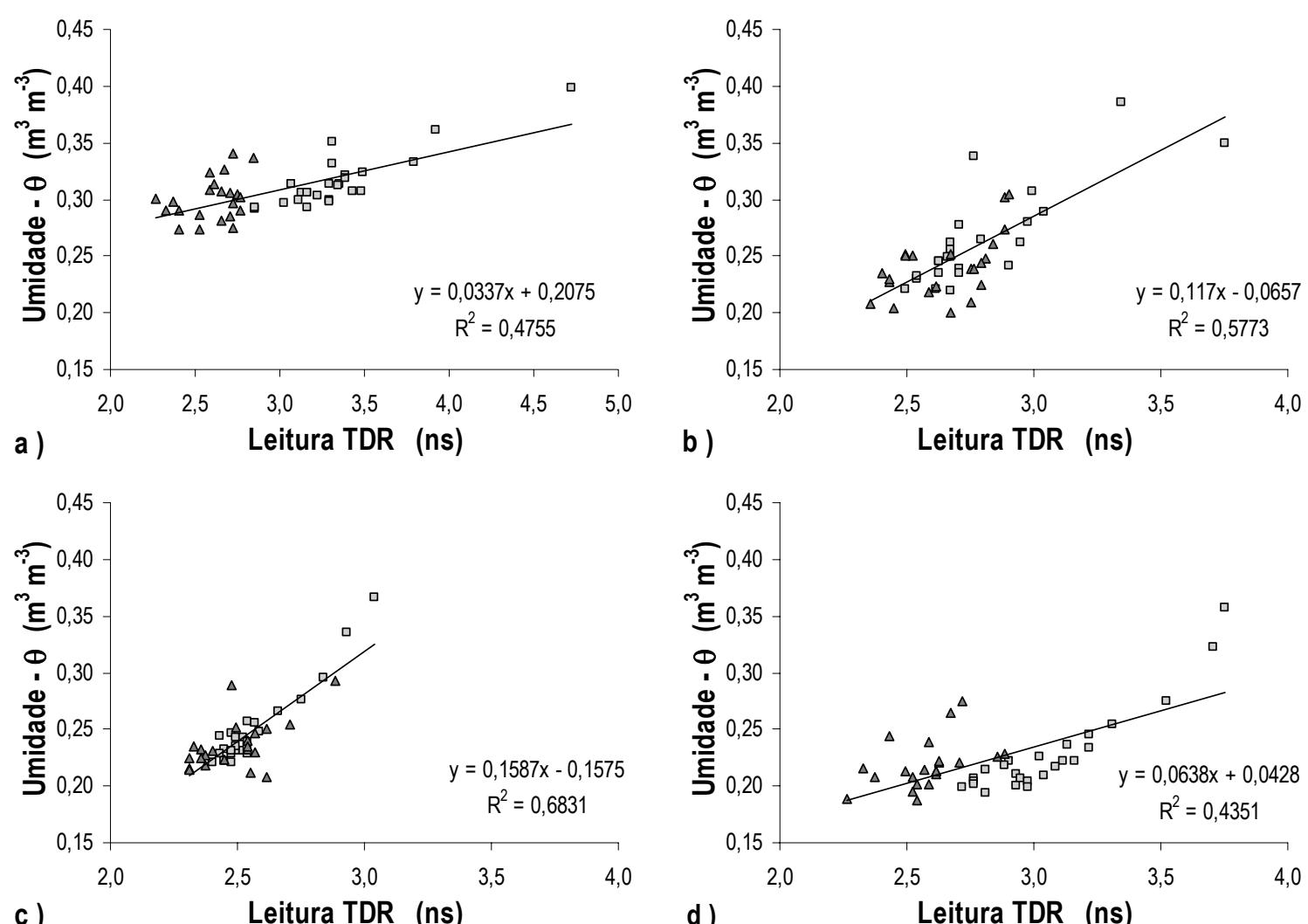

c) Leitura TDR (ns)

\section{b )}

Leitura TDR (ns)

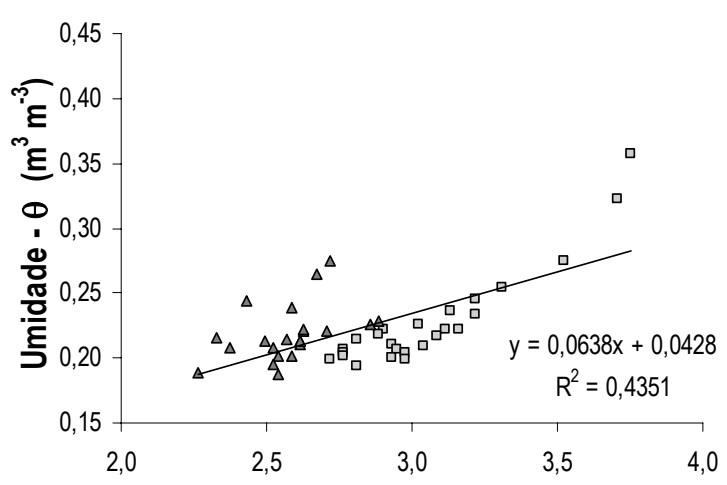

d)

Leitura TDR (ns)

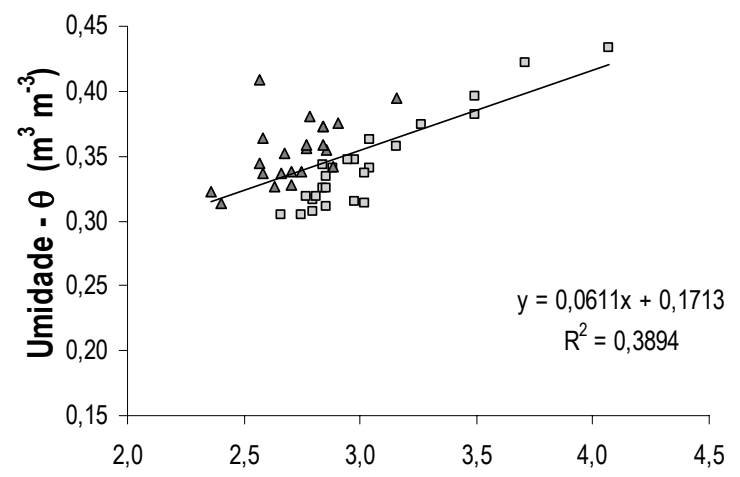

e)

Leitura TDR (ns)

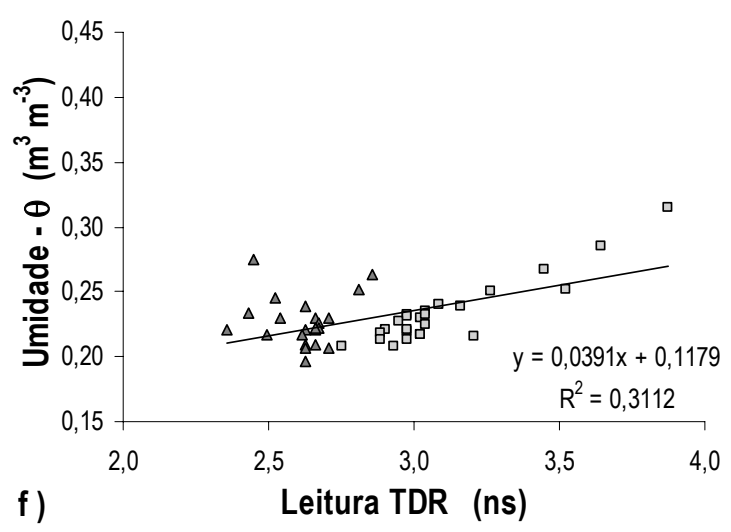

Anexo R-Exemplos de equações de calibração com os dados dos dois períodos para os segmentos da camada A. (a) bateria 1, (b) bateria 10, (c) bateria 19, (d) bateria 28, (e) bateria 36 e (f) bateria 45. ( $\square)$ Dados de 2000 e $(\Delta)$ de 2001. 

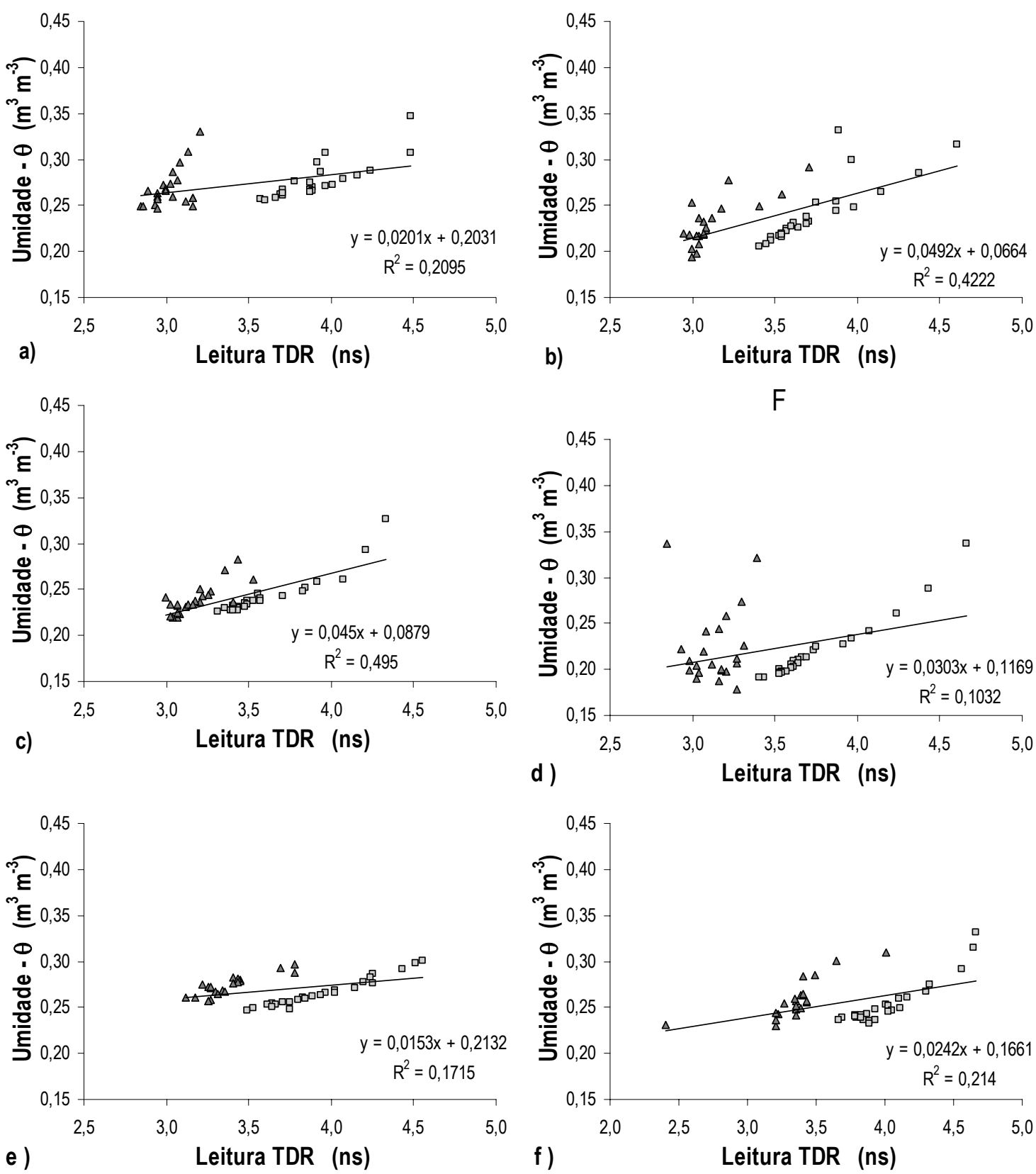

Anexo $S$ - Exemplos de equações de calibração com os dados dos dois períodos para os segmentos da camada B. (a) bateria 1, (b) bateria 10, (c) bateria 19, (d) bateria 28 , (e) bateria 36 e (f) bateria 45. (口) Dados de 2000 e ( $\Delta$ ) de 2001. 

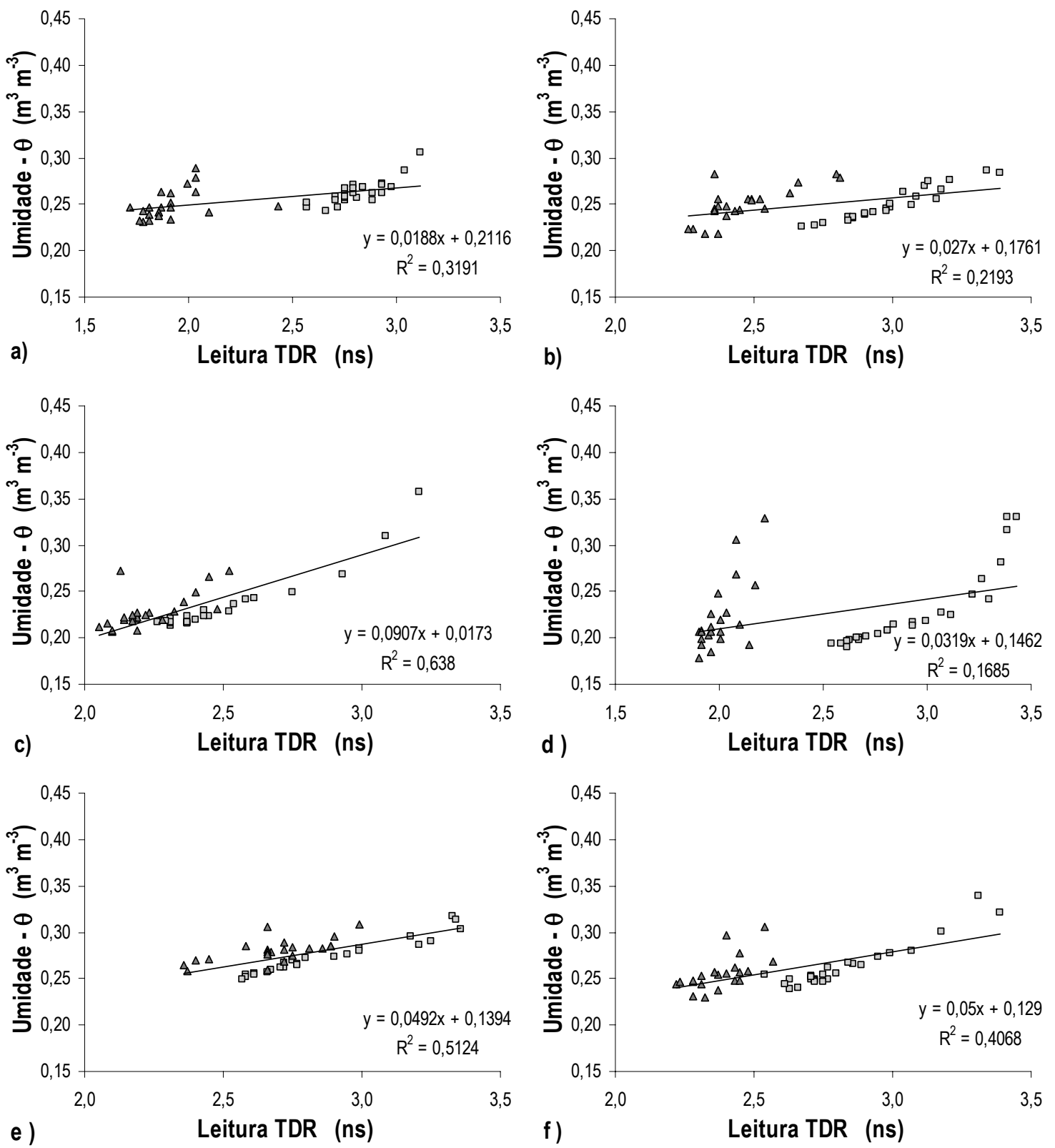

Anexo T - Exemplos de equações de calibração com os dados dos dois períodos para os segmentos da camada C. (a) bateria 1, (b) bateria 10, (c) bateria 19, (d) bateria 28 , (e) bateria 36 e (f) bateria 45. () Dados de 2000 e ( $\Delta$ ) de 2001. 

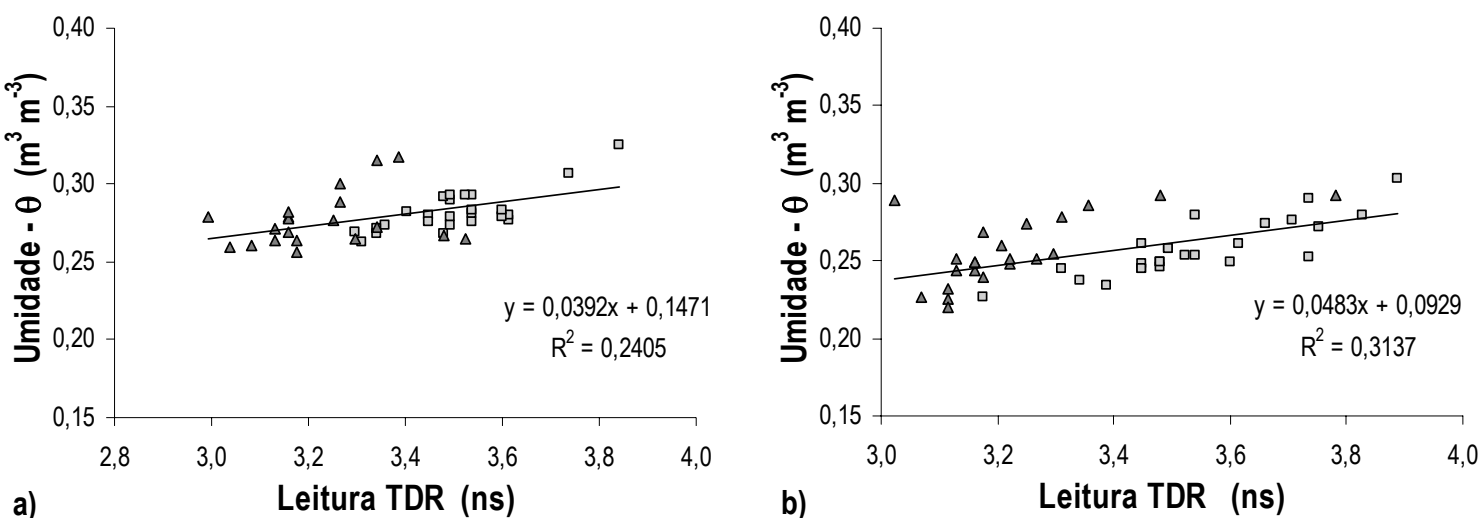

a)

Leitura TDR (ns)

b)
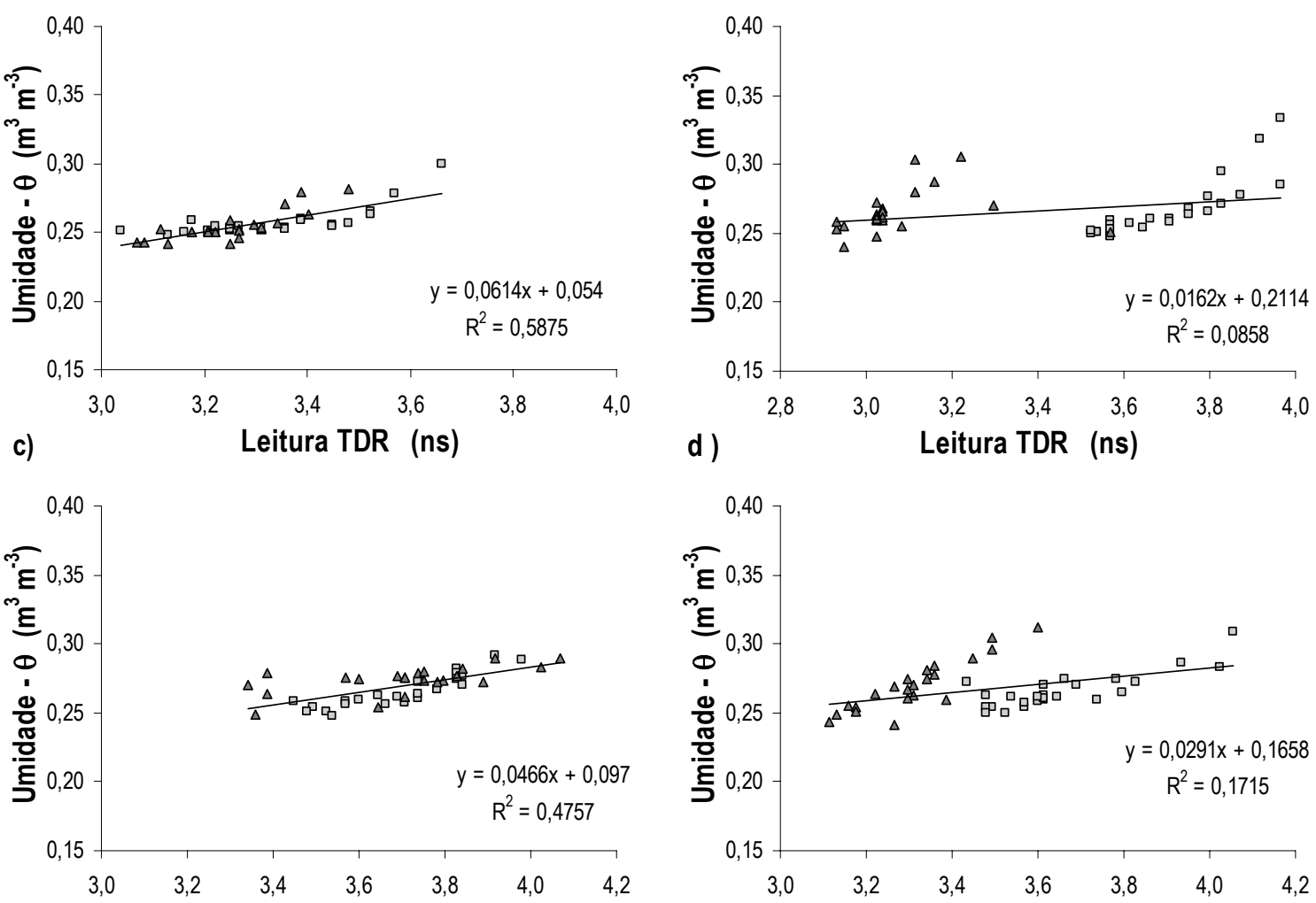

e)

Leitura TDR (ns)

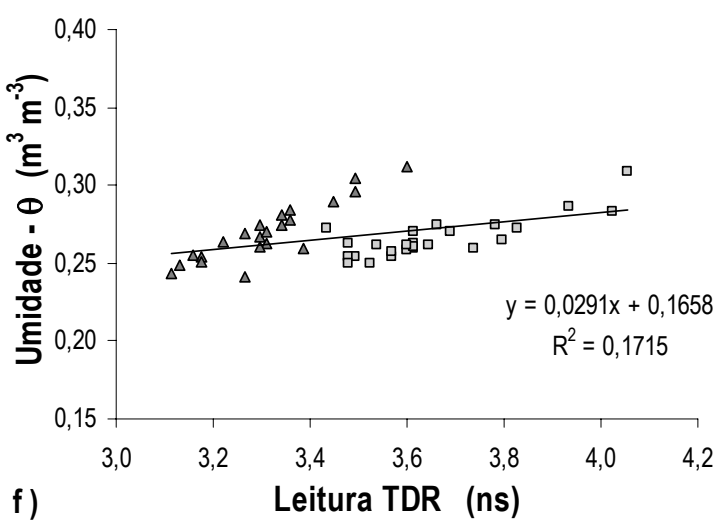

Anexo U-Exemplos de equações de calibração com os dados dos dois períodos para os segmentos da camada D. (a) bateria 1, (b) bateria 10, (c) bateria 19, (d) bateria 28, (e) bateria 36 e (f) bateria 45. ( $\square)$ Dados de 2000 e $(\Delta)$ de 2001. 

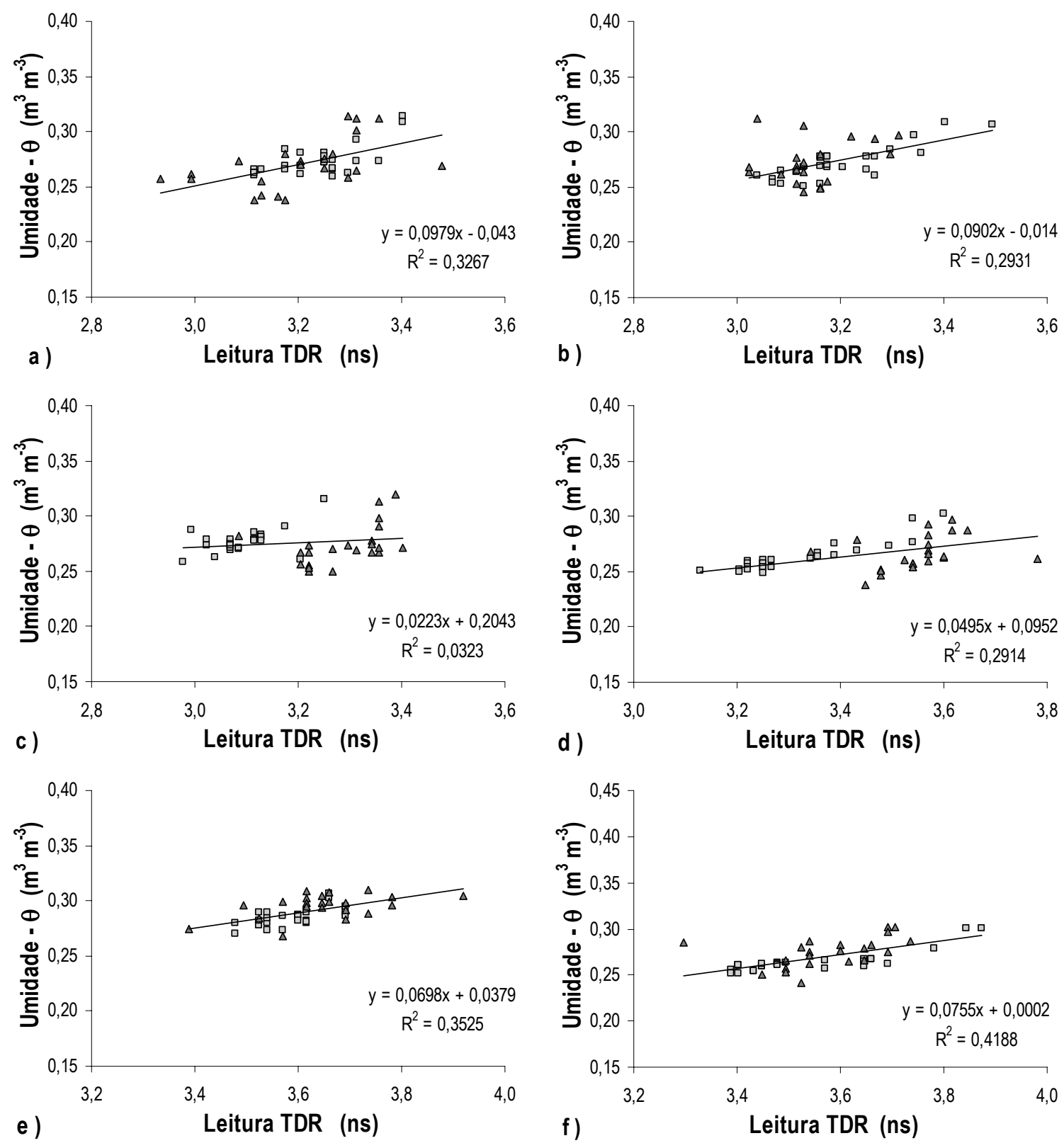

Anexo $\mathrm{V}$ - Exemplos de equações de calibração com os dados dos dois períodos para os segmentos da camada E. (a) bateria 1, (b) bateria 10, (c) bateria 19, (d) bateria 28, (e) bateria 36 e (f) bateria 45. (口) Dados de 2000 e $(\Delta)$ de 2001. 


\section{REFERÊNCIAS BIBLIOGRÁFICAS}

ARRUDA, F. B.; LELIS, L. G. L.; BARROS, S. B. M. Montagem e teste de tensiômetro simplificado. Campinas:CATI, 1987. 13 p. (Boletim Tecnico CATI, 112).

BAKER. J. M.; LASCANO, R. J. The spatial sensitivity of time domain reflectometry. Soil Science. v. 147, n. 5, p. 378-384, 1989.

BARTHEM, R. Vocabulário de metrologia legal. Instituto de Física-UFRJ. http://www.if.ufrj.br/metrologia (16 mar. 2001).

BRIDGE, B. J.; SABBURG, J.; HABASH, K. O.; BALL, J. A. R.; HANCOCK, N. H. The dielectric behavior of clay soils and its application to time domain reflectometry. Australian Journal of Soil Researches. n. 34, p. 825-835, 1996.

BRUCE R. R.; LUXMOORE, R. J. Water retention: field methods. In KLUTE, A. (Ed.). Methods of Soil Analisys I, Physical and Mineralogical Methods. Madison: Soil Science Societe of America, 1986. cap. 27, p. 663-686.

CASSEL, D. K.; KLUTE, A. Water potential: tensiometry. In KLUTE, A. (Ed.). Methods of Soil Analisys I, Physical and Mineralogical Methods. Madison: Soil Science Societe of America, 1986. cap. 23 p. 563-596.

CAUDURO, F. A.; DORFMAN, R. Manual de ensaios de laboratório e campo para irrigação e drenagem. Porto Alegre: PRONI - IPH-UFRGS, s.d., 216 p.

CHUDINOVA, S. M.; PONIZOVSKII, A. A. The effect of soil texture on time domain reflectometry calibration for soil water measurement. Eurasian Soil Science, v. 31, n. 1, p. 17-24, 1998.

COSTA NETO, P. L. O. Estatística. São Paulo: Edgard Blücher, 1977. 265 p. 
DALTON, F. N.; VAN GENUCHTEN, M. T. The time-domain reflectometry method for measuring soil water content and salinity. Geoderma, n. 38, p. 237-250, 1986.

DASBERG, S.; DALTON, F. N. Time domain reflectometry field measurements of soil water content and electrical conductivity. Soil Science Society of America Journal, n. 49, p. 293297, 1985.

DASBERG, S.; ALKSNIS, H.; DANIEL, P.; KALMA, J. D.; ZEGELIN, S. J. Calibration of the "Moisture Point" TDR system. Victoria: Cooperative Research Centre for Catchment Hydrology, 1995. 15 p. (Report 95/4).

DASBERG, S.; HOPMANS, J. W. Time domain reflectometry calibration for uniformly and nonuniformly wetted sandy and clayey loam soils. Soil Science Society of America Journal, n. 56 , p. 1341-1345, 1992.

DAVIS, J. L.; CHUDOBIAK, W. J. In-situ meter for measuring relative permittivity of soils. Geology Survey of Canada (Paper 75-1A), p. 75-79, 1975.

DIRKSEN, C. Soil physics measurements. Reiskirchen: Catena-Verlag, 1999, 154 p.

DIRKSEN, C.; DASBERG, S. Improved calibration of time domain reflectometry soil water content measurements. Soil Science Society of America Journal, n. 57, p. 660-667, 1993.

DOBSON, M. C.; ULABY, F.T.; HALLIKAINEN, M. T.; EL-RAYES, M. A. Microwave dielectric behavior of wet soil II. Dielectric mixing models. IEEE Transactions. Geoscience Remote Sensors. n. 23, p. 35-46, 1985.

DRUNGIL, C. E. C.; ABT, K.; GISH, T. J. Soil moisture determination in gravely soils with time domain reflectometry. Transactions of ASAE, n. 32, p. 177-180, 1989.

FELLNER-FELDEGG, $\mathrm{H}$. The measurement of dielectrics in time domain. The Journal of Physical Chemistry. v. 73, n. 3 p.616-623, 1969.

FENG, W.; LIN, C. P.; DESCHAMPS, R. J.; DRNEVICH, V. P. Theoretical model of a multisection time domain reflectometry measurement system. Water Resouces Research. v. 35, n. 8, p. 2321-2331, 1999. 
FLETCHER, J. E. A dielectric method for determining soil moisture. Soil Science Society of America Proceedings. v. 4, p. 84-88, 1939.

GARDNER, W. H. Water content. In KLUTE, A. (Ed.). Methods of Soil Analisys I, Physical and Mineralogical Methods. Madison: Soil Science Societe of America, 1986. cap. 21, p. 493-544.

GARDNER, W.; ISRAELSE, O. W.; EDLEFSEN, N. E.; CLYDE, D. The Capillary potential function and its relation to irrigation practice. Physics Review n. 20, p. 196, 1922.

GRANTZ, D. A.; PERRY, M. H.; MEINZER, F. C. Using time-domain reflectometry to measure soil water in hawaiian sugarcane. Agronomy Journal, n. 82, p. 144-146, 1990.

HERKELRATH, W. N.; HAMBURG, S. P.; MURPHY, F. Automatic, real-time monitoring of soil moisture in a remote field area with time domain reflectometry. Water Resources Research, v. 27, n. 5 , p. 875-864, 1991.

HIPP, J. E. Soil electromagnetic parameters as a function of frequency, soil density, and soil moisture. Proceedings IEEE, n. 62, p. 98-103, 1974.

HOEKSTRA, P.; DENALEY, A. Dielectrical properties of soil at UHF and microware frequencies. Journal of Geophysics Research. N. 79, p. 1699-1708, 1974.

HOOK, W. R.; LIVINGSTON, n. J.; SUN Z. J.; HOOK P. B. Remote diode shorting improves measurements of soil water by time domain reflectometry. Soil Science Society of America Journal, n. 56, p. 1384-1391, 1992.

HOOK, W. R.; LIVINGSTON, N. J. Propagation velocity errors in time domain reflectometry measurements of soil water content. Soil Science Society of America Journal, n. 59, p. $92-$ 96, 1995.

HOOK, W. R.; LIVINGSTON, N. J. Errors in converting time domain reflectometry measurements of propagation velocity to estimates of soil water content. Soil Science Society of America Journal, n. 60, p. 35-41, 1996.

HUISMAN, J. A.; SPERL, C.; BOUTEN, W.; VERSTRATEN, J. M. Soil water content measurements at different scales: accuracy of time domain reflectometry and groundpenetrating radar. Journal of Hydrology. n. 245, p. 48-58, 2001. 
JACOBSEN, O. H.; SCHJøNNING, P. A laboratory calibration of time domain reflectometry for soil water measurement including effects of bulk density and texture. Journal of Hydrology. n. 151, p. $147-157,1993$.

KENG, J. C.; TOPP, G. C. Measuring water content os soil columns in the laboratory: a comparison of gamma ray attenuation and TDR techniques. Canadian Journal of Soil Science, n. 63, p. 3-43, 1983.

KLUTE, A. Water retention: laboratory methods. In KLUTE, A. (Ed.). Methods of Soil Analisys I, Physical and Mineralogical Methods. Madison: Soil Science Societe of America, 1986. cap. 26 , p. $635-661$.

KLUTE, A.; GARDNER, W. R. Tensiometer response time. Soil Science n. 93, p. 204-207, 1965.

KLUTE, A.; DIRKSEN, C. Hydraulic conductivity and diffusivity: laboratory methods. In KLUTE, A. (Ed.), Methods of Soil Analisys I, Physical and Mineralogical Methods. Madison: Soil Science Societe of America, 1986. Cap. 28, p. 687-734.

KNIGHT, J. H. Sensitivity of time domain reflectometry measurements to lateral variations in soil water content. Water Resources Research, v. 28, n. 9, p. 2345-2352, 1992.

LIBARDI, P. L. Dinâmica da Água no Solo. 2.ed. Piracicaba: O próprio, 2000. 509 p.

LIDIEU, J.; DE RIDDER, P.; DE CLERCK, P.; DAUTREBANDE, S. A method of measuring soil moisture by time domain reflectometry. Journal of Hydrology, n. 88, p. 319-328, 1986.

MARCIANO, C. R.; MORAES, S. O.; SAAD, A. M.; LIBARDI, P. L. Variabilidade do potencial mátrico e do conteúdo de água no solo em experimento de manejo de irrigação. Revista Brasileira de Ciência do Solo, n. 22, p. 563-571, 1998.

MELLO FILHO, J. F.; LIBARDI, P. L.; JONG VAN LIER, Q.; CORRENTE, J. E. Método convencional e "bootstrap" para estimar o número de observações na determinação dos parâmetros da função $K(\Theta)$.Revista Brasileira de Ciência do Solo, n.26, p. 895-903, 2002.

MIYAMOTO, T.; KOBAYASHI, R. ANNAKA, T.; CHIKUSHI,J. Applicability of multiple length TDR probes to measure water distributions in an andisol under different tillage systems in Japan. Soil \& Tillage Research, n. 60, p. 91-99, 2001. 
MUALEM, Y. A new model for predicting the hydraulic conductivity of unsaturated porus media. Water Resources Researches, n. 12, p. 513-522, 1976.

NOBORIO, K. Measurements of soil water content and electrical conductivity by time domain reflectometry: a review. Computers and Electronics in Agriculture, n. 31, p. 213-237, 2001.

OR, D.; WRAITH, J. M. Temperature effects on soil bulk dielectrical permittivity measured by time domain reflectometry: a physical model. Water Resources Research, v. 35, n. 2, p. 371-383, 1999.

PEPIN, S.; LIVINGSTON, N. J.; HOOK, W. R. Temperature-dependent measurements errors in time domain reflectometry determinations of soil water. Soil Science Society of America Journal, n. 59, p. 38-43, 1995.

PIMENTEL-GOMES, F. Curso de estatística experimental. 14.ed. Piracicaba: O próprio, 2000. $477 \mathrm{p}$.

PONIZOVSKY, A. A.; CHUDINOVA, S. M.; PACHEPSKY, Y. A. Performance of TDR calibration models as affected by soil texture. Journal of Hydrology, v. 218, p. 35-43, 1999.

PESSOA, N. S. O Tensiômetro simplificado na determinação da umidade do solo. Campinas: CATI, 1983. 5 p. (Boletim Tecnico CATI, 176).

ROBINSON, D. A.; BELL, J. P.; BAHELOR, C. H. Influence of iron minerals on the determination do soil water content using dielectric techniques. Journal of Hydrology, v. 161, p. 169-180, 1994.

ROTH, C. H.; MALICKI, M. A.; PLAGGE, R. Empirical evaluation of the relationship between soil dielectric constant and volumetric water content as basis for calibrating soil moisture measurements. Journal of Soil Science, n.43, p. 1-13, 1992.

SABBURG, J.; BALL, J. A. R.; HANCOCK, N. H. Dielectric behavior of moist swelling soils at microwave frequencies. IEEE Transactions Geosciences in Remote Sensing, n. 35, p. 784-787, 1997. 
SERVIÇO BRASILEIRO DE APOIO ÀS MICRO E PEQUENAS EMPRESAS. Metrologia: Calibração. http://wwwsebrae-sc.com.br/sebraetib/conceitos/metrologia/calibração (04 out. 2001).

SEN, A. K.; SRIVASTAVA M. Regression Analysis: Theory and Applications. Nova lorque: Springer-Verlag., 1990. 347 p.

SERRARENS, D.; MACINTYRE J. L.; HOPMANS, J.W; BASSOI, L. H. Soil moisture calibration of TDR multilevel probes. Scientia Agrícola. v. 57, n. 2, p. 349-354, 2000.

SOUZA, L. D.; REICHARDT, K. Estimativas da capacidade de campo. Revista Brasileira de Ciência do Solo. N. 20, p. 183-189, 1996.

TOMASELLI, J. T. G. Influência de algumas características do solo sobre a calibração de um aparelho de TDR (time-domain reflectometry). Piracicaba, 1997. 109 p. Tese Doutorado - Centro Nacional de Energia na Agricultura, Universidade de São Paulo.

TOPP, G. C.; DAVIS, J. L. Measurements of soil water content using time domain reflectometry (TDR): a field evaluation. Soil Science Society of America Journal, n. 49, p. 19-24, 1985.

TOPP, G. C.; DAVIS, J. L.; ANNAN, A. P. Electromagnetic determination of soil water content: measurements in coaxial transmission lines. Water Resources Research. V. 16, N. 3, p. 574-582, 1980.

TOPP, G. C.; DAVIS, J. L.; ANNAN, A. P. Electromagnetic determination of soil water content using TDR: I. Applications to wetting fronts and steep gradients. Soil Science Society of America Journal, n. 46, p. 672-684, 1982a.

TOPP, G. C.; DAVIS, J. L.; ANNAN, A. P. Electromagnetic determination of soil water content using TDR: II. Evaluation of installation and configuration of parallel transmission lines. Soil Science Society of America Journal, n. 46, p. 672-684, 1982b.

VAN GENUCHTEN, M. T. A closed-form equation for predicting the hydraulic conductivity of unsaturated soils. Soil Science Society of America Journal, n. 44, p. 892-898, 1980. 
VOGELER, I.; CLOTHIER, B. E.; GREen, S. R.; SCOTTER, D. R.; TILLMAN, R. W. Characterizing water and solute movement by time domain reflectometry and disk permeametry. Soil Science Society of America Journal, n. 60, p. 5-12, 1996.

VUOLO, J. H. Fundamentos da teoria dos erros. 2.ed. São Paulo: Ed. Edgar Blüncher, 1996. $249 p$.

VUOLO, J. H. Avaliação e expressão de incerteza em medição. Revista Brasileira de Ensino de Física, v. 21, n. 3, p. 350-358, 1999.

WARRICK, A. W.; NIELSEN, D. R. Spatial variability of soil physical properties in the field. In HILLEL, D., (Ed.) Applications of Soil Physics. Nova lorque: Academy Press, 1980. p. 319344.

WHALLEY, W. R. Considerations of the use of time domain reflectometry (TDR) for measuring soil water content. Journal of Soil Science. n. 44, p. 1-9, 1993.

YU, C.; WARRICK, A. W.; CONKLIN, M. H. Derived functions of time domain reflectometry for soil moisture measurement. Water Resources Research, v. 35, n. 6, p. 1789-1796, 1999.

YU, C.; WARRICK, A. W.; CONKLIN, M. H.; YOUNG, M. H.; ZREDA, M. Two and three parameter calibrations of time domain reflectometry for soil moisture measurement. Water Resources Research, v. 33, n. 10, p. 2417-2421, 1997.

YOUNG, M. H.; FLEMING, J. B.; WIERENGA, P. J.; WARRICK, A. W. Rapid laboratory calibration of time domain reflectometry using upward infiltration. Soil Science Society of America Journal, n. 61, p. 707-712, 1997.

ZEGELIN, S. J.; WHITE, I.; JENKINS, D. R. Improved field probes for soil water content and electrical conductivity measurements using time domain reflectometry. Water Resources Research, n. 25, p. 2367-2376, 1989. 